\title{
Measure Guideline: Internal Insulation of Masonry Walls
}

J.F. Straube, K. Ueno, and C.J. Schumacher Building Science Corporation 


\section{This report received minimal editorial review at NREL.}

\section{NOTICE}

This report was prepared as an account of work sponsored by an agency of the United States government. Neither the United States government nor any agency thereof, nor any of their employees, subcontractors, or affiliated partners makes any warranty, express or implied, or assumes any legal liability or responsibility for the accuracy, completeness, or usefulness of any information, apparatus, product, or process disclosed, or represents that its use would not infringe privately owned rights. Reference herein to any specific commercial product, process, or service by trade name, trademark, manufacturer, or otherwise does not necessarily constitute or imply its endorsement, recommendation, or favoring by the United States government or any agency thereof. The views and opinions of authors expressed herein do not necessarily state or reflect those of the United States government or any agency thereof.

Available electronically at http://www.osti.gov/bridge

Available for a processing fee to U.S. Department of Energy

and its contractors, in paper, from:

U.S. Department of Energy

Office of Scientific and Technical Information

P.O. Box 62

Oak Ridge, TN 37831-0062

phone: 865.576.8401

fax: 865.576.5728

email: mailto:reports@adonis.osti.gov

Available for sale to the public, in paper, from:

U.S. Department of Commerce

National Technical Information Service

5285 Port Royal Road

Springfield, VA 22161

phone: 800.553 .6847

fax: 703.605 .6900

email: orders@ntis.fedworld.gov

online ordering: http://www.ntis.gov/ordering.htm

Printed on paper containing at least $50 \%$ wastepaper, including $20 \%$ postconsumer waste 


\title{
Measure Guideline: Internal Insulation of Masonry Walls
}

\author{
Prepared for: \\ Building America \\ Building Technologies Program \\ Office of Energy Efficiency and Renewable Energy \\ U.S. Department of Energy
}

Prepared by:

J.F. Straube, K. Ueno, and C.J. Schumacher

Building Science Corporation

30 Forest Street

Somerville, MA 02143

NREL Technical Monitor: Cheryn Engebrecht

Prepared Under Subcontract No. KNDJ-0-40337-00

July 2012 
[This page left blank] 


\section{Contents}

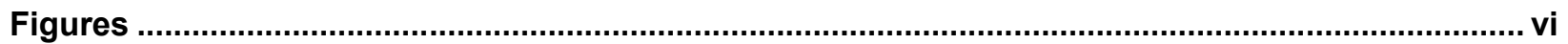

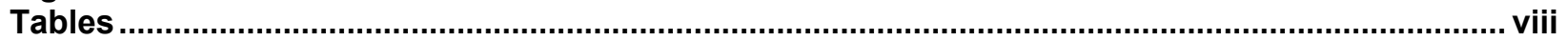

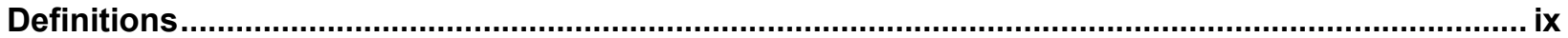

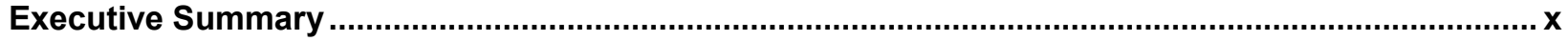

1 Introduction

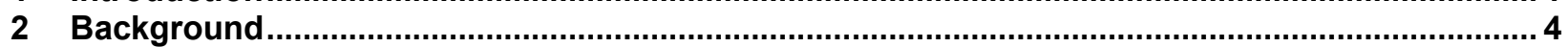

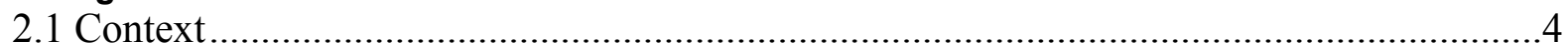

2.2 Exterior Insulation of Mass Masonry Structures ...................................................

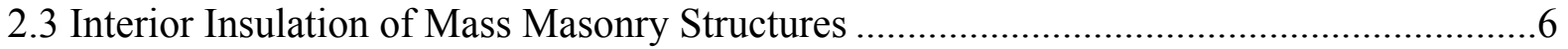

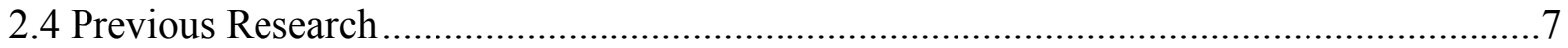

2.5 Relevance to Building America's Goals .................................................................. 7

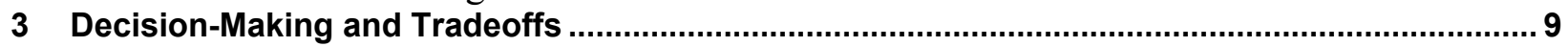

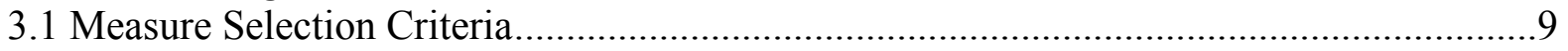

3.2 Cost Effectiveness...........................................................................................

3.3 Performance Tradeoffs and Other Benefits ............................................................... 10

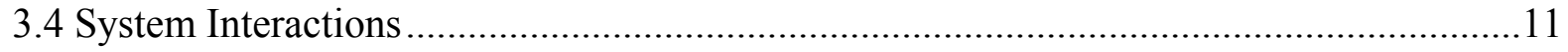

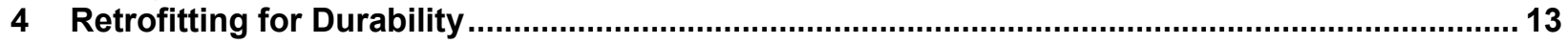

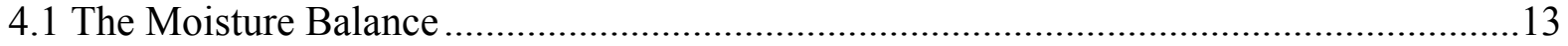

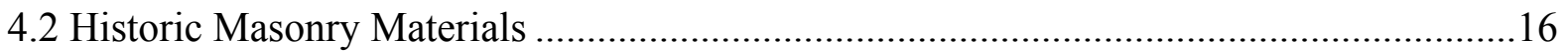

4.3 Durability Concerns .......................................................................................... 17

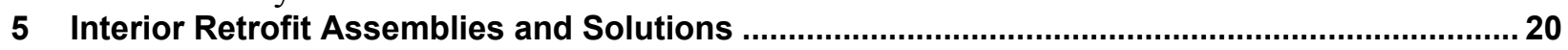

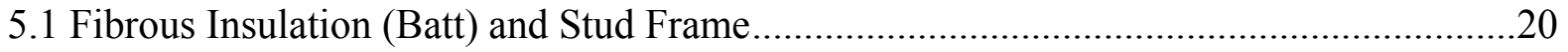

5.2 Spray Polyurethane Foam ..............................................................................22

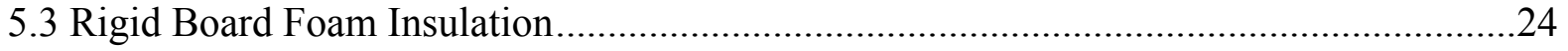

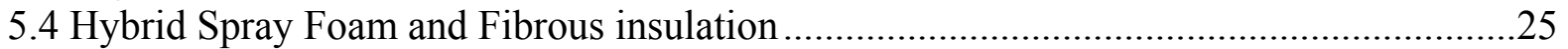

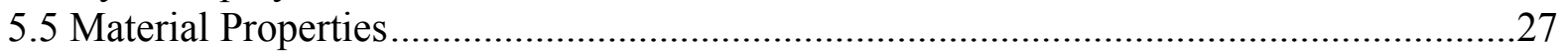

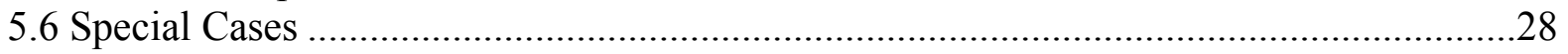

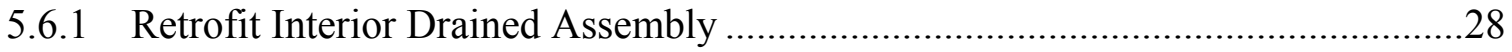

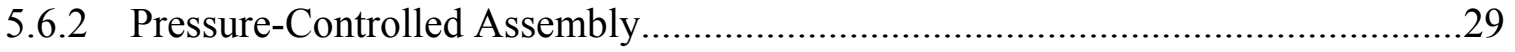

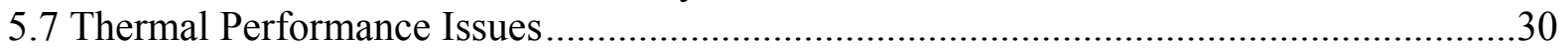

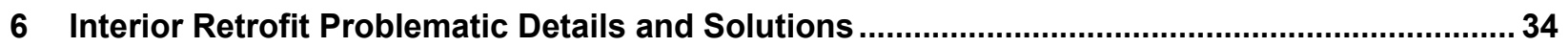

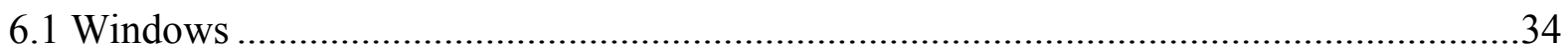

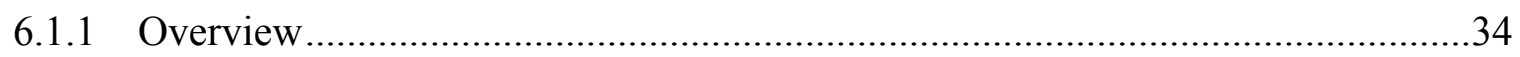

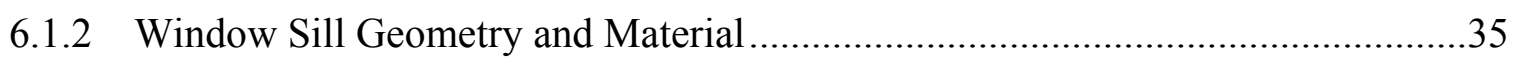

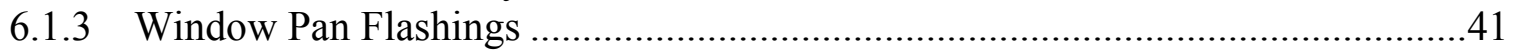

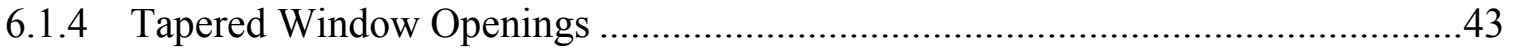

6.2 Exterior Bulk Water Concentration Details .................................................................44

6.2.1 Stone and Brick Detailing Courses ...................................................................4 44

6.2.2 Roof-Wall Interfaces.................................................................................... 46

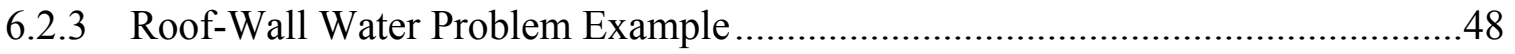

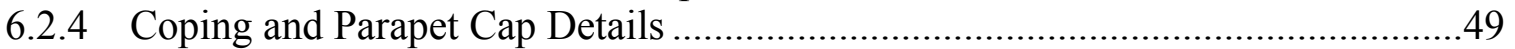

6.2.5 Downspouts, Rainwater Leaders, and Scuppers ..............................................53

6.3 Ground Contact Issues ...........................................................................................55

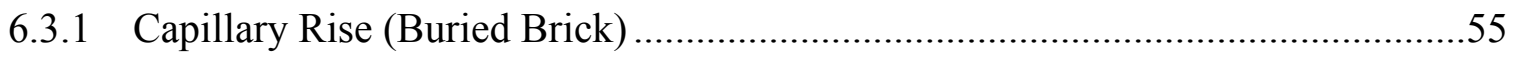

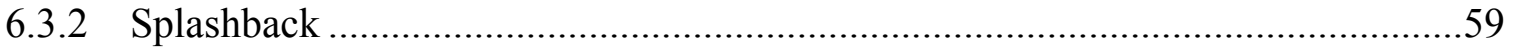

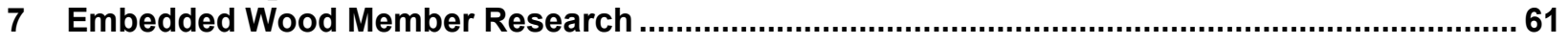




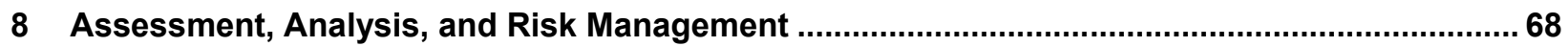

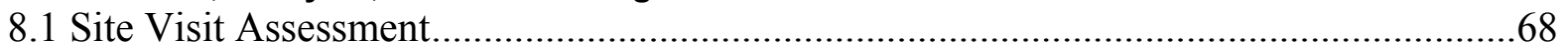

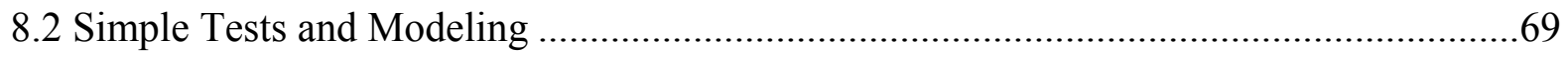

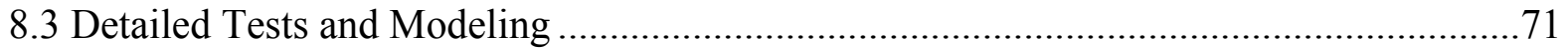

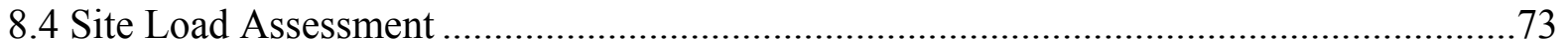

8.5 Prototype Monitoring ............................................................................................... 74

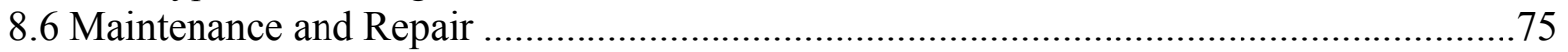

9 Conclusions

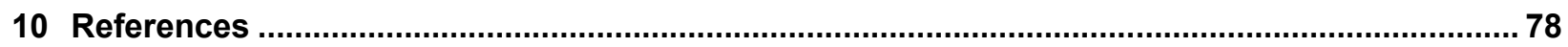

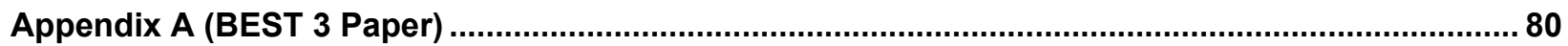

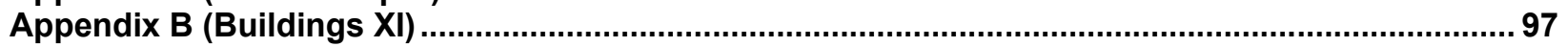

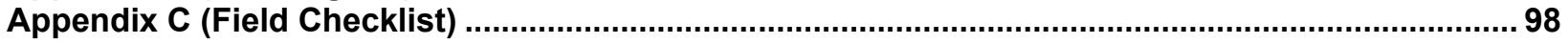

\section{Figures}

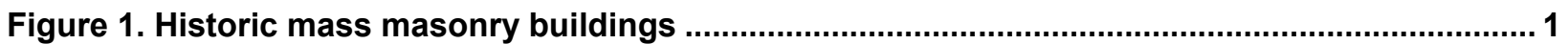

Figure 2. Habitat Merrimack Valley building and site evaluation (current Building America project)2

Figure 3. Byggmeister project building and site evaluation (current Building America project)....... 2

Figure 4. Exterior insulation retrofit overclad ................................................................................ 4

Figure 5. Exterior insulation retrofit approaches (Left: Exterior insulation and finish system; Right:

Insulated metal panel cladding) ............................................................................................. 5

Figure 6. Drained panel spray foam exterior insulation (and airtightening) retrofit of a solid

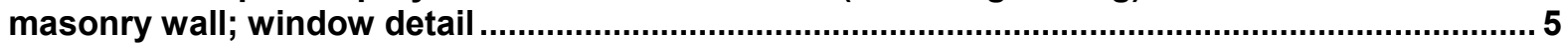

Figure 7. Exterior spray urethane foam retrofit on residential masonry.......................................... 6

Figure 8. Various retrofit installations of interior spray foam insulation on mass masonry ............. 7

Figure 9. Heat flux simulations with uninsulated, 1.5-in., and 3-in. ccSPF walls ............................11

Figure 10. Examples of mass masonry walls and rain control ...................................................... 13

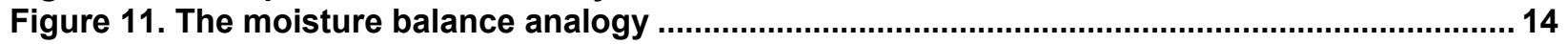

Figure 12. Moisture sources and mechanisms for an arbitrary enclosure wall ...............................15

Figure 13. Moisture removal mechanisms; no drainage and ventilation in mass masonry walls.... 15

Figure 14. Voids commonly found between wythes of brick in masonry walls ................................ 16

Figure 15. Left: Pre-retrofit temperature gradients through wall; Right: post-retrofit temperature

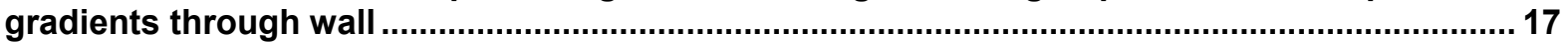

Figure 16. Steel angle bolted to masonry to transfer load out of beam pocket ............................... 18

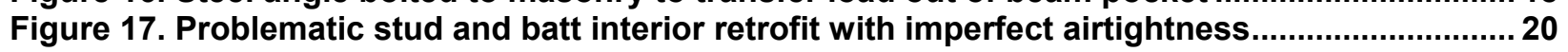

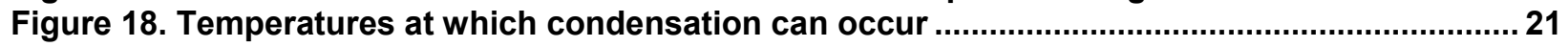

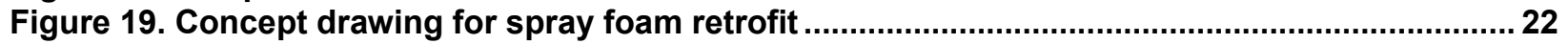

Figure 20. Interior spray-foam retrofit (insulation and airtightening) of brick wall with wood

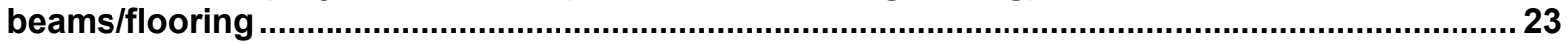

Figure 21. Conceptual drawing of rigid board foam retrofit, with liquid applied membrane ........... 24

Figure 22. Conceptual drawing of hybrid spray foam and fibrous (air-permeable) insulation

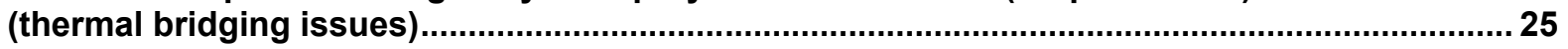

Figure 23. Hybrid spray foam/damp spray cellulose assembly (steel stud not recommended) ...... 26

Figure 24. Conceptual drawing of hybrid spray foam and fibrous (air permeable) insulation

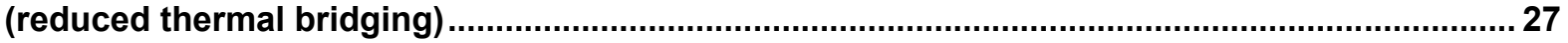

Figure 25. Retrofit interior drained assembly on mass masonry wall, with air gap membrane ....... 29

Figure 26. Concept drawing of pressure-controlled interior retrofit .................................................. 30

Figure 27. Clip tying framing to concrete masonry unit backup wall, steel clip shown; not

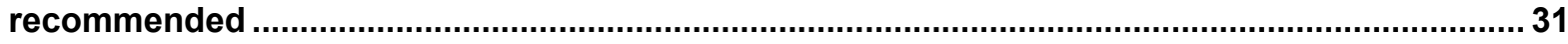

Figure 28. Polymer framing as alternate material with better thermal resistance ............................. 32

Figure 29. Improper drainage off window faces, and staining at window sill grout joints .............. 34

Figure 30. Window detail for interior retrofit; note thermal "wrap" at sill and pan flashing, and sloped, projecting sill with drip edge. 
Figure 31. Precast window sloped sill, close up of end dams

Figure 32. A high performance window sill, exhibiting end dams, steep slope, large projection, jamb extensions, and drip edge

Figure 33. Solid granite sloped sill, potential for water introduction into wall................................... 36

Figure 34. Drip edges and sloped sills are critical deflection elements ......................................... 37

Figure 35. Failed mortar joint at sill from concentrated runoff, resulting in brick failure ................. 37

Figure 36. Precast window sill drip edge details .............................................................................. 38

Figure 37. Left: Window sill without brick corbeling (left); Right: Window sill with brick corbeling,

showing different mortar erosion patterns.

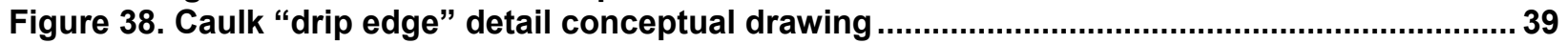

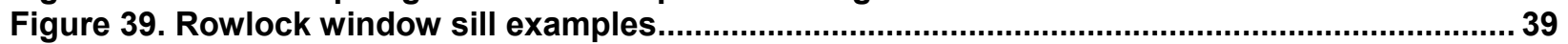

Figure 40. Left: Rowlock window sill with no projection; Right: Water deposition on wall below .. 40

Figure 41. Left: Metal overclad detail of existing rowlock sill; Right: Original detail .......................40

Figure 42. Example of overclad sill detail (formed metal) ............................................................ 41

Figure 43. Left: Problem rowlock detail; Right: Failure of brick at detail ...................................... 41

Figure 44. Conceptual drawing of window subsill pan and subsill reglet drip edge ....................... 42

Figure 45. Left: Membrane flashing wrapping window opening; Right: Exterior view of window assembly and completed unit ................................................................................................. 42

Figure 46. Left: Interior view of sill/jamb flashing details; Right: Head-jamb detail ......................... 43

Figure 47. Window opening with tapered jamb detail (sill left uninsulated; not recommended) ..... 43

Figure 48. Gypsum board at window openings with tapered jamb detail (sill left uninsulated; not recommended)

Figure 49. Staining on decorative arch coping stones, concentrations at joints .............................44

Figure 50. Steps in brickwork, and related cracking/FT damage ...................................................45

Figure 51. Water concentration at stone belt and cornice joints ................................................45

Figure 52. Unmaintained band course; plant growth at mortar joints .............................................. 46

Figure 53. Left: Retrofit roof over entrance; Right: Water runoff concentration at roof-wall interface46

Figure 54. Water runoff concentration at roof-wall interface (kickout flashing required) ................. 47

Figure 55. Water runoff concentration at roof-wall interface (kickout flashing required) .................. 47

Figure 56. Left: Interior paint/parging delamination; Right: Exterior conditions for comparison.... 48

Figure 57. Moisture issues at roof-wall and windows in retrofitted building ....................................48

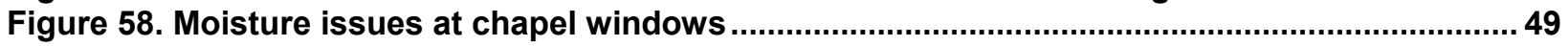

Figure 59. Severe FT damage at existing chimney; lack of projecting cap with drip edge................50

Figure 60. Coping detail and runoff staining at joints of previous coping design............................50

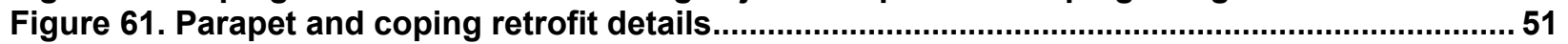

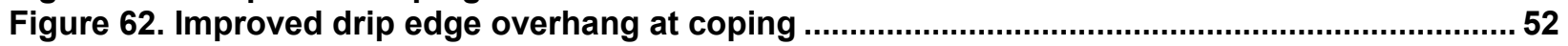

Figure 63. Stone parapet cap, with joints in stone coping ….......................................................... 52

Figure 64. Stone parapet cap retrofit options; membrane layer highlighted....................................53

Figure 65. Left: FT damage at downspout disconnection; Right: delamination of brick .................. 54

Figure 66. Disconnected downspout and related damage to masonry.............................................54

Figure 67. Left: Damaged pilaster at downspout; Right: Severe mortar erosion...................................55

Figure 68. Common masonry wall assembly with non-porous stone at grade ............................... 55

Figure 69. Left: Severe subfluorescence and spalling at basement window; Right: Stone shelf

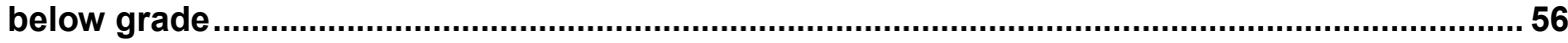

Figure 70. Left: Rear wall near subfluorescence damage visible in basement; Right: Buried

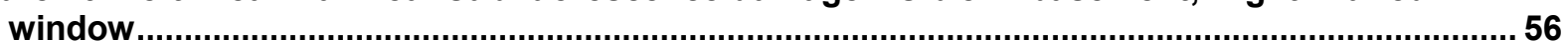

Figure 71. Pre-retrofit building interior at grade condition........................................................... 57

Figure 72. Exterior parking lot grade relative to interior conditions .............................................5 57

Figure 73. Air gap membrane below grade and top closure strip................................................58

Figure 74. Ground skirt foundation water control (with added insulation) ........................................58

Figure 75. Brick condition adjacent to front steps, splashback evident........................................... 59

Figure 76. Left: Embedded beam uninsulated case; Right: Insulated case .................................... 61

Figure 77. Left: Typical embedded beam; Right: 3-D representation of beam and floor ..................62

Figure 78. Left: Typical embedded floor joists; Right: Simulation representation ............................62

Figure 79. Heat loss through $42 \mathrm{ft}^{2}\left(4 \mathrm{~m}^{2}\right)$ of wall assembly with joist framing, various cases ........ 63

Figure 80 . Wood beam end ( 1 in. $[25 \mathrm{~mm}])$ moisture contents; uninsulated cases.......................... 64 
Figure 81. Wood beam end (1 in. [25 mm]) moisture contents; insulated cases (+ uninsulated) .... 64 Figure 82. Guidance on protection of embedded floor framing near grade .....................................66

Figure 83. Exterior details that demonstrate FT damage in existing masonry buildings ................ 69

Figure 84. Interior details showing previous moisture issues at window and roof-wall interface... 69

Figure 85. Brick liquid water uptake (A-value) testing ...................................................................... 70

Figure 86. Example WUFI model showing discretization and critical layers for FT failure...............70

Figure 87. FT temperature and moisture content graph for evaluation of risk ................................. 71

Figure 88. Left: Removal of brick sample; Right: dilatometry (dimensional change) measurements72 Figure 89. Determination of $S_{\text {crit }}$ value plotting degree of saturation against strain (dilation) .......... 72

Figure 90. Rain deposition factor (RDF) .............................................................................. 73

Figure 91. Instrumented occupied building (Waterloo, Ontario) with driving rain gauges ............... 74

Figure 92. Instrumentation plan and monitoring locations, prototype installation in Toronto,

Ontario

Unless otherwise noted, all figures were created by Building Science Corporation.

\section{Tables}

Table 1. Air Leakage Through Masonry Materials (Wilson 1961) .................................................21

Table 2. Excerpt from IRC Table R601.3.1, Requirements for Use of Class III Vapor Retarder ....... 26

Table 3. R-Value and Water Vapor Permeability Properties for Various Insulation Materials .......... 28

Table 4. Thermal Performance of Wood Frame Stud Wall Options, With Spray Foam Insulation ... 31

Unless otherwise noted, all tables were created by Building Science Corporation. 


\section{Definitions}

ASTM American Society for Testing and Materials

BSC Building Science Corporation

ccSPF Closed-cell spray polyurethane foam

DOE U.S. Department of Energy

EIFS Exterior Insulation and Finish Systems

EPS Expanded polystyrene

FT Freeze-thaw

IAQ Indoor air quality

ocSPF Open-cell spray polyurethane foam

PCF Pounds per cubic foot

RH Relative humidity

$\mathrm{S}_{\text {crit }} \quad$ Critical degree of saturation

SPF Spray polyurethane foam

WUFI Wärme- Und Feuchtetransport Instationär

XPS Extruded polystyrene 


\section{Executive Summary}

Load-bearing masonry buildings are a significant portion of the existing building stock. Given the Building America goals of reducing home energy use by 30\%-50\% (compared to 2009 energy codes for new homes and pre-retrofit energy use for existing homes), insulation and air sealing of mass masonry walls will need to be components of this work if mass masonry residential buildings are to be addressed.

Exterior insulation provides the ideal conditions for building durability; however, many buildings cannot be retrofitted with insulation on the exterior for reasons such as historic preservation, cost, zoning or space restrictions, or aesthetics. Adding insulation to the interior sides of walls of such masonry buildings in cold, and particularly cold and wet, climates may cause performance and durability problems. There are specific moisture control principles that must be followed for a successful insulated retrofit of a solid load-bearing masonry wall.

In terms of cost effectiveness, uninsulated masonry (even "thick" multi-wythe construction) would have an average $\mathrm{R}$ value of roughly $\mathrm{R}-5$, which is far below current energy code requirements; insulation has substantial benefits. The wintertime thermal mass benefits of leaving masonry uninsulated are negligible in heating-dominated climates, compared to locations with high diurnal swings around the interior set point (as found in milder climates).

Increasing the building airtightness (which would result from this interior retrofit) can cause indoor air quality problems: mechanical ventilation, pollution source control, and combustion safety measures must be implemented to manage this risk.

When examining the moisture problem, the fundamental premise is that mass masonry walls manage moisture in a different way than modern, drained assemblies. Therefore, the balance of moisture (into and out of the wall) is strongly affected by interior insulation. For one, the masonry wall becomes colder: the inside face of the masonry wall changes from seeing moderate temperatures to regularly experiencing freezing temperatures. In addition, the wall has reduced drying to the interior (by cooling the masonry, and by adding vapor-impermeable layers on the interior), and the amount of energy flow through the wall (and thus drying potential) has been minimized. In addition, moisture flow caused by air leakage into the interface between the masonry and the insulation can result in condensation problems; excellent airtightness is desirable to prevent this. Another issue is rot/corrosion of embedded elements: embedded wood timbers are a common element with durability concerns.

In terms of interior insulation assembly options, drywall on a steel stud wall filled with batt insulation is not recommended. It has a high likelihood of wintertime condensation and mold growth in the wall, caused by leakage of interior air into the cold interface between the insulation and the masonry. This would be exacerbated in a pressurized building.

A more successful approach involves spraying an airtight insulating foam directly to the interior side of the existing masonry: all air leakage condensation is strictly controlled, and it is the most practical approach to achieving high levels of airtightness in existing buildings. The spray foam also acts as a moisture barrier, and any small amount of incidental rain penetration will be localized and controlled. High-density closed cell polyurethane foam is generally a good solution 
for thinner applications (e.g., 2 in. of ccSPF), and open-celled semipermeable foams (e.g., 5 in. ocSPF) can be a good choice for greater thickness if the interior is kept at a low humidity during winter and the outdoor temperature is not too cold.

Rigid foam board insulation of various types has been used as the interior retrofit, but is far more difficult to build, as it requires great care in ensuring that the board is firmly in contact with the masonry (no gaps), and that a complete air barrier is formed. Note that bare masonry has been measured as a noticeable source of air leakage, thus showing the need for an air barrier layer, typically applied to the interior face of the masonry.

Another assembly option is to combine spray or rigid board foam with fibrous, air-permeable insulation (fiberglass or cellulose) to create a lower cost high-R wall assembly. The relative thickness of the foam layer is a function of condensation control, and thus climate conditions.

Thermal bridging through wood framing will have a minimal impact on thermal performance if wood stud framing allows for at least 1 in. of insulation (preferably 2 in.). However, thermal bridging through light-gauge steel framing has a significant impact: the gap for insulation between the framing and the masonry should be maximized; preferably, there should be minimal to no insulation placed within the steel stud bay. Steel stud clips back to the masonry also have a significant thermal bridging effect; they should be replaced with a thermally nonconductive material.

Controlling bulk water entry into the wall when doing interior masonry retrofits is of vital importance, especially as water leakage will no longer be visible from inside until damage occurs to interior finishes. If rain control cannot be addressed and upgraded, interior insulation should not be implemented. Various critical details were examined, showing problems and solutions.

Windows and doors are nonabsorbent, and hence shed all the rainwater that strikes them. To prevent masonry durability problems, rainwater surface drainage must not be concentrated on the wall below, and this water should be shed from the face of the building. Drainage and shedding are accomplished by a sloped sill detail with end dams, and a sufficient drip edge beyond the wall below. Rowlock window sills are especially vulnerable, as they are composed of individual bricks with mortar joints, which will be a source of water leakage. One possible solution to reduce water loading into the wall below is to overclad the rowlock course with metal flashing.

Leakage through the wall-to-window joint or the window unit itself can contribute to masonry moisture loading. To prevent this issue, a subsill pan flashing should be installed, which directs any of this water out onto the sill to the exterior.

Copings and parapet caps can suffer from problems such as inadequate slope, incorrect slope, inadequate overhangs, and inadequate drip edges: they can all cause accumulation of bulk water on the masonry below. Projecting drip edges and waterproofing under the cap are vital details to implement at these assemblies.

Details such as stonework and band courses can result in water concentration and deposition on the face of the building. Solutions include overclad caps and drip edges below these features. 
Roof-wall interfaces can be another source of water concentrations; details such as kickout flashings are critical to prevent these issues.

Downspouts, rainwater leaders, and scuppers, when improperly designed or when they fail to function, can concentrate a tremendous amount of water, making freeze-thaw (FT) damage very likely.

When brick is buried below grade, severe subfluorescence and spalling may result from capillary water uptake (moisture wicking) through the brick. The recommended solution to these buried brick issues is to eliminate capillary contact between the soil and the brick. Another risk close to grade is splashback; this is reduced with softer landscaping (not pavement), or by keeping roof and wall drainage away from the adjacent ground.

Another durability risk is the hygrothermal behavior of moisture-sensitive wood beams embedded in the load-bearing masonry. Simulations were run to examine the thermal and moisture behaviors of embedded beams before and after insulation. Overall, these simulations indicate substantial uncertainty in how embedded wood members in masonry actually behave in service after insulation retrofits. Further research is warranted, including the use of twodimensional hygrothermal simulations and in-situ measurements in both insulated and uninsulated configurations.

When considering the interior insulation of a masonry building, a series of steps are recommended to assess the risks associated with this retrofit, with greater certainty with added steps, as follows:

1. Site Visit Assessment (assessment of rain leakage, poor detailing, existing FT damage)

2. Simple Tests and Modeling (dry density, liquid water uptake, saturation moisture content, and basic hygrothermal/WUFI modeling)

3. Detailed Tests and Modeling (thermal conductivity, Fagerlund's critical degree of saturation or $\mathrm{S}_{\text {crit }}$ )

4. Site Load Assessment (assessment of driving rain load, run down patterns; monitoring of rain deposition with driving rain gauges)

5. Prototype Monitoring (retrofit of a small area of the building, and monitoring of temperature and moisture content, including comparisons to models)

6. Maintenance and Repair (creating a recommended program of inspection/repair, perhaps in the form of a building owner's manual).

Although many of these retrofits are being implemented in locations throughout North America, there are still major needs for continued work and research on this topic, including comparisons between models and in-service behavior, increasing the database of interior insulated mass masonry buildings, an improved understanding of rain loadings on walls, and research on clear sealants such as silanes and siloxanes. 


\section{Introduction}

Load-bearing brick masonry buildings are a significant portion of the existing building stock in the East Coast and Midwest regions of the United States (see Figure 1). However, adding insulation to the interior sides of walls of such masonry buildings in cold, and particularly cold and wet, climates may cause performance and durability problems in some cases. Exterior insulation provides the ideal conditions for building durability; however, many buildings cannot be retrofitted with insulation on the exterior for reasons such as historic preservation, cost, zoning or space restrictions, and aesthetics.
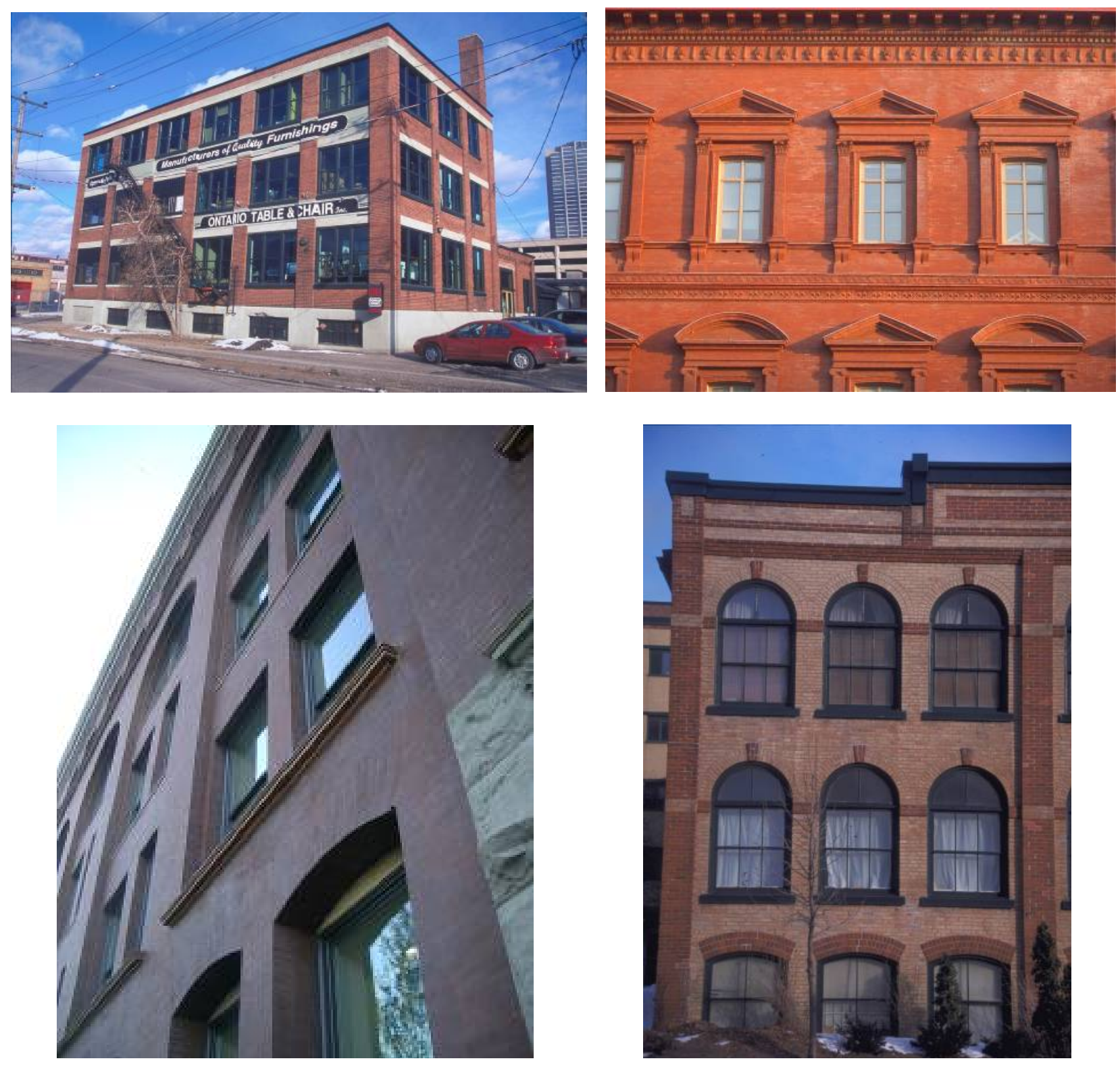

Figure 1. Historic mass masonry buildings

Interior insulation of existing mass masonry structures is a measure that is being implemented in current Building America projects, including the Habitat for Humanity of Merrimack Valley 
project in Lawrence, Massachusetts (Figure 2), and the Byggmeister brick row house renovation in Roxbury, Massachusetts (Figure 3).
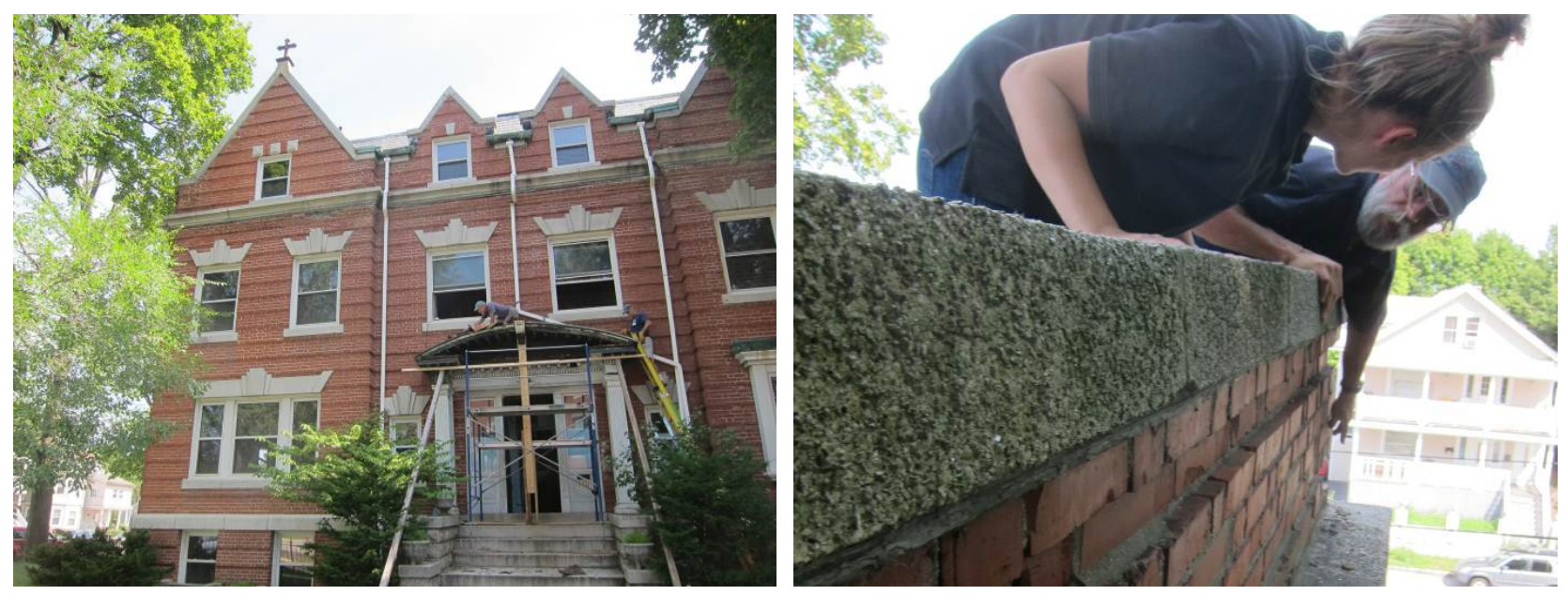

Figure 2. Habitat Merrimack Valley building and site evaluation (current Building America project)
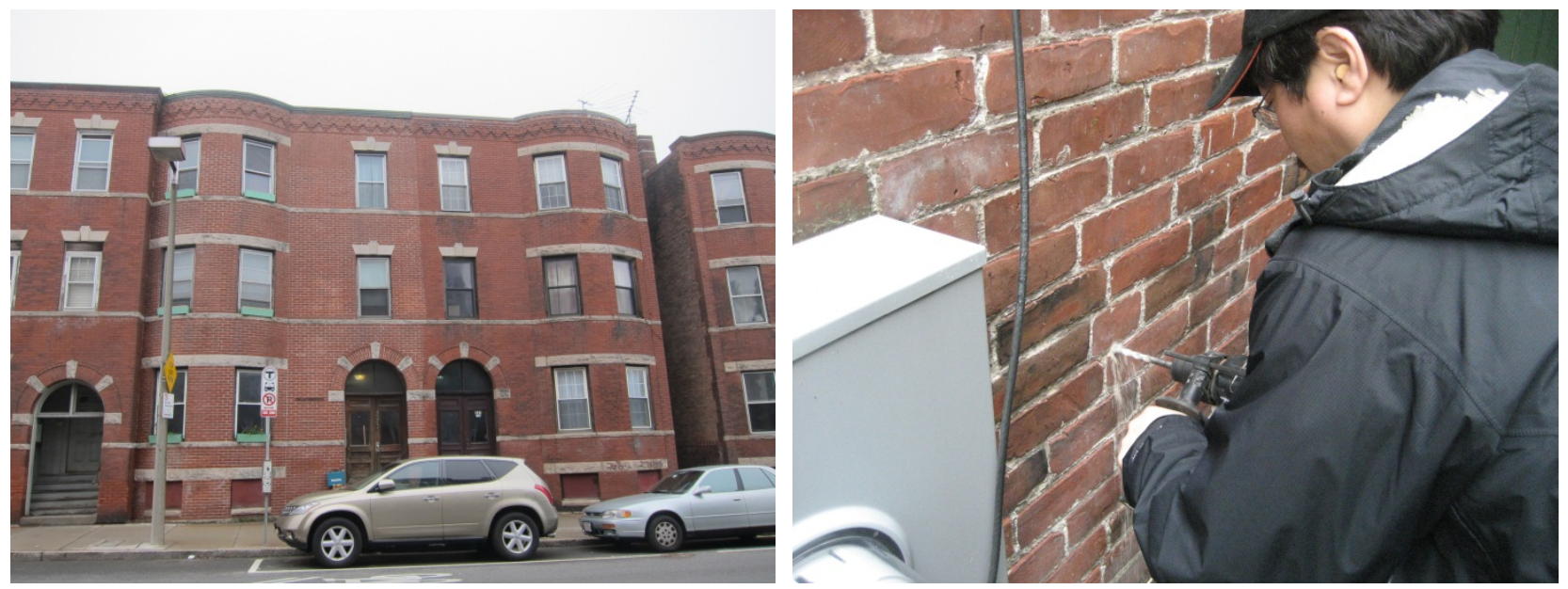

Figure 3. Byggmeister project building and site evaluation (current Building America project)

There are specific moisture control principles that must be followed for a successful insulation retrofit of a solid load-bearing masonry wall. This measure guideline presents the current stateof-the-art for guidance in terms of moisture-safe retrofits of mass masonry walls. This guideline is divided into the following sections:

- Background places the problem of masonry insulation in context, including the advantages of exterior insulation, the relative risks of interior insulation, and citations of previous research.

- Decision-Making and Tradeoffs covers further material, which includes cost effectiveness, performance tradeoffs (including quantification of energy benefits of mass versus insulation), and system interactions.

- Retrofitting for Durability describes the balance of wetting and drying that is occurring in building enclosure elements, and how this balance changes when mass masonry walls 
are retrofitted with interior insulation. It points out specific durability issues, such as freeze-thaw (FT) damage, interstitial condensation, and damage to embedded wood timbers.

- Interior Retrofit Assemblies and Solutions then covers a variety of interior insulation details that have shown good performance in service, as well as describing problematic assemblies, and why they are prone to failure. A further discussion of thermal performance (overall insulation value) is included in this section.

- Interior Retrofit Problematic Details and Solutions examines exterior water control detailing of masonry structures, which is key to a successful interior insulation retrofit; this could be considered a guide to conducting field reviews of these buildings. Some key details include windows, band courses, roof-wall interfaces, parapets, downspouts, and areas at or close to grade. A case study of a building that showed problems post-retrofit is also included, to show what can go wrong if water control details are not addressed.

- Embedded Wood Member Research is a summary of a conference paper that examined the effect of insulation on masonry-embedded wood structural members in detail, using three-dimensional thermal simulations, and one-dimensional hygrothermal simulations. Overall, these simulations indicate that there is substantial uncertainty in how embedded wood members in masonry actually behave in service after insulation retrofits. Further research is recommended, including more advanced hygrothermal simulations, and field monitoring.

- The final section, Assessment, Analysis, and Risk Management, presents a series of six recommended steps to assess the risks associated with this retrofit, and to determine what can be done to mitigate this risk. Each incremental step reduces uncertainties in the evaluation (and thus reduces risk). These steps included diagnostic tests and techniques to manage risk of FT damage to the masonry. 


\section{Background}

\subsection{Context}

Reducing the energy consumption of buildings has become increasingly imperative because of the combined demands of energy security, rising energy costs, and the need to reduce the environmental damage of energy consumption. In addition to new buildings, there is a vast stock of existing buildings, most of which have poorly insulated enclosures.

Upgrading, renovating, and converting buildings to new uses and higher performance levels involve numerous challenges. A socially, culturally, and economically important class of buildings is solid, usually load-bearing, masonry buildings, typically built before World War II. These buildings have value because they often have good reserves of structural capacity, are located near urban centers, are beautiful or historically significant, and often offer flexible, lowcost space that can be easily converted to housing.

\subsection{Exterior Insulation of Mass Masonry Structures}

Retrofitting existing buildings on the exterior (Figure 4 through Figure 7), is the best possible technical solution: exterior insulation provides the highest level of durability, energy efficiency, and comfort with the least technical risk. Specifically, externally applied insulation and air/water control layers have the following advantages:

- The insulation and air/water control layers can easily be made continuous and thus protect the existing structure (masonry) from rain, condensation, and temperature swings.

- Thermal bridging at floors and partitions is eliminated.

- Thermal mass benefits are enhanced.

- Access to conduct the work is often easier.
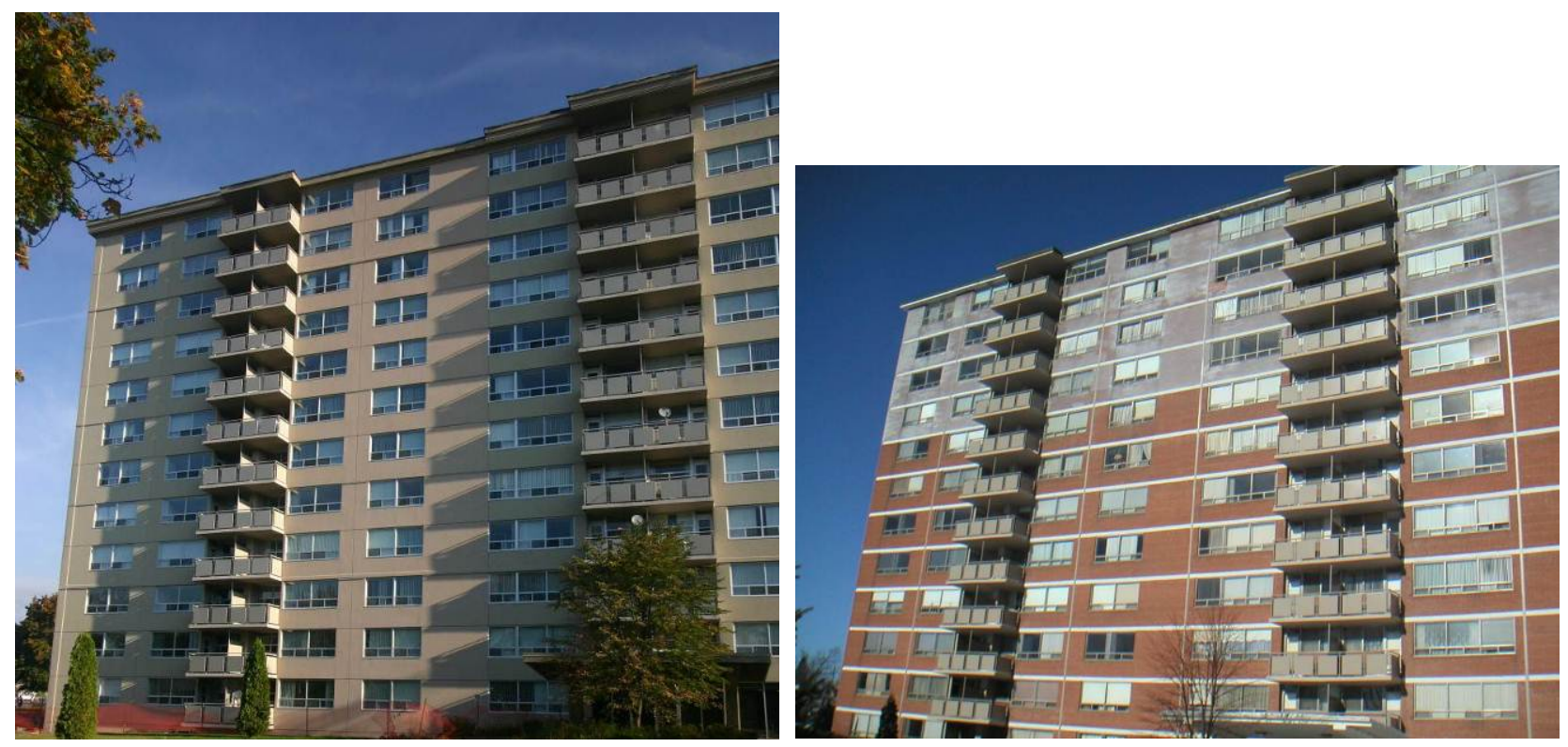

Figure 4. Exterior insulation retrofit overclad 


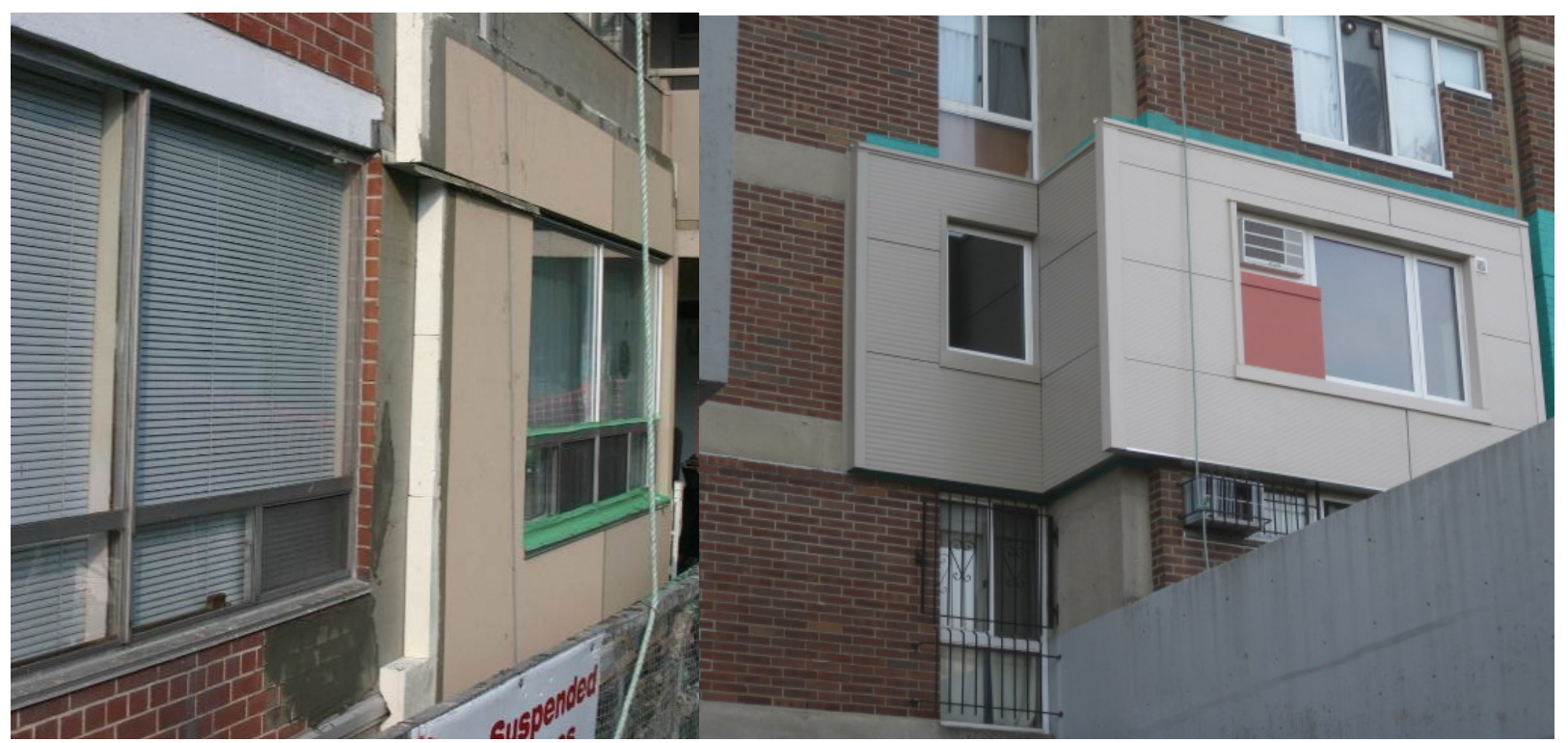

Figure 5. Exterior insulation retrofit approaches (Left: Exterior insulation and finish system; Right: Insulated metal panel cladding)

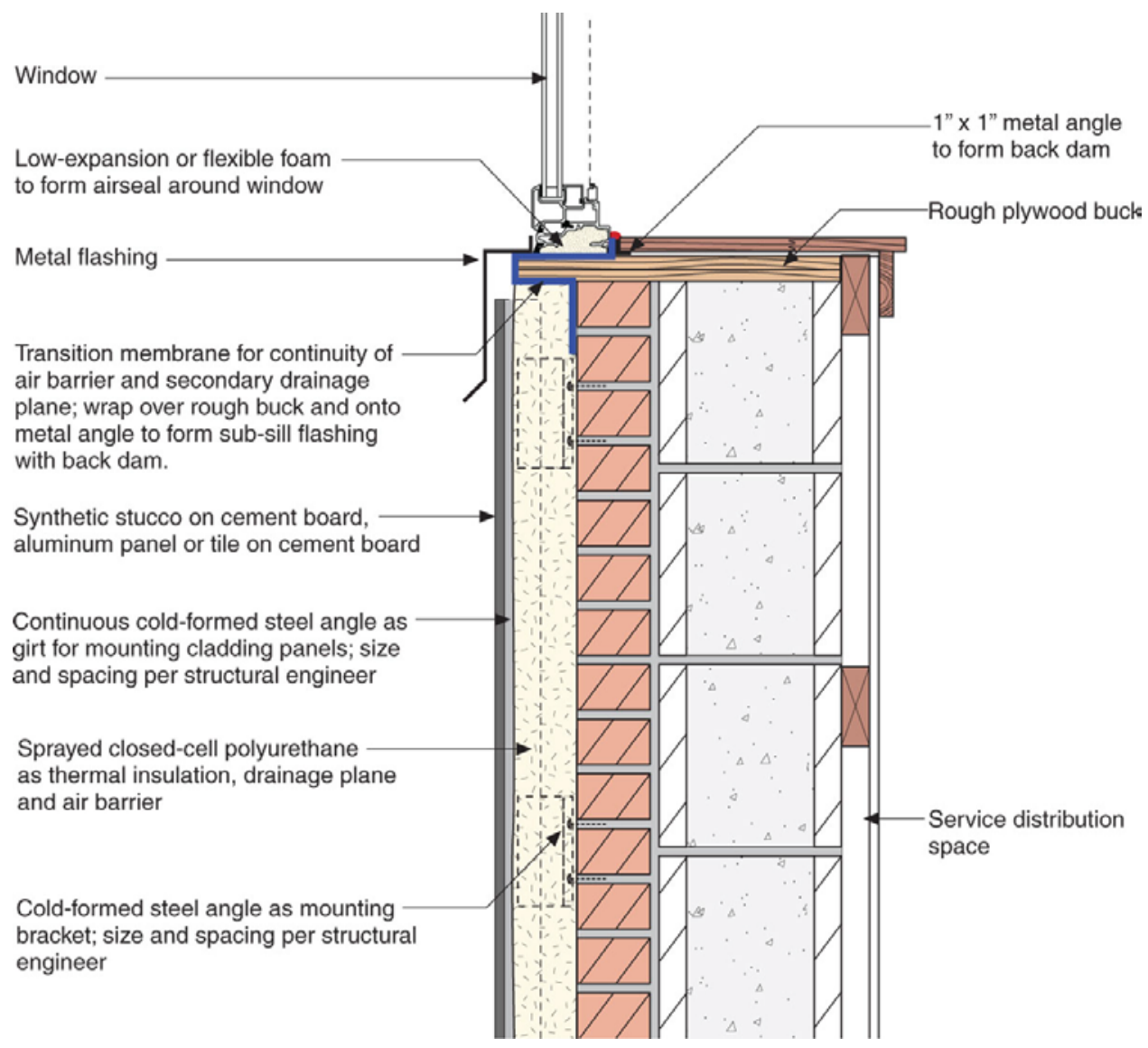

Figure 6. Drained panel spray foam exterior insulation (and airtightening) retrofit of a solid masonry wall; window detail 

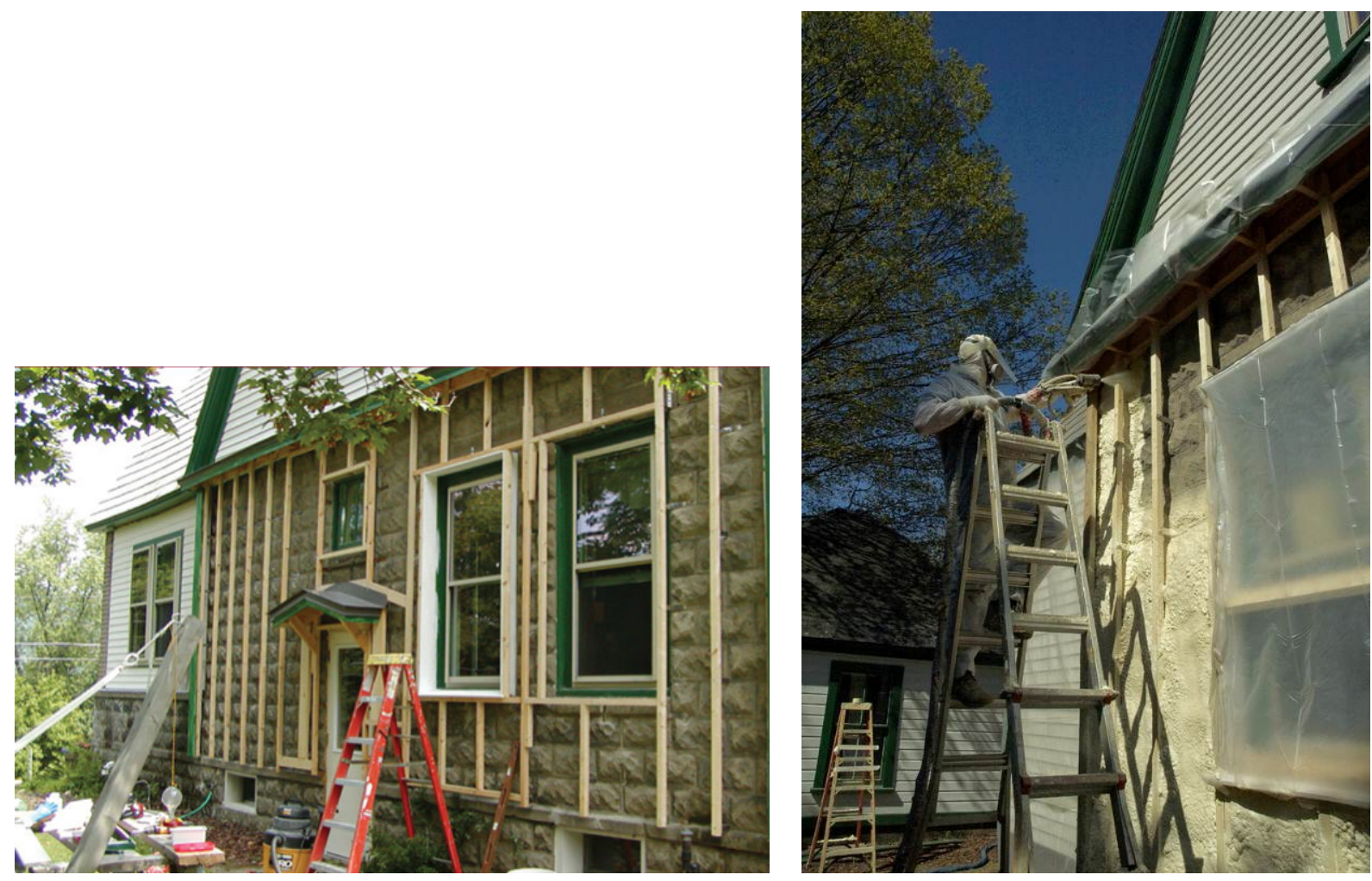

Figure 7. Exterior spray urethane foam retrofit on residential masonry

Given the option, exterior insulation (in the form of an overclad such as exterior insulation and finish system/EIFS, drained panel systems over insulation and membrane, or similar) should always be the preferred, least risk retrofit.

\subsection{Interior Insulation of Mass Masonry Structures}

Despite the advantages of exterior insulation, many buildings must be retrofitted on the interior, for reasons such as historic preservation, zoning or space restrictions, or aesthetics (Figure 8). Load-bearing masonry buildings often (not always) have historic significance and highly valued aesthetics that preclude exterior retrofits.

Interior retrofits of load-bearing masonry are often desired to preserve the exterior appearance. There are many possible interior insulation approaches that are, by and large, reasonably well understood. Adding insulation, increasing airtightness, replacing windows, and improving rain control constitute a normal retrofit package. Adding insulation to the walls of such masonry buildings in cold (and particularly cold and wet) climates may cause performance and durability problems, particularly rot and FT damage.

There are specific moisture control principles that must be followed for a successful interior retrofit of a solid masonry wall. The goal of this measure guideline is to present the current stateof-the-art for guidance in terms of moisture-safe retrofits of solid masonry walls, with some discussion of specific details that have higher durability risks. This guideline provides engineering, architectural, and contractor guidance for assessing and minimizing the risk of FT damage arising from the interior insulation of mass wall assemblies. It also provides similar guidance for assessing and managing the decay risk of embedded wood structural members. 


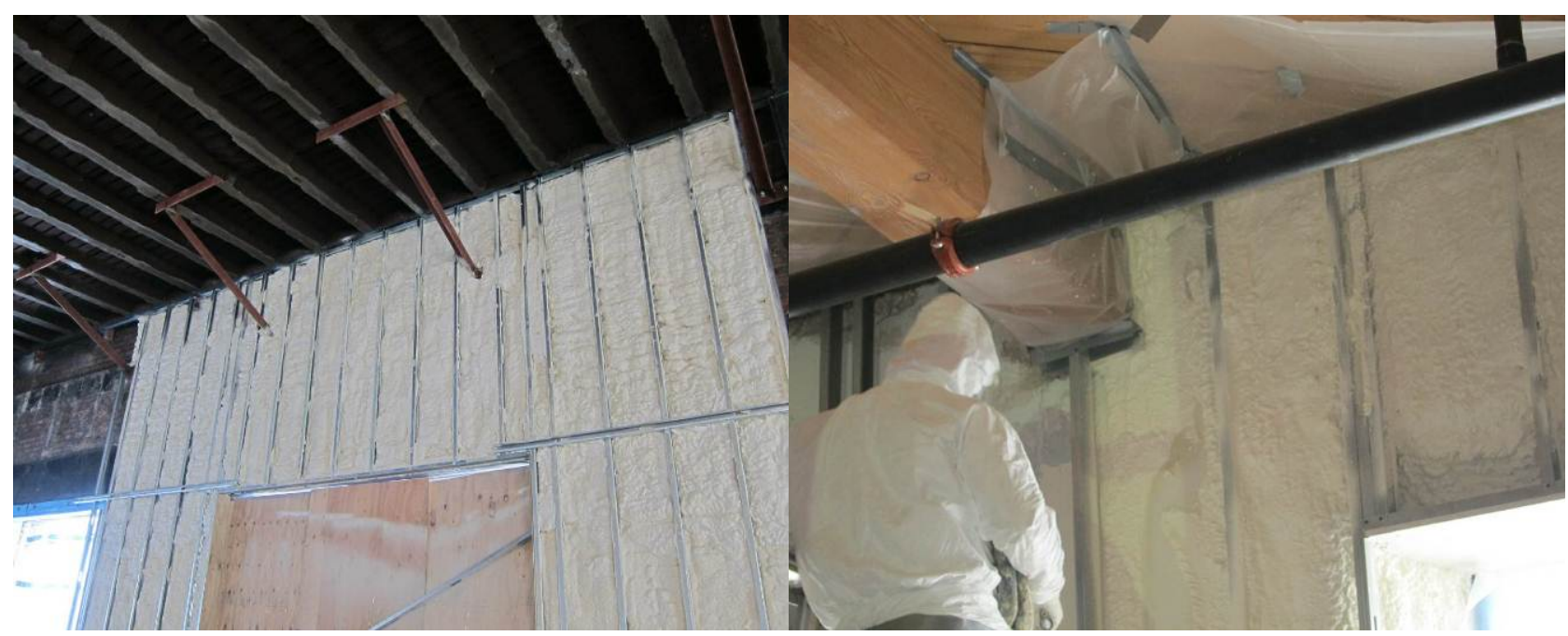

Figure 8. Various retrofit installations of interior spray foam insulation on mass masonry

\subsection{Previous Research}

It has long been known that exterior insulation provides the ideal conditions for building durability and performance (Hutcheon 1964). This approach is further described by Lstiburek (2007a).

Numerous obstacles to more wide-scale deployment of interior retrofits include concerns about FT damage caused by reduced outward heat flow and reduced inward drying, and the potential for decay of wood structural framing members (typically floor joists) that are embedded in mass assemblies. The problems and some case studies of interior retrofits are outlined by practitioners such as Gonçalves (2003), Maurenbrecher et al. (1998), and Straube and Schumacher (2002, 2004).

The masonry FT issue has been examined by (among others) Mensinga et al. (2010), who propose the use of material property testing as an input to hygrothermal simulations, using a limit states design approach. The embedded floor joist decay issue has been studied by some practitioners (Dumont et al. 2005; Morelli 2010), but many issues remain unresolved.

\subsection{Relevance to Building America's Goals}

The goal of the U.S. Department of Energy's (DOE) Building America program is to reduce home energy use by $30 \%-50 \%$ (compared to 2009 energy codes for new homes and pre-retrofit energy use for existing homes). It is clear that uninsulated above-grade and below-grade masonry walls will be significant sources of heat loss in any heating-dominated climate. This will render achieving those targets difficult (if not impossible) without insulating and air sealing.

However, it is important to avoid retrofits that result in undesirable outcomes such as poor indoor air quality (IAQ) (from mold or other microbial growth), damage to the structure, or aesthetic problems on the building exterior. If a significant number of these retrofits become associated with problems, this can result in major negative publicity for retrofit programs. Determining safe thresholds and guidance for these retrofits is therefore imperative.

Most of the construction that can benefit from this research is in locations with older building stock (mass masonry). The greatest concentrations are likely on the East Coast and in the 
Midwest (cold climates), although these types of buildings are definitely present throughout country.

Potentially millions of housing units could benefit from a better understanding of the moisture risks associated with interior retrofits, and the means of reducing the risks.

\section{Critical Takeaways}

Retrofitting existing buildings on the exterior is the best possible technical solution: exterior insulation provides the highest level of durability, energy efficiency, and comfort with the lowest technical risk.

In cases where an exterior retrofit is not possible, adding interior insulation to the walls of masonry buildings in cold (and particularly cold and wet) climates may cause performance and durability problems, particularly rot and FT. 


\section{Decision-Making and Tradeoffs}

\subsection{Measure Selection Criteria}

The first decision that needs to be made is whether to pursue an interior or exterior retrofit, or for that matter, to do nothing. Doing nothing is typically not an option, as the concerns that drove the interest in a retrofit must be addressed.

It is always technically superior to undertake an exterior retrofit. An interior retrofit may or may not be less expensive, depending on such factors as access and whether a gut rehabilitation (full replacement of services at the exterior wall) is planned. Exterior retrofits typically have an advantage over interior insulation with respect to energy performance (thermal bridging at floor, thermal mass effects, etc.). However, this is only one small facet of the decision-making process: issues as aesthetics, historic significance, improved comfort, and the lifespan of the project tend to dominate this decision instead. These types of decisions are beyond the scope of this work.

The major decisions that need to be made - once an interior retrofit has been decided on - are related to the techniques of how to apply insulation and ensure airtightness, which materials to use, and how to deal with durability and rain control concerns.

The choices for materials and techniques tend to be divided between interior studwork filled with low-density, air permeable insulation (e.g., fiberglass batt), and studwork on the inside of semipermeable foam insulations. There are significant differences because of the risks of interstitial condensation and durability, which will be discussed in Section 5.

\subsection{Cost Effectiveness}

Load-bearing masonry has a wide range of thermal properties. However, even a thick multiwythe load-bearing masonry wall is likely to have an R-value in the range of R-3.2 to R-6.8, with an average R-value of around R-5. Surface heat transfer coefficients ("air films") of another R-1 may result in thermal performance comparable to that of a high-end (triple glazed) modern window; however this level of insulation is too low for most practical purposes (considering current energy costs, building durability, health, and thermal comfort issues). Hence, insulation is often added during retrofits.

The R-values of uninsulated masonry walls are also substantially below modern code requirements for cold climates. For Zones 5 and 6, the typical opaque-wall "true" R-value requirements are in the range of $\mathrm{R}-12$ to $\mathrm{R}-17$, as calculated from $\mathrm{U}$ values given in the 2009 International Energy Conservation Code/IECC, Table 402.1.3 (ICC 2009).

Thermal insulation follows the law of diminishing returns: return on investment decreases with increasing insulation thickness. Given that these wall assemblies are being changed from uninsulated (base case) to insulated (final) assemblies, it is likely that the initial inch or two of insulation should be highly cost effective. Optimization would be a function of insulation cost and climate zone.

In many (perhaps most) cases of insulation retrofits of load-bearing masonry buildings, the energy savings are not that important to the owner. Instead, insulating and air sealing are being pursued to meet modern expectations for thermal comfort, to control rain penetration, and to 
ensure IAQ. This desire covers the cost of mobilization and the initial levels of intervention: energy efficiency and payback calculations become important only once the minimum performance has been met. Therefore, the marginal cost of adding another inch of insulation above the minimum accepted for performance should be entered into the payback calculations.

Building Science Corporation's (BSC) current retrofit recommendations include the use of closed-cell air-impermeable spray foam as an interior insulation material for mass masonry walls. Closed-cell spray polyurethane foam (ccSPF) has a typical installed price of roughly $\$ 1.00 /$ board foot; when normalized by R-value (instead of volume) this is equivalent to around $\$ 0.16 / \mathrm{ft}^{2} \cdot \mathrm{R}$. In comparison, typical loose-fill fibrous insulations are sold at $\$ 0.02-0.04 / \mathrm{ft}^{2} \cdot \mathrm{R}$; note that this is a material cost, not an installed cost. If a 1:1 material-to-installation cost ratio is assumed for this estimate, the use of ccSPF is still roughly two to four times as expensive as the lowest cost loose fill materials. However, as will be discussed in the measure guideline, the use of air permeable, moisture-sensitive fibrous insulations in this application result in assemblies with higher risk of moisture-related failures.

\subsection{Performance Tradeoffs and Other Benefits}

Basic benefits of the retrofit insulation of uninsulated masonry walls include energy savings and thermal comfort improvements for occupants (brought about by radiant surface temperature effects and air leakage reduction). The assemblies under discussion could meet the requirements for modern energy codes, as discussed earlier.

One belief that appears to be common among less technical practitioners is that insulation of mass masonry structures is unnecessary, as thermal mass effects provide sufficient benefits. Basic energy models can be used to show that thermal mass is not significant to energy performance for buildings located in heating-dominated (cold) climates. Thermal mass is of greater benefit in locations with high diurnal swings around the interior set point, as commonly found in the U.S. Southwest. This was demonstrated using a one-dimensional hygrothermal model (WUFI; Künzel 2002), tabulating heat flux through uninsulated and insulated wall assemblies in a cold climate such as Burlington, Vermont, in DOE Zone 6 (see Figure 9). The addition of $1.5 \mathrm{in}$. of insulation (closed cell spray polyurethane foam) resulted in a $60 \%$ reduction in heat flux through the walls relative to the uninsulated case. Increasing this insulation to 3 in. resulted in a 75\% reduction compared to the uninsulated case (an improvement, but demonstrating diminishing returns).

Note, however, that this analysis is not intended to be a dismissal of thermal mass as a concept: energy savings can be obtained by combining insulation with thermal mass; temporal load shifting effects can be another benefit. 

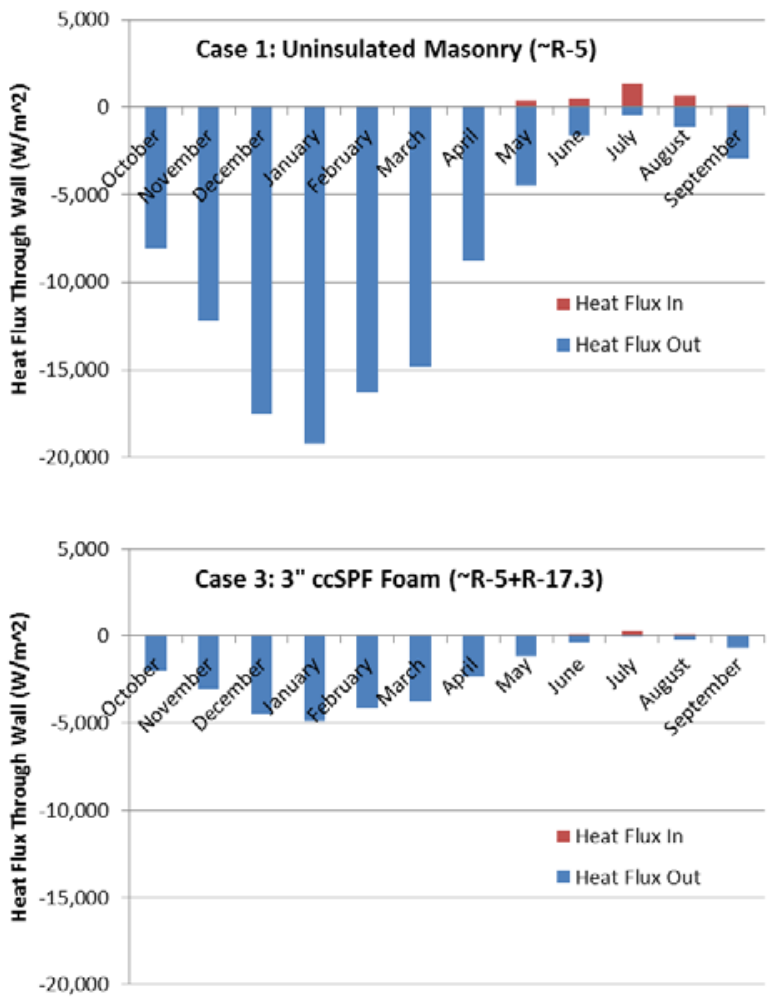

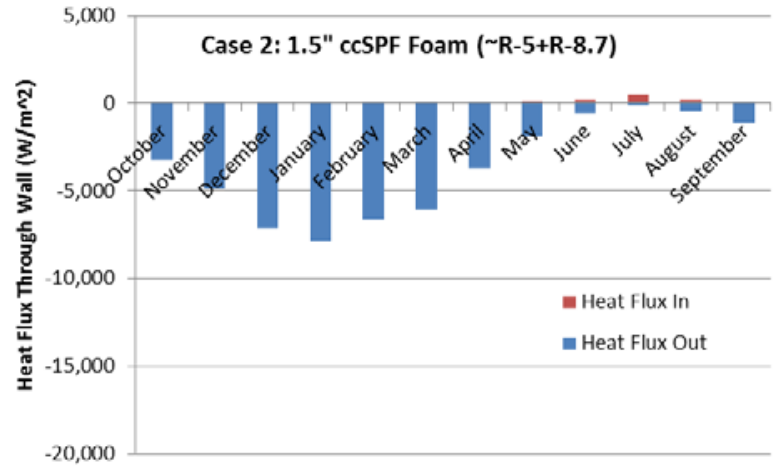

Climate: Burlington, Vermont

Case 2 (add 1.5 in. ccSPF, R-8.7) $\approx 60 \%$ reduction in heat flow through walls versus uninsulated case

Case 3 (add 3 in. ccSPF, R-17.3) $\approx 75 \%$ reduction in heat flow through walls versus uninsulated case

Figure 9. Heat flux simulations with uninsulated, 1.5-in., and 3-in. ccSPF walls

\subsection{System Interactions}

If an interior retrofit improves both the insulation value and airtightness, numerous risks must be assessed. Both goals may reduce the durability of the masonry, because the masonry will — by definition - be colder for longer periods of time than before, and will have less drying capacity, both because it is colder and because the interior layers added by the retrofit will restrict vapor diffusion. The colder post-retrofit masonry will also make air leakage condensation much more likely in cold weather. Concerns also exist for any moisture-sensitive floor structure that is embedded in the masonry: wood beams are especially sensitive to decay after an interior retrofit is completed.

Increasing the building airtightness can cause IAQ problems. To manage this risk, mechanical ventilation and pollution source control must be implemented. Like all buildings, when airtightening is undertaken, there is a concern about the possibility of back drafting atmospherically vented combustion appliances. Closed combustion appliances (drawing combustion air from the exterior) can be specified to eliminate this risk. Alternately, spillage testing can be conducted and vents added to furnace/boiler rooms to minimize the risk. Combustion appliances could be moved outside the building enclosure, but this loses the benefit of recapturing system losses within the conditioned space. This approach often results in less than ideal air barrier performance as well. 


\section{Critical Takeaways}

A multi-wythe load-bearing masonry wall is likely to have an R-value in the range of R-3.2 to R6.8 , with an average R-value of around R-5, which is substantially below modern codes. Given that these wall assemblies are being changed from uninsulated (base case) to insulated (final) assemblies, it is likely that the initial inch or two of insulation should be highly cost effective.

Recommendations in this report call for air-impermeable ccSPF as an interior insulation material for mass masonry walls, which is substantially more expensive than fibrous insulation such as fiberglass batt. However, the latter is not recommended, as it results in assemblies with higher risk of moisture-related failures.

One belief that appears to be common among less technical practitioners is that insulation of mass masonry structures is unnecessary, as thermal mass effects provide sufficient benefits. Basic energy models can be used to show that thermal mass is not significant to energy performance for buildings located in heating-dominated (cold) climates: retrofit of insulation is necessary to obtain any reasonable energy performance.

Increasing the building airtightness - which would result from this interior retrofit — can cause IAQ problems. Mechanical ventilation, pollution source control, and combustion safety measures must be implemented to manage this risk. 


\section{Retrofitting for Durability}

Almost all modern wall assemblies are designed and constructed using different materials to satisfy the various functions of the building enclosure (structure, control of moisture, heat and air, and interior and exterior finish, as discussed in Straube and Burnett 2005). Solid load-bearing masonry assemblies are by their nature durable. However, the manner in which they manage moisture is quite different than modern, framed, multilayer assemblies (Figure 10). It is important to understand the difference in behavior to support decision-making during retrofits.

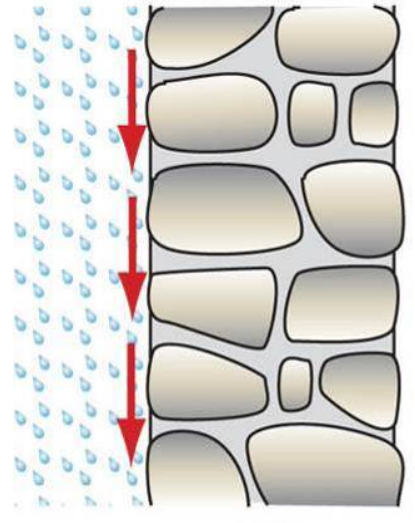

Rubble

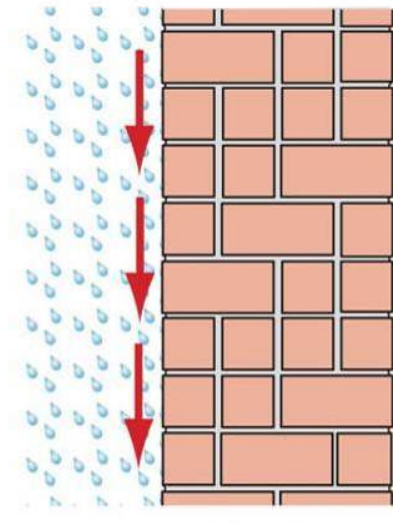

Solid Masonry

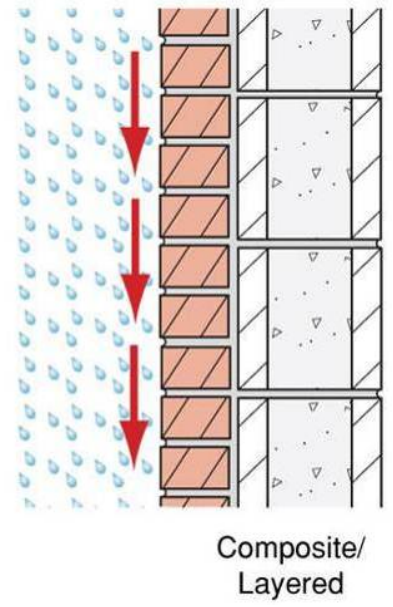

Figure 10. Examples of mass masonry walls and rain control

The primary concern with insulating older load bearing masonry buildings in cold climates is the possibility of causing FT damage of the brickwork and decay in any embedded wood structure. Both concerns are related to excess moisture content; hence, a review of moisture in building enclosures, particularly walls, is appropriate.

\subsection{The Moisture Balance}

For a moisture-related problem to occur, at least five conditions must be satisfied:

- A moisture source must be available.

- There must be a route or means for this moisture to travel.

- There must be some driving force to cause moisture movement.

- The materials involved must be susceptible to moisture damage.

- The moisture content must exceed the material's safe moisture content for a sufficient length of time.

To avoid a moisture problem one could, in theory, choose to eliminate any one of the conditions listed. In reality, it is practically impossible to remove all moisture sources, to build walls with no imperfections, or to remove all forces driving moisture movement (Straube and Burnett 2005). It is also not economical to use only materials that are not susceptible to moisture damage. Therefore, in practice, it is common to address two or more of these prerequisites to reduce the 
probability of exceeding the safe moisture content and the amount of time the moisture content is exceeded.

All enclosure design requires a balance of wetting and drying (Figure 11). Wetting occurs at different times than drying, so storage bridges the time between wetting and drying. If a balance between wetting and drying is maintained, moisture will not accumulate over time, the safe moisture content will not be exceeded, and moisture-related problems are unlikely. The storage capacity and the extent and duration of wetting and drying, however, must always be considered when assessing the risk of moisture damage.

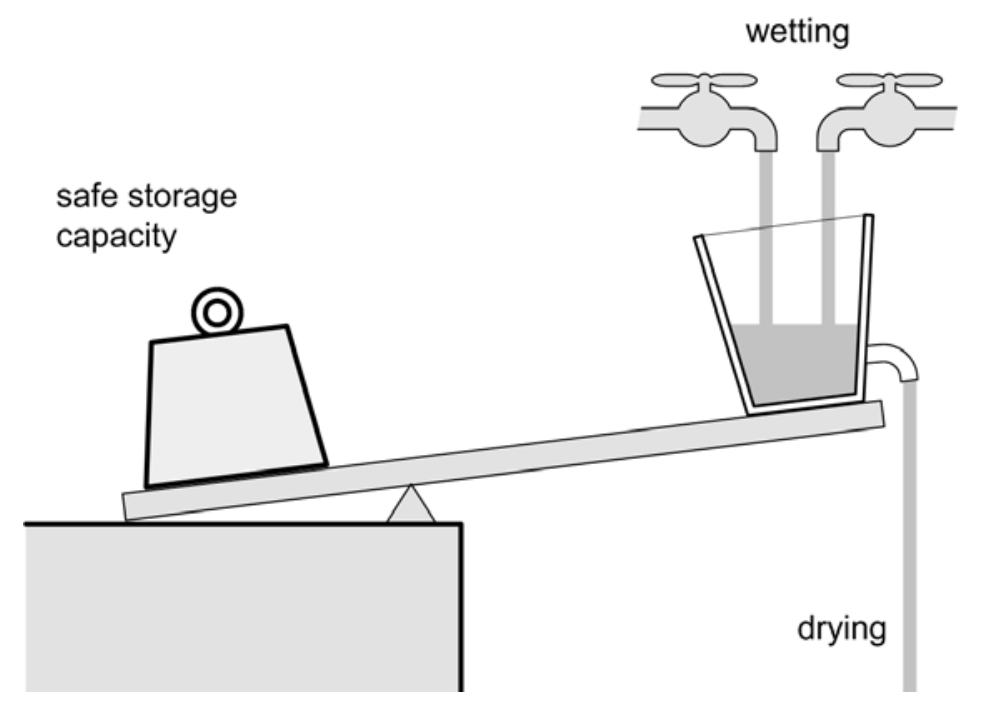

Figure 11. The moisture balance analogy

(Straube and Burnett 2005)

The four major sources of moisture for the above-grade building enclosure are (Figure 12):

- Precipitation, especially driving rain

- Water vapor in the air transported by diffusion and/or air movement through the wall (from either the interior or exterior); inward vapor drives caused by inward thermal gradients/solar heating are a particular vapor diffusion phenomenon relevant here (see Lstiburek 2006; Straube and Burnett 2005)

- Built-in and stored moisture

- Liquid and bound groundwater. 


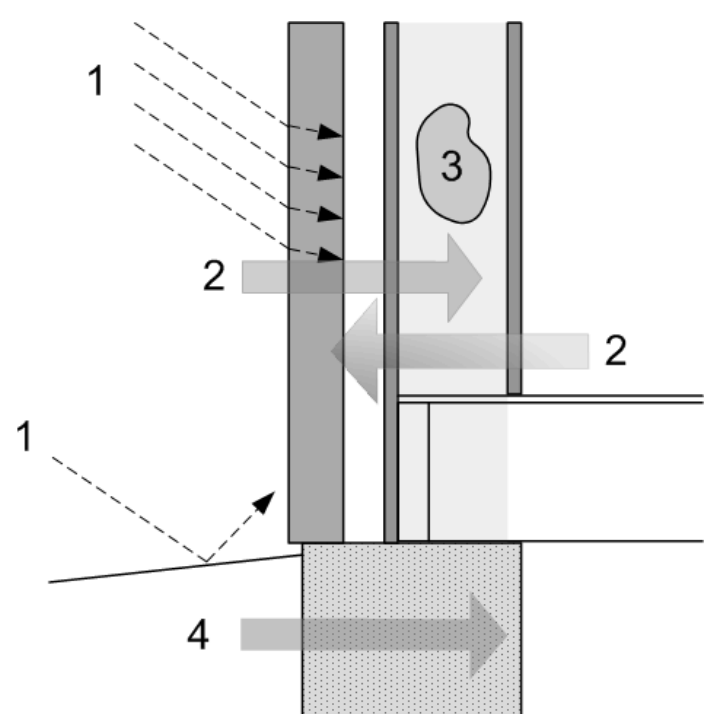

Figure 12. Moisture sources and mechanisms for an arbitrary enclosure wall

A wall assembly's drying potential is an important factor in assessing its vulnerability to moisture problems. Moisture is usually removed from any generic enclosure assembly by (Figure 13):

- Evaporation of water transported by capillary suction through microscopic pores to the inside or outside surfaces

- Vapor transport by diffusion (through microscopic pores), air leakage (through cracks and holes), or both, either outward or inward

- Drainage through small cracks and openings, driven by gravity

- Ventilation (ventilation drying), the intentional flow of air behind the cladding.

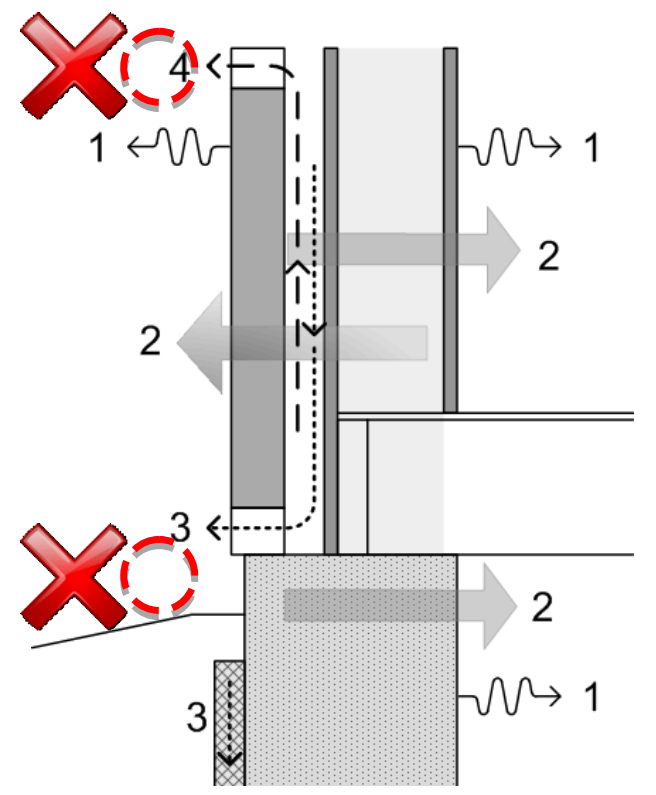

Figure 13. Moisture removal mechanisms; no drainage and ventilation in mass masonry walls 
Solid masonry walls were never designed to use mechanisms 3 and 4 (drainage and ventilation) to provide drying. In some cases, drainage and ventilation may be added to the inside face of a masonry wall (see Section 5.6.1). This is desirable (as it converts the load-bearing masonry wall to a masonry veneer wall from the point of view of hygrothermal performance), but it is often not practical (because of floor joist and partition wall penetrations), and may actually increase the risk of failure.

\subsection{Historic Masonry Materials}

There are many types of masonry walls that must be considered in a retrofit. In many cases, the masonry is multi-wythe clay brick; however, there are many possible conditions that occur in practice. Examples include natural stone masonry (ashlar or rubble, of many different types of stone), a mix of brick and terracotta backup wall, or even concrete masonry units faced with brick. As each of these materials responds differently to moisture, each may require a different approach.

To add further complexity, clay brick masonry walls were often built with different quality of bricks in different parts of the wall assembly. Bricks that had been perfectly fired were used on the exterior as face brick, over- and under-fired bricks were installed in the core, and bricks of intermediate quality used on the interior (BIA 1988, Ritchie, 1971). This is not a universal observation, but a common one. All of the brick types, manufactured by the same kiln at the same time, can have very different properties.

The wall assemblies described as solid masonry may in fact contain many hollow spaces (Figure 14). Voids, sometimes full-height, sometimes story height, and sometimes only 16-24 in. high are often found between layers of masonry. These voids act as capillary breaks, and may allow water to accumulate or concentrate, as they are invariably not intentionally drained.
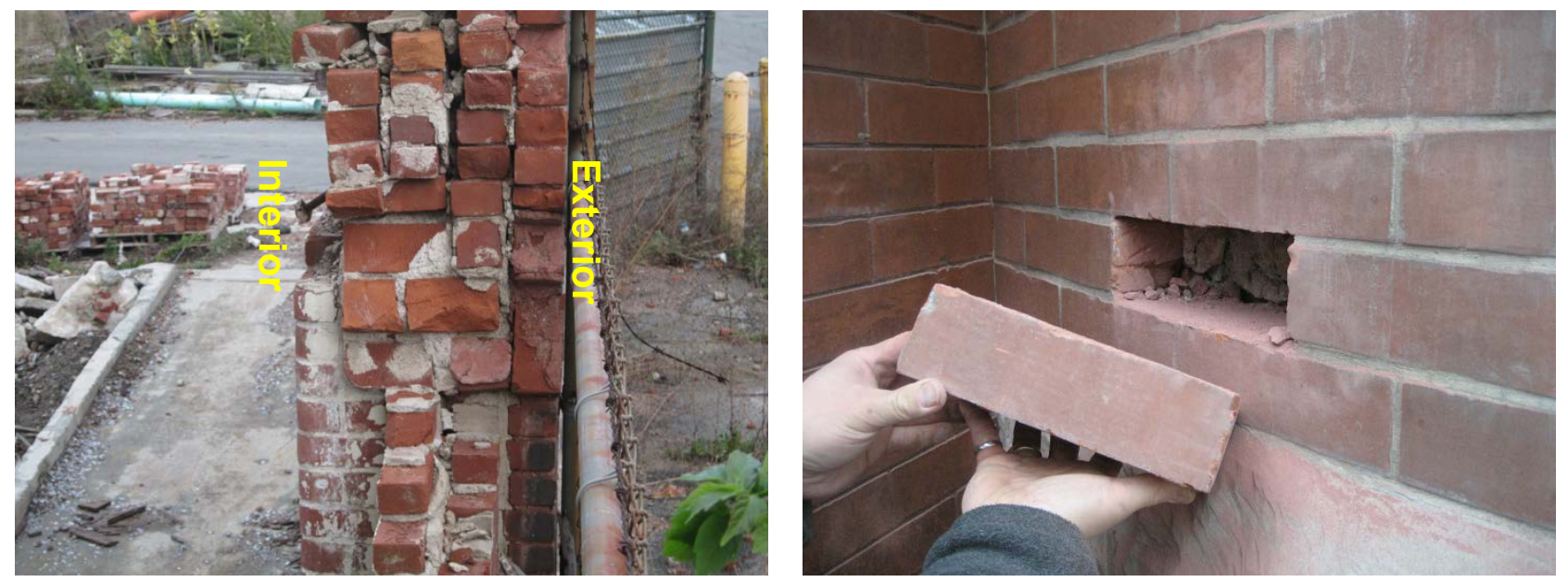

Figure 14. Voids commonly found between wythes of brick in masonry walls

The interior of masonry walls may be finished with plaster, often gypsum or lime-cement based, and sometimes installed over furring strips and/or lath. In some cases, a layer of bitumen is applied between the interior finish and the masonry. These finish layers may need to be removed as part of the retrofit, if they are moisture sensitive (like gypsum), or if they form a void that can create unintentional air leakage (such as furring and lath). 


\subsection{Durability Concerns}

Generally, the outside layers of the masonry experience the same rain and similar temperatures pre- and post-retrofit: the exterior $\sim 1 / 2$ in. of masonry experiences the same temperature regime, and the same rain wetting.

The biggest changes occur at the inside face of the masonry wall. Before the retrofit, the assembly experienced moderate temperatures close to interior conditions (Figure 15, left). After the retrofit, the inside face will experience much colder temperatures and often wetter conditions (Figure 15, right). With just modest levels of insulation, the interior face of the masonry can regularly experience freezing temperatures. Hence, the concern is whether there is a potential for FT damage created by the retrofit.

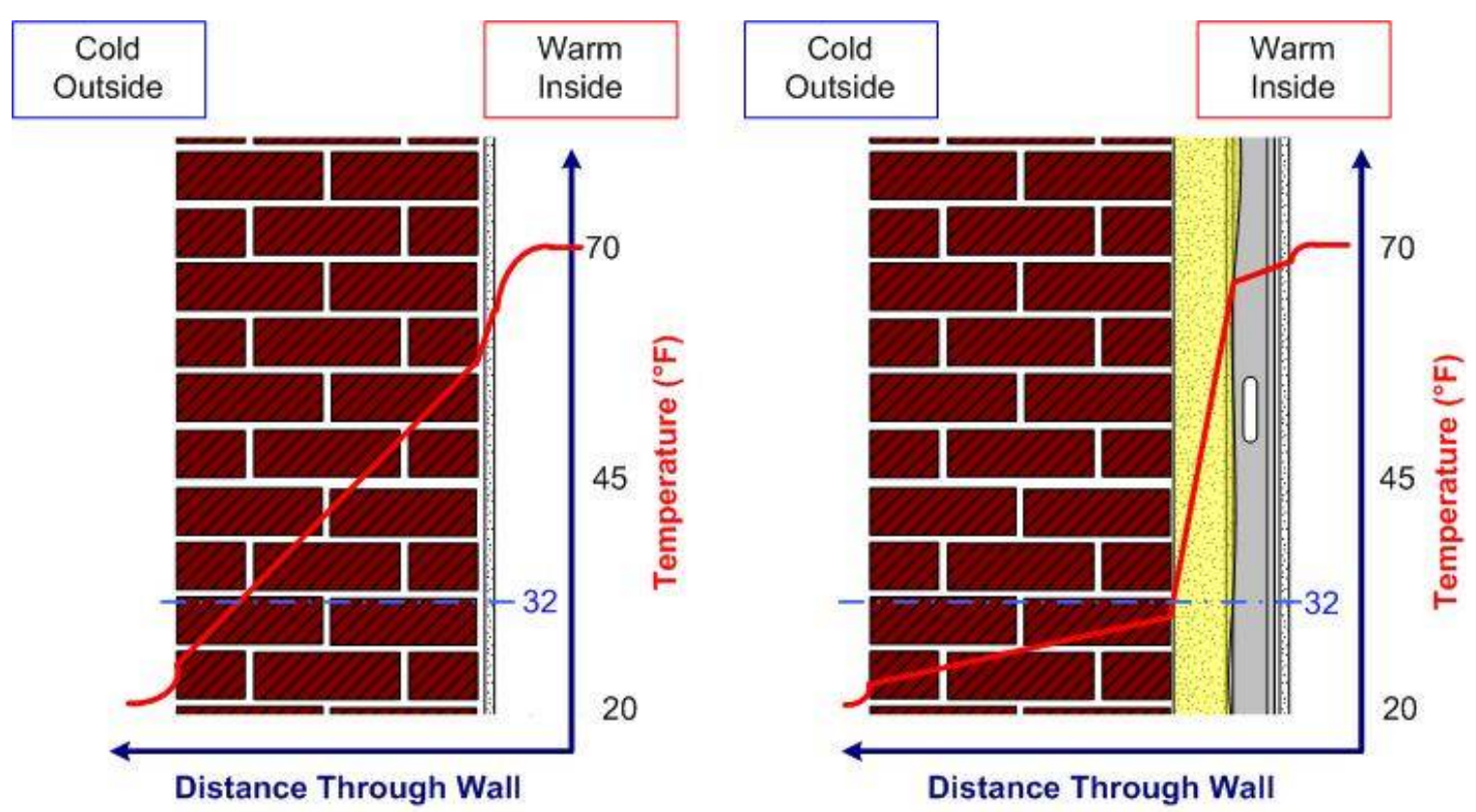

Figure 15. Left: Pre-retrofit temperature gradients through wall; Right: post-retrofit temperature gradients through wall

Other impacts of interior insulation retrofits are that the assembly had reduced drying to the interior (by cooling the masonry, and by adding vapor impermeable layers on the interior), and the amount of energy flow through the wall (and thus drying potential) has been minimized.

There is also a condensation risk at the masonry-to-insulation interface. In the early days of masonry retrofits (1970s oil crisis), steel stud and fiberglass batt were often installed and covered with polyethylene on the interior. However, air leakage could bypass imperfectly installed polyethylene vapor barriers/air barriers, resulting in condensation problems. This condensationbased wetting would occur in a layer that is cold enough to precipitate condensation, and often would drop below freezing. Although this interface is hidden, it became a durability issue, manifested as the assembly degrading and FT spalling in some cases. We have no documented cases of this occurring, but this type of failure has been described second- and third-hand by numerous sources. To avoid this problem, excellent airtightness on the interior is desirable. 
It is worth noting that only partial success in air sealing the assembly from the interior can be much more dangerous than a rigorous, correctly executed air barrier. A small air leak in an otherwise insulated assembly will still result in a condensation on the cold surface. In contrast, a gross air leak might result in localized warming of the masonry surface, reducing the amount of condensation. However, the latter case should never be relied on to provide good performance; uncontrolled air leakage may still find cold surfaces to condense on. Overall, half measures result in greater risk than full measures.

In the post-retrofit building, an additional durability risk is the fact that bulk water entry (as addressed by exterior bulk water control methods such as flashings and overhangs) will not be as evident from interior inspection. Interior signs of bulk water intrusion (e.g., visible leaks, "bubbling" plaster, efflorescence, and wet window sills) are often the first signs of problems, which are typically noticed and reported by building occupants. Any type of interior retrofit reduces the visibility of these indicators: this makes continuing exterior upkeep and water control a critical factor over the future service life of the building.

Another durability concern is rot/corrosion of embedded elements. A counteracting aspect of this issue with interior insulation retrofits is that although the assembly may have higher moisture contents, it is also much colder during winter months - which slows the rate of both corrosion (chemical reactions) and rot (biological reactions).

Embedded wood timbers are a common embedded element with durability concerns. A number of solutions are being pursued, including borate injections into the wood, metal wedges next to the member (to provide passive heat flow), active heating, or construction of a load-bearing structure inside the masonry (Figure 16), and cutting off the end of the beam.
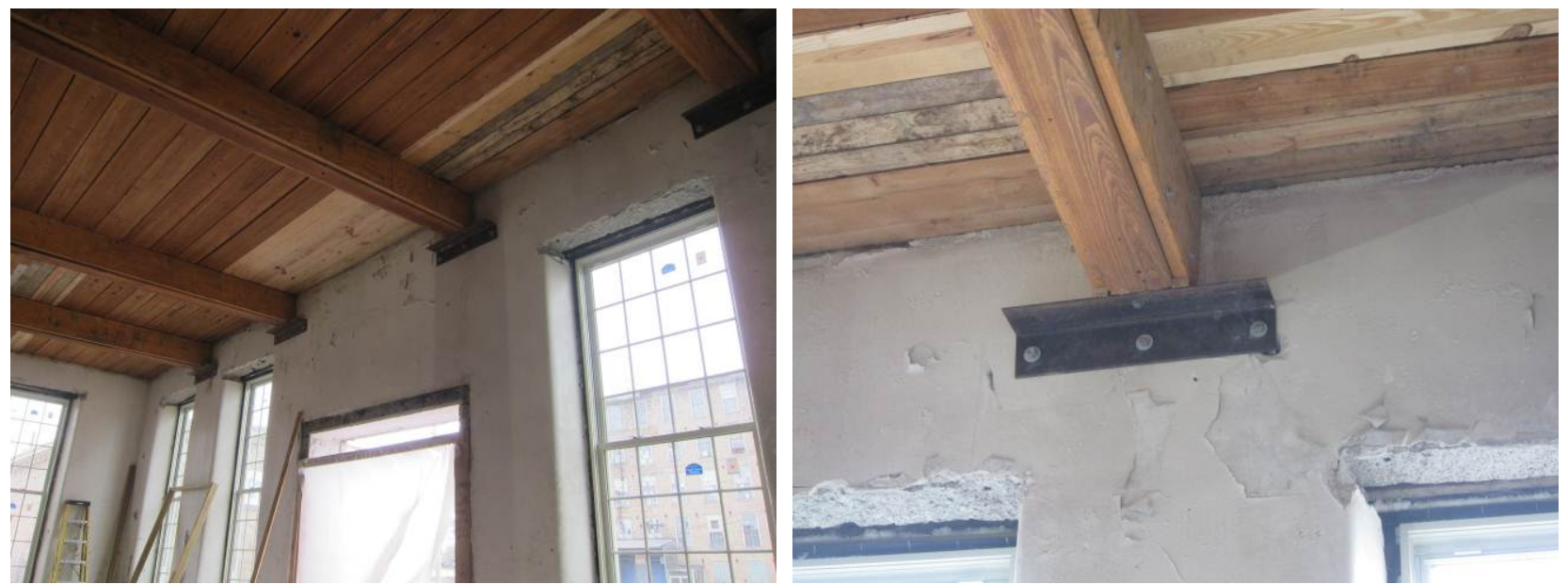

Figure 16. Steel angle bolted to masonry to transfer load out of beam pocket

Windows and door penetrations must be given careful consideration during the retrofit process. Ensuring rain control and thermal continuity (avoiding thermal flanking) are paramount for good performance and require good detailing. A minimum insulation value around window openings is required to prevent condensation. Rain penetration at the window-to-wall interface and the effects of surface features (sills, lintels, drips) on rain shedding or concentration features must be addressed. 


Critical Takeaways
In mass masonry walls, moisture is managed in a different way than in modern, drained
assemblies. Therefore, the balance of moisture (into and out of the wall) is a critical aspect that is
affected by the application of interior insulation.
The outside layers of the masonry experience the same rain and similar temperatures pre- and
post-retrofit. However, the inside face of the masonry wall changes from seeing moderate
temperatures to regularly experiencing freezing temperatures.
Other impacts of interior insulation retrofits are that the assembly had reduced drying to the
interior (by cooling the masonry, and by adding vapor impermeable layers on the interior), and
the amount of energy flow through the wall (and thus drying potential) has been minimized.
Moisture flow caused by air leakage into the interface between the masonry and insulation can
result in condensation problems. Excellent airtightness on the interior is critical to avoid
problems.
Another issue is rot/corrosion of embedded elements: embedded wood timbers are a common
element with durability concerns.
The interior of masonry walls may be finished with plaster, and sometimes installed over furring
strips or lath. These finish layers may need to be removed as part of the retrofit, if they are
moisture sensitive (like gypsum), or if they form a void that can create unintentional air leakage
(such as furring and lath).




\section{Interior Retrofit Assemblies and Solutions}

As described in Section 4, there are numerous approaches to adding insulation and increasing the airtightness of masonry walls from the interior. In all cases, avoiding a gap between the existing masonry and the new insulation is important.

\subsection{Fibrous Insulation (Batt) and Stud Frame}

A common assembly includes drywall on a steel stud wall filled with batt insulation (Figure 17). A small (1/2-in. to 2-in.) air gap may be intentionally installed on the inside of the existing masonry wall, or one can form because of the dimensional variations that occur in existing buildings. The drywall finish often acts as the air barrier in this situation, and either paint, Kraft facings, polyethylene sheet, or aluminum foil backing acts as a vapor control layer. (Note that multi-wythe masonry is usually quite air permeable, and is not in itself sufficient as an air control layer; see Table 1). There are numerous serious problems with this approach.

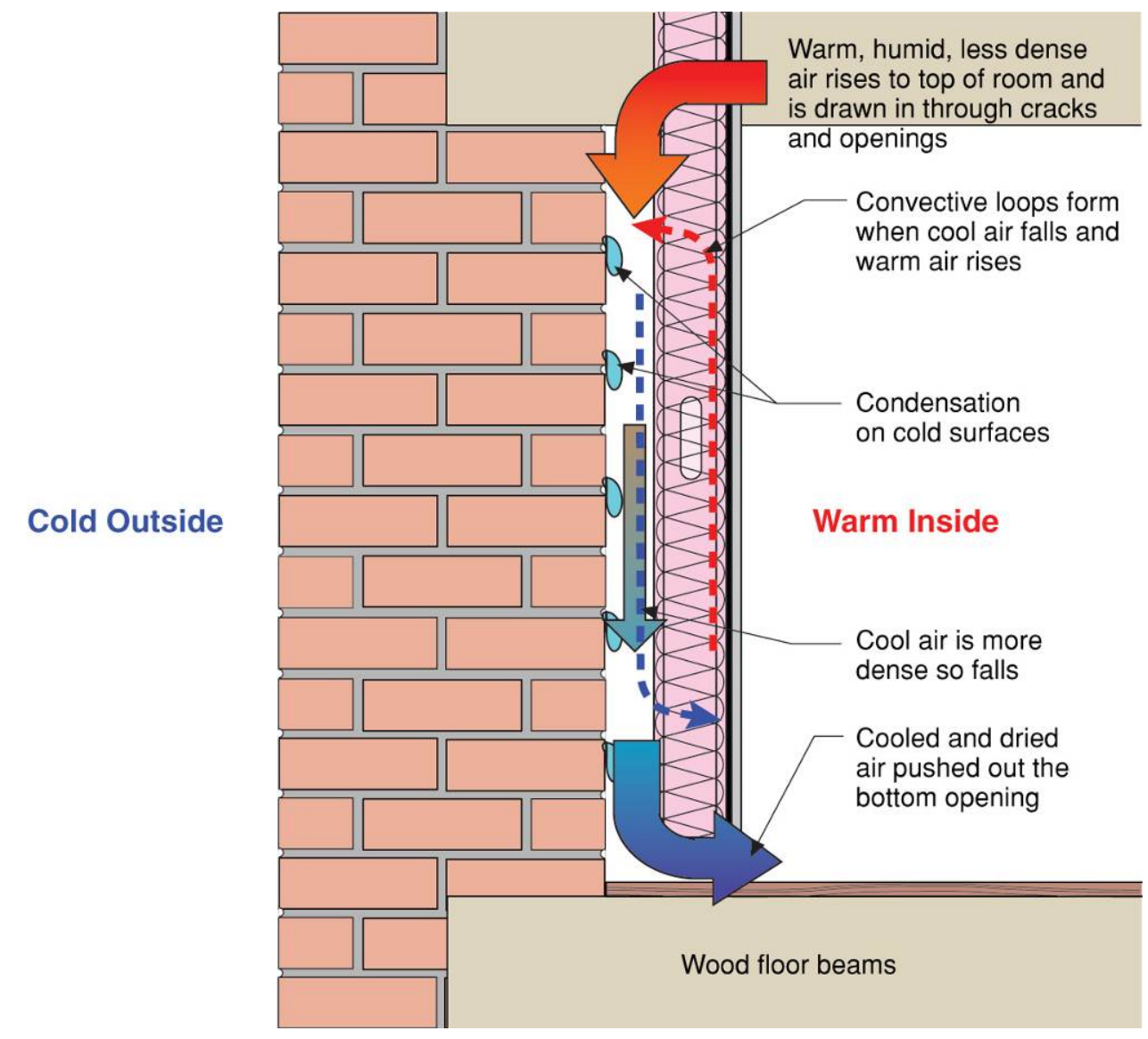

Figure 17. Problematic stud and batt interior retrofit with imperfect airtightness

First, there is a high likelihood of condensation and mold growth in the wall. As shown in Figure 18 , if the interior conditions vary between $68^{\circ} \mathrm{F} / 25 \%$ relative humidity (RH) and $71^{\circ} \mathrm{F} / 30 \% \mathrm{RH}$, the dew point temperature will vary between $32^{\circ} \mathrm{F}$ and $40^{\circ} \mathrm{F}$. Hence, when the back of the masonry drops below these temperatures (likely during cold weather) condensation would occur if airflow behind the masonry were to occur. Reducing RH typically reduces condensation risks; 
however, the problem-causing indoor conditions are already at the lower end of typical occupant comfort levels.

Table 1. Air Leakage Through Masonry Materials (Wilson 1961)

\begin{tabular}{c|c}
\hline Assembly & $\begin{array}{c}\text { Equivalent Orifice, } \\
\text { Areas, in. }\end{array}$ \\
\hline 13-in. porous brick wall, no plaster, $\mathbf{1 0 0} \mathbf{f t}^{\mathbf{2}}$ & 3.1 \\
Wall as above, 3-coat plaster, $\mathbf{1 0 0} \mathbf{f t}^{\mathbf{2}}$ & 0.054 \\
\hline
\end{tabular}

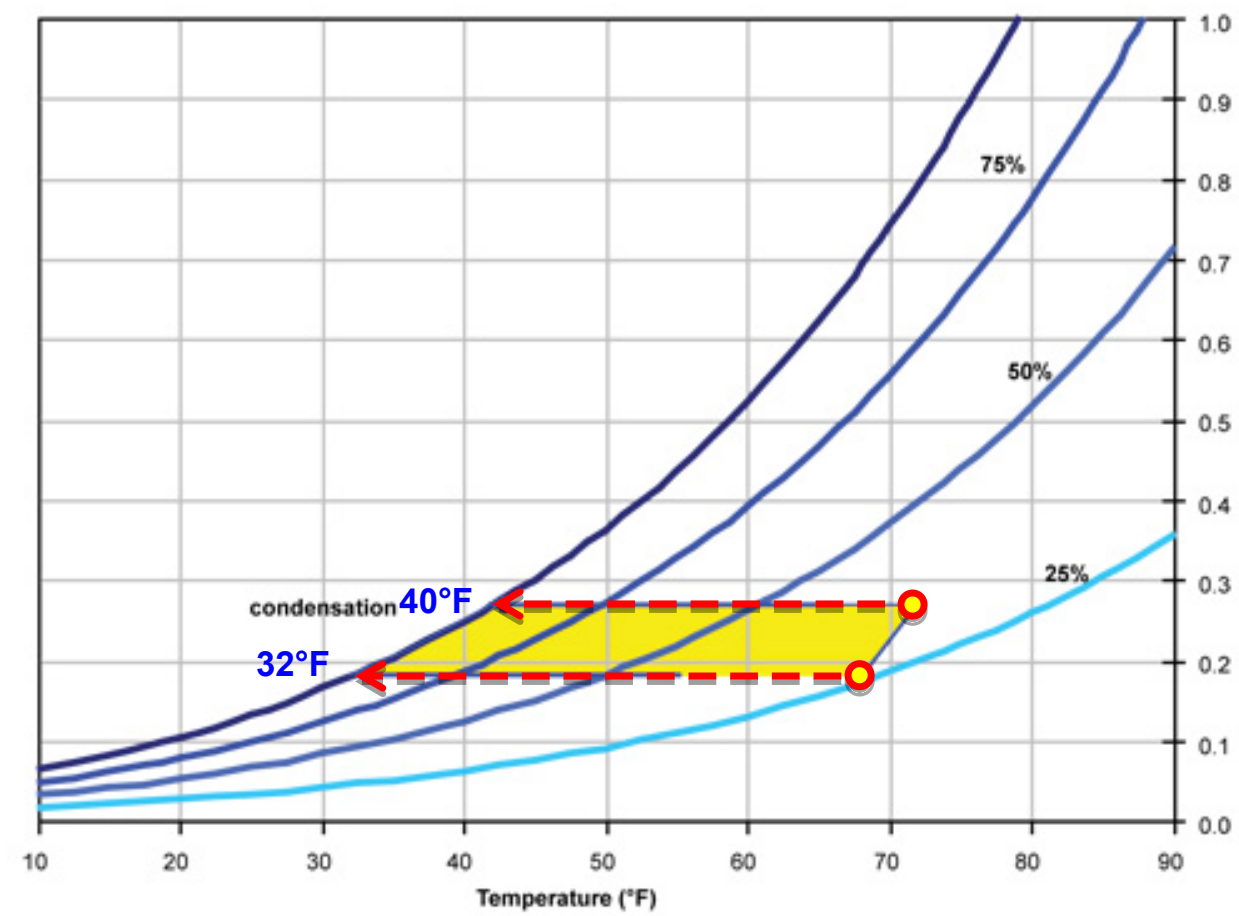

Figure 18. Temperatures at which condensation can occur

If higher interior humidities and colder outdoor temperatures are experienced, serious condensation is likely with even very small leaks past the drywall air barrier. Compounding this concern is the common practice of pressurizing such buildings. This is intended to prevent comfort problems from drafts through uncontrolled air leaks, but it also ensures that air will leak outward in sufficient volumes to cause damaging quantities of condensation on the back of the cold, insulated masonry.

If steel studs are used, this approach will not provide insulation to the desired level. Steel studs are thermal bridges, and in the scenario given, are theoretically capable of providing only about R-7. In practice, installing batt between studs with no backing is very difficult, and it is almost certain that the batts will not be properly installed. Finally, air may loop within the insulation via the air gap between the masonry and the batt, reducing the R-value even further and providing an additional path for moisture transfer. 
Hence, this scheme suffers from a number of limitations. It does not provide a reasonable level of insulation, it increases wintertime wetting during the coldest weather (the same period during which there is a risk of FT damage), and it creates a mold and an IAQ risk. Given the serious limitations and the questionable benefits of this scheme, it cannot be recommended for any interior insulation retrofits.

\subsection{Spray Polyurethane Foam}

A more successful approach involves spraying an airtight insulating foam directly to the back of the existing masonry (Figure 19). The interior finishes must all have high vapor permeance or be back-vented. This retrofit has the advantage that all air leakage condensation is strictly controlled, and it is the most practical approach to achieving high levels of airtightness in existing buildings. The spray foam also acts as a moisture barrier, and any small amount of incidental rain penetration will be localized and controlled. Hence, interior finishes will be protected, and water will not run down and collect at floor penetrations. Water that is absorbed into the masonry can wick to the outside (where it will evaporate and diffuse into the exterior air) or wick to the inside, where it will diffuse through the semipermeable spray foam and interior finishes.

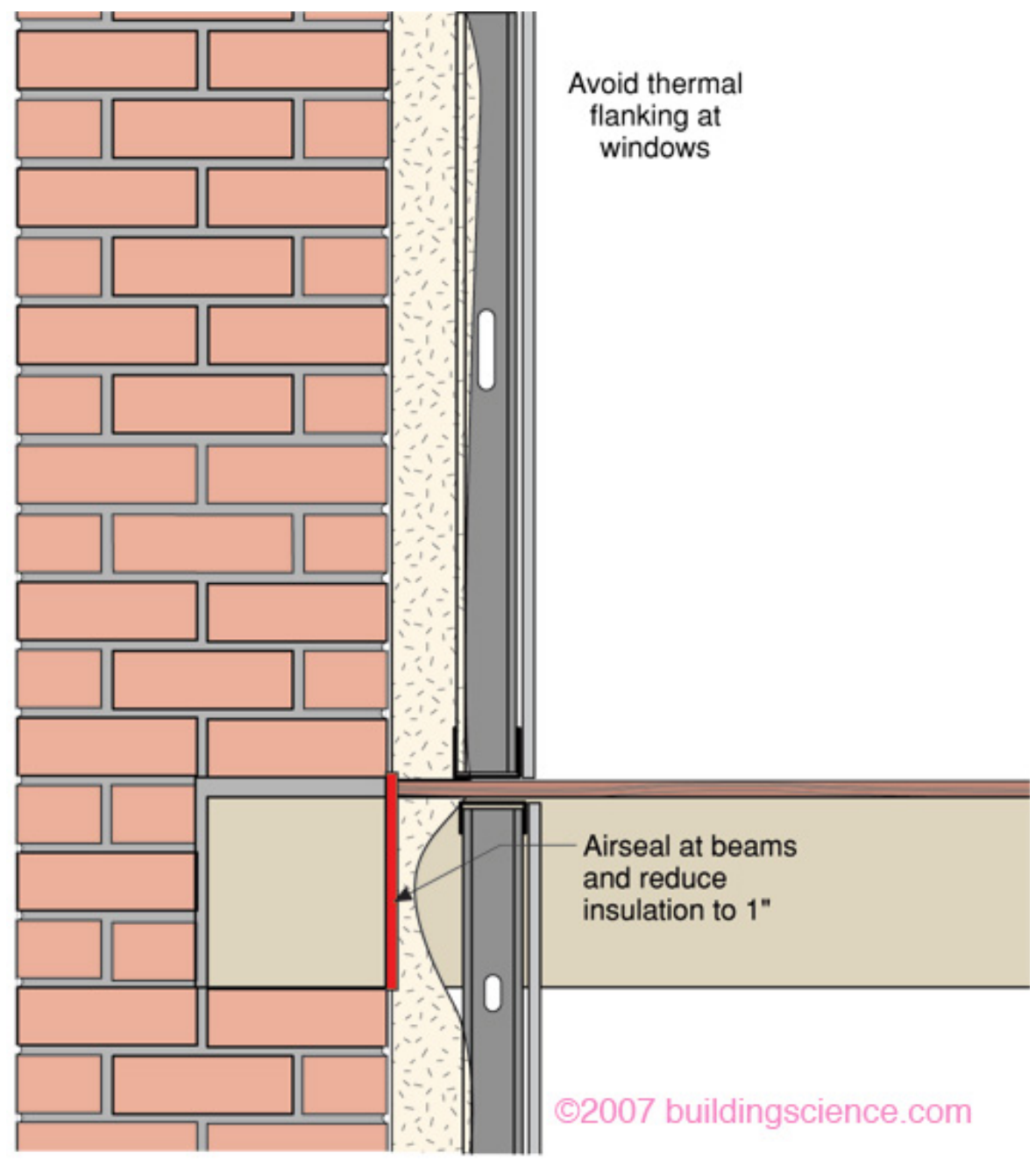

Figure 19. Concept drawing for spray foam retrofit 
The application of 2 in. to 4 in. of foam after a steel stud wall has been installed is straightforward (see Figure 20). The empty stud space is ideal for distribution of services and allows the easy application of a drywall finish. It is best to keep the steel studs more than 1 in. back from the wall ( 2 in. is recommended) to allow foam to adhere to the masonry at all spots and to control thermal bridging and the moisture nanoclimate experienced by the outer flange of the studs.
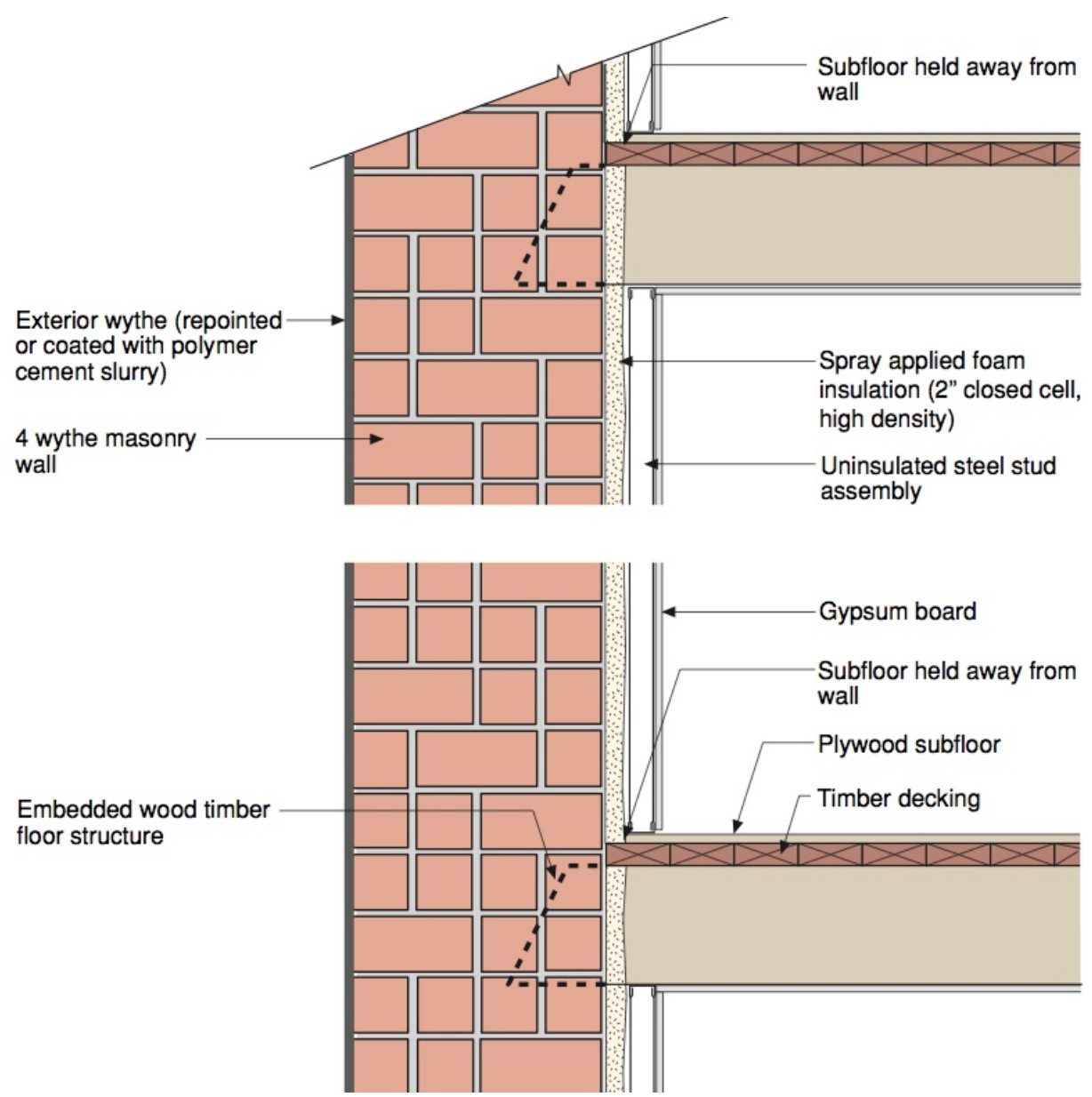

Figure 20. Interior spray-foam retrofit (insulation and airtightening) of brick wall with wood beams/flooring

This approach raises the question of the choice of interior vapor permeance for the foam. In general, the interior layers should be chosen to have the highest vapor permeance possible while also avoiding wintertime diffusion condensation wetting. This strategy provides the highest level of inward drying during warmer weather. High-density ccSPF is generally a good solution for thinner applications (e.g., 2 in. of 2 PCF ccSPF has a permeance of about 1 perm and a thermal resistance of over R-12), but open-celled semipermeable foams (5 in. has a permeance of about 13 perms and a thermal resistance of almost R-20) can be a good choice for greater thickness if the interior is kept at a low humidity during winter and the outdoor temperature is not too cold. Intermediate-density closed-cell foams (1 PCF foam, $\sim 3-5$ perm-in.) are also a potential option, depending on interior and exterior conditions. Hygrothermal simulation can be used to identify suitable materials for a particular application; further information is presented in Sectio5.5. 


\subsection{Rigid Board Foam Insulation}

In many cases, rigid foam board insulation of various types has been used as the interior retrofit (see Figure 21). For thin layers (e.g., $1 / 2$ in.) of insulation, a semipermeable foam such as extruded polystyrene (XPS) or unfaced polyisocyanurate can be used, but for thicker layers (e.g., greater than $2 \mathrm{in}$.), the more permeable expanded polystyrene board (EPS) is preferred. This will vary depending on the vulnerability of the wall and required drying. These options can be judged based on information provided in Table 3. This method has been used successfully, but is far more difficult to build as it requires great care in ensuring that the board is firmly in contact with the masonry (any gaps may allow convective loops to transport moisture and heat), and that a complete air barrier is formed.

A liquid-applied, highly vapor-permeable air and water barrier should be applied to the back of the masonry. This prevents any localized water leakage from penetrating and collecting at floor penetrations. The coating also acts as the primary air barrier, while being vapor permeable to allow water vapor to move in either direction. The foam boards should be attached with serpentine patterns of adhesive. An interior air flow retarder, perhaps in the form of taped and sealed joints, is also required to prevent interior air from contacting the cold masonry. Material compatibility must be ensured before selection of air flow retarder system components (e.g., adhesion of air barrier sealants to EPS foam, or glass fiber-faced polyisocyanurate).

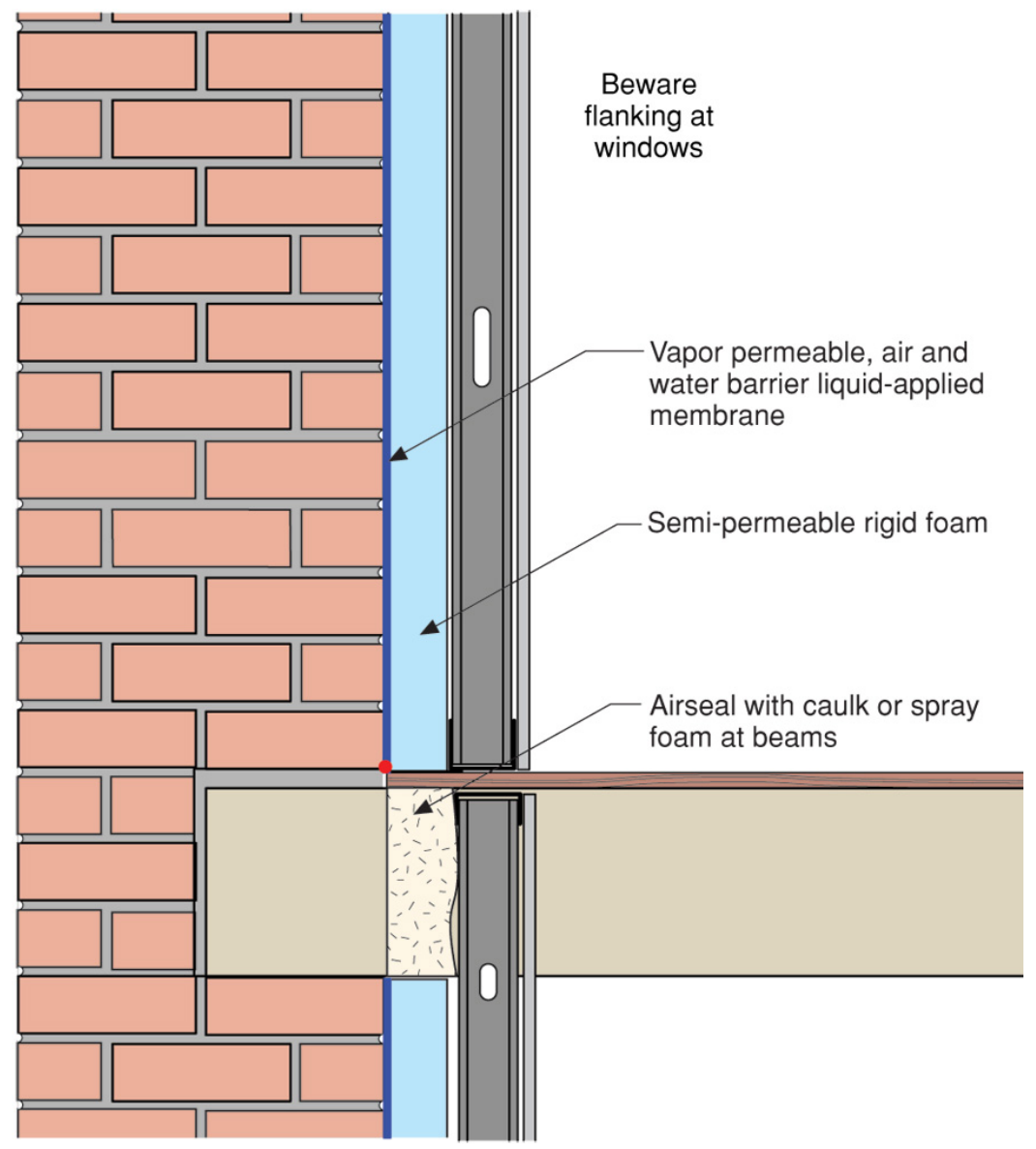

Figure 21. Conceptual drawing of rigid board foam retrofit, with liquid applied membrane 
Note that bare masonry has been documented to be a source of air leakage, as demonstrated by Wilson (1961) and shown in Table 1. The measured air leakage (3.1 in. ${ }^{2} / 100 \mathrm{ft}^{2}$ surface area) is higher than the base leakage rate requirements in many energy efficiency programs (e.g., 2.5 in. ${ }^{2} / 100 \mathrm{ft}^{2}$ surface area). However, an air barrier (such as a three-coat plaster parge) renders the air leakage through the assembly negligible.

A liquid-applied membrane may not be needed if the masonry shows neither signs of rain leakage nor excessive air leakage.

\subsection{Hybrid Spray Foam and Fibrous insulation}

Another assembly option is to combine two different insulation materials, which meet the needs of the assembly in two different ways, thus creating a hybrid approach (see Figure 22). An airimpermeable, moisture-insensitive insulation, such as spray foam or rigid board foam, is installed directly against the masonry. Interior to that, lower cost air-permeable insulation such as fiberglass batt or spray, or cellulose damp spray or dense pack, is installed into the framed cavity, followed by interior finishes. When this type of assembly is used in light frame construction using spray foam, it is commonly referred to as flash and batt (Maines 2011) or flash and blow.

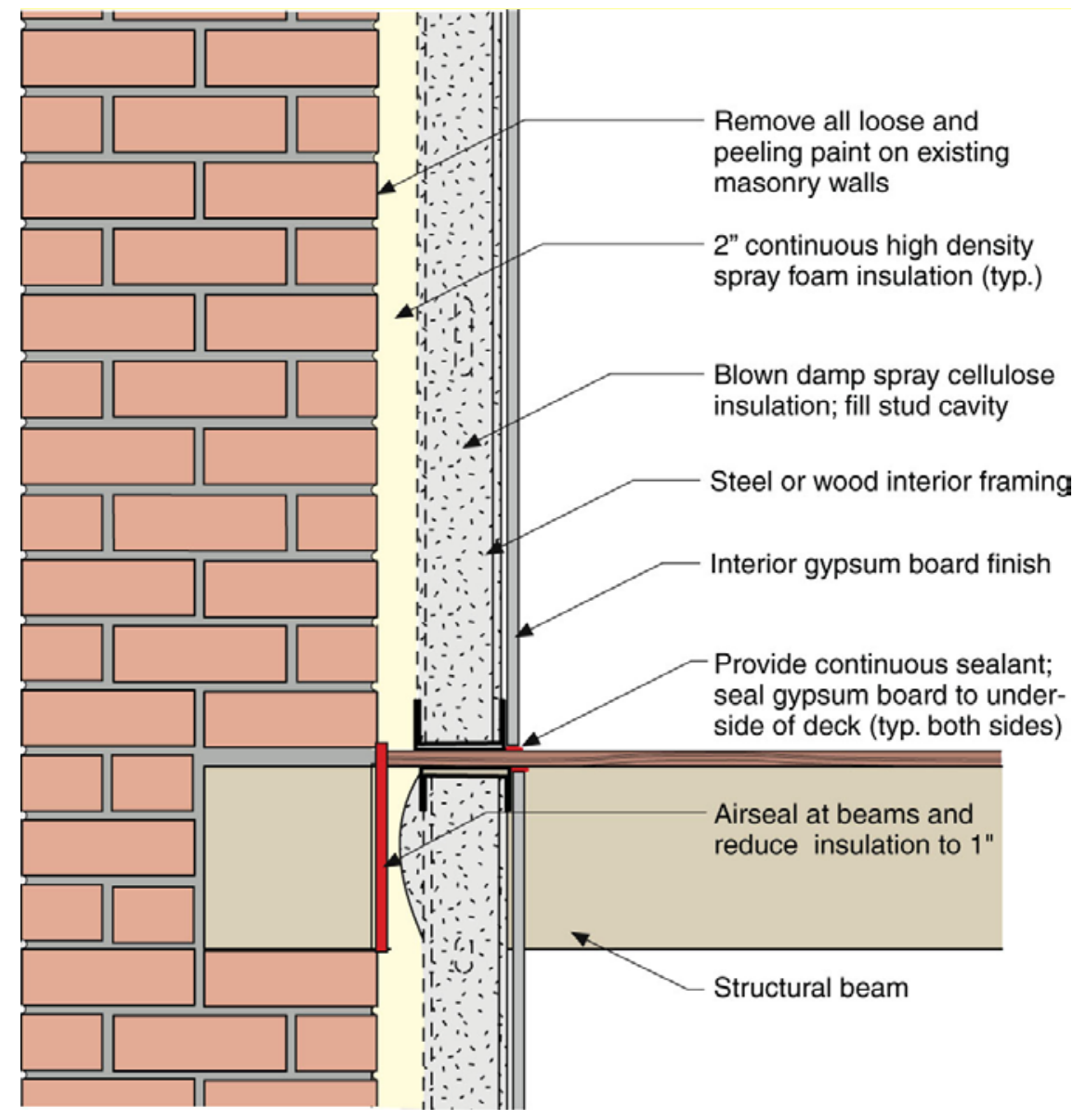

Figure 22. Conceptual drawing of hybrid spray foam and fibrous (air-permeable) insulation (thermal bridging issues) 
The intent is to provide higher overall R-values, but without the cost of significant thicknesses of spray foam or rigid foam insulation. In addition, limiting the thickness of foam insulation allows more drying to the interior of the masonry wall, as air-permeable insulations are essentially vapor open (do not significantly reduce vapor diffusion; see Section 5.5). This assembly typically results in higher R-values than the previous assemblies. The reduced heat flow will affect the exterior masonry; this effect should be evaluated on a case-by-case basis.

The air-impermeable insulation (spray foam or rigid foam board) should be sufficiently thick to prevent interstitial condensation at the inboard side of the foam in cold weather. This will vary based on exterior conditions (coldest temperatures), interior conditions (temperature and humidity), the ratio of R-values of the two insulation layers, and the amount of air leakage that occurs into the assembly. However, a reasonable guideline is the 2009 International Residential Code/IRC (ICC 2009) recommendations for allowing the use of a Class III vapor retarder (latex paint) as the interior vapor control layer, in lieu of a Class I or Class II vapor retarder. The recommended values are stated in terms of rigid foam/exterior insulation thickness versus stud bay/air permeable insulation thickness, by climate zone (Table 2).

Table 2. Excerpt from IRC Table R601.3.1, Requirements for Use of Class III Vapor Retarder

\begin{tabular}{c|c|c}
\hline DOE Climate Zone & $\mathbf{2} \times \mathbf{4}$ Wall & $\mathbf{2} \times \mathbf{6}$ Wall \\
Zone 4 Marine & R-2.5 & (5.5-in. Stud Insulation) \\
Zone 5 & R-5.0 -3.75 \\
Zone 6 & R-7.5 & R-7.5 \\
Zones 7 and 8 & R-10 & R-11.25 \\
\hline
\end{tabular}

The examples shown below in Figure 23 use steel framing with damp spray cellulose insulation, inboard of 2 PCF ccSPF insulation. There is significant thermal bridging through the steel studs, which diminishes the value of the cavity insulation.
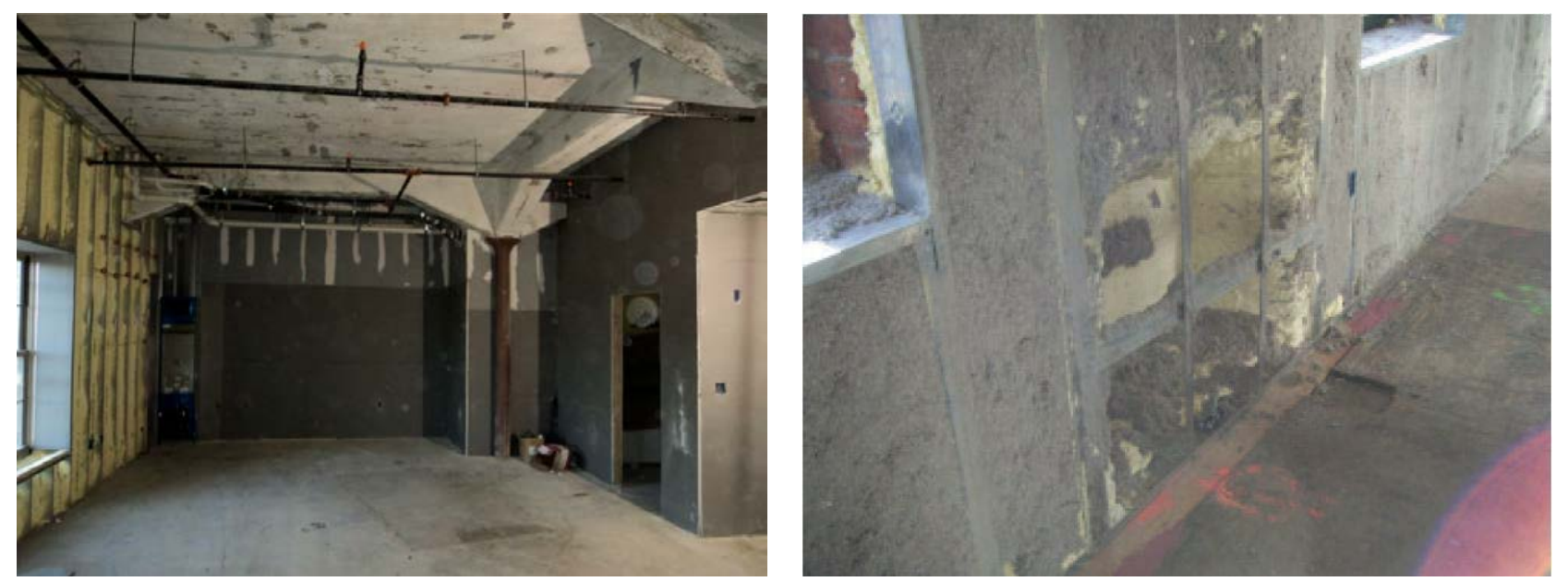

Figure 23. Hybrid spray foam/damp spray cellulose assembly (steel stud not recommended)

Instead, a higher performance assembly would use a narrower steel framing (e.g., 1 5/8 in.), increasing the gap between the spray foam and the framing (see Figure 24). Insulation should fill 
the space outboard of the framing, leaving the stud bays mostly empty. The studs can be tied back to the masonry using nonmetallic, thermally nonconductive clips, as discussed below.

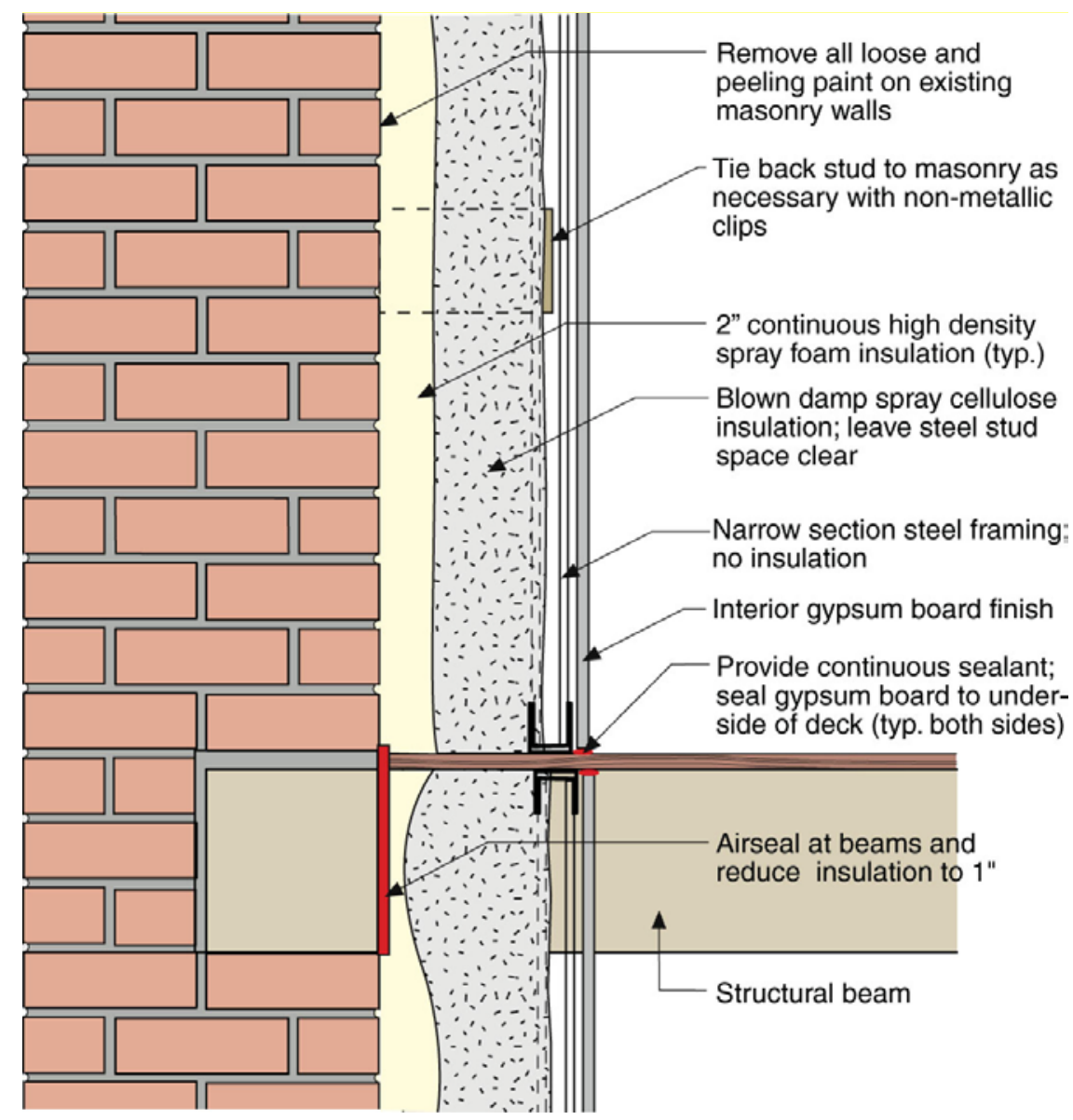

Figure 24. Conceptual drawing of hybrid spray foam and fibrous (air permeable) insulation (reduced thermal bridging)

\subsection{Material Properties}

The recommendations above include a variety of materials, with a range of material properties. To summarize and compare the values, Table 3 shows insulating value (R/in.) and water vapor permeability (perm-in.); the values are taken primarily from ASHRAE (2009).

Overall, material selection is based on insulating value and vapor permeability: lower vapor permeability reduces risks of interior-sourced vapor diffusion-based condensation on the masonry-insulation interface in wintertime. However, low vapor permeability also reduces the amount of drying that can occur to the interior. The balance between these attributes will be a function of the existing wall assembly, the exterior climate, and the interior climate.

It can be noted that air-permeable insulation materials (cellulose, fiberglass, mineral fiber; shown in italics) are essentially vapor open: they are not recommended as standalone materials for interior masonry retrofits in cold climates. The table also shows the potential condensation risks associated with open-cell $(0.5 \mathrm{PCF})$ foam, given its high vapor permeability. 
Table 3. R-Value and Water Vapor Permeability Properties for Various Insulation Materials

\begin{tabular}{c|c|c}
\hline Material & $\begin{array}{c}\text { Insulating Value } \\
\text { (R/in.) }\end{array}$ & $\begin{array}{c}\text { Vapor } \\
\text { Permeability } \\
\text { (perm-in.) }\end{array}$ \\
\hline $\begin{array}{c}\text { Closed-Cell (2 PCF) Polyurethane } \\
\text { Spray Foam }\end{array}$ & $\begin{array}{c}1.6-2.2 \\
\text { Rpen Cell (0.5 PCF) Polyurethane }\end{array}$ & 88 \\
Spray Foam & R-3.5/in. typical & $3.5-5.0$ \\
Intermediate Density ( 1 PCF) & R-4.5 to R-5/in. typical & 0.8 \\
Polyurethane Spray Foam & R-5/in. typical & $2.0-3.8$ \\
Extruded Polystyrene (XPS) & R-4/in. typical \\
Expanded Polystyrene (EPS) & R-3.5/in. typical & $80-120$ \\
Cellulose (Dry Blown, 2 PCF) & R-3.5/in. typical & 120 \\
Fiberglass Batt, 1 PCF & R-4.2/in. typical & $48-171$ \\
Mineral Fiber (2-12 PCF) & & \\
\hline
\end{tabular}

This table does not include the effect of capillary active insulation materials, which transport condensation at the masonry-insulation interface back to the interior via liquid transport. A discussion of this topic is beyond the scope of this measure guideline.

\subsection{Special Cases}

There are countless variations in masonry retrofits: materials, age, condition, expected use, and tolerance for risk influence the types of solutions. The solutions shown in Section 5.5 are appropriate for a significant majority of likely cases, but two special cases that have been used are discussed in Section 5.6.1 and Section 5.6.2.

\subsubsection{Retrofit Interior Drained Assembly}

Mass or storage walls, by their nature, do not require a separate drainage system, instead relying on safe storage of moisture in the mass of the system. However, there are cases where leakage occurs in the existing building, or thin (e.g., 2-wythe) masonry provides inadequate storage.

In these cases, it may be feasible and desirable to change the rain control strategy of a wall from the original storage/reservoir approach to a drained approach. This need can be evaluated onsite by looking for staining and rot, and from historical knowledge of facility maintenance staff. An example of such as assembly is shown in Figure 25.

However, the interior drainage detail is difficult to implement, high risk, and should be considered a last choice. One troubling detail is drainage of the flashing connection at the floor slab interruptions. The drilling of the sloped drained hole to the outside is a particularly difficultto-execute (and hence high-risk) detail. There is a substantial risk of a small failure in this bulk water control system, which could result in water leakage to the interior after the retrofit, or worse, a continuing water concentration hidden behind the interior assembly, which saturates and damages the masonry over time. 

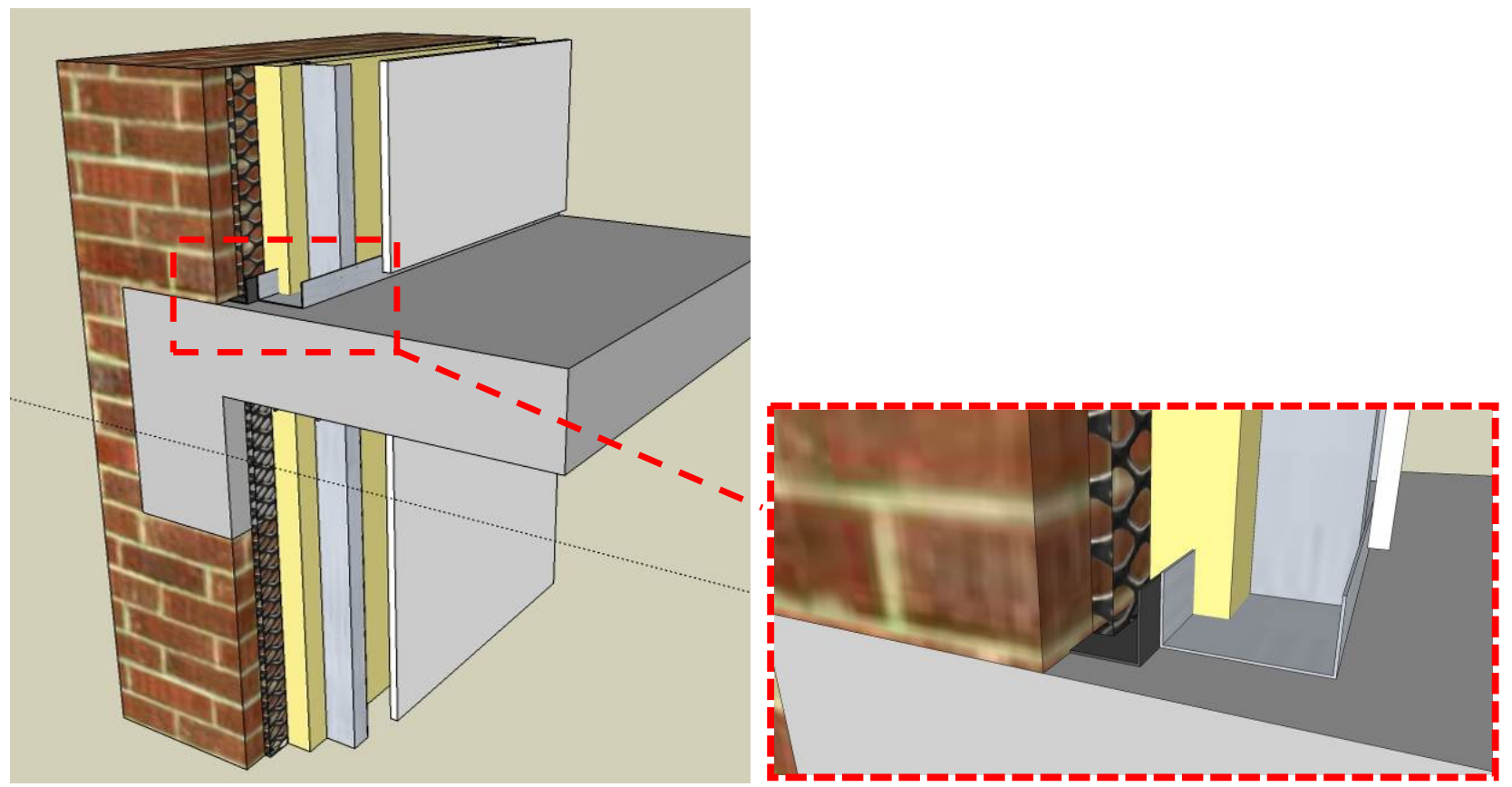

Figure 25. Retrofit interior drained assembly on mass masonry wall, with air gap membrane

\subsubsection{Pressure-Controlled Assembly}

Although rarely justified or necessary, projects with very high historic significance, occupancies with high indoor humidities, or assemblies with particularly moisture-sensitive components may require active pressure control. Outdoor air (at low outdoor dew point temperatures) heated to indoor temperature can be forced into a buffer space between the new insulation and the interior finish (Figure 26). This air maintains the interior of the finish at the ideal indoor temperature, and ensures that air leakage condensation cannot occur even with high humidity.

Highly vapor-permeable insulation is often preferred in such an arrangement because it allows the masonry wall to dry to the inside as well as the outside.

The energy and operating maintenance cost of operating fans and increasing the temperature of the interior finish will be higher than passive solutions; hence, this approach is recommended for special conditions only. 


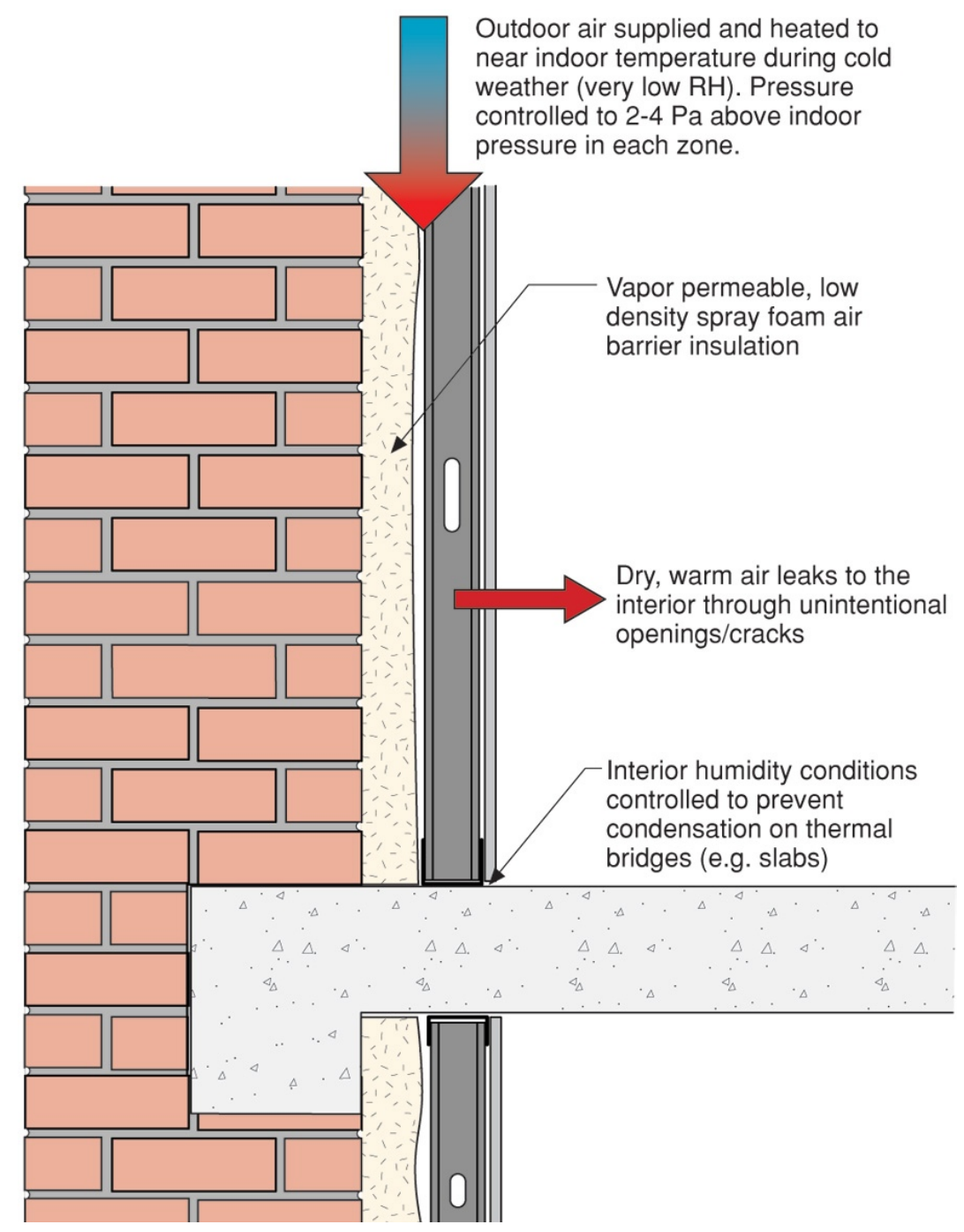

Figure 26. Concept drawing of pressure-controlled interior retrofit

\subsection{Thermal Performance Issues}

In general, it is best to maintain a clear space between any interior framing and the masonry to allow full insulation coverage and continuity of the air barrier, as shown in Figure 19 and Figure 21. This gap also ensures there is no capillary contact between the potentially wet masonry and the vulnerable framing.

Thermal bridging through the framing will have a minimal impact on thermal performance if the gap allows for at least $1 \mathrm{in}$. (preferably $2 \mathrm{in}$.) of insulation. Although the nominal stud bay insulation values are R-13 and R-19 for $2 \times 4$ and $2 \times 6$ walls, respectively, thermal bridging reduces their effective R-values, as noted in Table 4.

The table shows that for maximum R-value in a minimum depth, maximizing the clear space gap and minimizing the framing factor results in the most favorable result (R-21 in 5.5 in. for $2 \times 4$ 24 in. o.c. with 2-in. gap). 
Table 4. Thermal Performance of Wood Frame Stud Wall Options, With Spray Foam Insulation

\begin{tabular}{c|c|c|c|c}
\hline Assembly & $\begin{array}{c}\text { Clear Space } \\
\text { Insulation }\end{array}$ & $\begin{array}{c}\text { Stud Bay } \\
\text { Insulation }\end{array}$ & $\begin{array}{c}\text { Total R- } \\
\text { Value }\end{array}$ & $\begin{array}{c}\text { Assembly } \\
\text { Depth }\end{array}$ \\
\hline $\mathbf{2} \times \mathbf{4}$ Nominal & R-6 $(1$ in. ccSPF $)$ & R-8 $(16$ in. o.c. $)$ & R-14 & 4.5 in. \\
\hline $\mathbf{2} \times \mathbf{6}$ Nominal & R-6 $(1$ in. ccSPF $)$ & R-12 $(16$ in. o.c. $)$ & R-18 & 6.5 in. \\
$\mathbf{2} \times \mathbf{4}$ Nominal & R-12 $(2$ in. ccSPF $)$ & R-8 $(16$ in. o.c. $)$ & R-20 & 5.5 in. \\
$\mathbf{2} \times \mathbf{6}$ Nominal & R-12 $(2$ in. ccSPF $)$ & R-12 $(16$ in. o.c. $)$ & R-24 & 7.5 in. \\
$\mathbf{2} \times \mathbf{4}$ Nominal & R-6 $(1$ in. ccSPF $)$ & R-9 $(24$ in. o.c. $)$ & R-15 & 4.5 in. \\
$\mathbf{2} \times \mathbf{6}$ Nominal & R-6 $(1$ in. ccSPF $)$ & R-14 $(24$ in. o.c. $)$ & R-20 & 6.5 in. \\
$2 \times \mathbf{4}$ Nominal & $R-12(2$ in. ccSPF $)$ & R-9 $(24$ in. o.c. $)$ & R-21 & 5.5 in. \\
$\mathbf{2} \times \mathbf{6}$ Nominal & R-12 $(2$ in. ccSPF $)$ & R-14 $(24$ in. o.c. $)$ & R-22 & 7.5 in. \\
\hline
\end{tabular}

Light-gauge steel studs (in contrast to wood studs) will experience a more significant impact. As a rule, R-12 to R-20 of insulation installed between 3.5 to 6 in. deep steel studs at 16- to 24 -in. centers will provide an R-value limited to a maximum of about R-7. The use of steel framing makes it more important to maximize the gap for insulation between the framing and the masonry. Preferably, there should be minimal to no insulation placed within the steel stud bay, as its value is reduced by thermal bridging effects.

This previous analysis does not include the effect of the steel clips, sometimes used to tie the framing back to the masonry wall (Figure 27). This effect can be significant if the clips comprise a significant portion of the studs and are made of steel, because the clip cuts directly though insulation. Reducing the number of clips, or even replacing them with stainless steel (one fourth the conductivity of carbon steel) would make a major improvement. If a single row of 4-in. tall light-gauge (18 to 20) clips are used at mid-height, the impact on R-value should be modest (perhaps 10\% reduction in R-value).

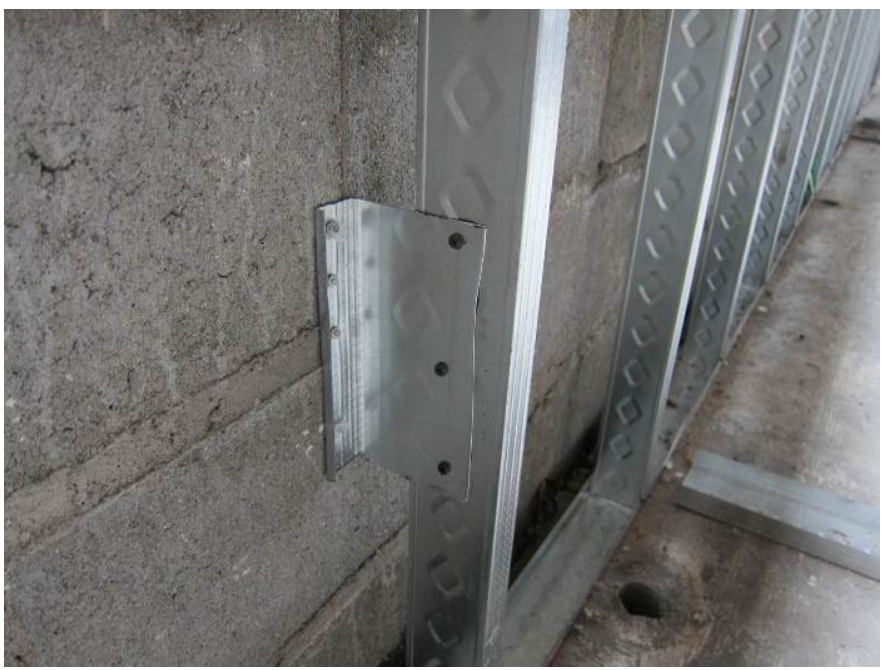

Figure 27. Clip tying framing to concrete masonry unit backup wall, steel clip shown; not recommended

If these clips could be replaced with a thermally nonconductive material such as fiberglass, more significant improvements would be possible. Off-the-shelf product options include extruded 
polyvinyl chloride nonstructural studs (see Figure 28), and pultruded fiberglass profile standoffs. Alternatively, any plastic or thermally nonconductive material that provides sufficient stiffness during spray foam application would improve performance relative to metal clips.

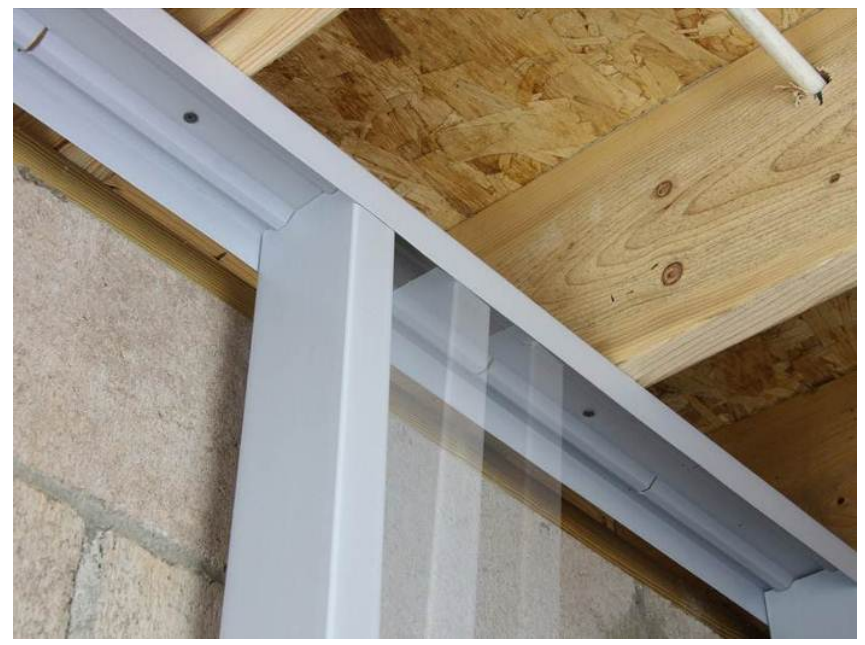

Figure 28. Polymer framing as alternate material with better thermal resistance

Concentrated heat locations such as radiators located on exterior walls create a greater interiorexterior temperature difference than that experienced at the main field of the wall. Additional insulation measures may be warranted at these locations to reduce heat flux.

\section{Critical Takeaways}

Drywall on a steel stud wall filled with batt insulation has a number of serious problems. There is a high likelihood of wintertime condensation and mold growth in the wall, because of interior air leaks into the cold interface between the insulation and the masonry. This problem is exacerbated by pressurizing the interior space, which results in air leakage outward in sufficient volumes to cause damaging quantities of condensation on the back of the cold insulated masonry.

A more successful approach involves spraying an airtight insulating foam directly to the interior side of the existing masonry: all air leakage condensation is strictly controlled, and it is the most practical approach to achieving high levels of airtightness in existing buildings. The spray foam also acts as a moisture barrier, and any small amount of incidental rain penetration will be localized and controlled.

When choosing foam insulation, remember that high-density closed cell polyurethane foam is generally a good solution for thinner applications (e.g., 2 in. of ccPCF), and open-celled semipermeable foams (e.g., 5 in. ocSPF) can be a good choice for larger thickness if the interior is kept at a low humidity during winter and the outdoor temperature is not too cold.

Rigid foam board insulation of various types has been used as the interior retrofit but is far more difficult to build, as it requires great care in ensuring that the board is firmly in contact with the masonry (no gaps), and that a complete air barrier is formed. A liquid-applied, highly vapor- 
permeable air and water barrier should be applied to the back of the masonry for water control (from the masonry) and air control (inside to outside).

Bare masonry can be a source of air leakage: the measured air leakage is higher than the base leakage rate requirements in many energy efficiency programs. This shows the need for an air barrier layer as a portion of the interior retrofit assembly, typically applied to the interior face of the masonry.

Another assembly option is to combine spray or rigid board foam with fibrous, air-permeable insulation (fiberglass or cellulose) to create a lower cost high-R wall assembly. However, minimum thicknesses of foam should be applied to prevent interstitial condensation.

In cases where bulk leakage occurs through the existing wall, it may be feasible and desirable to change the rain control strategy of a wall from the original storage/reservoir approach to a drained approach with the retrofit of an interior assembly. However, the interior drainage detail is difficult to implement, high risk, and should be considered a last choice.

Although rarely justified or necessary, projects with very high historic significance, occupancies with high indoor humidities, or assemblies with particularly moisture-sensitive components may require active pressure control. This involves using heated and dried air to pressurize a buffer space between the insulation and the interior finish. The energy and operating maintenance costs of operating fans and increasing the temperature of the interior finish will be higher than passive solutions.

Thermal bridging through wood framing will have a minimal impact on thermal performance if wood stud framing allows for at least 1 in. of insulation (preferably 2 in.). For maximum R-value in a minimum depth, maximize the clear space gap and minimize the framing factor.

Thermal bridging through light-gauge steel framing has a significant impact; typical steel stud (3.5 in. and 5.5 in.) insulated assemblies provide an R-value limited to a maximum of about R-7. The gap for insulation between the framing and the masonry should be maximized; preferably, there should be minimal to no insulation placed within the steel stud bay.

Steel stud clips back to the masonry also have a significant thermal bridging effect; they should be replaced with a thermally nonconductive material.

\section{Contractor/Homeowner Safety}

Spray polyurethane foam creates potential hazards during installation, creating requirements for evacuation of the house during installation, work personal protective equipment, and ventilation requirements. Some fires have been linked with the application of spray polyurethane foam. Further information is available at the industry website below.

Spray Polyurethane Foam Health and Safety American Chemistry Council www.spraypolyurethane.org/ 


\section{Interior Retrofit Problematic Details and Solutions}

This section covers a variety of details commonly seen on mass masonry buildings that are associated with water concentrations, and thus, increased risk in an interior retrofit situation.

\subsection{Windows}

\subsubsection{Overview}

Windows and doors are nonabsorbent, and hence shed all the rainwater (wind-driven rain) that strikes them. The shapes of windows and doors also tend to concentrate water, especially at the lower corners (Figure 29). To maximize durability, a critical requirement is to avoid concentration of rainwater surface drainage, and to encourage the shedding of water away from the face of the building.
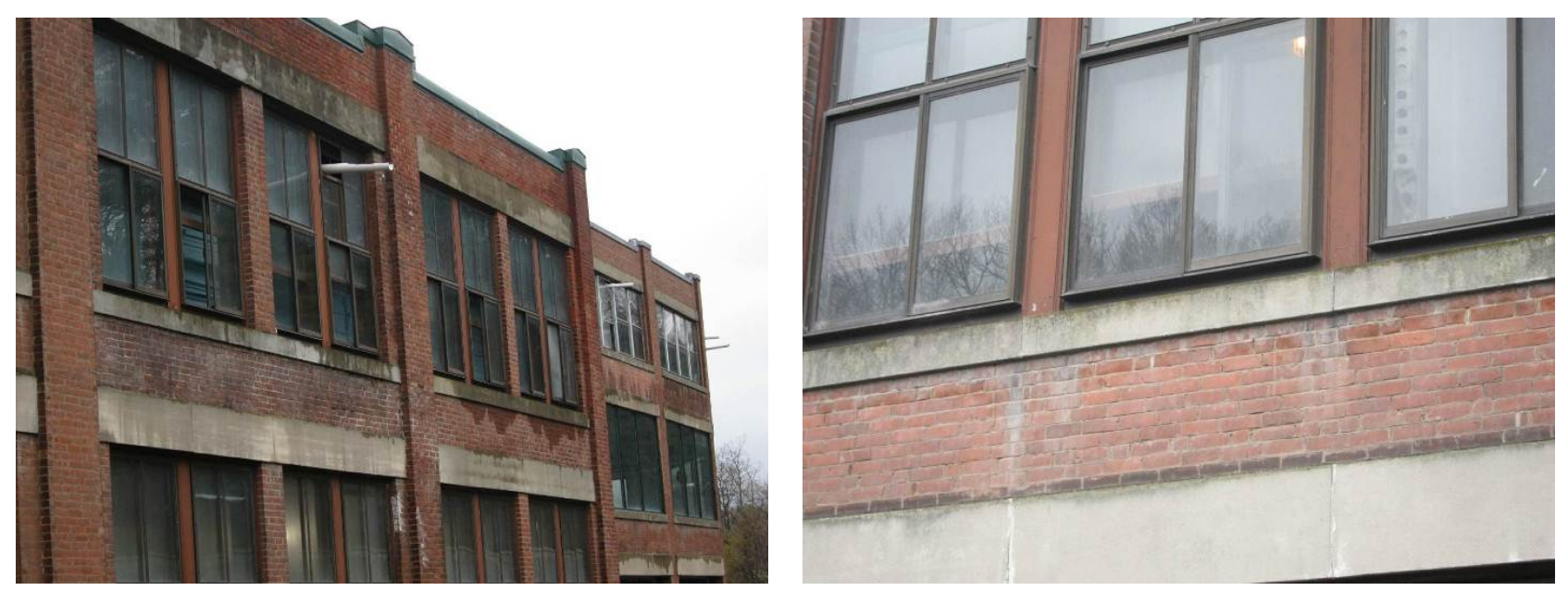

Figure 29. Improper drainage off window faces, and staining at window sill grout joints

At the same time, leakage through the rough opening (often finished with exposed sealant that fails over time) and/or through the window frame itself demands the installation of robust subsill flashing. All of this must be accomplished by ensuring that the air and thermal control layers remain continuous (Figure 30). 


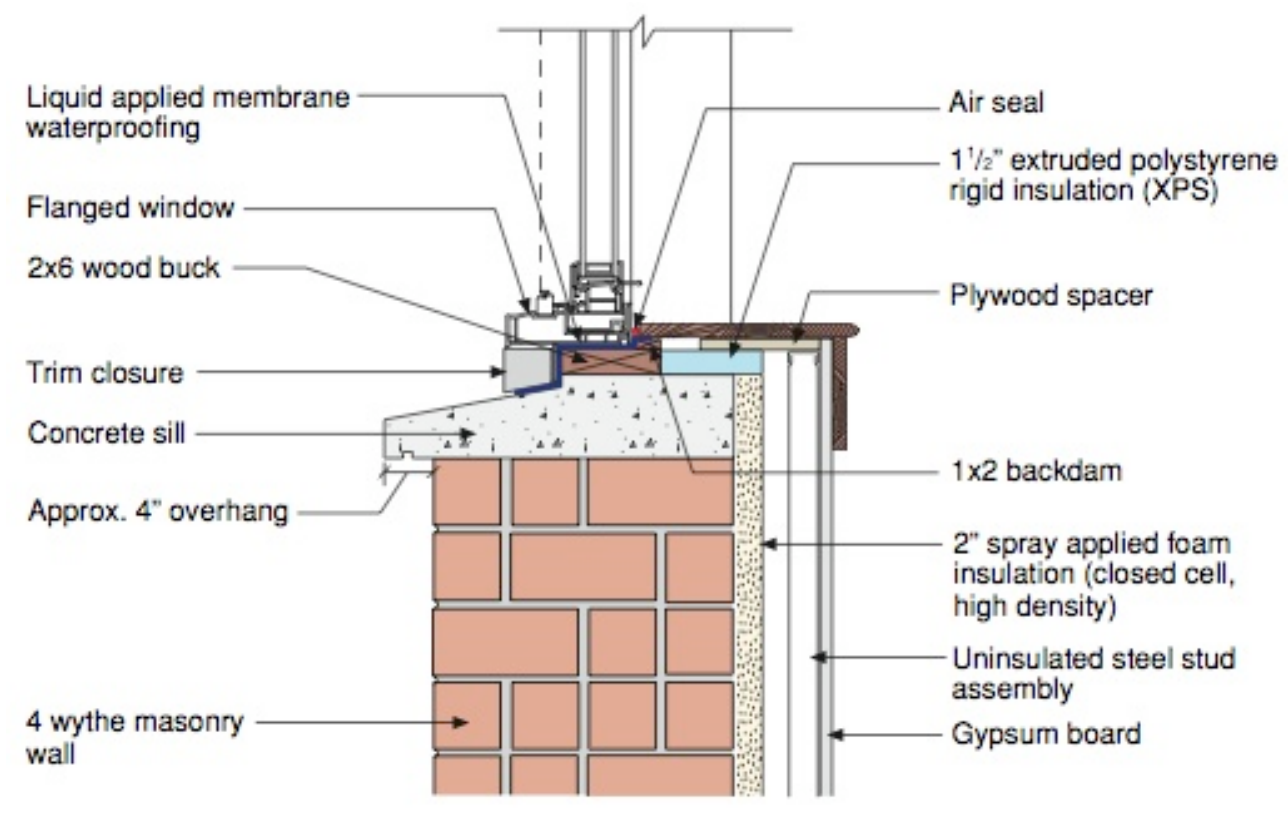

Figure 30. Window detail for interior retrofit; note thermal "wrap" at sill and pan flashing, and sloped, projecting sill with drip edge

\subsubsection{Window Sill Geometry and Material}

Existing historic window sills were often designed reflecting good water control practices. For instance, precast (concrete) or carved solid stone sills were typically shaped with an exterior sloping surface to drain incident rainwater, and end dams to prevent lateral runoff into the wall (Figure 31 and Figure 32).
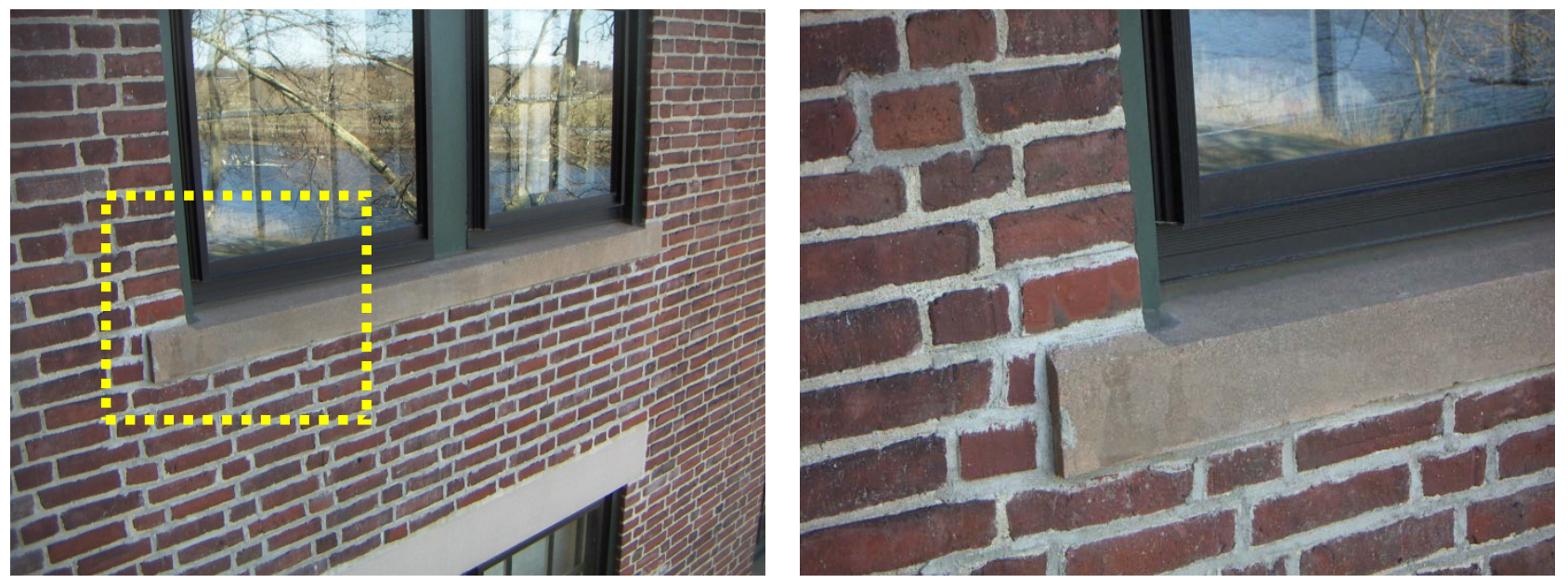

Figure 31. Precast window sloped sill, close up of end dams 


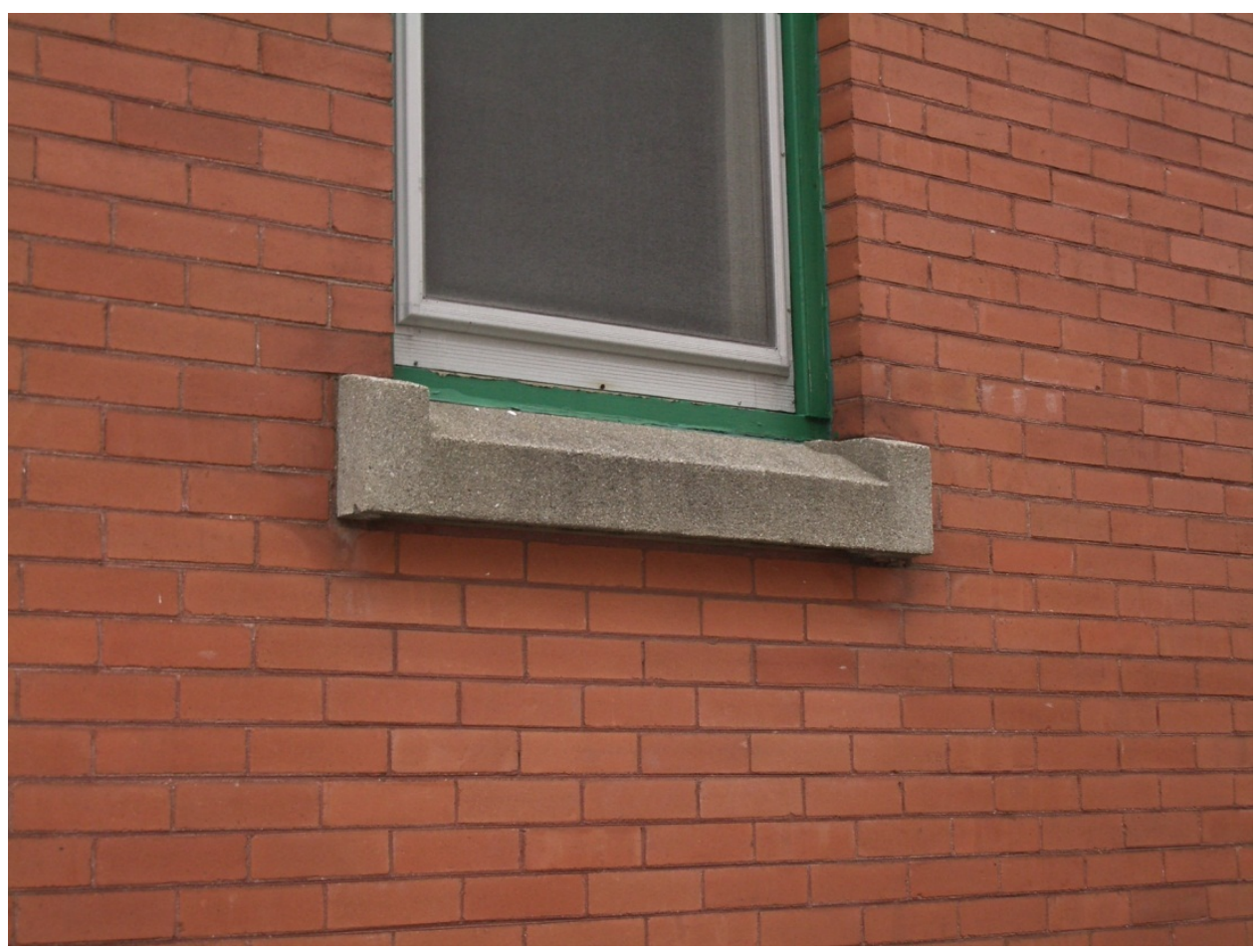

Figure 32. A high performance window sill, exhibiting end dams, steep slope, large projection, jamb extensions, and drip edge

Historic solid stone sills are not immune to problems: a solid granite sill is shown in Figure 33, which is sloped to the exterior. Granite is a very durable material, with high FT resistance. However, end dams are not carved into the sill; erosion of the mortar joints at the ends of the sill increases the risk of introducing water deep into the wall due to lateral runoff. This has the potential to cause FT damage deep inside the wall, because water is introduced at an inner wythe (more vulnerable layer of brick). The joint must be repointed at least, and potentially sealed with a high-durability caulk and backer rod detail. Furthermore, these details must be maintained over time to ensure durability.
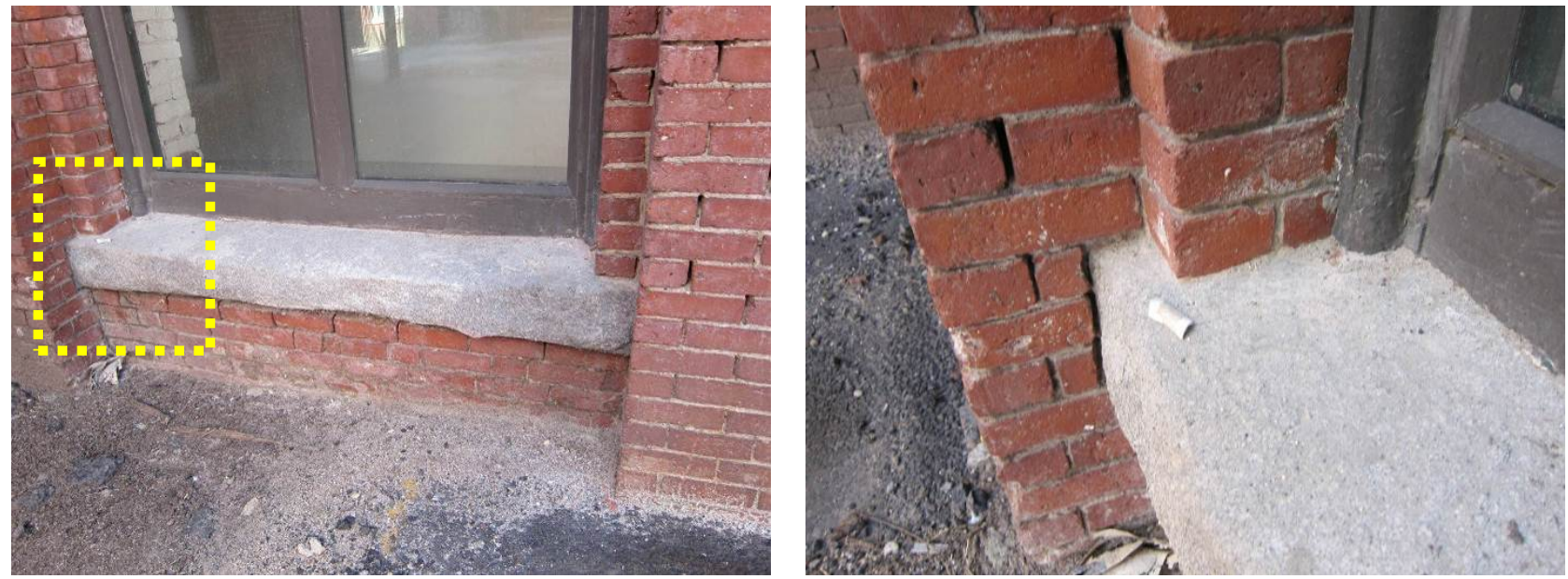

Figure 33. Solid granite sloped sill, potential for water introduction into wall 
Another critical aspect of the window sill is how the runoff water is handled. Ideally, a drip edge should be designed into the sill that has a minimum projection of $1 / 2$ in. $(12 \mathrm{~mm})$ beyond the wall below, to ensure that surface tension does not deposit water on the wall (Figure 34).
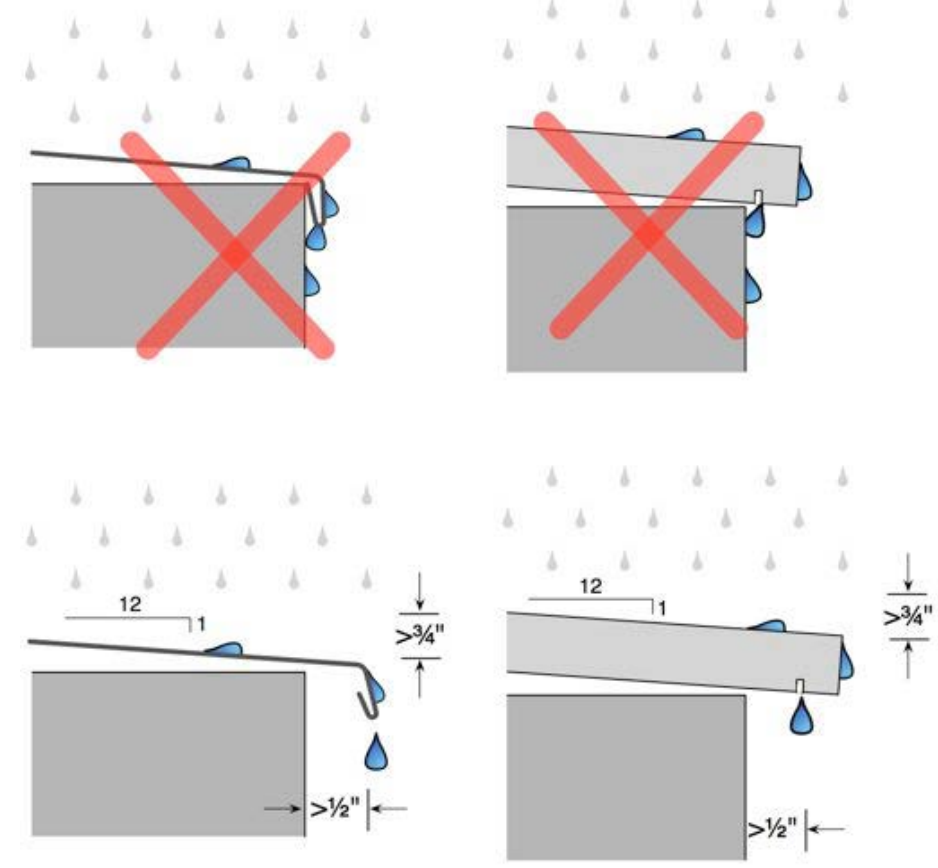

Figure 34. Drip edges and sloped sills are critical deflection elements

(Straube 2011)

An example of a failure to shed water is shown in Figure 35. The water concentration created by the window is deposited onto the wall below, resulting in efflorescence staining.

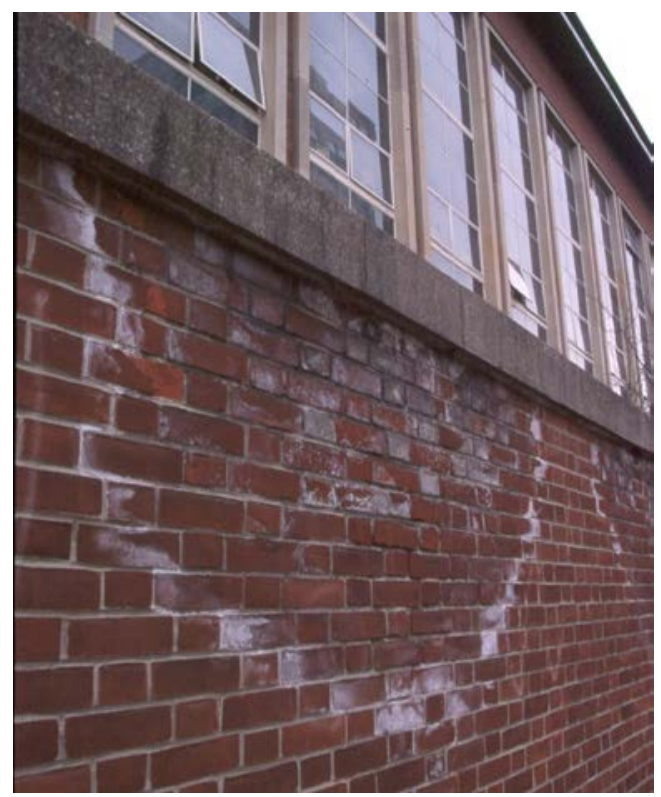

Figure 35. Failed mortar joint at sill from concentrated runoff, resulting in brick failure 
Many existing precast window sills have drip edge details built in to their undersides, as shown in Figure 36. These types of details typically provide excellent performance and durability.
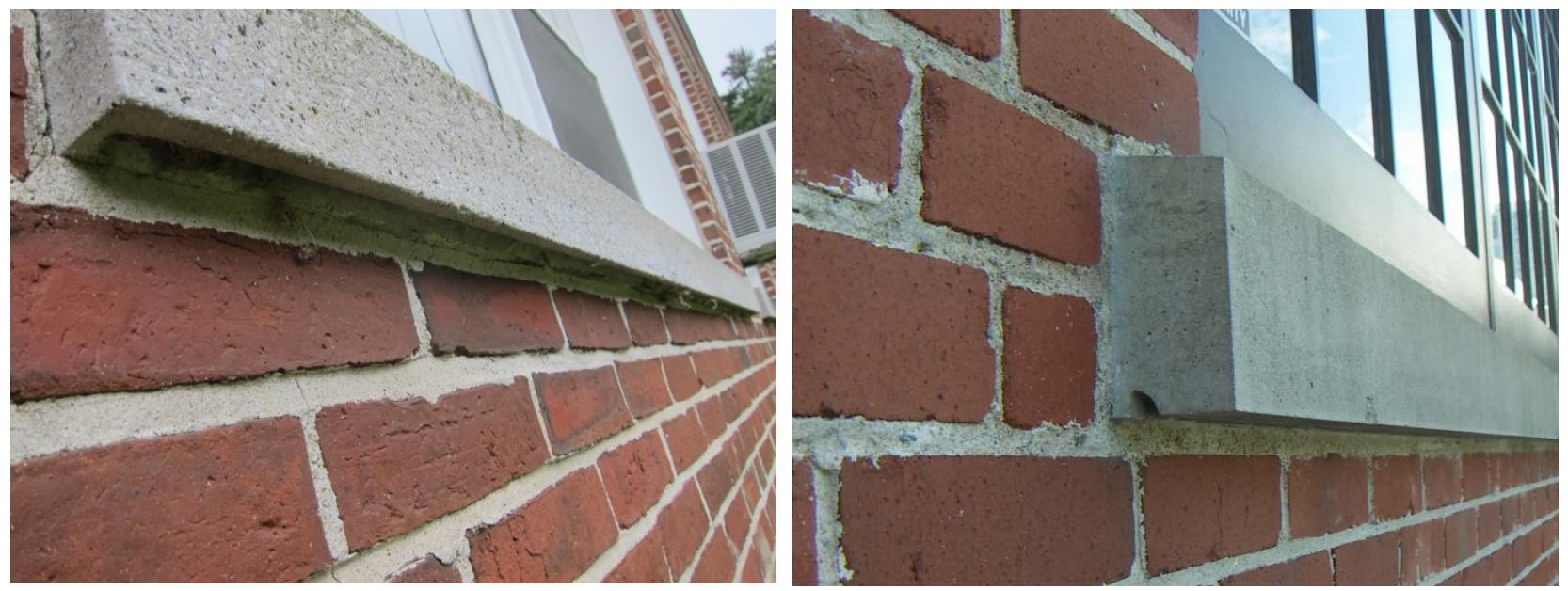

Figure 36. Precast window sill drip edge details

Informative patterns of water deposition can be seen in this building with granite sills: some of the sills have no corbeling below them (Figure 37, left); others have a brick corbel detail (Figure 37, right). Staining and mortar erosion was more severe at the corbeled detail (right), as the water draining from the sill is more likely to run onto the brick below from surface tension, as opposed to dripping free from the noncorbeled sill "lip" (left). This shows the importance of a projecting overhang at the sill.
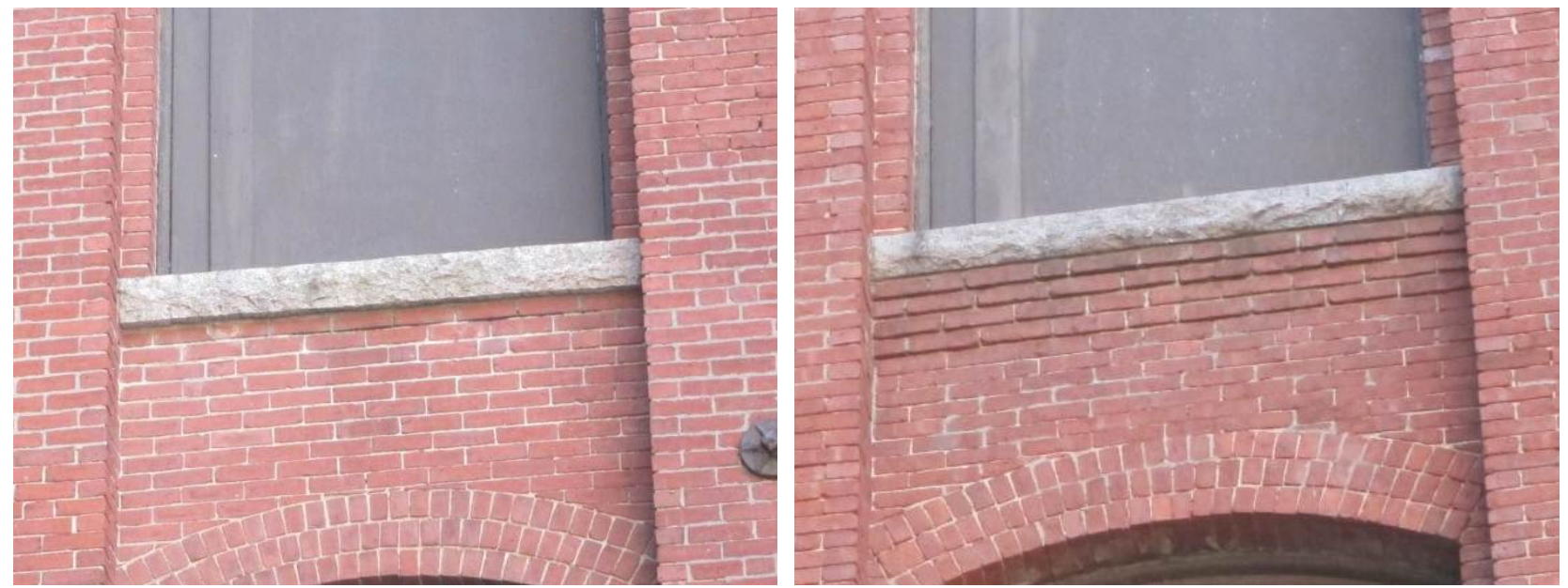

Figure 37. Left: Window sill without brick corbeling (left); Right: Window sill with brick corbeling, showing different mortar erosion patterns

When the existing sills do not have a drip edge or sufficient projection to shed water, several remedial solutions are available. One is to cut a "drip groove" in the underside of the sill (as per Figure 34, left), to provide a break to surface tension. Another is to cut the mortar under the sill and reglet in a formed metal drip edge, as shown in Figure 44. However, both are likely to cause issues in a historic building due to modification of the historic fabric, or the change of external appearance. 
A possible option in such historic buildings is a caulk "drip edge" on the underside of the sill (see Figure 38). Its success or failure will hinge on how far the drip can project beyond the wall face, and perhaps the geometry/tooling of the caulk bead (forming a sufficiently sharp edge to break surface tension). This can be tested in small-scale mockups by implementing this measure and using water spray testing of the existing window to determine the water shedding abilities.

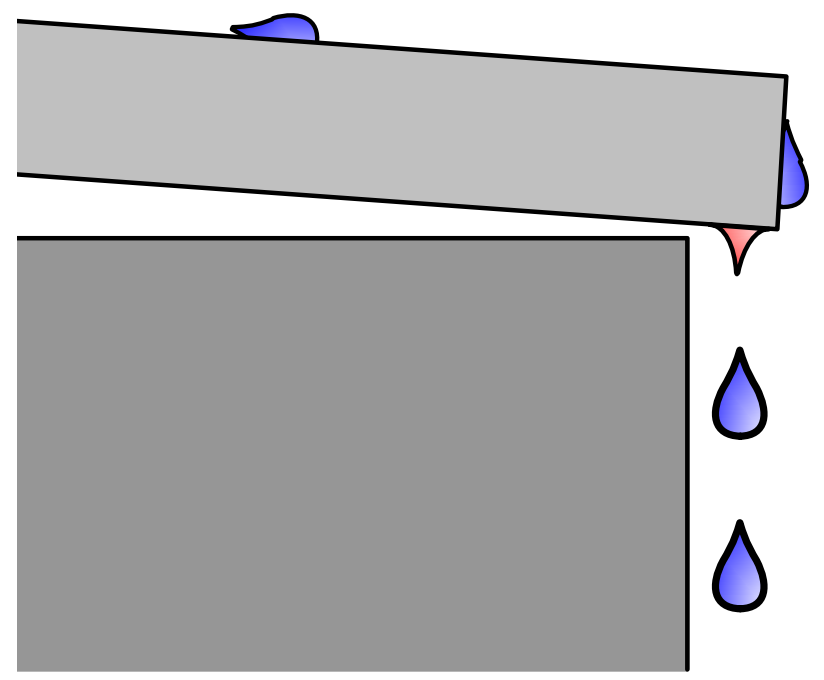

Figure 38. Caulk "drip edge" detail conceptual drawing

Caulk has much lower durability than metal flashing or a masonry cut groove; therefore, it becomes a continuing maintenance item to ensure building durability. A high-durability silicone or polyurethane caulk would be recommended at a minimum; adhesion of the caulk to the substrate is critical for durability of this detail.

Another problematic sill detail is the rowlock brick sill (Figure 39). Recommended construction details for a rowlock sill are provided by BIA (2005). Rowlock sills are more vulnerable than the previously described stone or cast sills, as they are composed of individual bricks with mortar joints, which will be a source of water leakage.


Figure 39. Rowlock window sill examples 
This becomes an even greater issue if the rowlock course has insufficient slope $\left(15^{\circ}\right.$ minimum as per BIA 2005) or inadequate projection for draining water (Figure 40). These issues (combined with leakage at the window- wall interface, or through the window itself) can result in additional water deposition on the masonry below the window, and thus staining and possibly damage interior finishes (Figure 40, right).
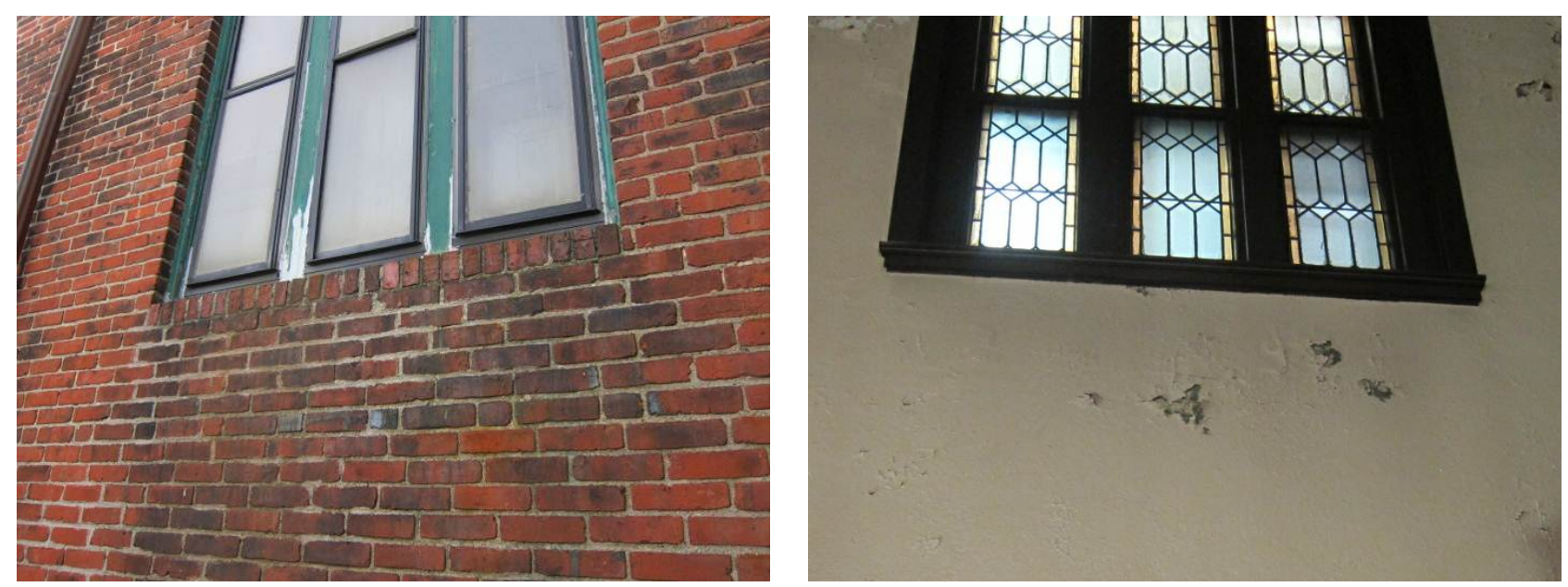

Figure 40. Left: Rowlock window sill with no projection; Right: Water deposition on wall below

One possible solution to reduce water loading into the wall below is to overclad the rowlock course with metal (or similar) flashing. An example is shown in Figure 41, which was a remediation detail for a problem sill.
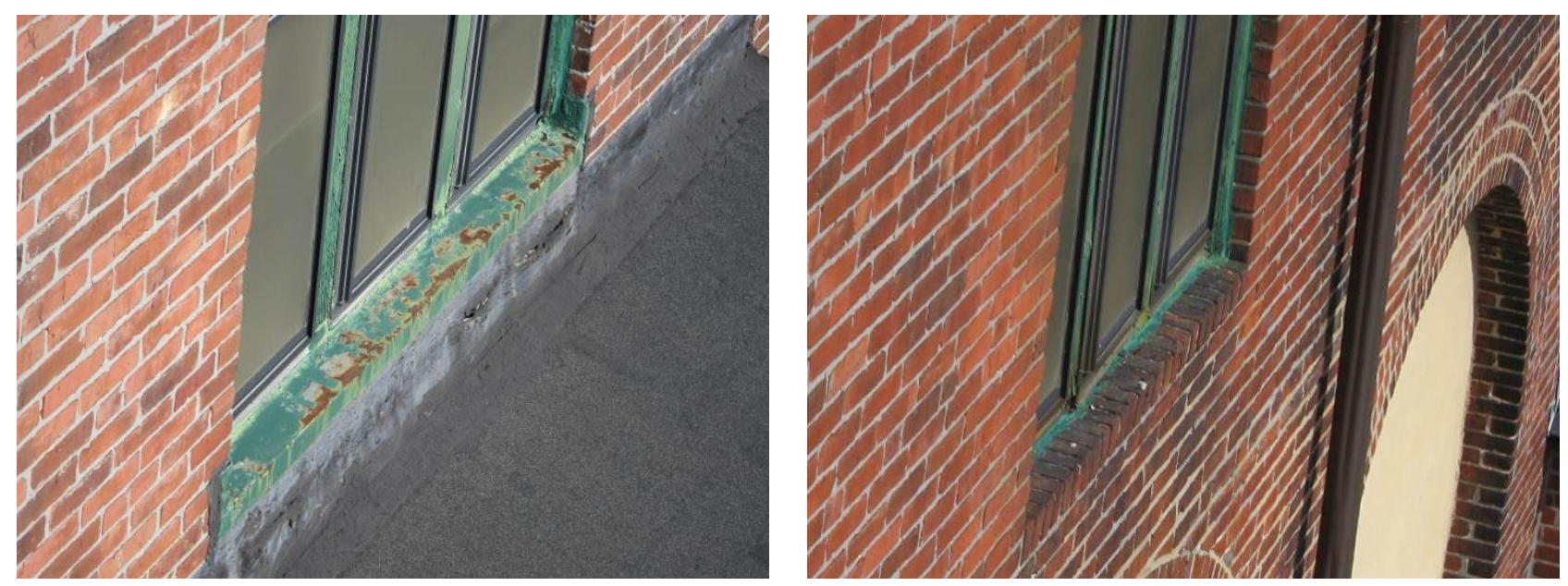

Figure 41. Left: Metal overclad detail of existing rowlock sill; Right: Original detail

Another metal sill example is shown in Figure 42: the formed metal has a substantial projecting drip edge, which provides greater protection for the wall below. 

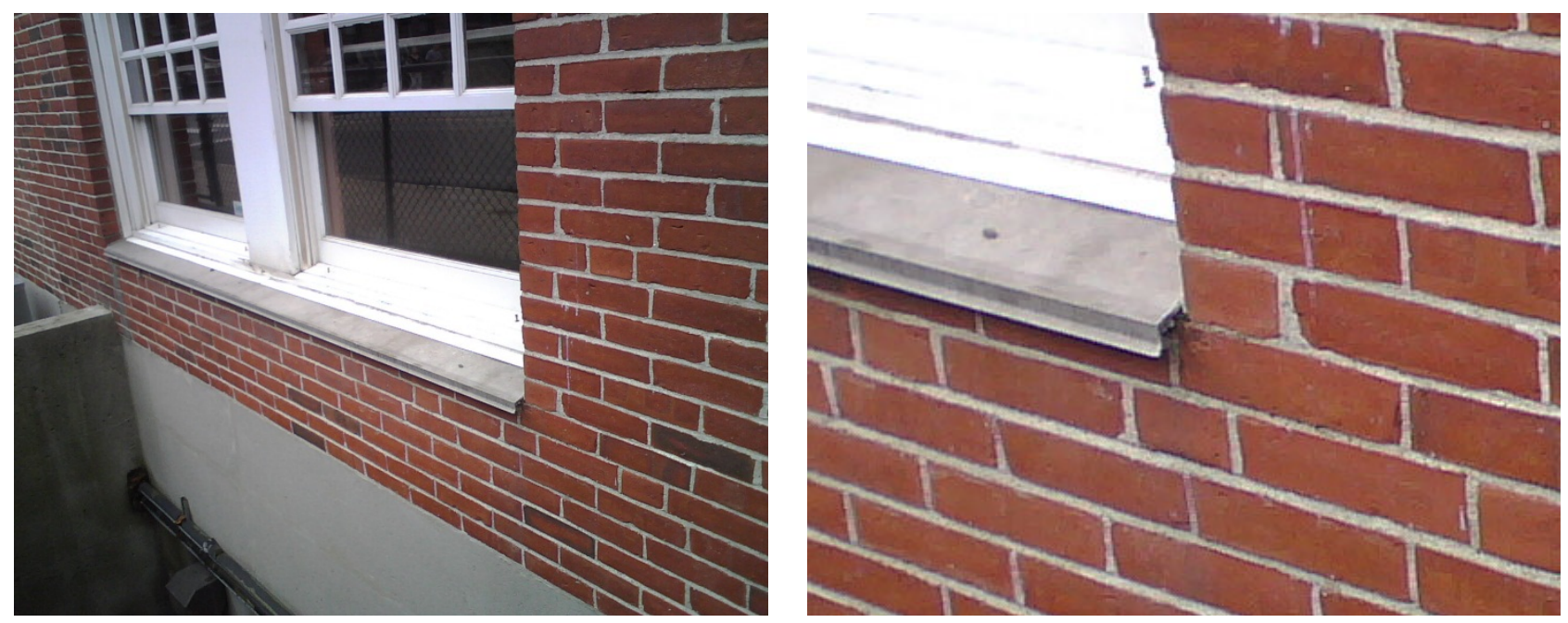

Figure 42. Example of overclad sill detail (formed metal)

One remediation strategy that is known to cause problems is to remove the rowlock course, add a waterproof membrane or copper flashing layer underneath, and rebuild the rowlock course (Figure 43). The resulting assembly accumulates water in the "pan" of the membrane, causing premature failure. A possible alternative might be a weeped/drained pan detail.
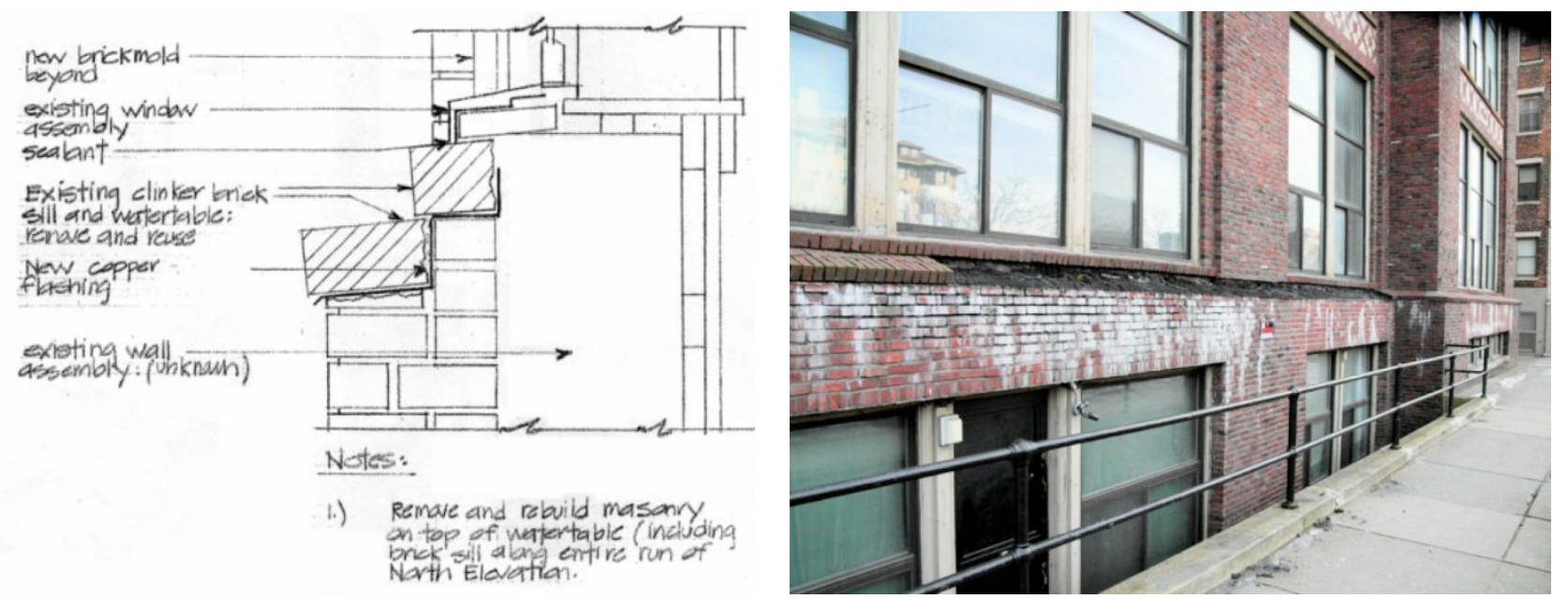

Figure 43. Left: Problem rowlock detail; Right: Failure of brick at detail

\subsubsection{Window Pan Flashings}

As described in Section 6.1.2, leakage through the wall-to-window joint or the window unit itself can contribute to masonry moisture loading. This can be reduced by a subsill pan flashing, which directs any of this water out onto the sill, as shown in Figure 44. This sill pan detail must include a back dam detail or slope (to prevent water ingress to the interior from the pan), and end dams (to prevent drainage of the pan laterally into the wall). 


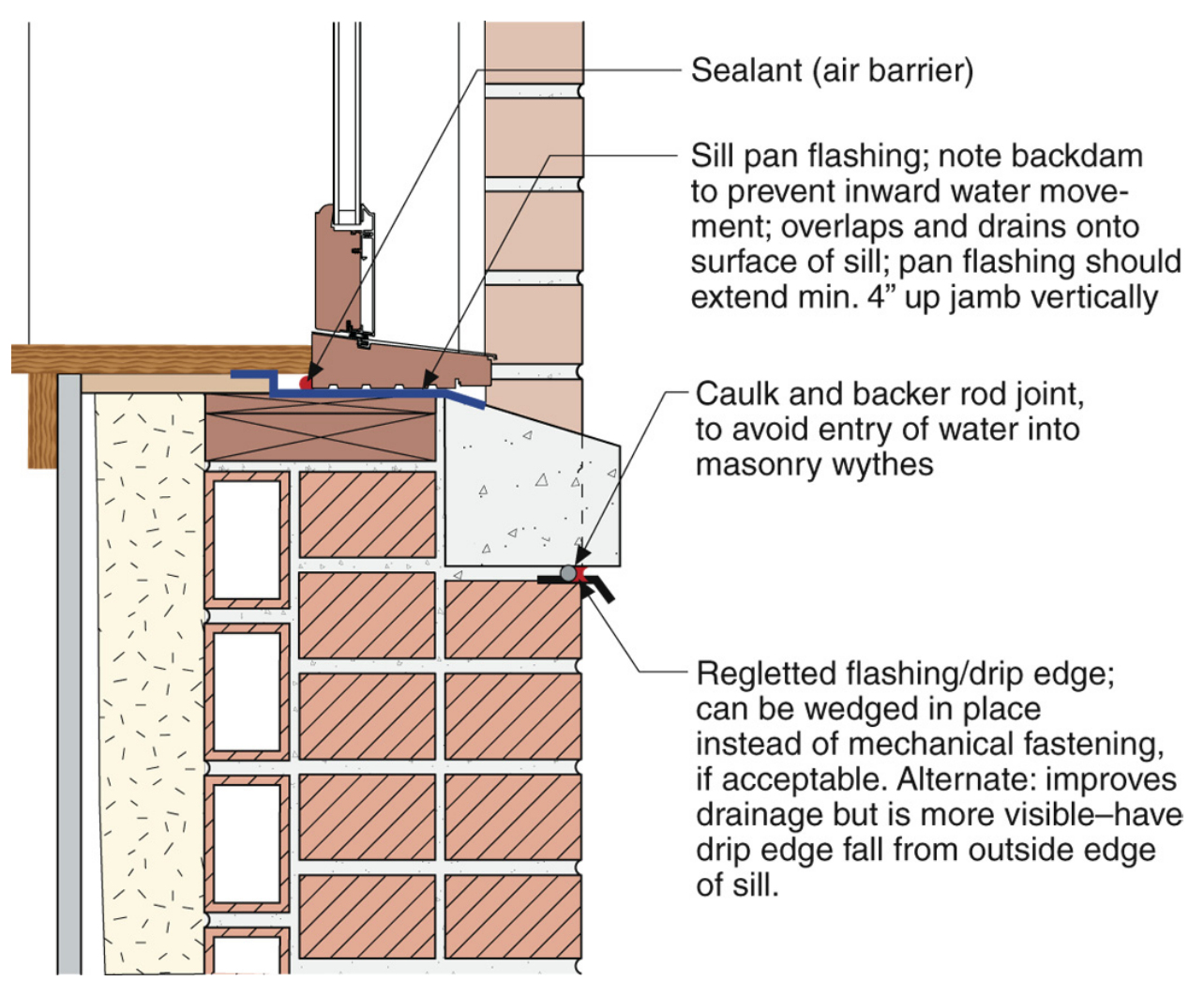

Figure 44. Conceptual drawing of window subsill pan and subsill reglet drip edge

An example of field-implemented window details is shown in Figure 45. The masonry window rough opening was first lined with pressure-treated lumber $2 x$ stock rough bucks, which were in turn covered with a self-adhered membrane flashing. The membrane is formed into a sill pan that drains to the exterior. Note that in the images below, the original wood sill was removed from the opening, and an extension sill was fabricated to drain the exterior of the window away from the wall. The joint between the window exterior and masonry is sealed with a caulk and backer rod detail.
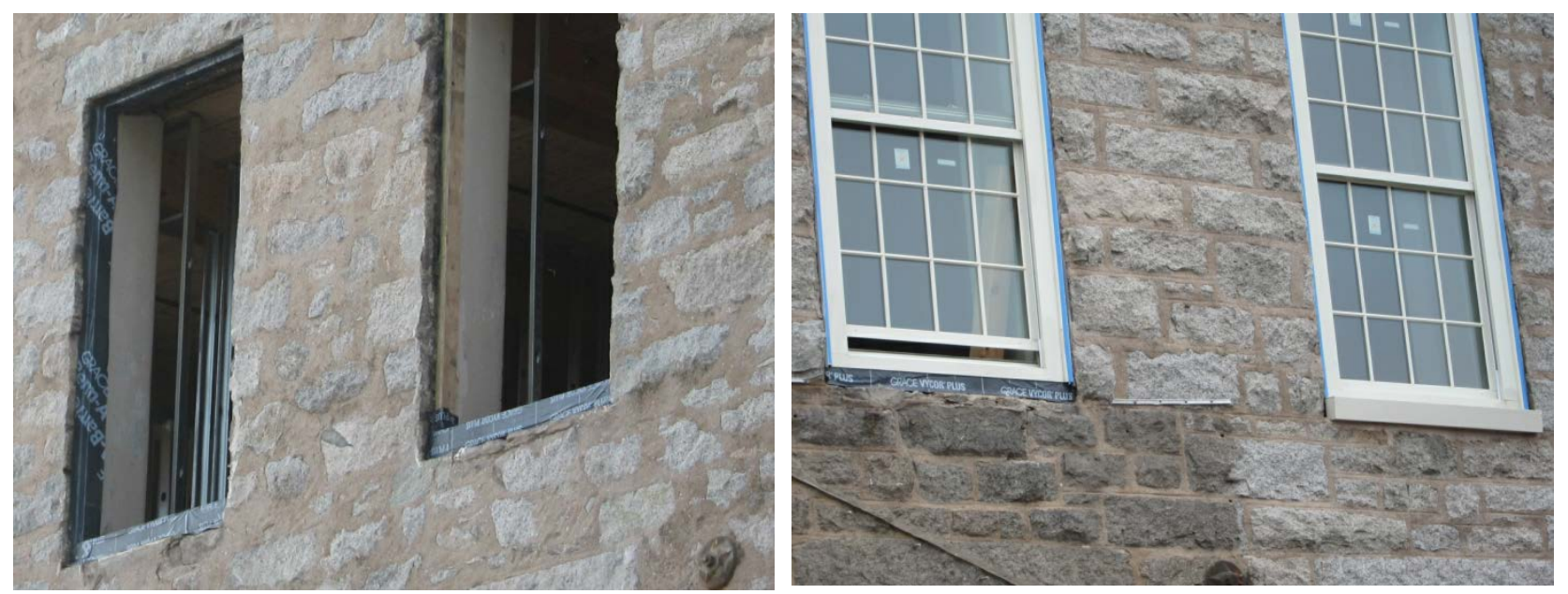

Figure 45. Left: Membrane flashing wrapping window opening; Right: Exterior view of window assembly and completed unit 
Figure 46 shows the interior side of these details, including the pressure-treated rough buck, plywood spacers, and self-adhered membrane. Note that the window is elevated from the sill with shims, which allows for drainage from the sill pan.
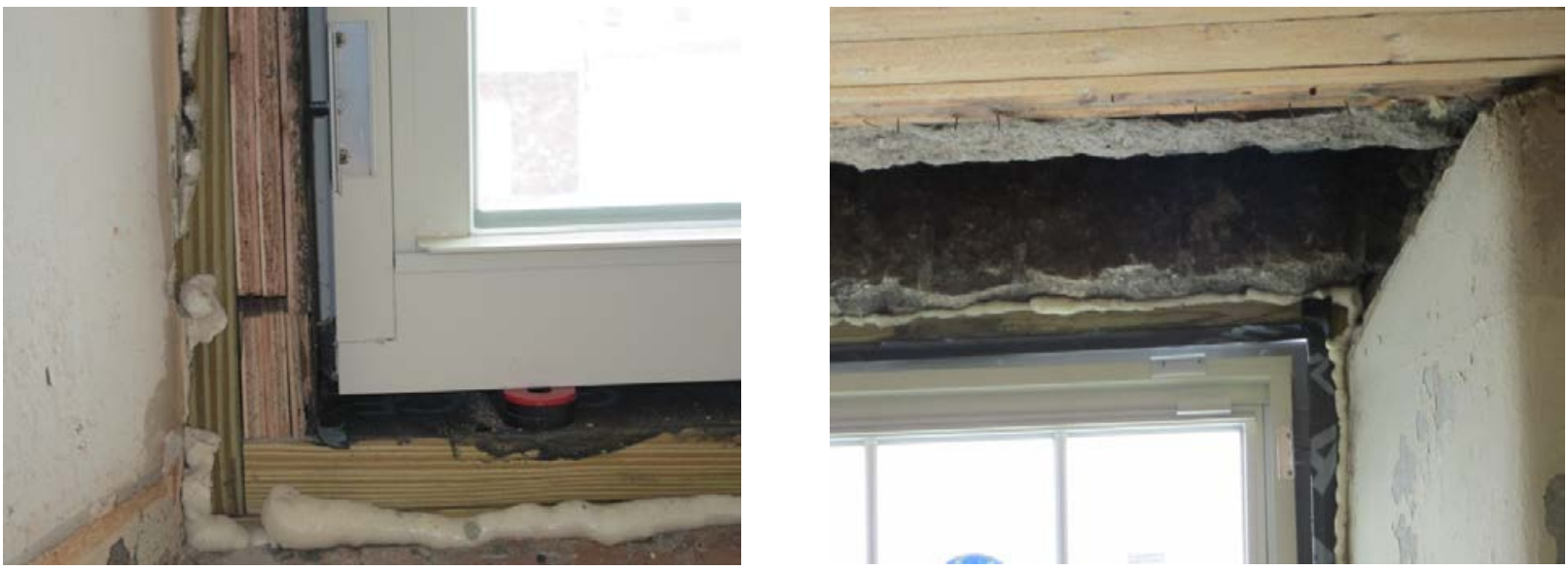

Figure 46. Left: Interior view of sill/jamb flashing details; Right: Head-jamb detail

Given the complication of using self-adhered membrane to wrap an opening made of disparate materials (interior masonry or plaster, wood buck, exterior masonry), one possible option is to use liquid-applied membranes to form the sill pan and rough opening lining.

\subsubsection{Tapered Window Openings}

Many mass masonry buildings have deep window openings as an existing design feature. However, this results in limited available space to provide insulation at the opening, because of window clearance issues and historic requirements to maintain window profiles. Reducing the insulation thickness at openings will have some impact on thermal control, but if a minimum of about R-5 is maintained, condensation and excess heat loss can be managed.

The detail shown in Figure 47 shows the tapered insulation required based on the window profile and available space. Note that it shows an insulated steel stud assembly, which is not recommended, because of poor thermal performance (thermal bridging).
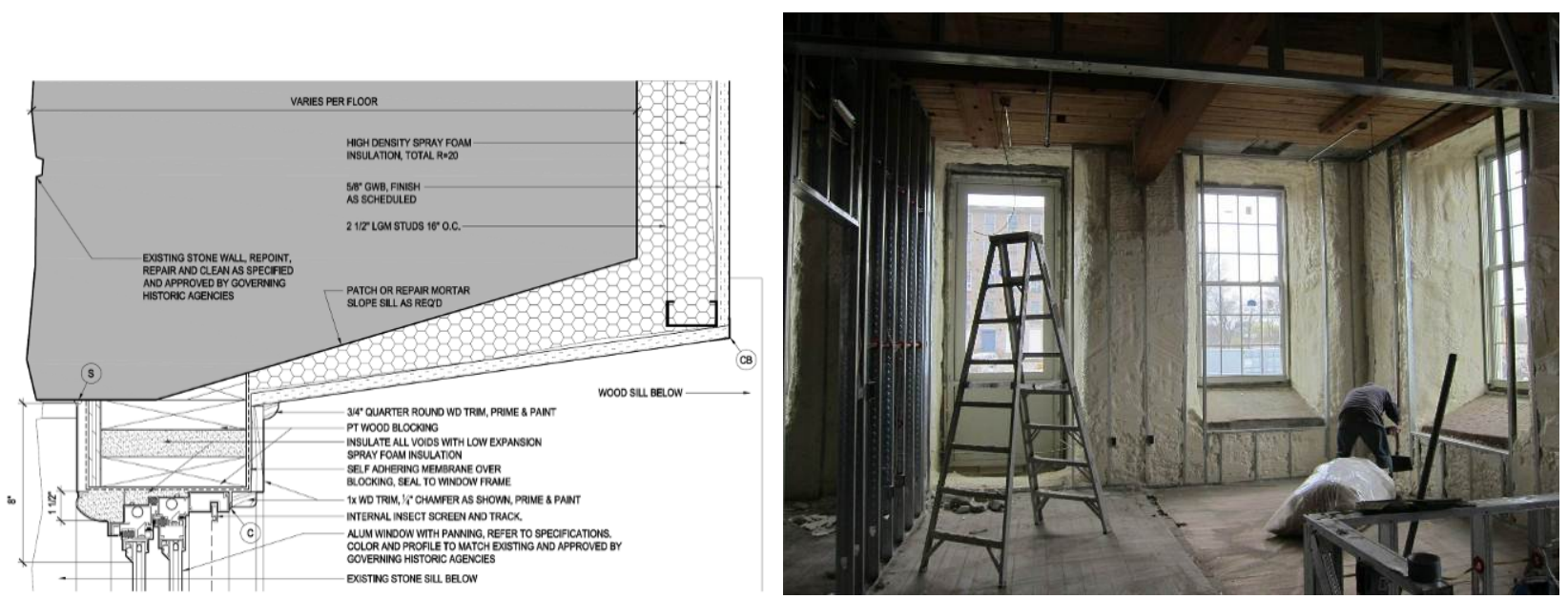

Figure 47. Window opening with tapered jamb detail (sill left uninsulated; not recommended) 
This installation had to meet historic preservation requirements; therefore, the brick sill was left exposed as a historic detail (see Figure 48). This is not recommended, because of poor energy performance, potential condensation issues, and possible comfort complaints (occupant "seeing" a larger cold radiative surface).
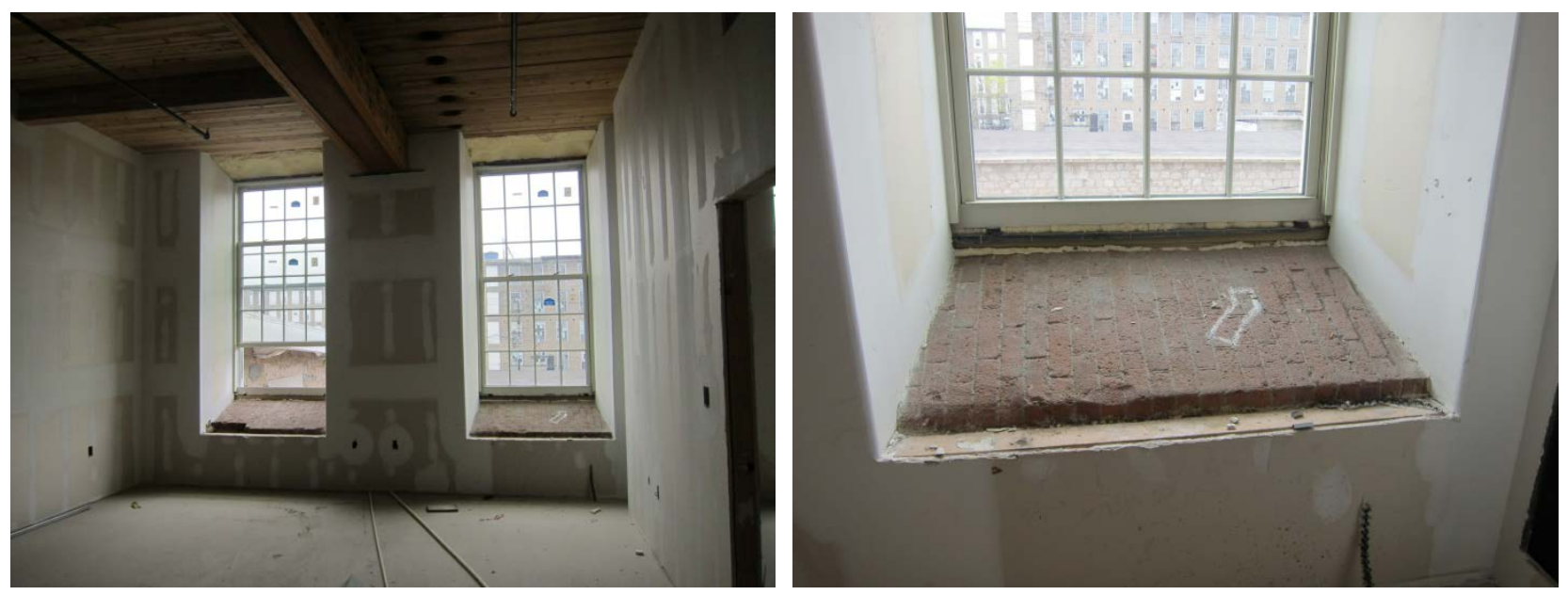

Figure 48. Gypsum board at window openings with tapered jamb detail (sill left uninsulated; not recommended)

\subsection{Exterior Bulk Water Concentration Details}

Items such as masonry details and band courses and roof-wall intersections can also be particularly problematic in introducing greater moisture into the wall, as they increase the risk of premature failure.

\subsubsection{Stone and Brick Detailing Courses}

Details such as stonework and band courses can result in water concentration and deposition on the face of the building. These water concentrations can often cause FT spalling damage. For instance, staining was visible on a decorative arch at the front of a building, at the joints of the stone coping (Figure 49).
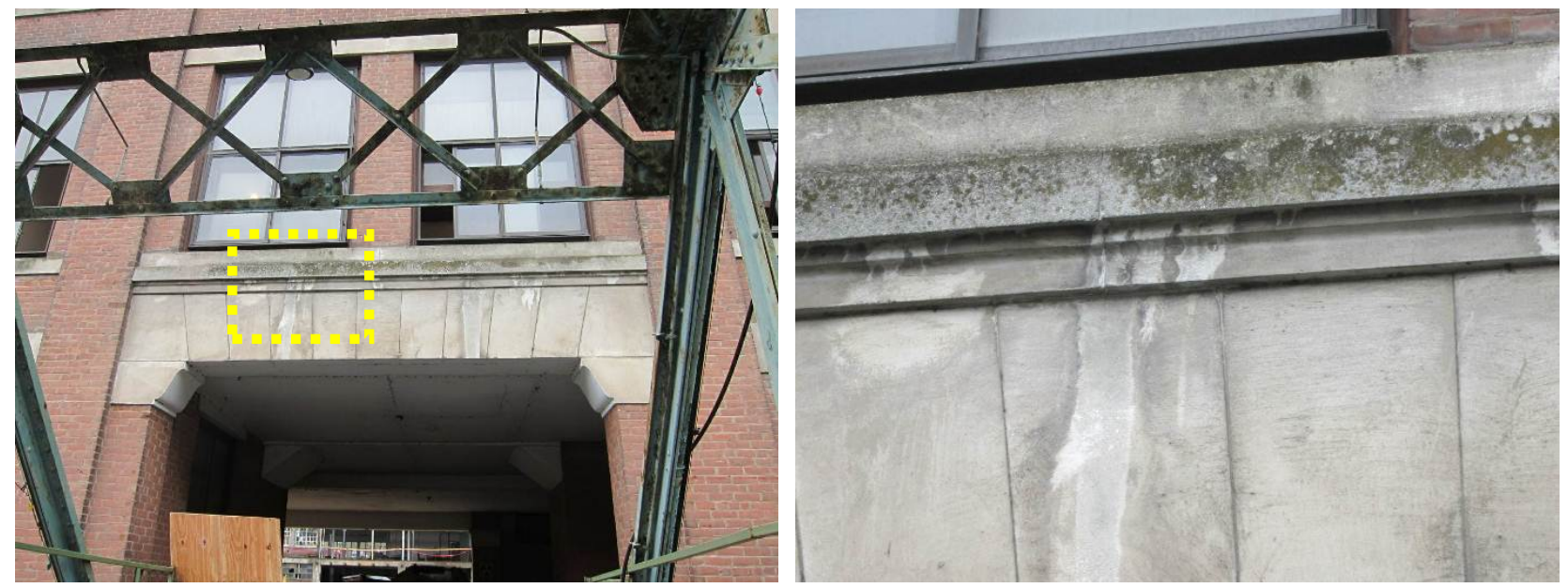

Figure 49. Staining on decorative arch coping stones, concentrations at joints 
Another problem is an inward stepped detail; the example shown in Figure 50 steps inward in four 1-in. steps from the basement to the first floor, to accommodate a change in wall thickness. The steps in the brickwork also create ledges for rainwater to collect. The brick in these areas will tend to have higher moisture contents, and is more likely to suffer FT degradation. An improvement on this detail would be a regletted metal sloped cap, if it is aesthetically acceptable.
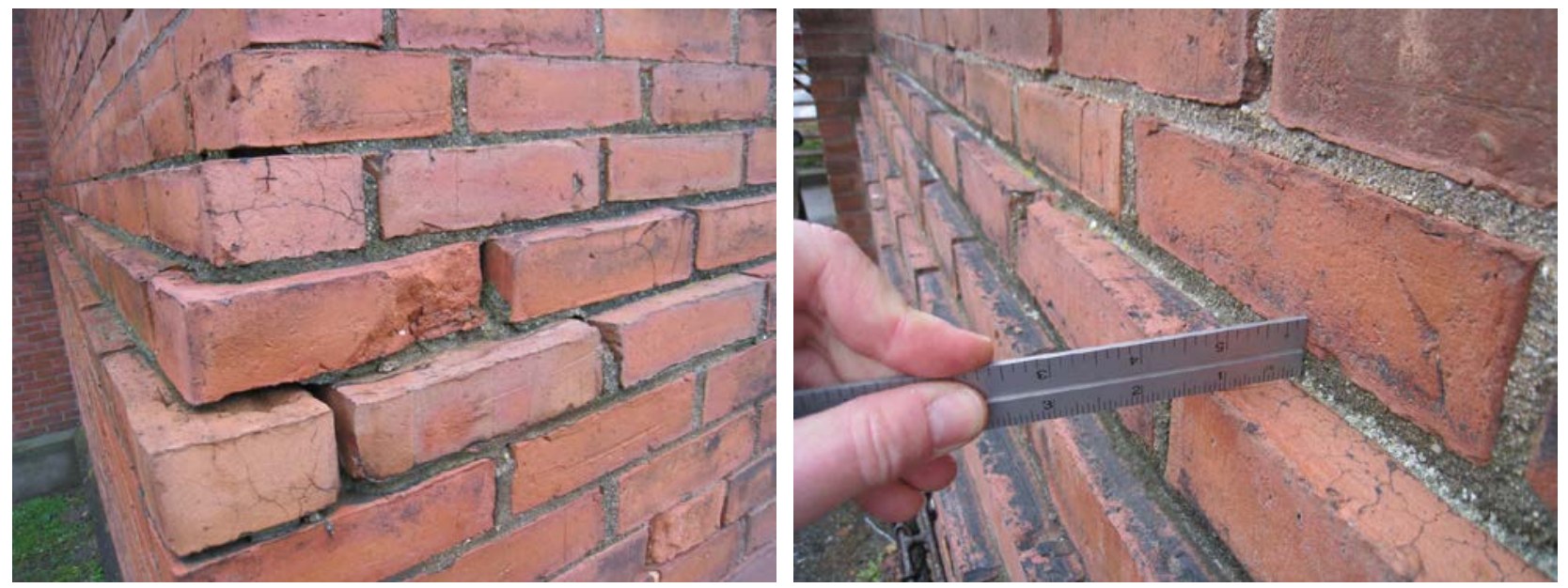

Figure 50. Steps in brickwork, and related cracking/FT damage

The front face of the same building has a stone belt course at the basement to first floor interface in lieu of the stepped brickwork. The belt serves as a much more effective transition to the wider masonry wall at the basement level (relative to the stepped detail on the back portion of the building). The granite stones are highly durable and their sloped profile does an effective job of shedding water; however, the mortar at the joints between stones has eroded and is causing local concentrations of high moisture at the brickwork immediately below, as shown in Figure 51 (left). The mortar should be repointed and maintained to avoid damage.

The front face of the building also has decorative stone elements as a cornice above the second story windows and as a coping at the top of the parapet (as pictured in Figure 51, right).

Although a cornice nominally provides an overhang (and thus protection) to the wall underneath, the mortar has failed at the joints, resulting in water concentrations. The cornice joints require repointing, and all of the coping stones should also be checked for proper position and adequate structural attachment. A metal overclad would provide longer term water shedding.
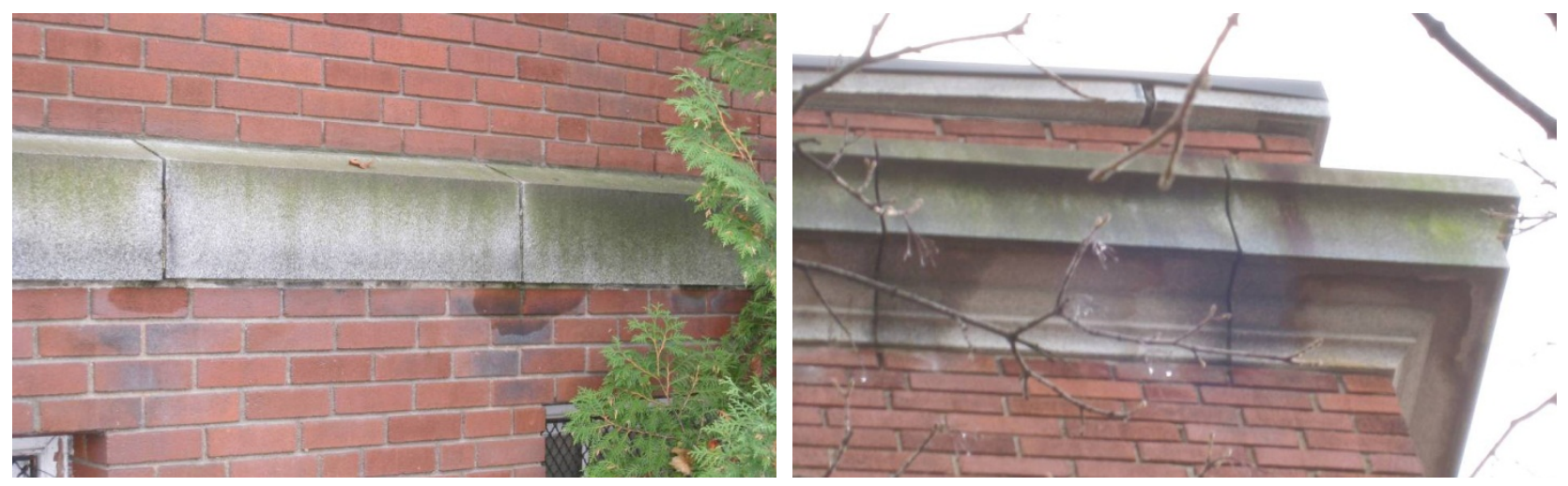

Figure 51. Water concentration at stone belt and cornice joints 
Another set of similar problem details is shown in Figure 52; there has been sufficient erosion of the mortar joints at the band detail that plant growth is occurring at various joints. This shows the general importance of maintenance; noticeable FT damage is visible below the left-hand image, below the band course.
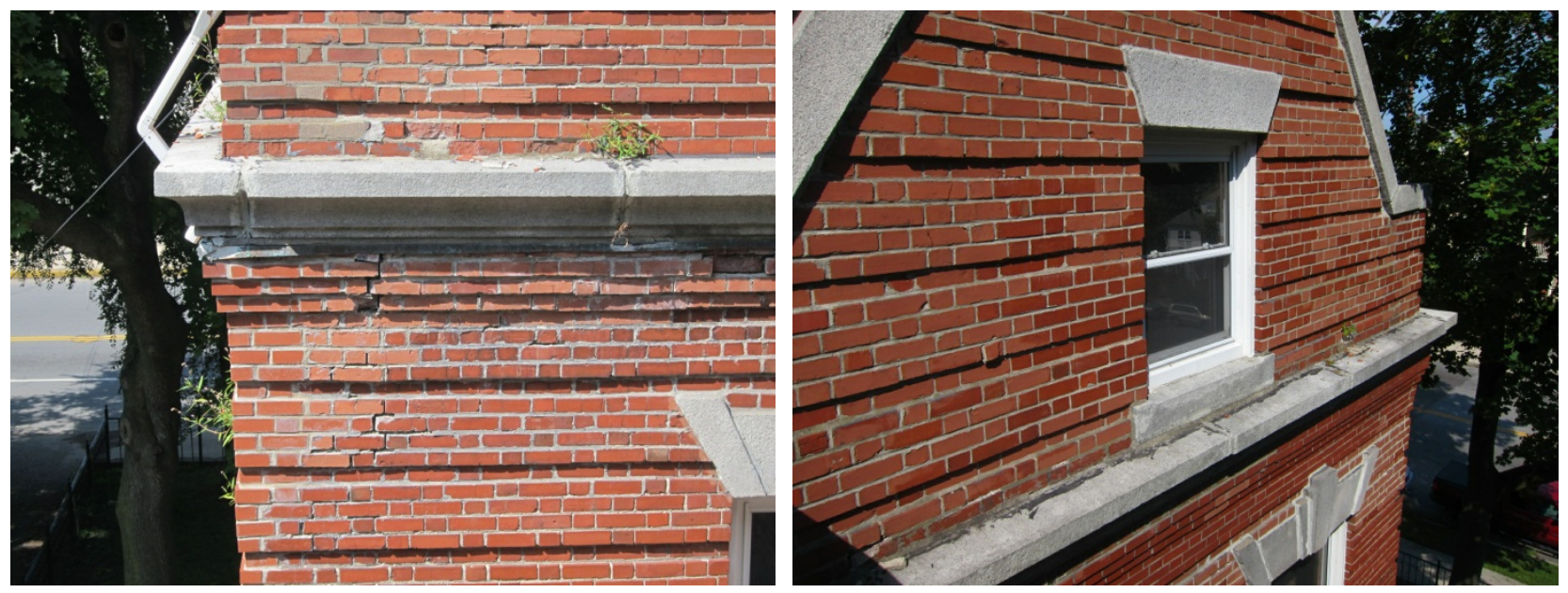

Figure 52. Unmaintained band course; plant growth at mortar joints

\subsubsection{Roof-Wall Interfaces}

Roof-wall interfaces can also be another source of water concentrations. For instance, Figure 53 and Figure 54 show roofs that were retrofitted to building entrances. The gutters and kickout flashings on these roofs were not properly configured to direct water away from the adjacent masonry walls. As a result, significant and visible moisture has accumulated. The addition of kickout flashings could reduce the water loading associated with these roofs.
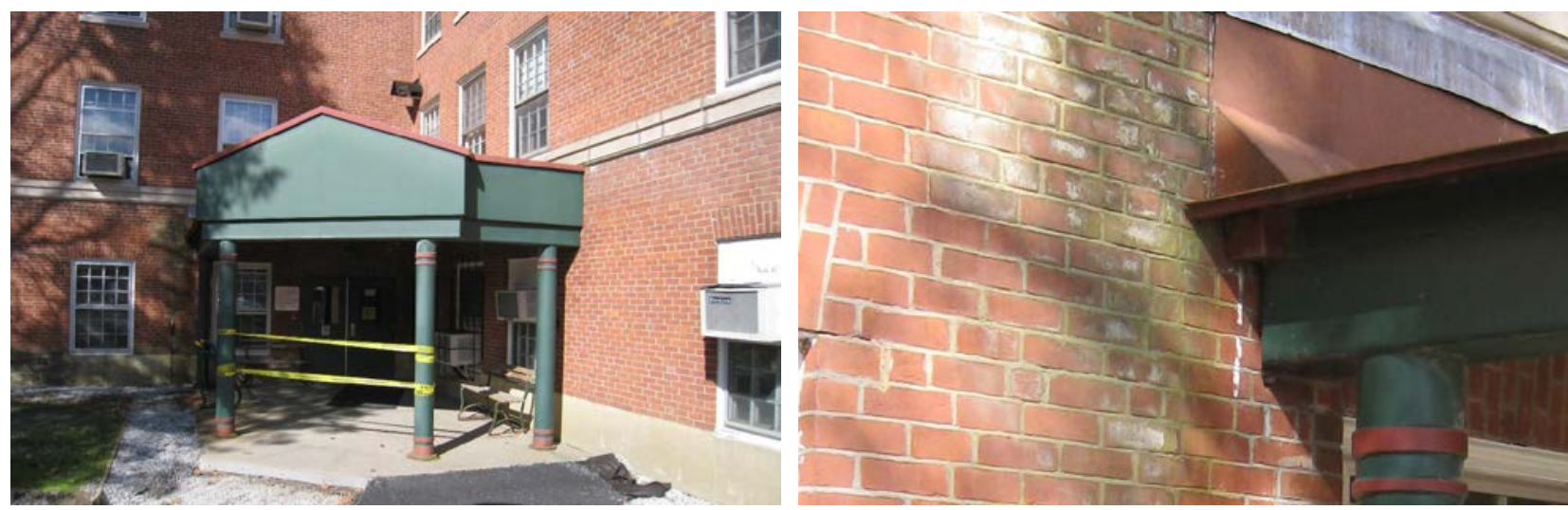

Figure 53. Left: Retrofit roof over entrance; Right: Water runoff concentration at roof-wall interface 


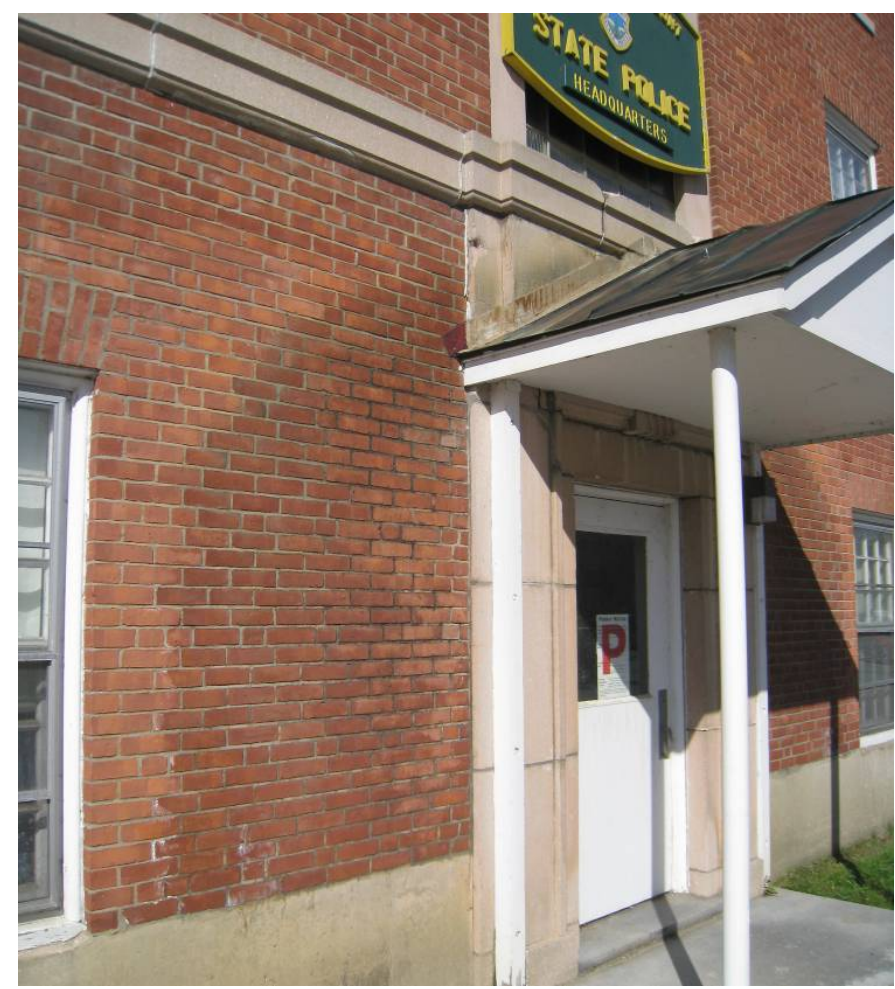

Figure 54. Water runoff concentration at roof-wall interface (kickout flashing required)

A similar type of detail is shown in Figure 55: a lower low-slope roof (stucco building, right) is terminated into the wall of the brick building. The current geometry results in water accumulation on the wall below: this problem is evidenced by the green staining on the wall (see green box in Figure 34). This could be prevented with the addition of a kickout flashing.

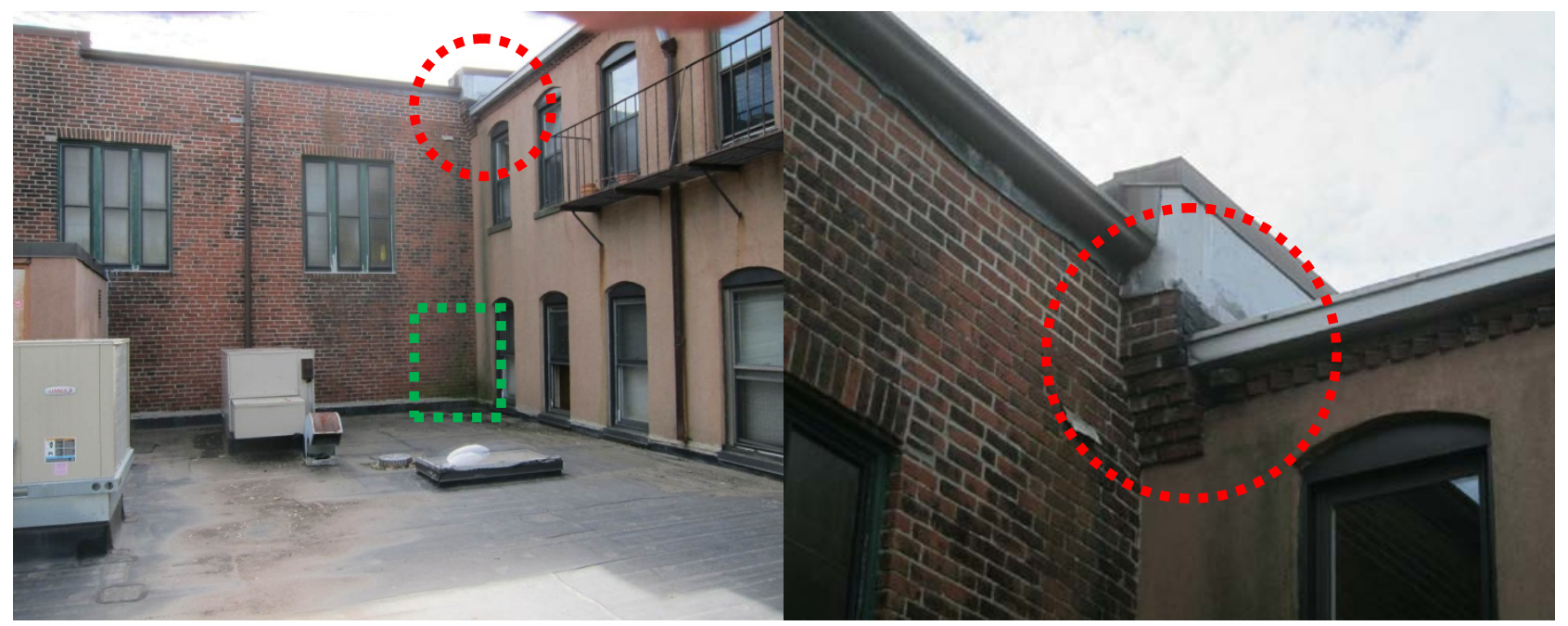

Figure 55. Water runoff concentration at roof-wall interface (kickout flashing required)

Another example of moisture ingress at a roof-wall condition is shown in Figure 56. Severe interior efflorescence and delamination of the interior parging/paint was noted. An attached roof structure (now demolished) appears to be associated with the localized bulk water issues seen from the interior. 

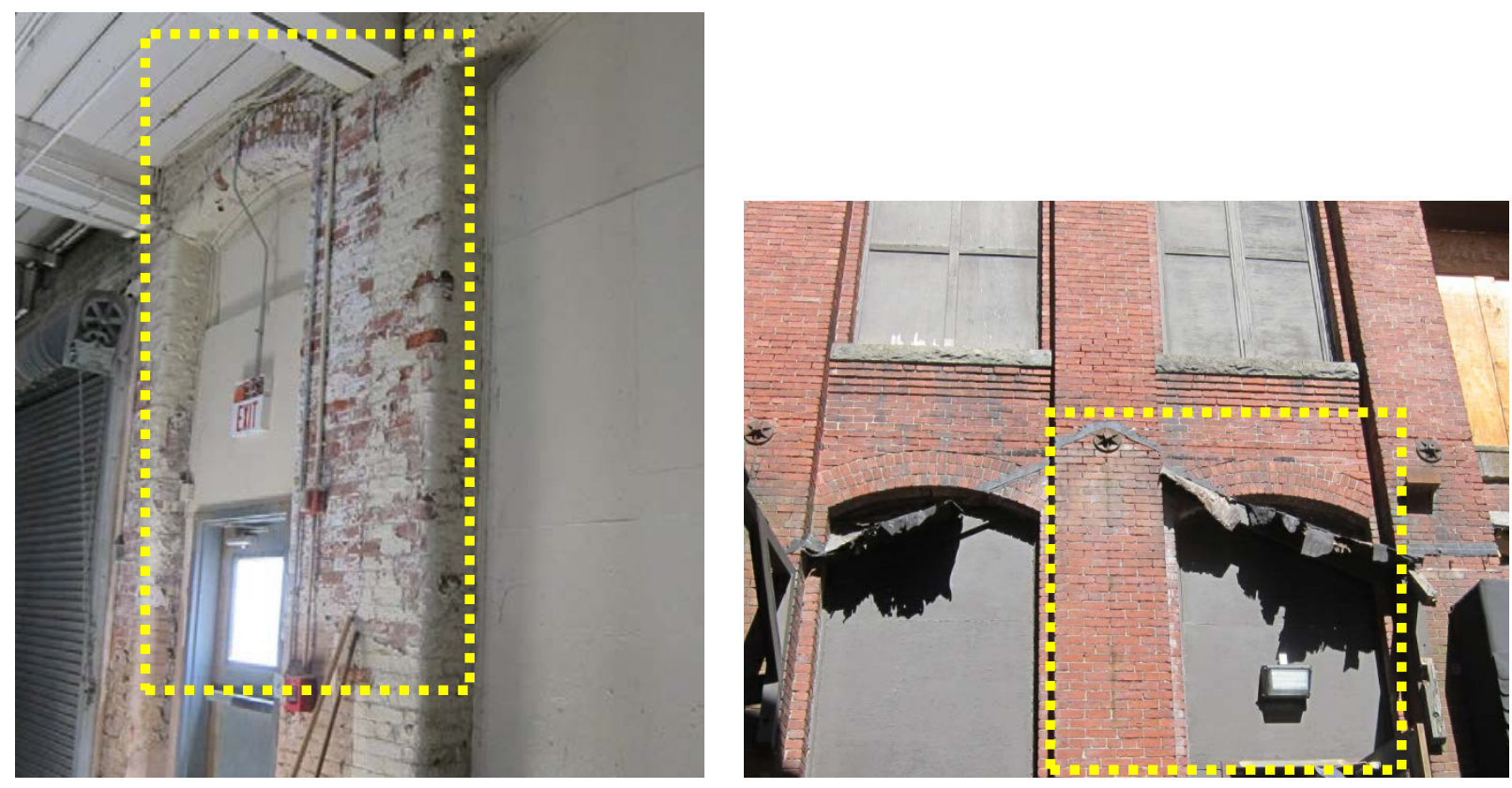

Figure 56. Left: Interior paint/parging delamination; Right: Exterior conditions for comparison

\subsubsection{Roof-Wall Water Problem Example}

As discussed above, mass storage walls are dependent on a balance of wetting and drying to prevent water entry to the interior. Figure 57 (center and right) shows a building that was insulated on the interior with urethane foam and steel stud framing, and then exhibited problems in service. The building owner initially reported mold issues around the window penetrations on the top floor of the building (particularly at arch-top windows), on all orientations. Closer examination showed that this was not mold, but re-emulsification of gypsum drywall compound caused by bulk water penetration.
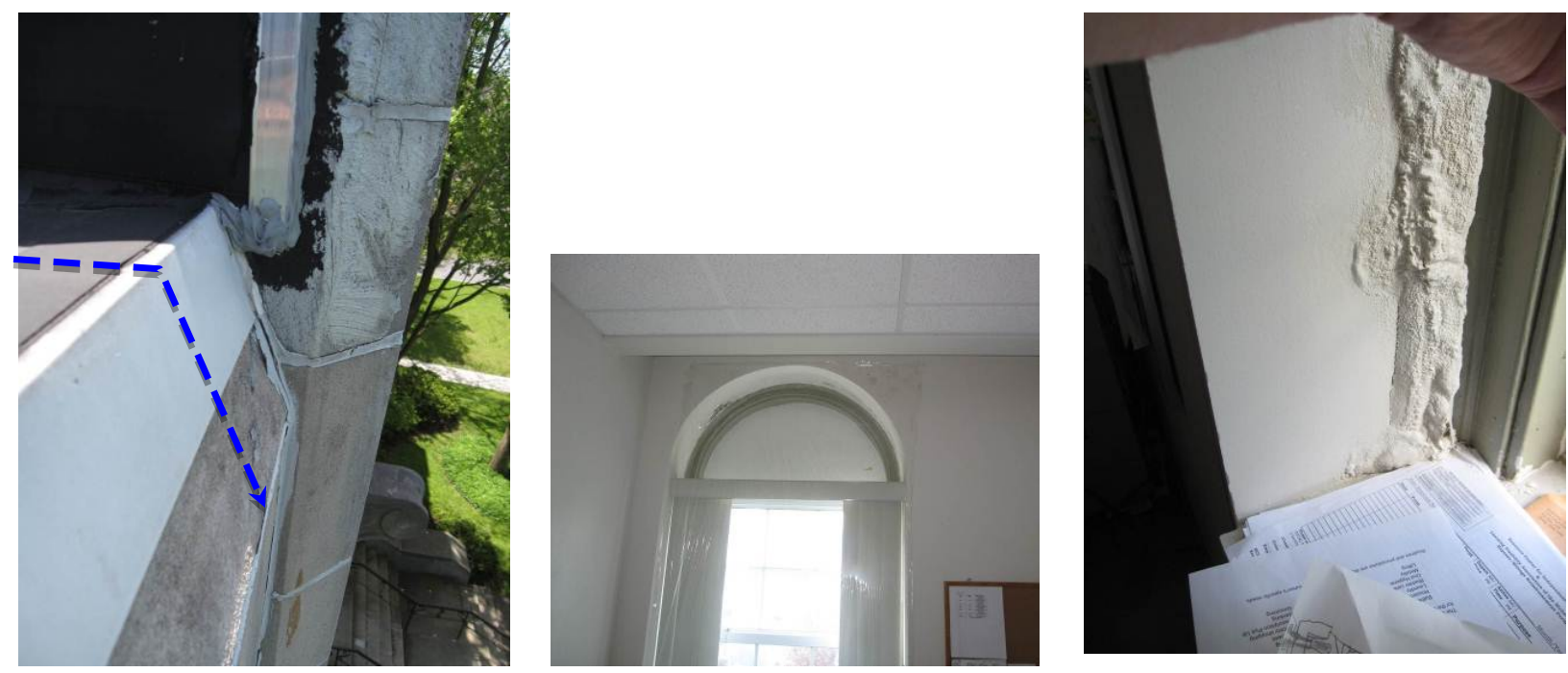

Figure 57. Moisture issues at roof-wall and windows in retrofitted building

(Credit: Terry Brennan/Camroden, used by permission) 
A diagnosis of the building exterior revealed a series of details that concentrate exterior rainwater at vulnerable locations. For instance, the roof-wall interface coping deposits rainwater directly onto the existing stonework, where it concentrates at the unmaintained (and open) grout joint (Figure 57, left). A preferred detail would be a metal water shedding detail that covers the entire sloping stonework, with a drip edge $1 \mathrm{in}$. off the face of the stonework, to shed the water from the masonry.

Another location where the damage could be examined more closely was at arch-top windows where the cement plaster arch formed a "tunnel" to the interior (Figure 58), with spray foam on the exterior wall. The damage was in the form of plaster degradation and rust of the plaster reinforcement mesh and steel framing.
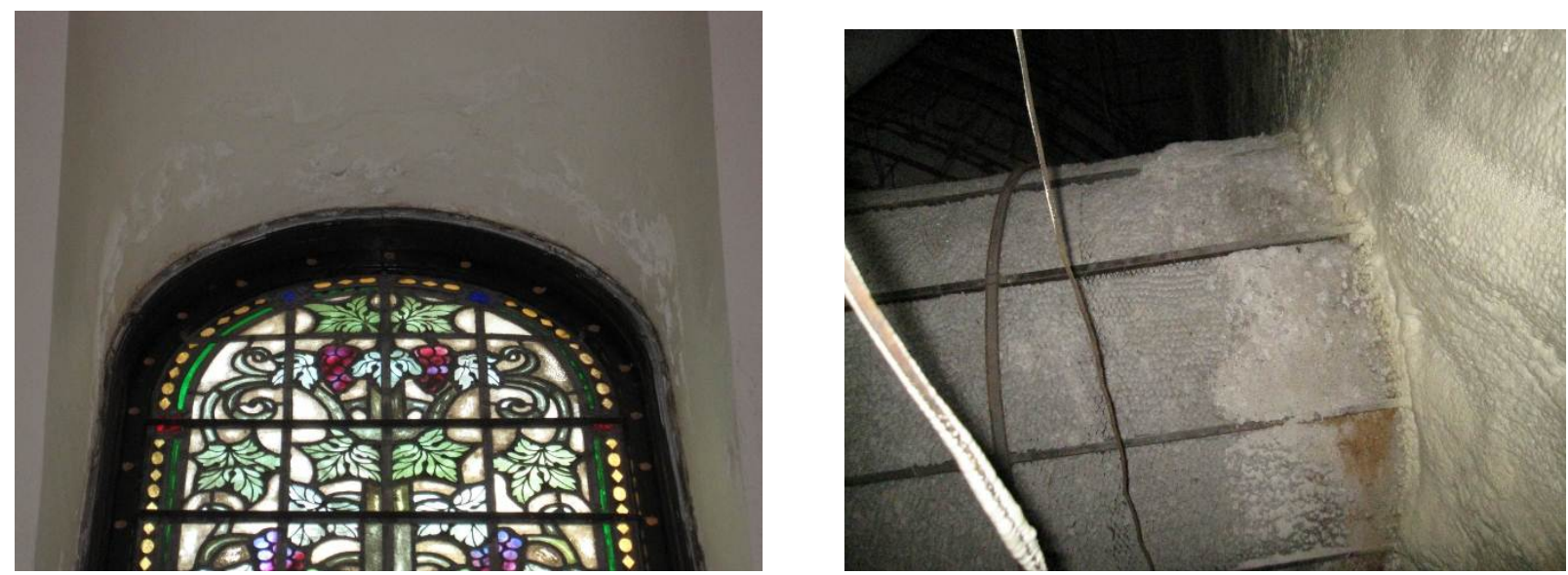

Figure 58. Moisture issues at chapel windows

(Credit: Terry Brennan/Camroden, used by permission)

Investigation revealed that the problem windows were surrounded by wet masonry; the nonproblem windows had dry masonry (as confirmed by measurements with a electrical capacitance moisture meter). All windows that showed damage had obvious water management defects in the brickwork above. This shows the prime importance of controlling bulk water entry into the wall, especially as leakage will no longer be visible from inside until damage occurs to interior finishes. If rain control cannot be addressed and upgraded, interior insulation should not be implemented.

\subsubsection{Coping and Parapet Cap Details}

Normally, copings deflect water off a building instead of collecting and focusing it. However, problems such as inadequate slope, incorrect slope, inadequate overhangs, or inadequate drip edges can all cause accumulation of bulk water on the masonry below, sometimes with severe damage, as shown in Figure 59. 


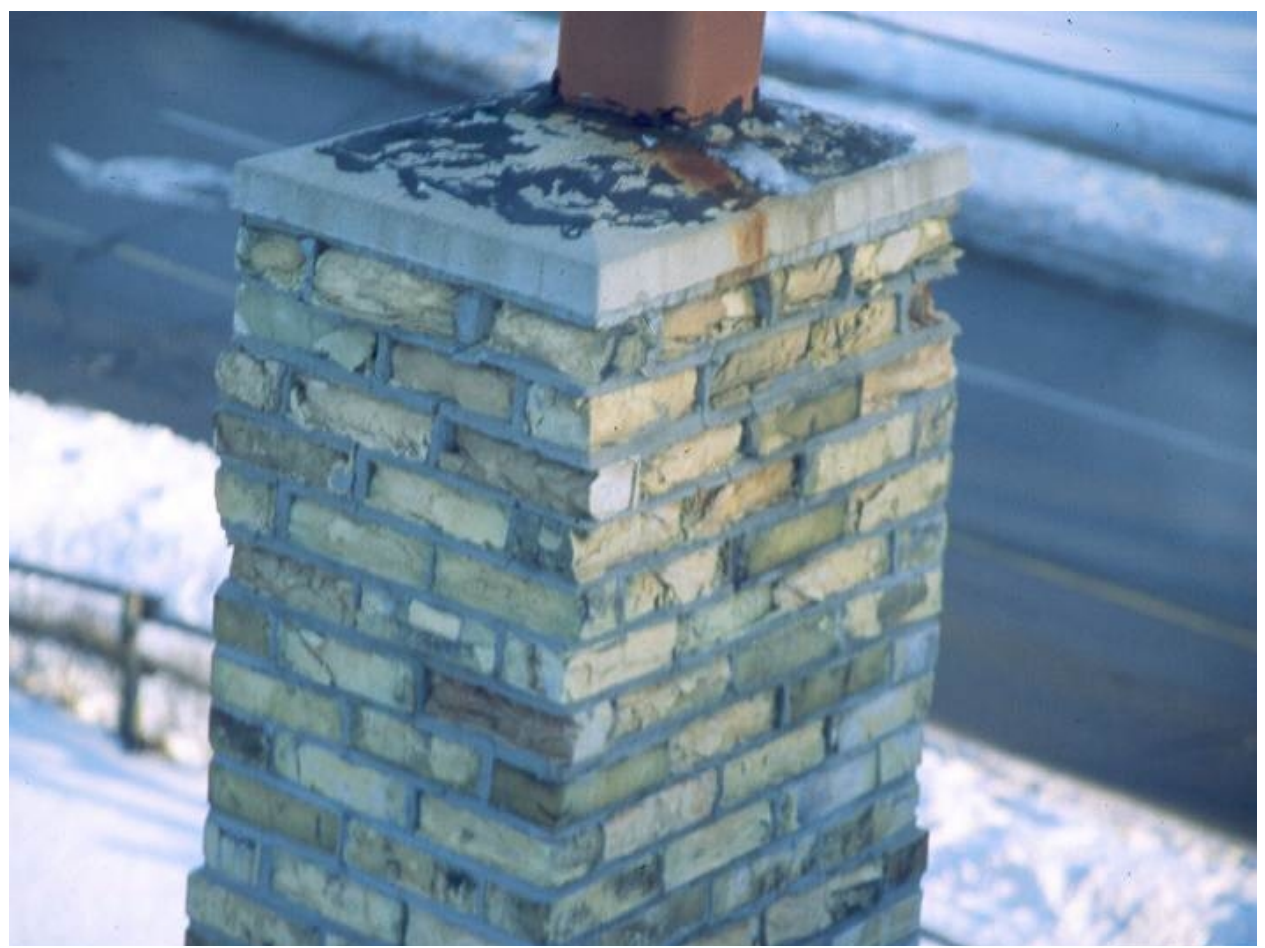

Figure 59. Severe FT damage at existing chimney; lack of projecting cap with drip edge

The continuous metal coping shown in Figure 60 replaced an earlier design that concentrated water onto the wall below at periodic joints. The newer design appears to correct this flaw, but it would benefit by projecting the drip edge further off the wall.

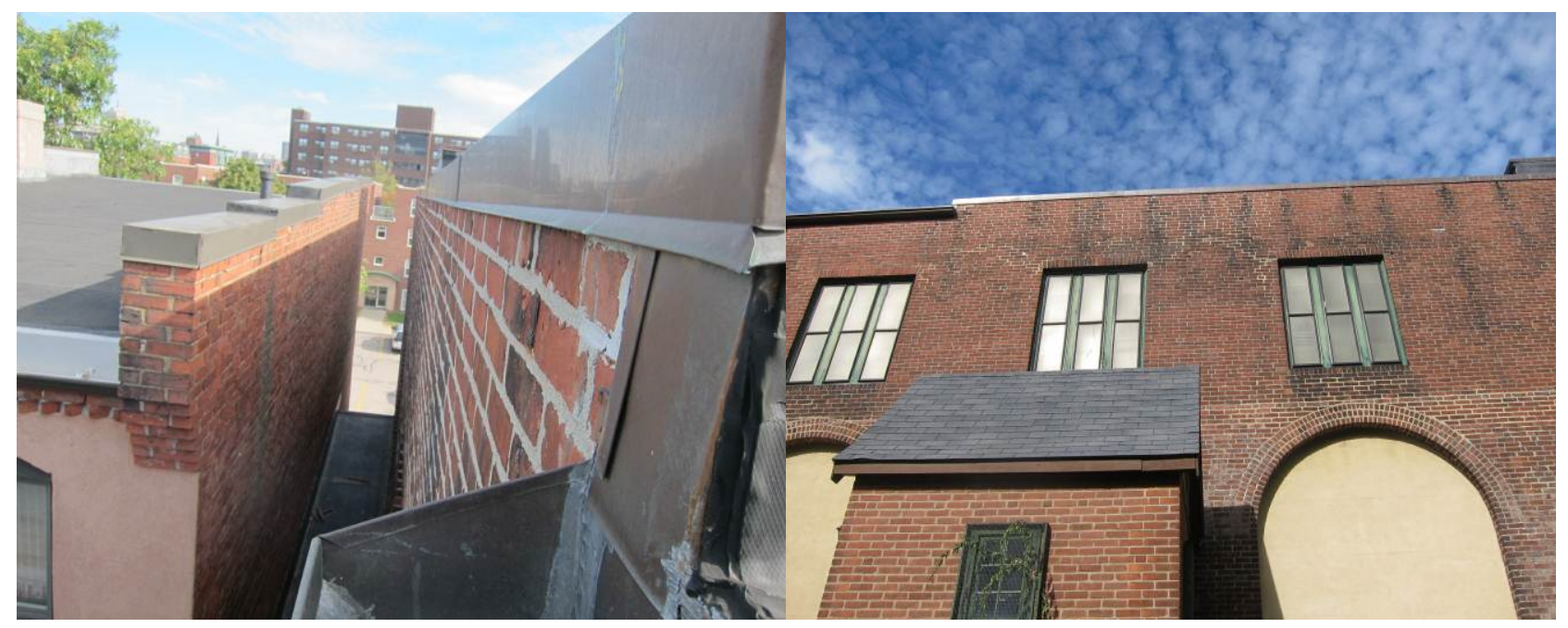

Figure 60. Coping detail and runoff staining at joints of previous coping design

The highest performing (and easiest to apply) metal coping or cap flashing options include the following key features:

- Coping is sloped inward (onto the roof membrane) with a 2:12 slope; this reduces the amount of runoff that could potentially deposit onto the masonry and ensures that water 
does not pond on a horizontal surface (which could penetrate through any failed coping joint).

- The waterproof membrane wraps up and over the parapet to prevent wetting from the interior side and to prevent any entry of water into the top of the parapet at joints or failures of the metal coping (see Figure 61).

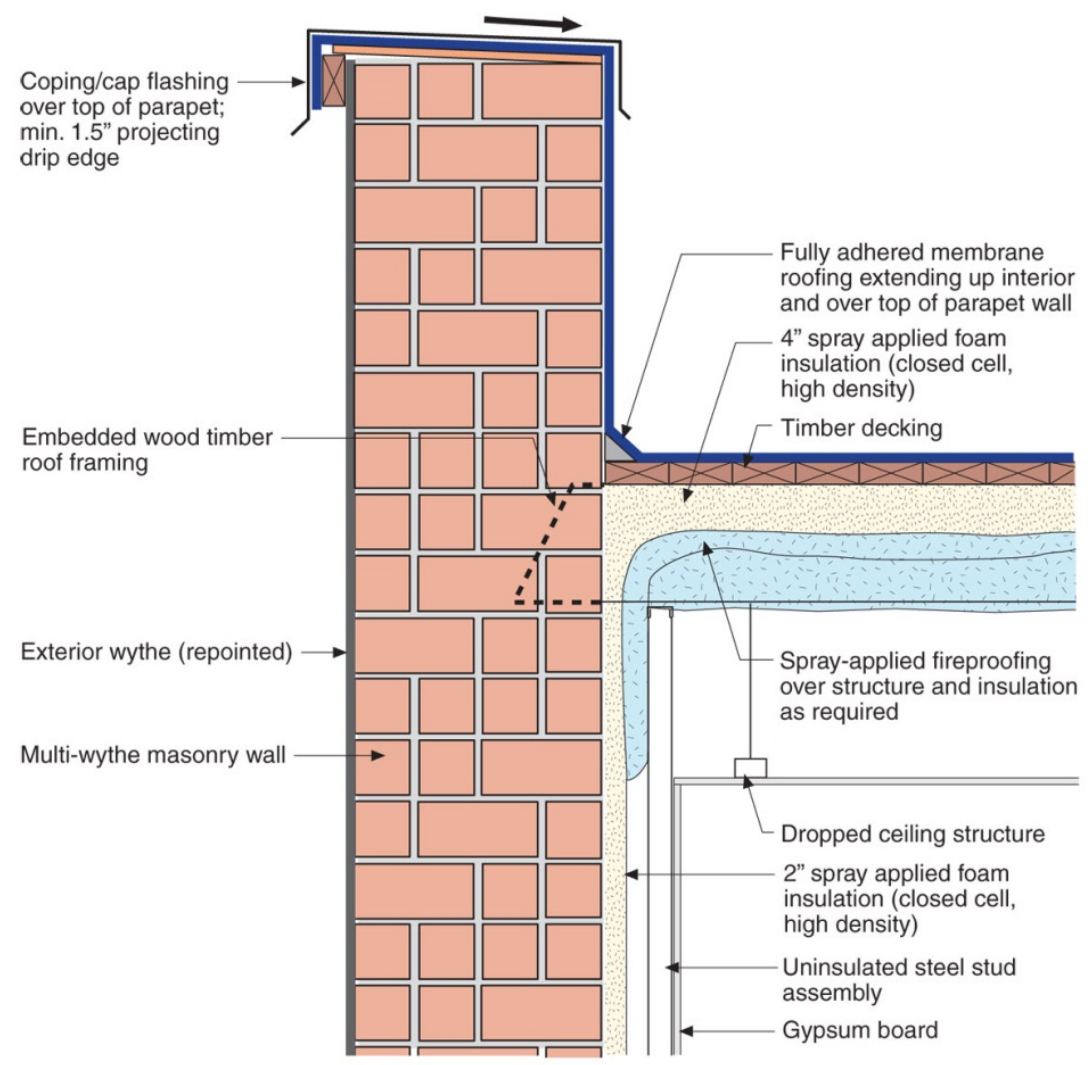

Figure 61. Parapet and coping retrofit details

- The drip edge should project away from the wall below; a 11/2-in. projection can easily be built out with dimension lumber, and provides a significant upgrade in protection. A projecting drip edge that is angled to direct water away from the wall reduces water deposition compared to more vertical drip edges.

Examples of the built-out drip edge detail are shown in Figure 62. 


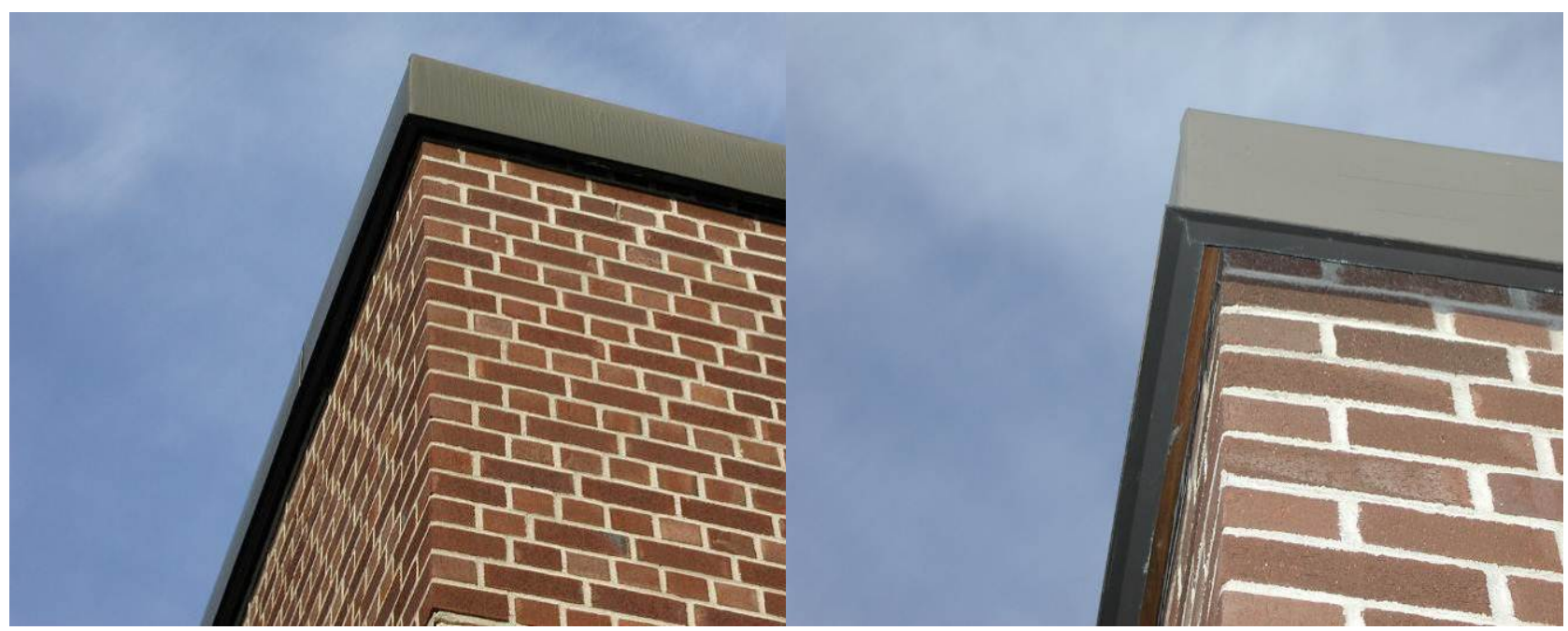

Figure 62. Improved drip edge overhang at coping

Another common type of parapet detail is a segmented stone cap (Figure 63). The joints between stones can channel water and concentrate it onto the wall below. Furthermore, the failure of the upward-facing mortar joint can become a major entry point of bulk water. At a bare minimum, the joints between masonry parapets should be repointed, raked out $1 / 2 \mathrm{in}$., and filled with sealant.

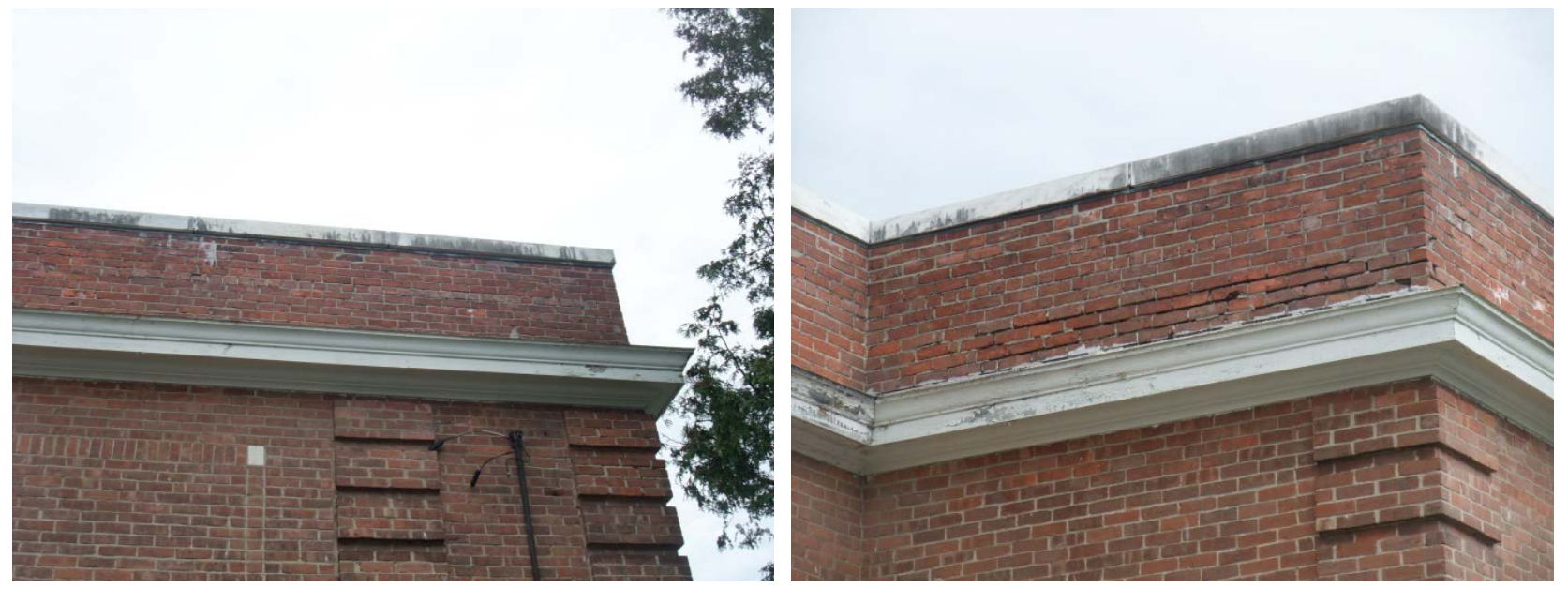

Figure 63. Stone parapet cap, with joints in stone coping

An improvement beyond this would be to use the roof membrane wrap, as shown in the previous metal cap flashing example (Figure 61), and in Figure 64. 

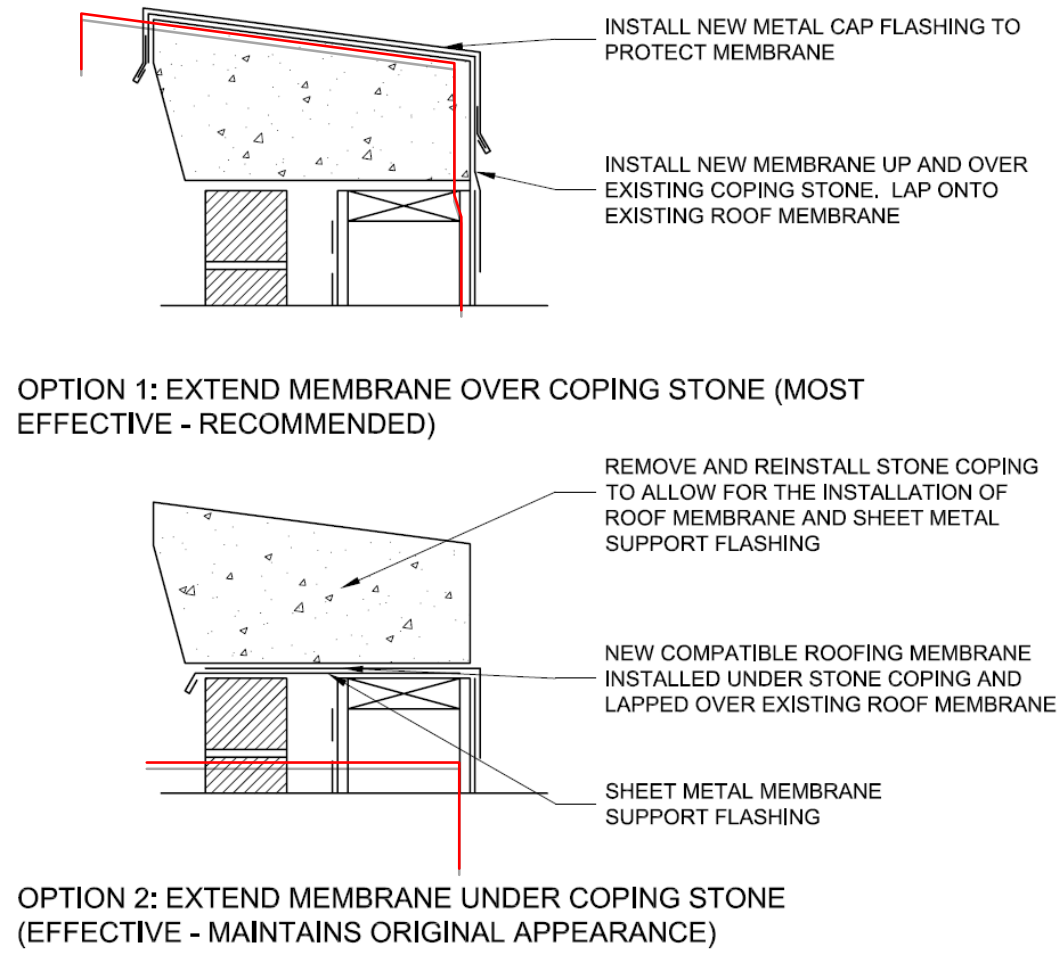

Figure 64. Stone parapet cap retrofit options; membrane layer highlighted

The most effective option is to wrap the top of the stone with membrane up and over the stone (Option 1), protected by a metal cap. However, if this is unacceptable for aesthetic reasons, the membrane could be wrapped under the stone cap, and a projecting drip edge placed below the stone (Option 2). Note that this solution requires some type of mechanical attachment of the stone through the membrane, which can in turn become a failure point.

\subsubsection{Downspouts, Rainwater Leaders, and Scuppers}

Downspouts, rainwater leaders, and scuppers deserve particular mention because of their risk of exterior water concentration. If functional, these should not concentrate rainwater on a wall. However, when they are improperly designed or fail to function as intended in service, the amount of water they can concentrate is so large that FT damage is likely. Figure 65 shows an example of the damage that was caused in the past by a disconnected downspout. Figure 66 shows masonry damage and staining from poor handling of downspout runoff. 

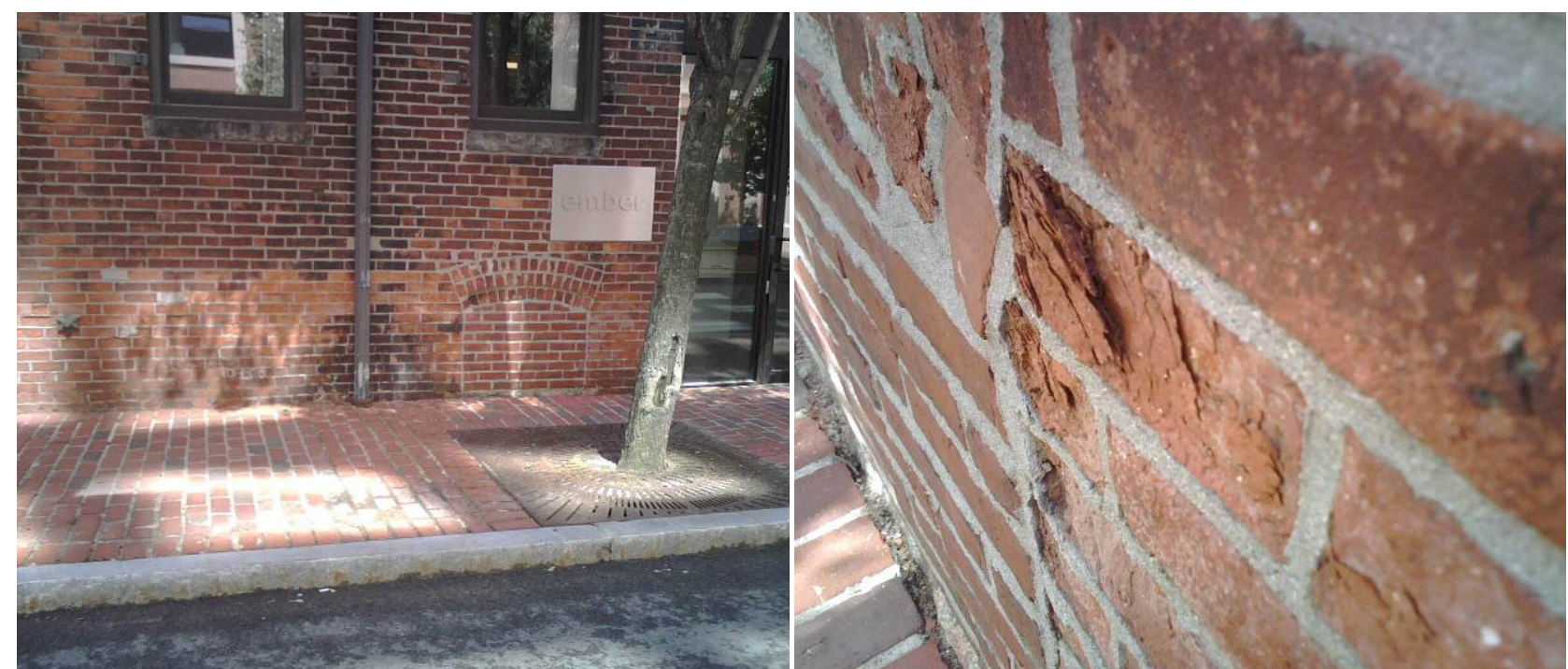

Figure 65. Left: FT damage at downspout disconnection; Right: delamination of brick

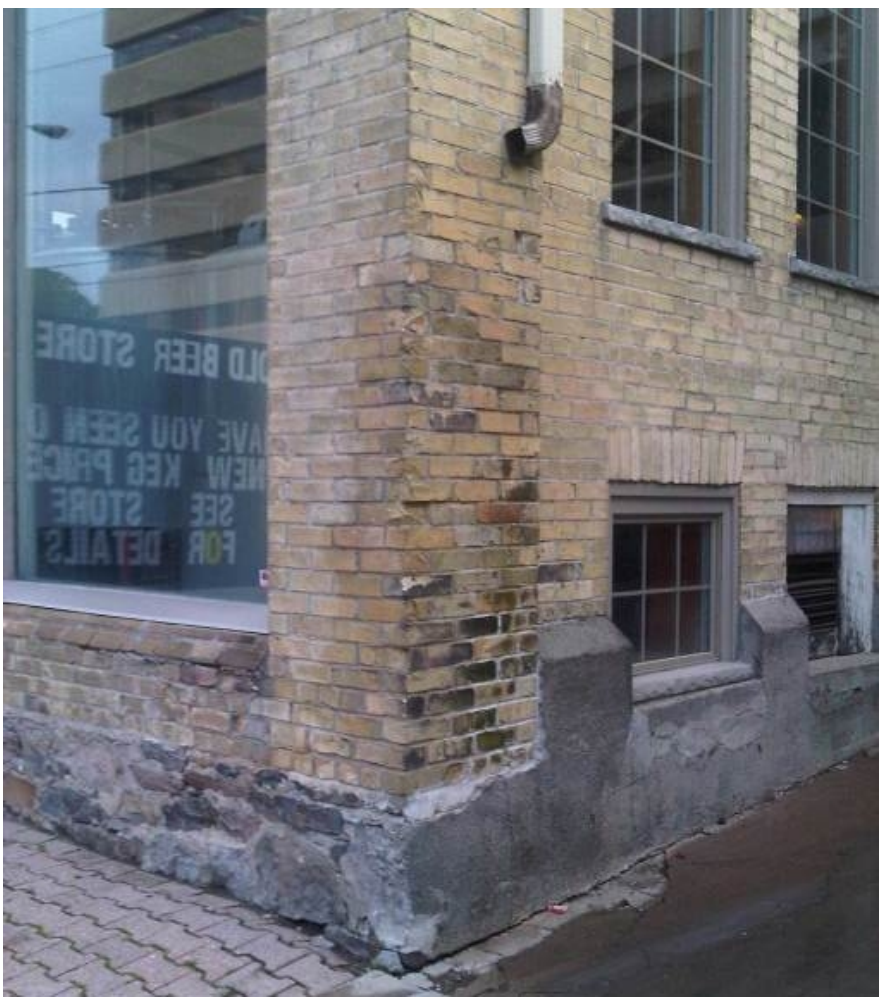

Figure 66. Disconnected downspout and related damage to masonry

Note that a disconnected downspout can be used to gauge the performance of the brick under severe loadings: Figure 67 shows a disconnected downspout at the pilaster of a building on its north side; the mortar at this location has completely eroded. However, the brick does not show FT damage, which may be an indication of good FT resistance. 

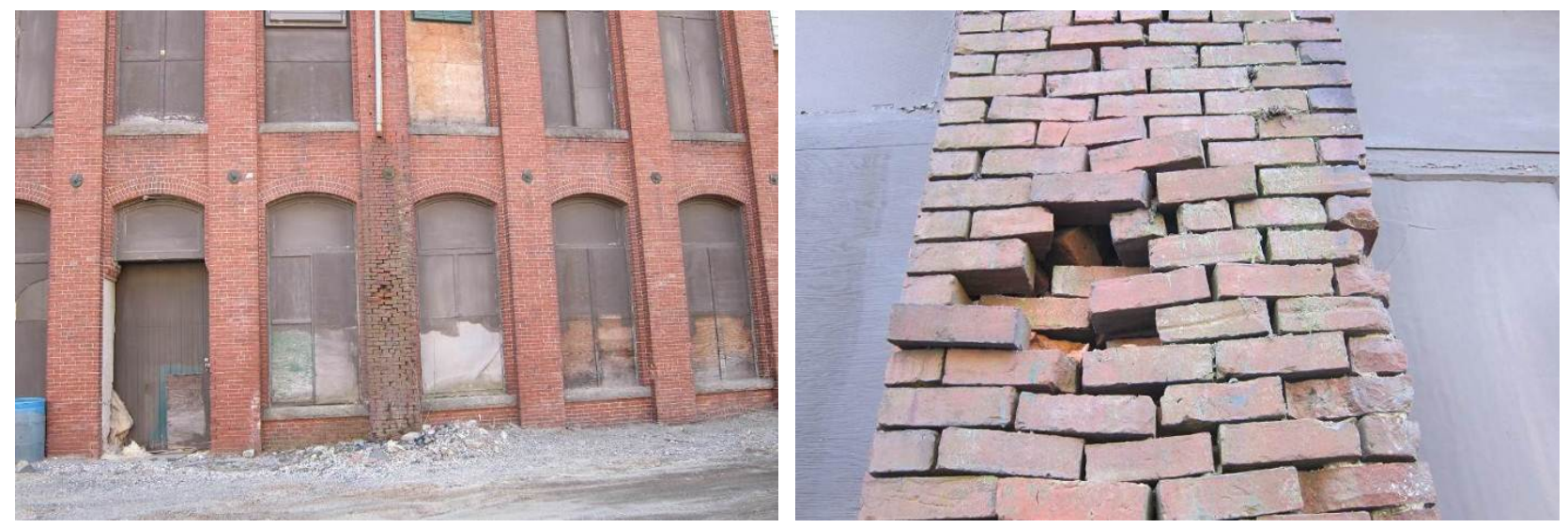

Figure 67. Left: Damaged pilaster at downspout; Right: Severe mortar erosion

Continuous maintenance of these details is required for a building in service. The potential damage from disconnected downspouts is so severe that it may be worth considering elimination of scuppers and downspouts, and instead replacing them with drains directed to the interior of a low-slope roof. Failure of these details would not typically result in concentrated loading of water on the exterior masonry. However, potential changes in structural loading caused by plugged roof drains must be accounted for when modifying drainage.

\subsection{Ground Contact Issues}

Another location where masonry structures are vulnerable and often show signs of moisture distress are the portions that are close to grade. The damage can occur by a combination of capillarity (wicking of ground or surface water through bulk of the mass masonry) or splashback of concentrated rainfall from the roof onto the wall surface.

\subsubsection{Capillary Rise (Buried Brick)}

It is relatively common for masonry walls to transition from brick to solid stone where the wall goes below grade, as shown in Figure 68. This stone is typically less porous than brick, and therefore has less capillary water uptake (wicking of liquid water from below grade).
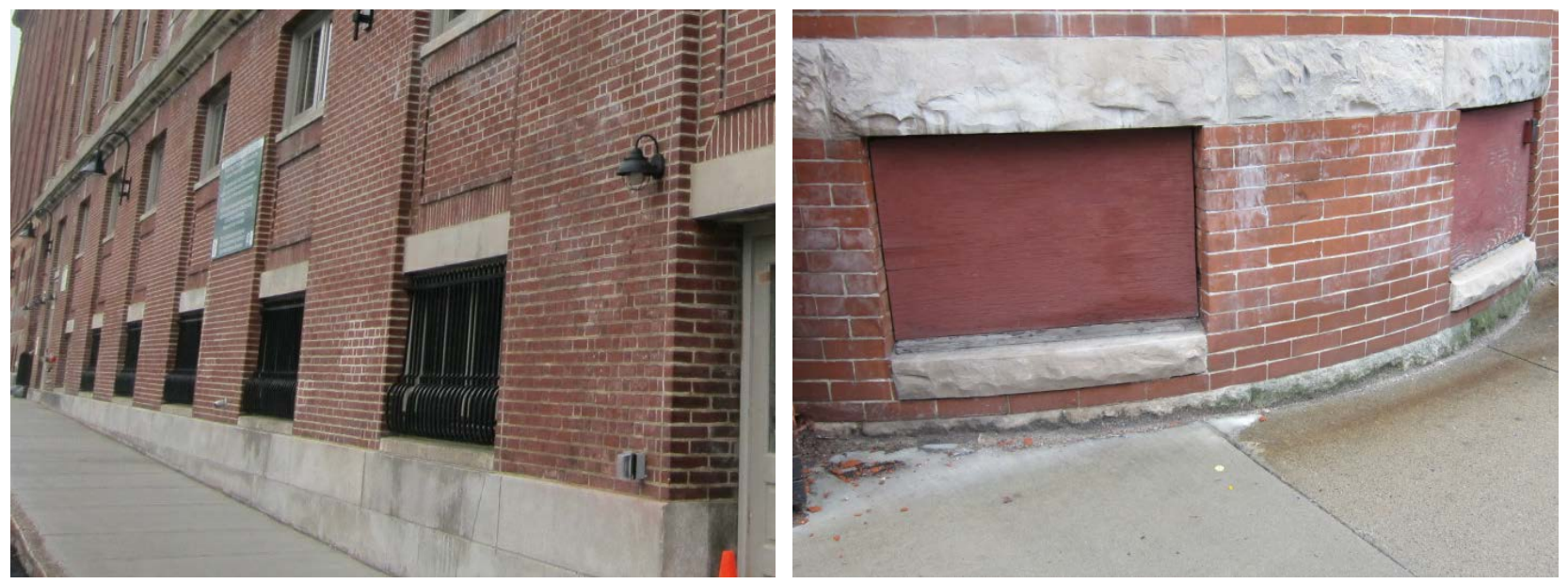

Figure 68. Common masonry wall assembly with non-porous stone at grade

However, it is not uncommon for grade to be raised around the building since original construction. In one example, the foundation was rubble stone (likely granite) below grade, 
which transitions to brick above grade (see Figure 69). However, severe subfluorescence and spalling were seen near a basement window (see Figure 70).
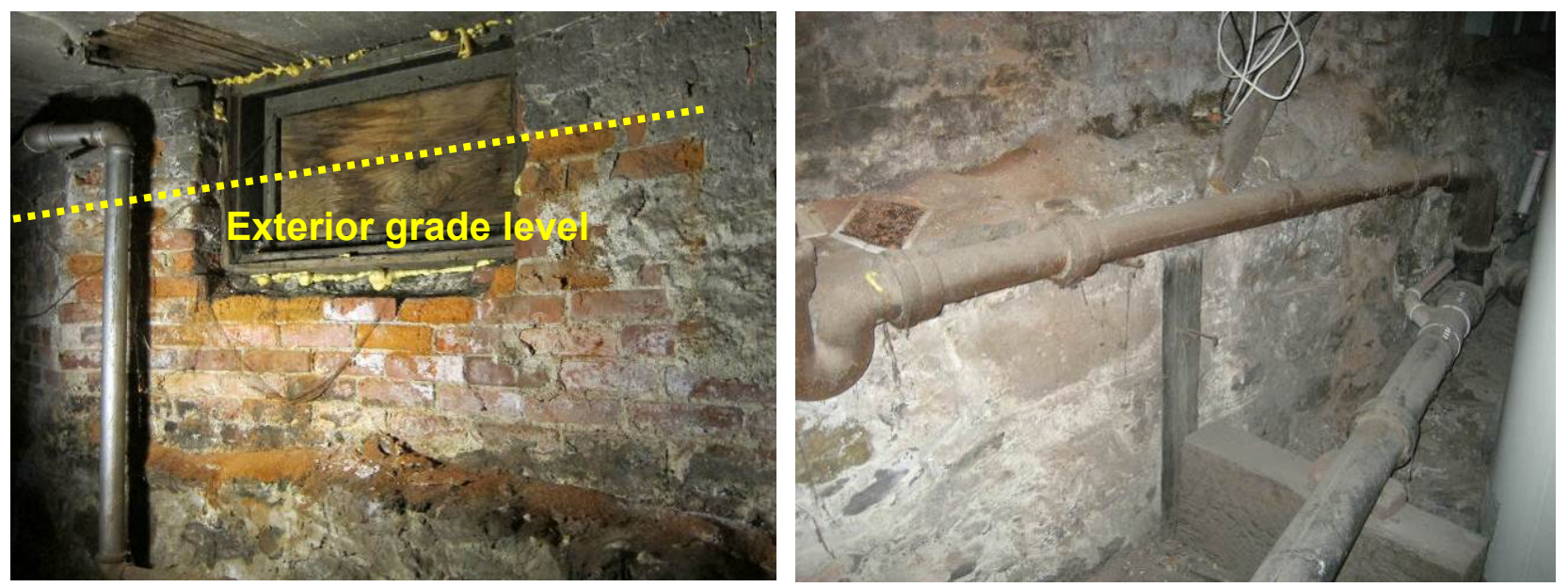

Figure 69. Left: Severe subfluorescence and spalling at basement window; Right: Stone shelf below grade
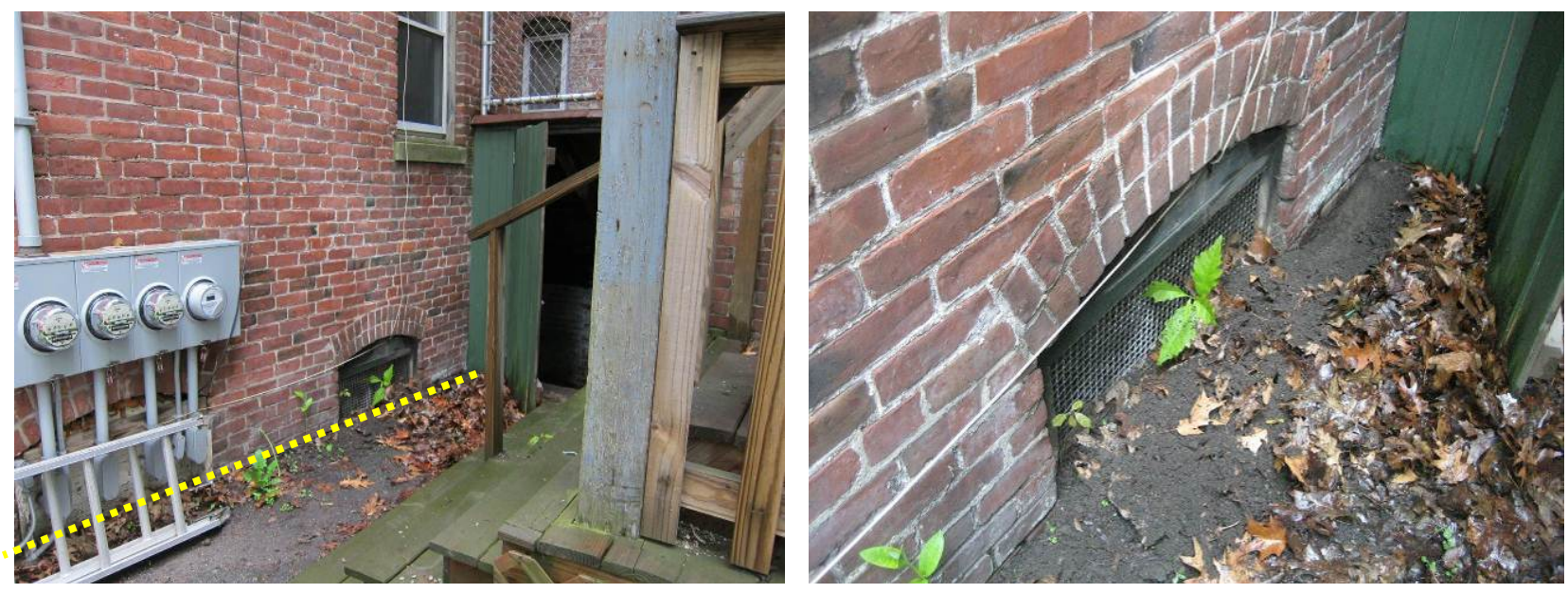

Figure 70. Left: Rear wall near subfluorescence damage visible in basement; Right: Buried window

The cause of this damage became apparent on the exterior of the building: exterior grade has been raised higher than the stone courses, resulting in buried brick courses. This causes moisture loading from the soil into the brickwork, capillary uptake, and thus the interior spalling.

A similar case is shown in Figure 71: the brick wall has been buried below grade (postconstruction) by roughly a foot, because of the increase in elevation of the parking lot, as shown in Figure 72. As a result, there was severe efflorescence along this portion of the interior, as shown in Figure 71. Again, this was due to capillarity (moisture wicking) through the brick at the below-grade contact with soil. 

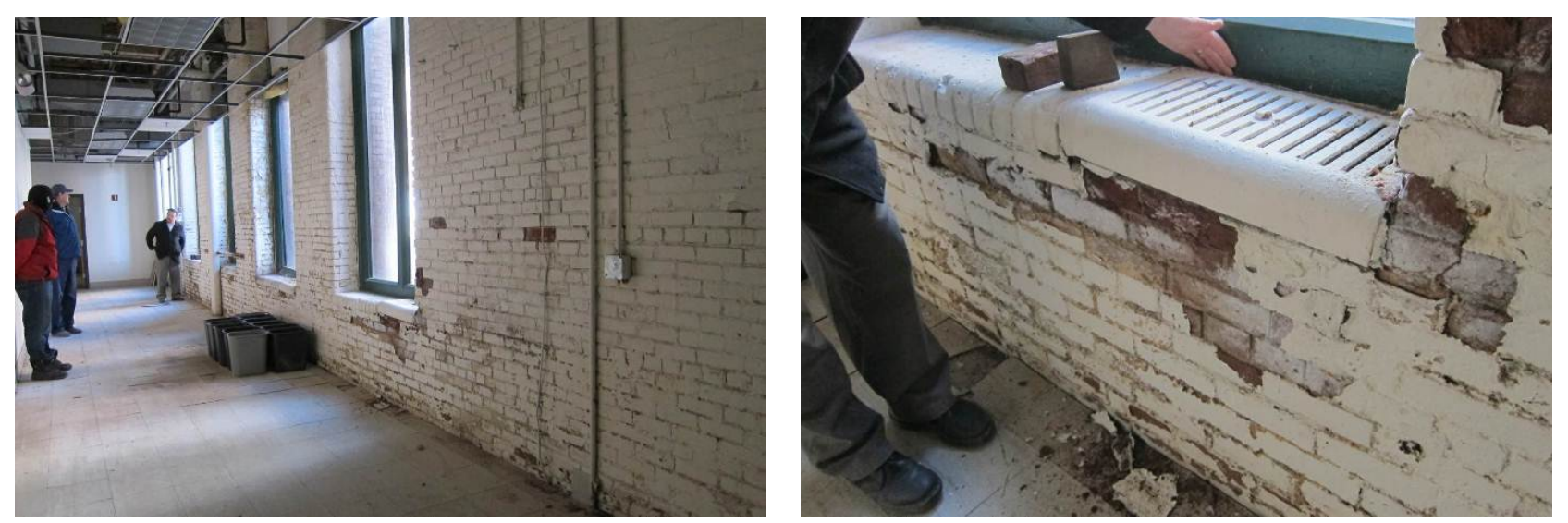

Figure 71. Pre-retrofit building interior at grade condition
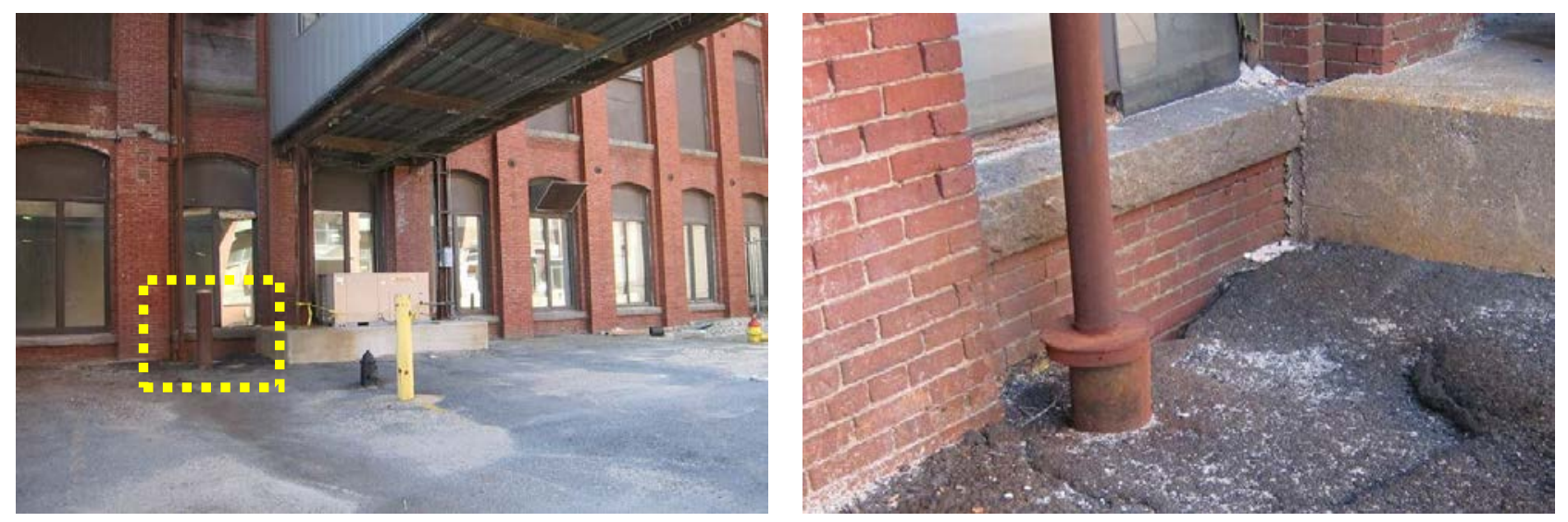

Figure 72. Exterior parking lot grade relative to interior conditions

The existing detail at this area was simply buried steel or iron plates against the building at the buried window openings, to provide lateral support for the soil. In some cases, the soil underneath the asphalt has subsided, resulting in negative grade issues that introduce substantial water to the below grade portion of the wall (see Figure 72).

The recommended solution to these buried brick issues is to eliminate capillary contact between the soil and the brick, which will prevent this wicking issue in the future. One design is an air gap membrane applied to the vertical surface to grade, over dampproofing applied to the brick after excavation of the below grade space. This creates an airspace that allows drainage of any water that enters the space, and provides a moisture-impermeable layer protecting the brick from the surrounding soil. The top of the air gap membrane is terminated at grade with a closure strip (see Figure 73). 

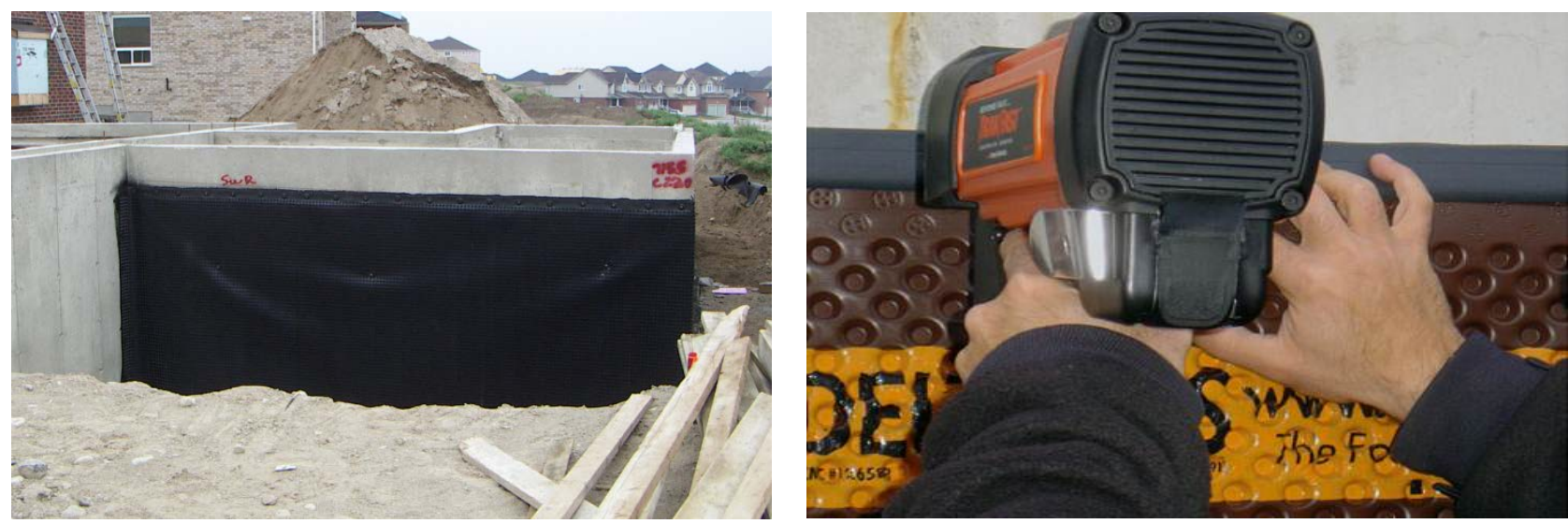

Figure 73. Air gap membrane below grade and top closure strip

Ideally, this drainage mat would be terminated below grade at a field of free-draining fill, and the water directed to daylight or a storm sewer. However, to prevent these capillarity problems, it may be sufficient to route this water to a location below the brick wall that keeps groundwater out of contact with the brick.

Alternatively, if the foundation contains a basement and there are drainage and bulk groundwater issues in that space, both of these issues (bulk water and capillarity) could be simultaneously resolved by the addition of a ground roof or skirt detail (Figure 74). This functions not only to separate the foundation wall from soil capillarity, but also prevents entry of surface and ground drainage water into the basement. It can easily be leveraged into an exterior foundation insulation detail with the addition of moisture-insensitive insulation boards (XPS or mineral wool) at the ground roof membrane layer.

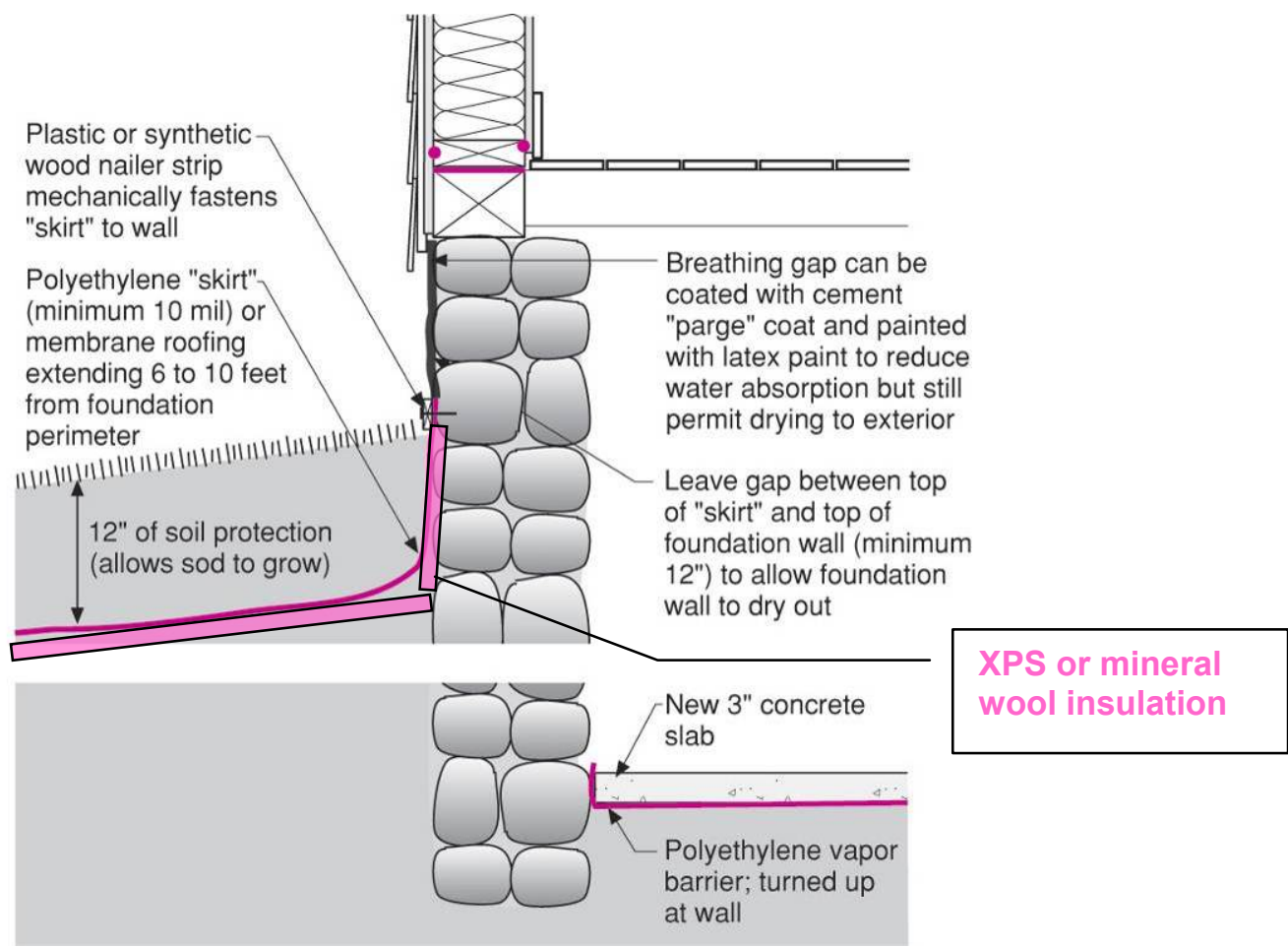

Figure 74. Ground skirt foundation water control (with added insulation) 


\subsubsection{Splashback}

Another damage function at the brick wall close to grade is splashback, or bouncing of concentrated roof-drained water back onto the exterior wall. An example is shown near the front porch/stoop in Figure 75; the pattern of splashed dirt/water is apparent.
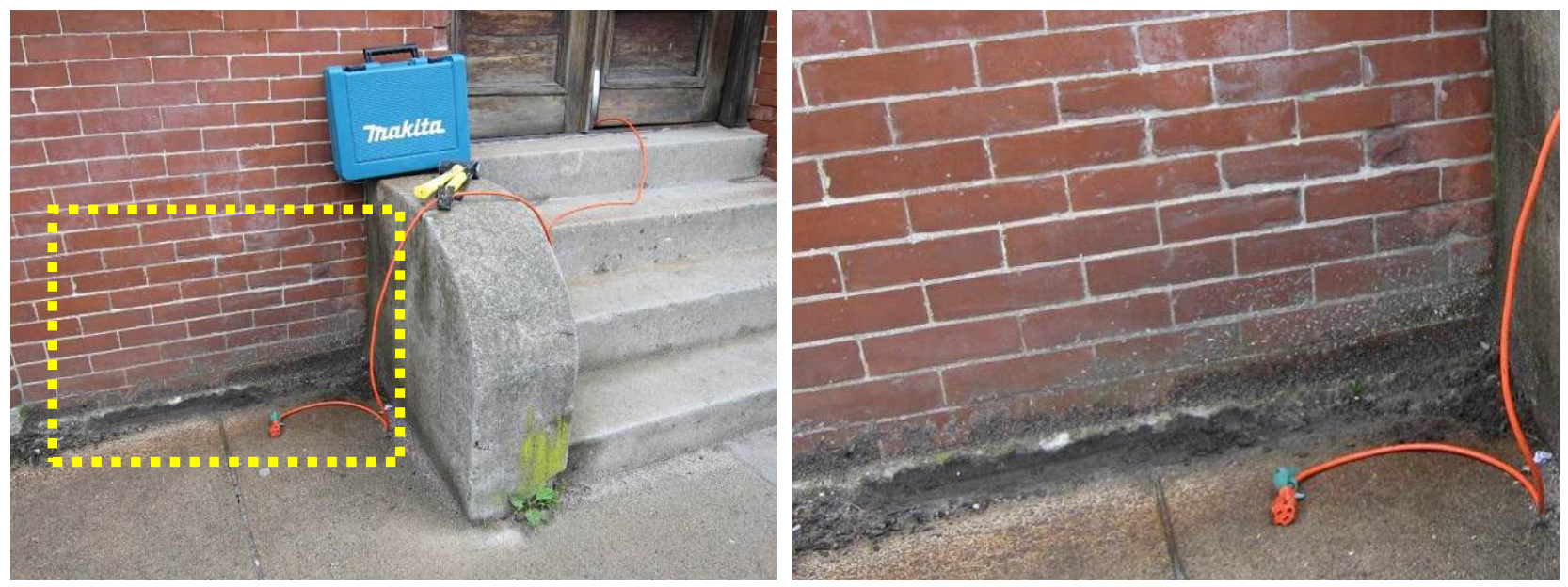

Figure 75. Brick condition adjacent to front steps, splashback evident

Note that occurrence of splashback is worst at hard pavement surfaces; issues are reduced with softer landscaping. Of course, keeping roof and wall drainage away from the adjacent ground reduces splashback.

\section{Critical Takeaways}

Controlling bulk water entry into the wall when doing interior masonry retrofits is of vital importance, especially as water leakage will no longer be visible from inside until damage occurs to interior finishes. If rain control cannot be addressed and upgraded, interior insulation should not be implemented.

Windows and doors are nonabsorbent, and hence shed all the rainwater that strikes them. To prevent masonry durability problems, rainwater surface drainage must not be concentrated on the wall below, and this water should be shed from the face of the building. Drainage and shedding are accomplished by a sloped sill detail with end dams, and a sufficient drip edge $(1 / 2$ in. minimum) beyond the wall below.

Rowlock window sills are especially vulnerable, as they are composed of individual bricks with mortar joints, which will be a source of water leakage. One possible solution to reduce water loading into the wall below is to overclad the rowlock course with metal (or similar) flashing.

Leakage through the wall-to-window joint or the window unit itself can contribute to masonry moisture loading. To prevent these issues, a subsill pan flashing should be installed, which directs any of this water out onto the sill to the exterior.

Copings and parapet caps can suffer from problems such as inadequate slope, incorrect slope, inadequate overhangs, or inadequate drip edges: they can all cause accumulation of bulk water 
on masonry below. Projecting drip edges and waterproofing under the cap are vital details to implement at these assemblies.

Details such as stonework and band courses can result in water concentration and deposition on the face of the building. These water concentrations can often cause FT spalling damage. Solutions include overclad caps and drip edges below these features.

Roof-wall interfaces can also be another source of water concentrations; details such as kickout flashings are critical to prevent these issues.

Downspouts, rainwater leaders, and scuppers, when improperly designed or when they fail to function, can concentrate a tremendous amount of water, making FT damage very likely. Continuous maintenance of these details is required for a building in service; it may be worth considering eliminating scuppers and downspouts, instead replacing them with drains directed to the interior of a low-slope roof. Structural impacts of clogged drains and ponding must be taken into account).

When brick is buried below grade, severe subfluorescence and spalling may result, because of capillary water uptake (moisture wicking) through the brick. The recommended solution to these buried brick issues is to eliminate capillary contact between the soil and the brick. These options include use excavation and installation of an air gap membrane, or sheet or liquid-applied dampproofing.

Another risk close to grade is splashback, or bouncing of concentrated roof-drained water back onto the exterior wall. These issues are reduced with softer landscaping ( not pavement), or by keeping roof and wall drainage away from the adjacent ground. 


\section{Embedded Wood Member Research}

Another durability risk is the hygrothermal behavior of moisture-sensitive wood beams embedded in load-bearing masonry walls. Interior insulation reduces the beam end temperatures, reduces available drying potential, and results in higher RH conditions in the beam pocket: all these factors pose a greater risk to durability. Proposed solutions to protect embedded members include borate injections into the wood, metal plates next to the member (to provide passive heat flow), active heating, or construction of a load bearing structure inside the masonry, and cutting off the end of the beam. This topic is summarized below, and covered in detail in the conference paper "Masonry Wall Interior Insulation Retrofit Embedded Beam Simulations" (Appendix A), which was presented at the Building Enclosure Science \& Technology (BEST) Conference, BEST3 April 2-4, 2012, in Atlanta, Georgia.

Three-dimensional wintertime static thermal simulations of large (beams) and small (joists) embedded wood members in masonry assemblies showed the expected patterns, of colder wintertime beam end temperatures after the retrofit of interior insulation (Figure 76). Figure 77 and Figure 78 show the wood assembly with the masonry wall hidden.
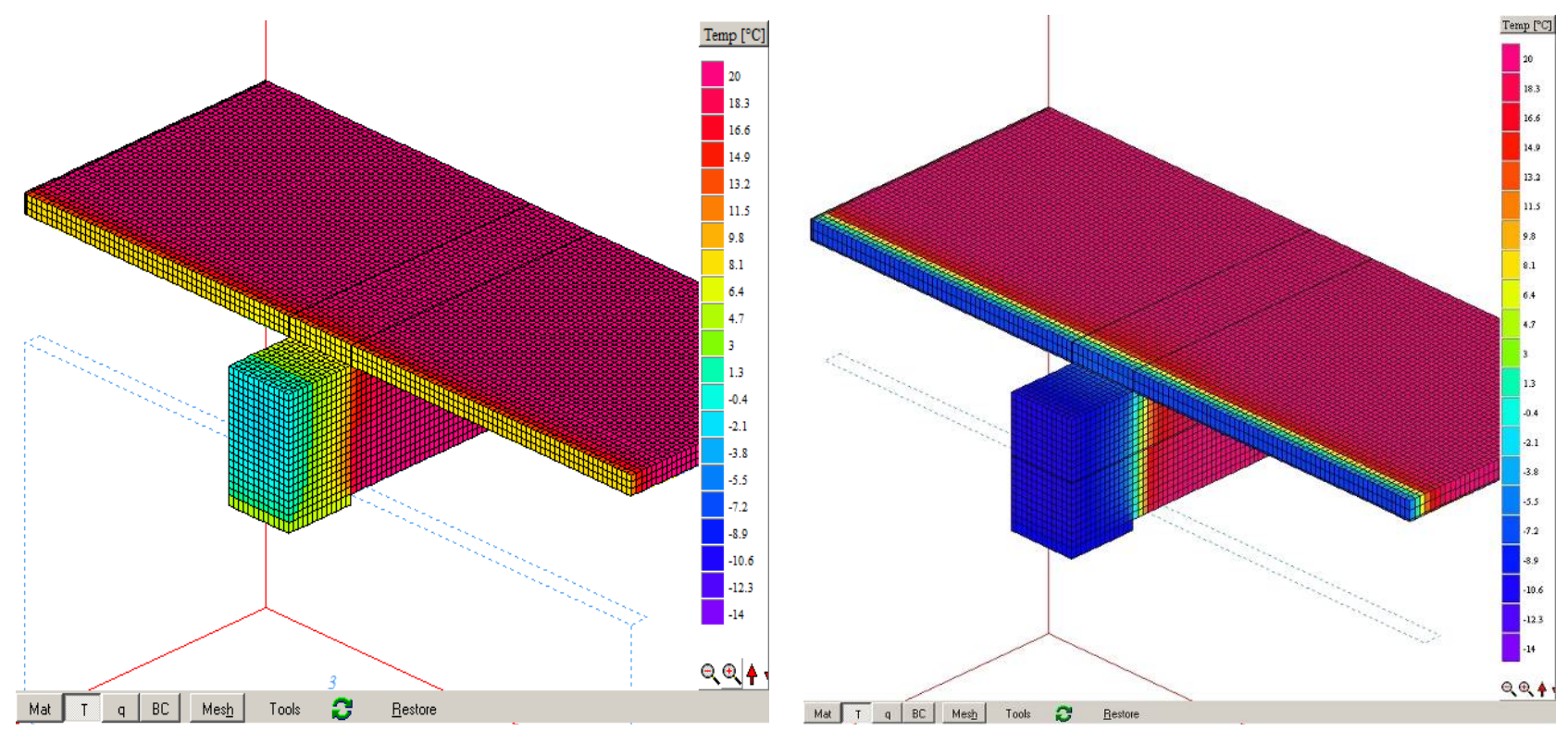

Figure 76. Left: Embedded beam uninsulated case; Right: Insulated case 

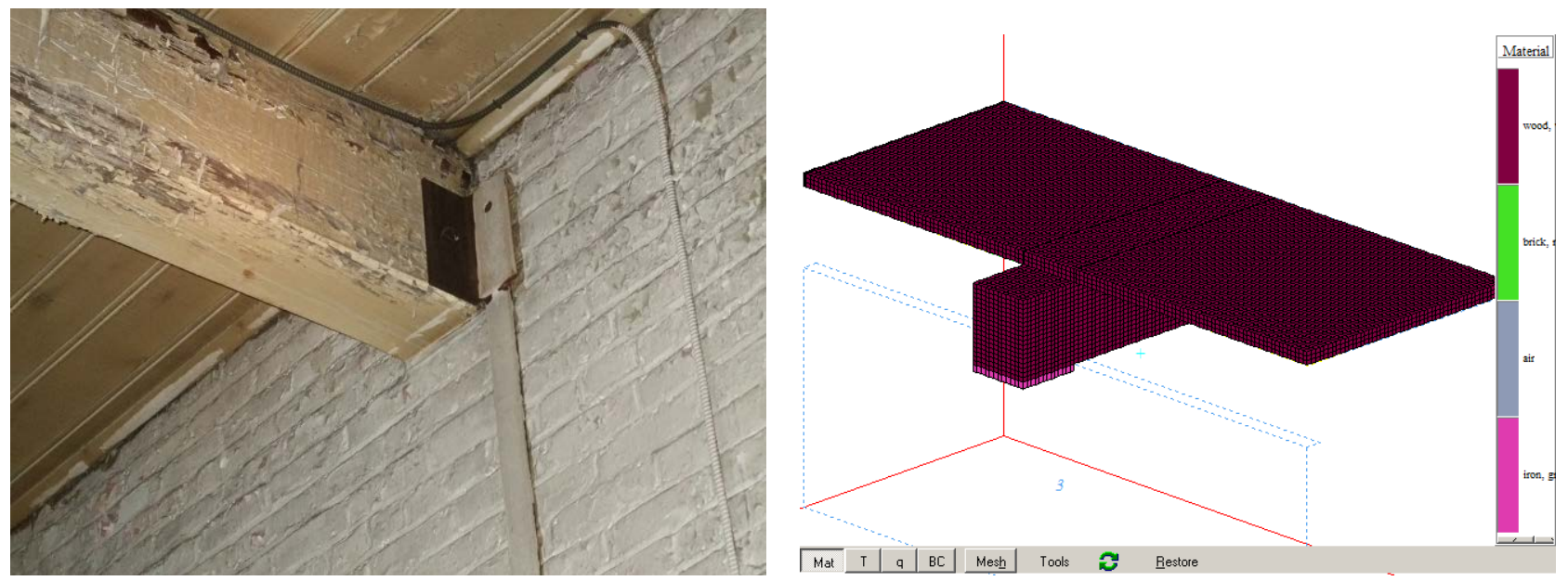

Figure 77. Left: Typical embedded beam; Right: 3-D representation of beam and floor
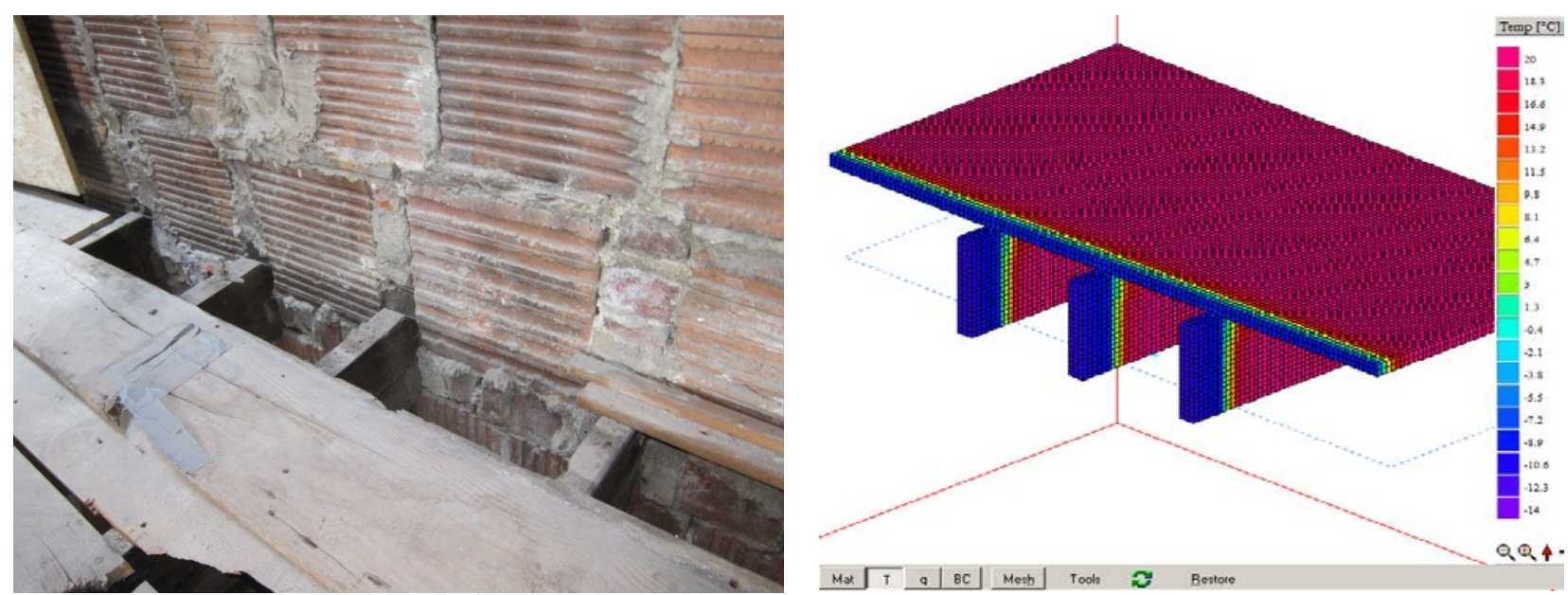

Figure 78. Left: Typical embedded floor joists; Right: Simulation representation

Various methods to allow greater heat flow were then simulated, with the goal of raising wintertime beam end temperatures. The use of passive aluminum plates adjacent to the beams and joists showed a moderate increase in beam end temperatures, with some penalty in overall assembly heat flux. The analogous joist case showed higher beam end temperatures, but it seems unlikely to be executed in practice, because many plates are required. In addition, these plates create some wintertime condensation risk. The use of thinned (1-in. thick versus 2 -in. thick) insulation near beam ends showed little effect on beam end temperatures. The elimination of insulation at the rim joist area resulted in temperatures close to original conditions; however, static thermal simulations indicate that there might be significant risk of wintertime condensation within the cavities at typical interior humidity conditions. In addition, this measure loses a significant fraction of the energy savings of the fully insulated case (double the heat loss).

A comparison of heat flux through various joist assemblies (uninsulated, insulated, insulated with aluminum plates, and uninsulated band joist) is shown in Figure 79. 


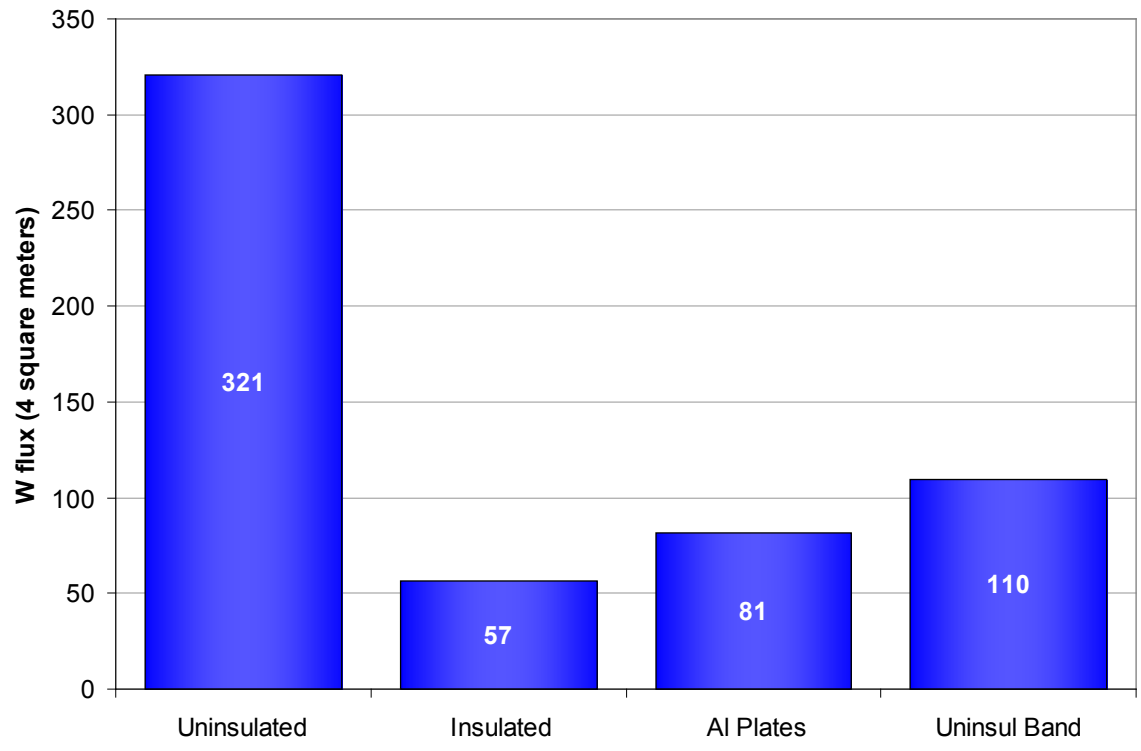

Figure 79. Heat loss through $42 \mathrm{ft}^{2}\left(4 \mathrm{~m}^{2}\right)$ of wall assembly with joist framing, various cases

However, temperature behavior alone is not sufficient to gauge durability risk: it is a function of moisture accumulation in the vulnerable wood portions as well as temperature. Therefore, onedimensional hygrothermal simulations were run. These simulations rely on a modification of material properties (thermal conductivity) to run uninsulated and insulated cases in a onedimensional model. The moisture content of the outermost 1 in. $(25 \mathrm{~mm})$ of the beam was plotted as a measure of relative performance. In addition, interior air was introduced into the air space between wood and masonry at various rates.

Simulations with initial assumptions showed that air leakage has a strong effect on wood moisture content: the uninsulated case showed summertime moisture peaks of almost $35 \%$, which is unrealistic for sustained durability. Increasing airflow rates into the pocket resulted in lower moisture contents (Figure 80). 


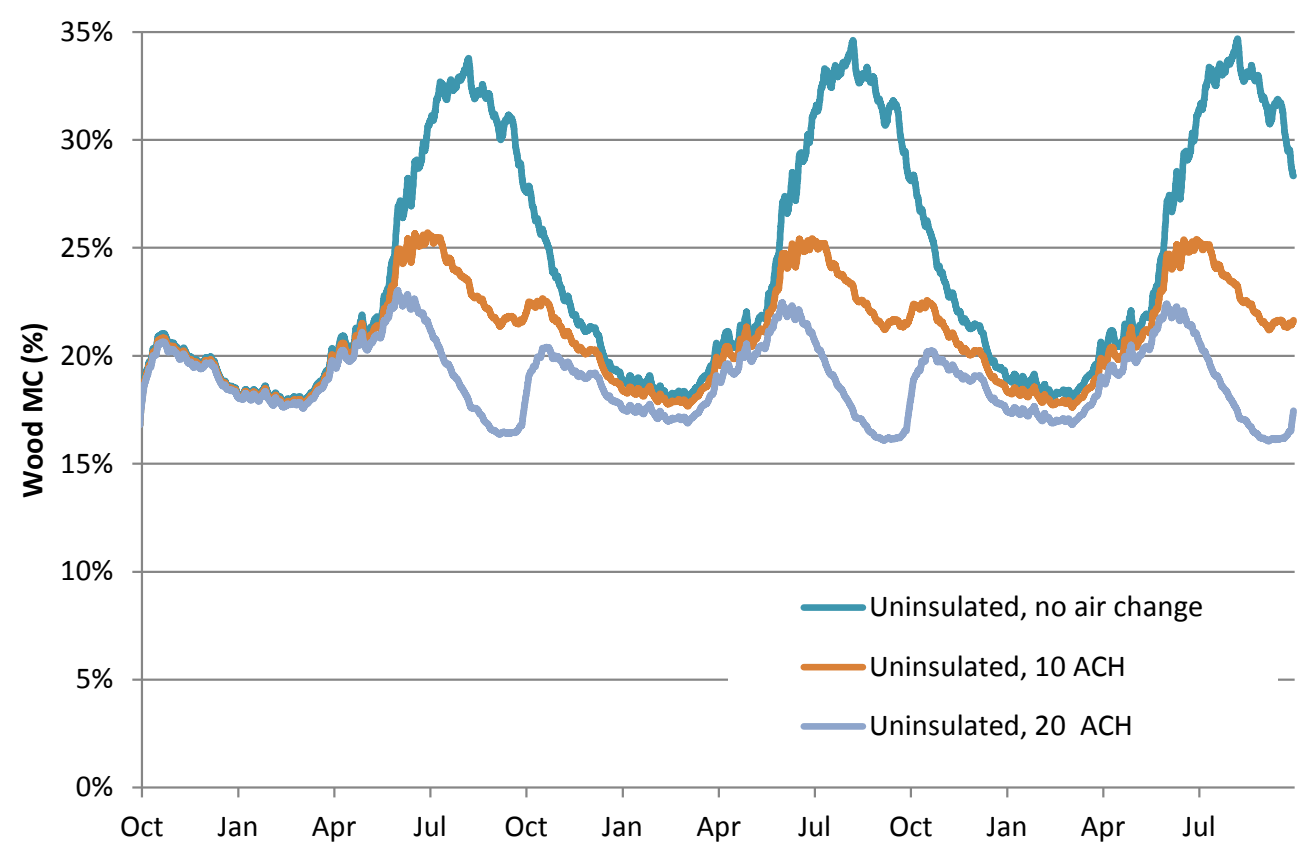

Figure 80. Wood beam end (1 in. [25 mm]) moisture contents; uninsulated cases

The addition of insulation (with airflow) resulted in wood moisture contents lower than the uninsulated (no airflow) cases; however, peaks were still in the $30 \%$ range. The addition of airflow lowered summertime moisture contents (Figure 81).

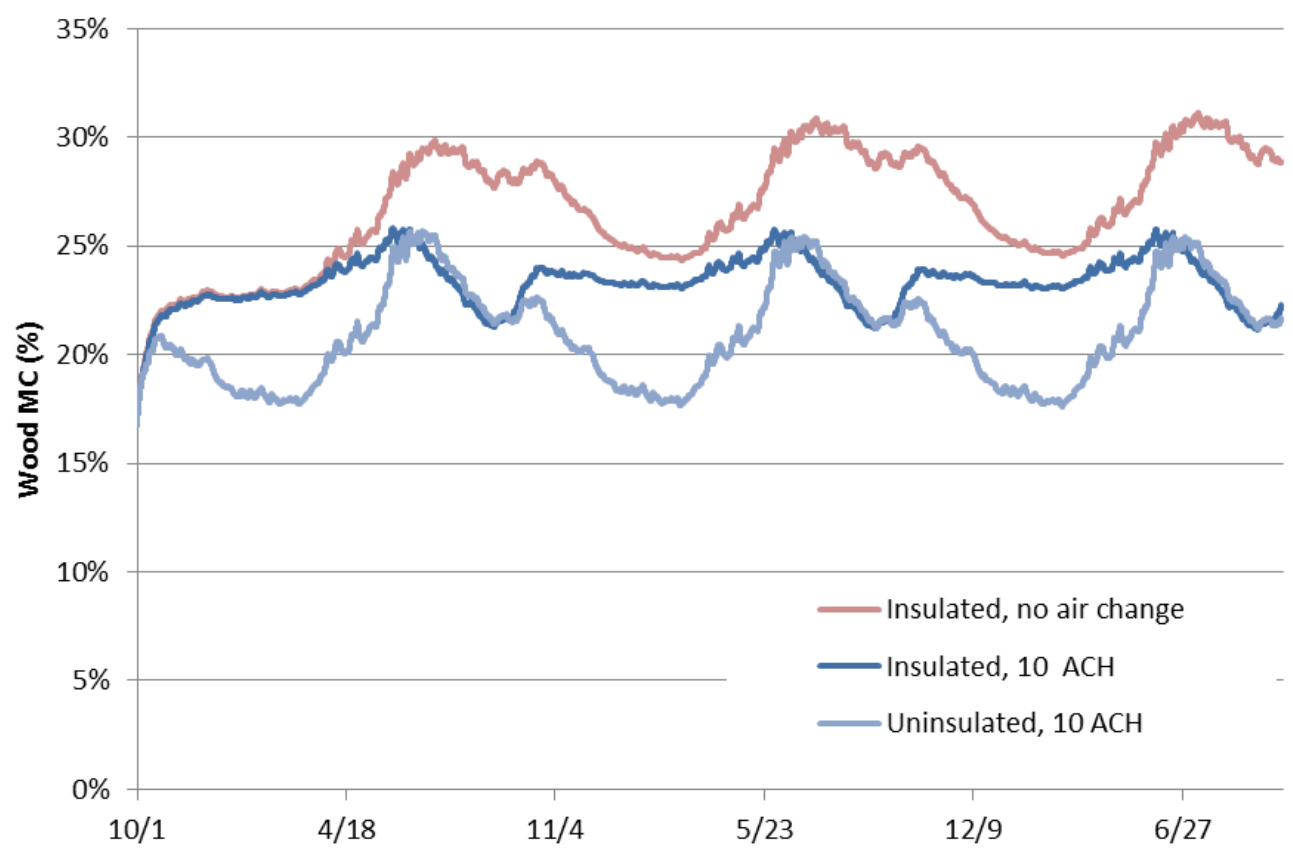

Figure 81. Wood beam end ( $1 \mathrm{in.}$ [ $25 \mathrm{~mm}$ ) moisture contents; insulated cases (+ uninsulated) 
A final set of simulations was run using an exterior masonry assembly with different material properties, which resulted in markedly different beam end moisture contents. Uninsulated performance was in the $13 \%-17 \%$ moisture content range, and insulated in the $13 \%-21 \%$ range.

Overall, these simulations indicate substantial uncertainty in how embedded wood members in masonry actually behave in service after insulation retrofits. The properties of the exterior masonry have a tremendous effect on the beam end moisture contents: not only material properties (e.g., liquid water uptake), but also macroscopic effects (not simulated here) such as infill between brick wythes. The effect of airflow into the beam pocket can be significant, but actual air change rates are unknown. In addition, Morelli (2010) demonstrated that rainwater exposure can have a tremendous effect on beam pocket RH conditions. Finally, it is acknowledged that these one-dimensional hygrothermal simulations are a workaround for a complex three-dimensional problem. One-dimensional simulations do not account for flanking effects seen by alternate moisture movement paths (e.g., wood beam versus adjacent air gap).

These factors suggest that further research is warranted: at a minimum, the use of twodimensional hygrothermal simulations, with more refined assumptions for air change rates. However, even these may prove to be of limited applicability, given the effect of material property assumptions. Ideally, in-situ measurements of beam pocket temperatures, $\mathrm{RH}$, and wood moisture content (in both insulated and uninsulated configurations, and various orientations and rainfall exposure levels) would provide the greatest insight into true behavior. The exposure conditions may prove to be one of the key factors, based on Dumont et al. (2005): liquid water loading such as capillarity from the ground, splashback from adjacent rainfall, or poor rain control detailing might provide crucial differences between success and failure.

Given the uncertainty pointed out by research, definitive guidance on the vulnerability of embedded wood members, in terms of a go/no-go situation, are difficult to formulate. Of course, all of the methods described in previous chapters for reducing the water exposure of the masonry through careful rain shedding details are critical to reduce risks at the beam pockets. One specific case is embedded beam ends that are located near grade; capillarity from ground contact and splashback can increase risks of moisture damage. Lstiburek (2007b) provided recommendations for adding a stainless steel reglet element into the masonry (to cut the capillary uptake path) in various configurations, depending on the proportions of the exposed above-grade portion of the wall (see Figure 82). This detail also includes the use of a sacrificial mortar parge coat to deal with efflorescence/subfluorescence effects of capillary flow. 

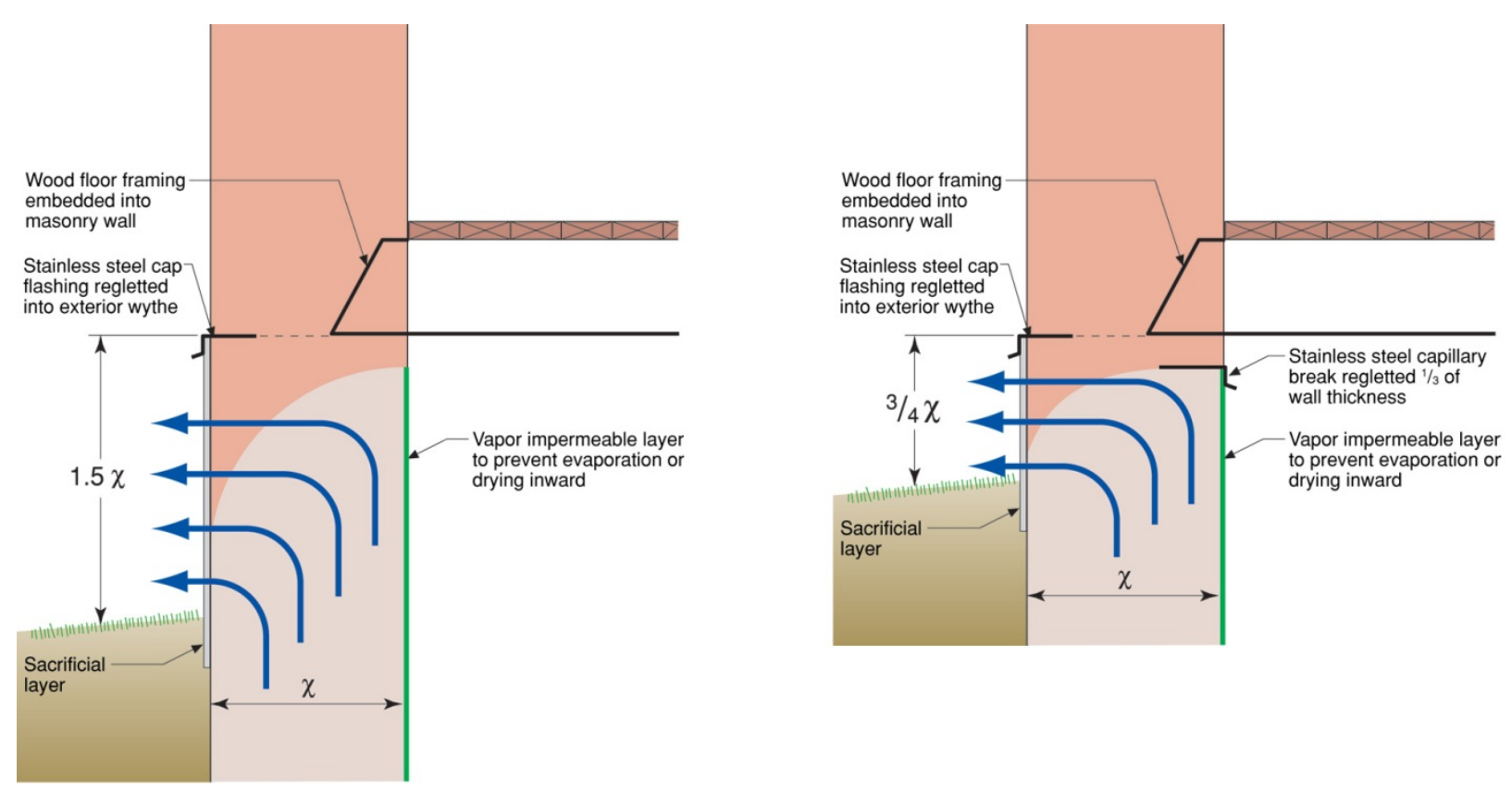

Figure 82. Guidance on protection of embedded floor framing near grade

(Lstiburek 2007b)

\section{Critical Takeaways}

Another durability risk is the hygrothermal behavior of moisture-sensitive wood beams embedded in the load-bearing masonry. Interior insulation reduces the beam end temperatures, reduces available drying potential, and results in higher $\mathrm{RH}$ conditions in the beam pocket.

Three-dimensional wintertime static thermal simulations of embedded wood members in masonry assemblies showed the expected patterns of colder wintertime beam end temperatures after the retrofit of interior insulation.

Various methods to allow greater heat flow were then simulated: passive aluminum plates adjacent to the beams and joists showed a moderate increase in beam end temperatures, but with limited effect at beams and low chance of adoption at joists. In addition, these plates create some wintertime condensation risk.

The use of thinned (1-in. thick versus 2 -in. thick) insulation near beam ends showed little effect on beam end temperatures.

The elimination of insulation at the rim joist area resulted in temperatures close to original conditions; however, static thermal simulations indicate that there might be significant risk of wintertime condensation within the cavities at typical interior humidity conditions. In addition, this measure loses a significant fraction of the energy savings of the fully insulated case. 
Hygrothermal simulations demonstrated substantial uncertainty in how these members actually behave in service after insulation retrofits, including the effects of the masonry material, exposures, and airflow.

Further research is warranted, including the use of two-dimensional hygrothermal simulations, and in-situ measurements of beam pocket temperatures, relative humidity, and wood moisture content (comparing insulated and uninsulated configurations). 


\section{Assessment, Analysis, and Risk Management}

When considering the interior insulation of a masonry building, a series of steps is recommended to assess the risks associated with this retrofit, and to determine what can be done to mitigate this risk. They are presented here as six steps: each incremental step reduces uncertainties in the evaluation (and thus reduces risk). They are, in rough order of importance:

1. Site Visit Assessment (assessment of rain leakage, poor detailing, existing FT damage)

2. Simple Tests and Modeling (dry density, liquid water uptake, saturation moisture content, and basic hygrothermal/WUFI modeling)

3. Detailed Tests and Modeling (thermal conductivity, Fagerlund's Critical Degree of Saturation or $\mathrm{S}_{\text {crit }}$ )

4. Site Load Assessment (assessment of driving rain load, run down patterns; monitoring of rain deposition with driving rain gauges)

5. Prototype Monitoring (retrofit of a small area of the building, and monitoring of temperature and moisture content, including comparisons to models)

6. Maintenance and Repair (creating a recommended program of inspection/repair, perhaps in the form of a building owner's manual)

These steps are covered in more detail in the sections below.

\subsection{Site Visit Assessment}

A site visit to the building that assesses the existing conditions is the primary and most important component for evaluating the risks associated with an interior insulation retrofit, and what details must be addressed to reduce these risks. This step includes examinations of the exterior and the interior of the building.

The exterior will often show signs of water accumulation/deposition, bulk water (rainwater) leakage, and/or FT damage to the existing masonry. This is discussed by Lstiburek (2010). Areas of particular vulnerability include the parapet (because of colder temperatures and rain deposition), chimneys, near grade locations, and areas below windows. Examples of these types of vulnerable locations are shown in Figure 83. Section 6, Interior Retrofit Problematic Details and Solutions, covers many of the commonly seen problematic details and provides recommendations for how to reduce their effects prior to interior insulation.

In addition to the location of these issues, these observations can provide insight into the severity of the water issues (large versus small), and possibly the frequency (often versus rare), which will provide some guidance about the type of remediation needed. 

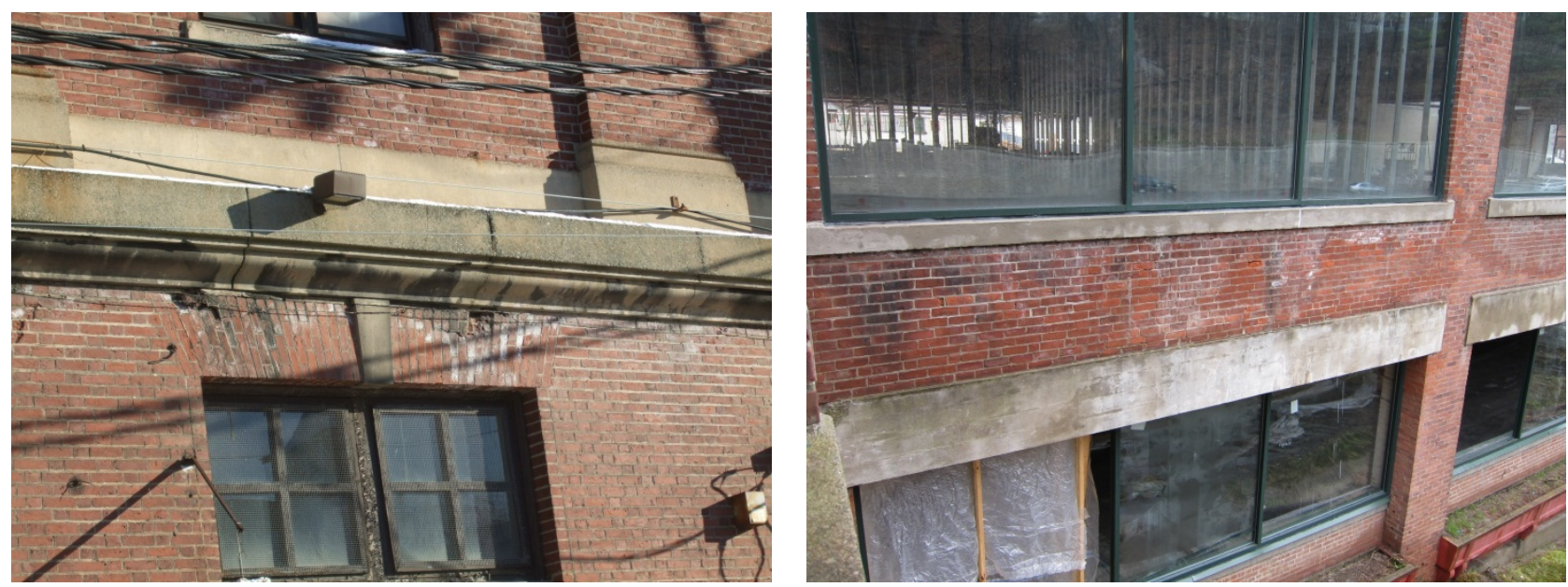

Figure 83. Exterior details that demonstrate FT damage in existing masonry buildings

The interior can show patterns of bulk water leakage and/or deposition of rainwater onto the face of the masonry; examples at windows and a roof-wall interface are shown in Figure 84. These observations not only provide indications of problems that must be solved before interior retrofits, but they also show locations that might have problems in the future. One question is whether bulk water leakage problems will be detectable in the future from the interior; a lack of warning lends itself to more robust water control methods on the exterior.
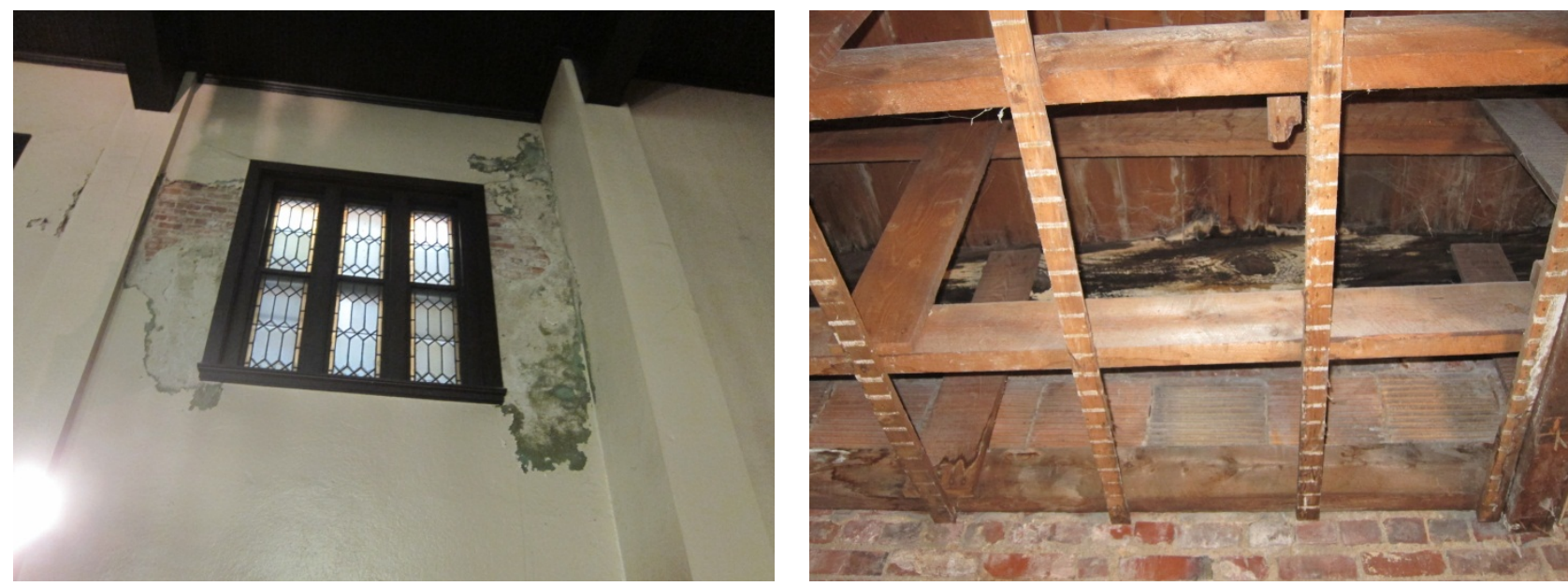

Figure 84. Interior details showing previous moisture issues at window and roof-wall interface

\subsection{Simple Tests and Modeling}

The next step would involve the use of simple material property tests of the various layers of masonry, and using these measured material properties in one-dimensional hygrothermal simulations. These materials are typically collected from the appropriate layers of the building (typically from less prominent areas, for aesthetic reasons), as seen in Figure 88.

The material properties that can be easily done with limited time and resources are water uptake value (a.k.a., A-value, or water absorption coefficient, in units of $\mathrm{kg} / \mathrm{m}^{2} \mathrm{~s}^{0.5}$ or $\mathrm{kg} / \mathrm{m}^{2} \mathrm{~h}^{0.5}$ ), dry density, and saturation moisture content (storage) (see Figure 85). 

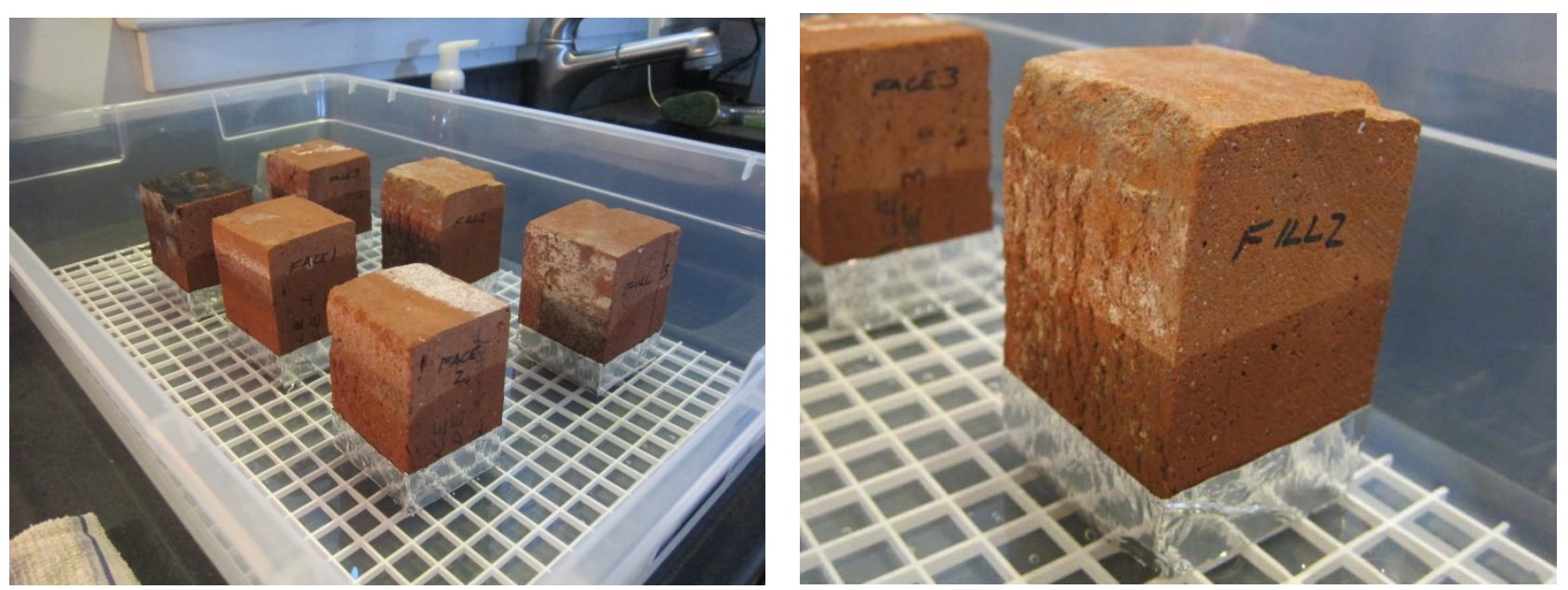

Figure 85. Brick liquid water uptake (A-value) testing

The hygrothermal (e.g., WUFI) modeling requires knowledge and experience on the part of the modeler in interpreting the results. In addition, comparisons to measured data and real experience with the actual building are invaluable for understanding the simulation results. There are many choices required in the modeling, including discretization of layers, material property choices, rainfall exposure, orientation, selection of exterior climates, and selection of interior conditions (see Figure 86). This process is discussed by Straube and Schumacher (2002, 2004).

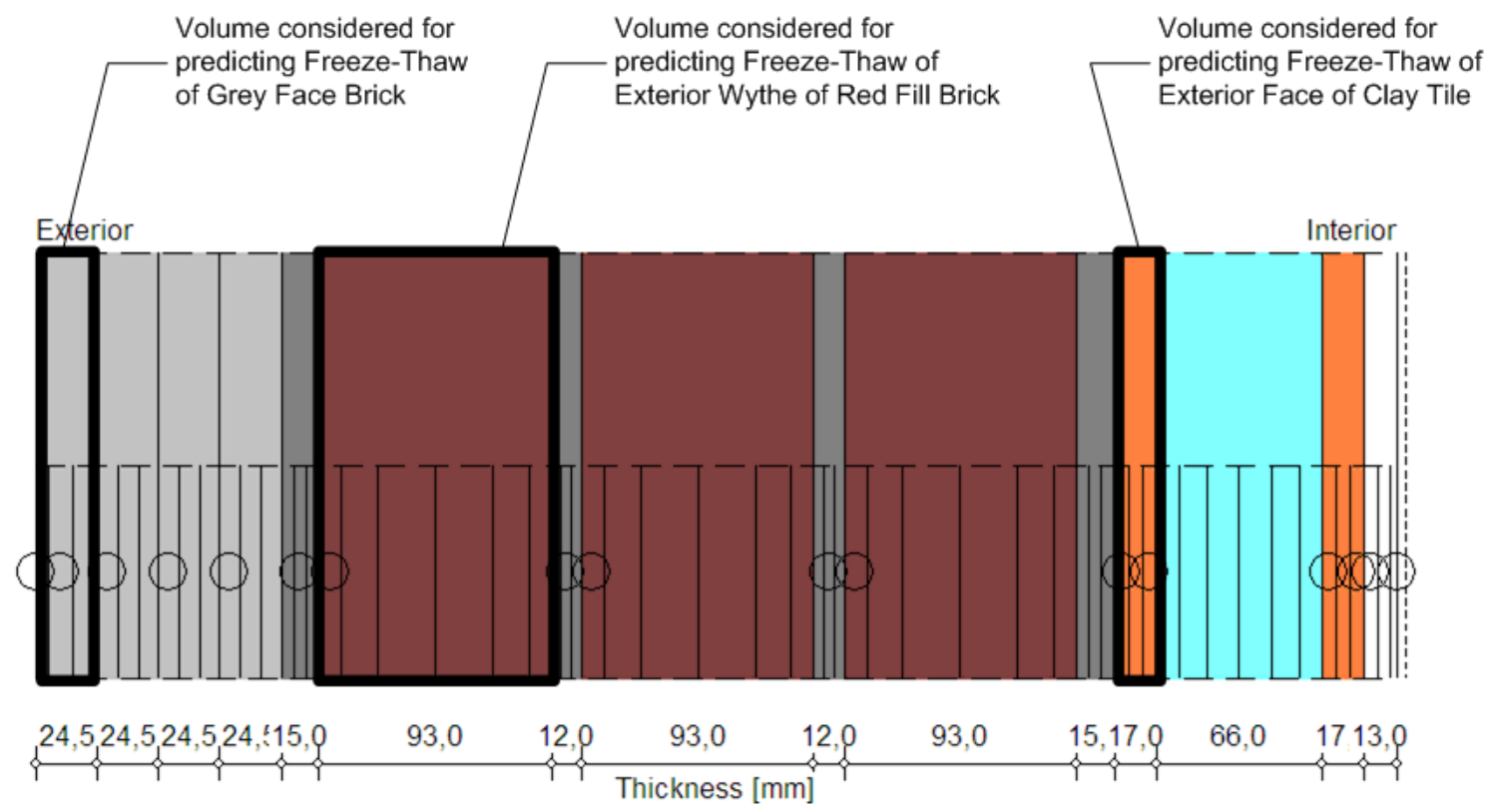

Figure 86. Example WUFI model showing discretization and critical layers for FT failure

The results of the simulations are then post-processed, examining whether various critical layers experience the conditions required for a damaging freeze thaw cycle:

The masonry must have a moisture above $S_{\text {crit }}$ at water contents below $S_{\text {crit }}$, no FT damage will occur regardless of the number of FT cycles; above $S_{\text {crit }}$, damage is measurable after only a few cycles (Mensinga et al. 2010). Note that without direct testing for the $\mathrm{S}_{\text {crit }}$ value, this would require an assumed threshold value. 
The masonry must go through an FT cycle: freezing occurs in the pores of the brick below $32^{\circ} \mathrm{F}$ $\left(0^{\circ} \mathrm{C}\right)$; a typical threshold is $23^{\circ} \mathrm{F}\left(-5^{\circ} \mathrm{C}\right)$. Thawing then occurs above $32^{\circ} \mathrm{F}\left(0^{\circ} \mathrm{C}\right)$; both steps are required for an FT cycle.

Both conditions must be met to have FT action, which damages the masonry. This process can be plotted, as shown in Figure 87 for a specific layer of the simulation. The orange line shows temperature in the examined layer, and the shaded orange area shows pore freezing temperatures. The blue line shows masonry moisture content, with the $\mathrm{S}_{\text {crit }}$ value indicated by the blue shaded area. This graph shows a low-risk situation, with no FT cycles while above $\mathrm{S}_{\text {crit }}$ (damaging FT cycles).

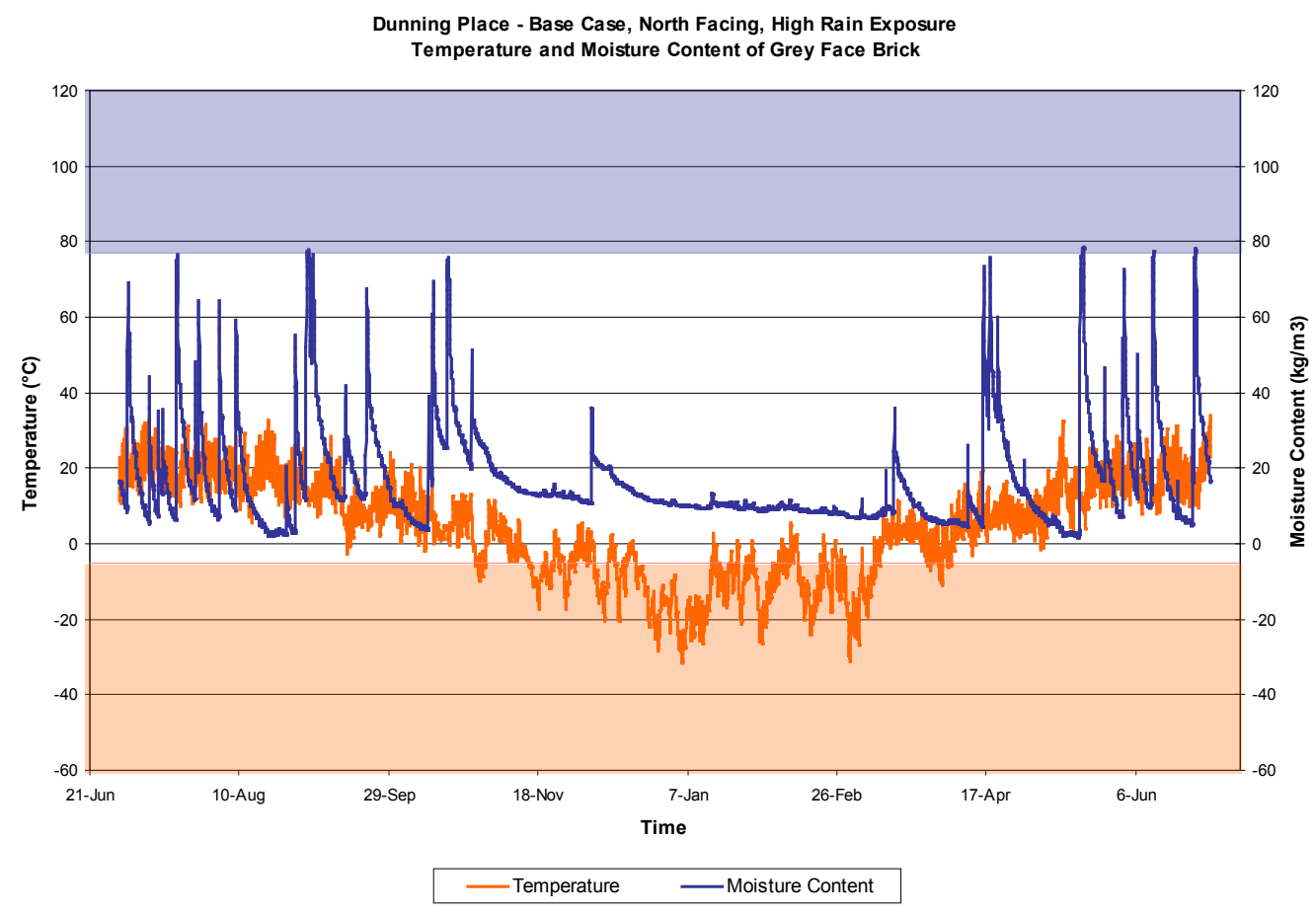

Figure 87. FT temperature and moisture content graph for evaluation of risk

These methods are discussed in more detail by Straube and Schumacher $(2002,2004)$ as well.

\subsection{Detailed Tests and Modeling}

If time and budget allow, or if the building is of critical importance that requires additional levels of care, additional material property testing can be conducted on representative masonry samples. These measurements include thermal conductivity, and direct quantitative measurement of FT resistance, or $\mathrm{S}_{\text {crit, }}$ as discussed by Lstiburek (2010) and Mensinga et al. (2010).

Note that previous research has demonstrated that current ASTM tests used in industry (ASTM $\mathrm{C} 62$ and $\mathrm{C} 67$, and the cold soak/boil or $\mathrm{c} / \mathrm{b}$ ratio) are not reliable determinants of FT risks, resulting in both false positives and false negatives (Butterworth and Baldwin 1964; Litvan 1975). This has been part of the impetus to develop and improve direct measurement of FT resistance. 
The fundamental problem with the existing FT resistance measurements is that they are digital tests (pass/fail). In reality, there is a continuum of performance, based on the degree of exposure of the brick. The developed technique measures $\mathrm{S}_{\text {crit }}$ of a masonry material. The measurement involves removal and preparation of brick samples from the building, FT cycling at various moisture contents, and measuring dimensional changes of the sample (a.k.a., frost dilatometry; see Figure 88).
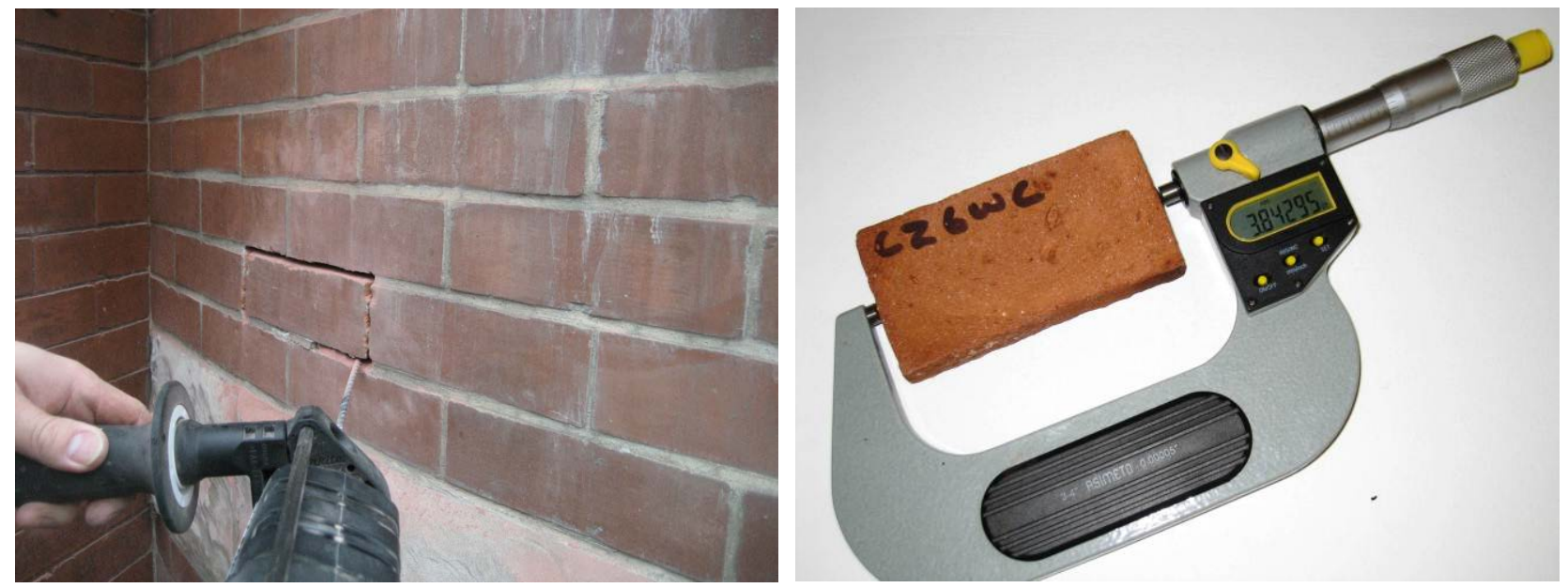

Figure 88. Left: Removal of brick sample; Right: dilatometry (dimensional change) measurements

$\mathrm{S}_{\text {crit }}$ level can be determined by plotting sample dimensions before and after thermal cycling at various moisture contents (Figure 89). If the sample grows, then FT degradation is occurring and the sample's moisture content is above the $\mathrm{S}_{\text {crit }}$ threshold.

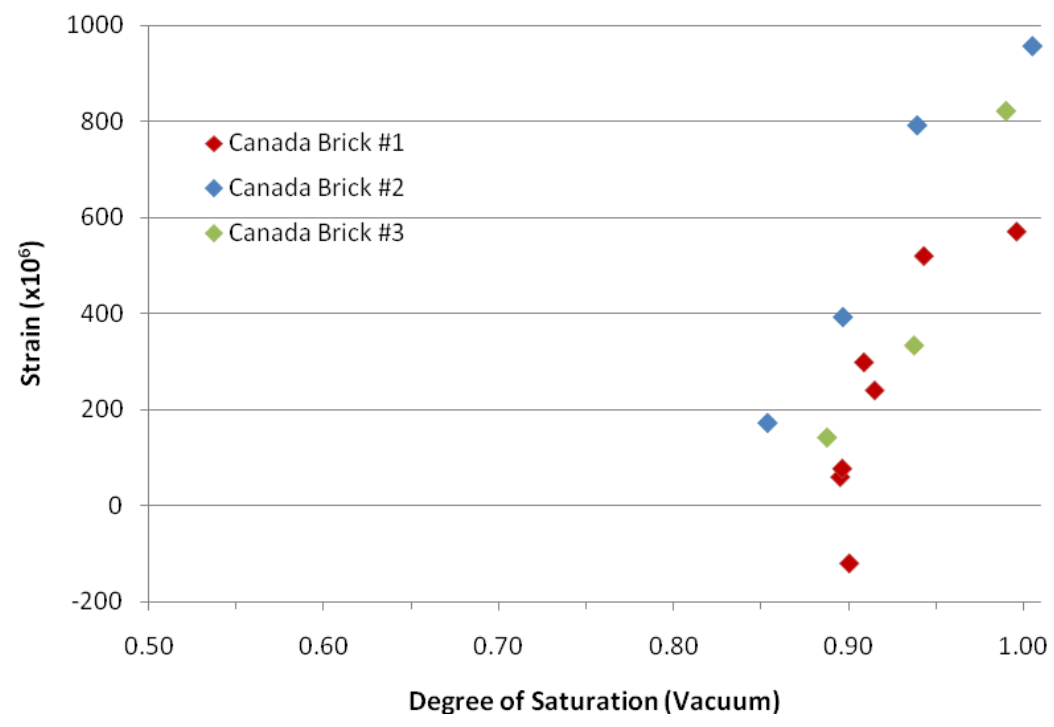

Figure 89. Determination of $S_{\text {crit }}$ value plotting degree of saturation against strain (dilation)

This threshold $\mathrm{S}_{\text {crit }}$ value can subsequently be used as a limit state in evaluating hygrothermal model outputs, per Section 8.2. 


\subsection{Site Load Assessment}

Driving rain, or wind-driven rain onto the exposed walls (faces) of a masonry building, is the single largest moisture load (input), while simultaneously suffering from a large degree of uncertainty. Assumptions can be made about the driving rain exposure of the building, based on shape/features (see Figure 90), local terrain/shielding, and local climate.

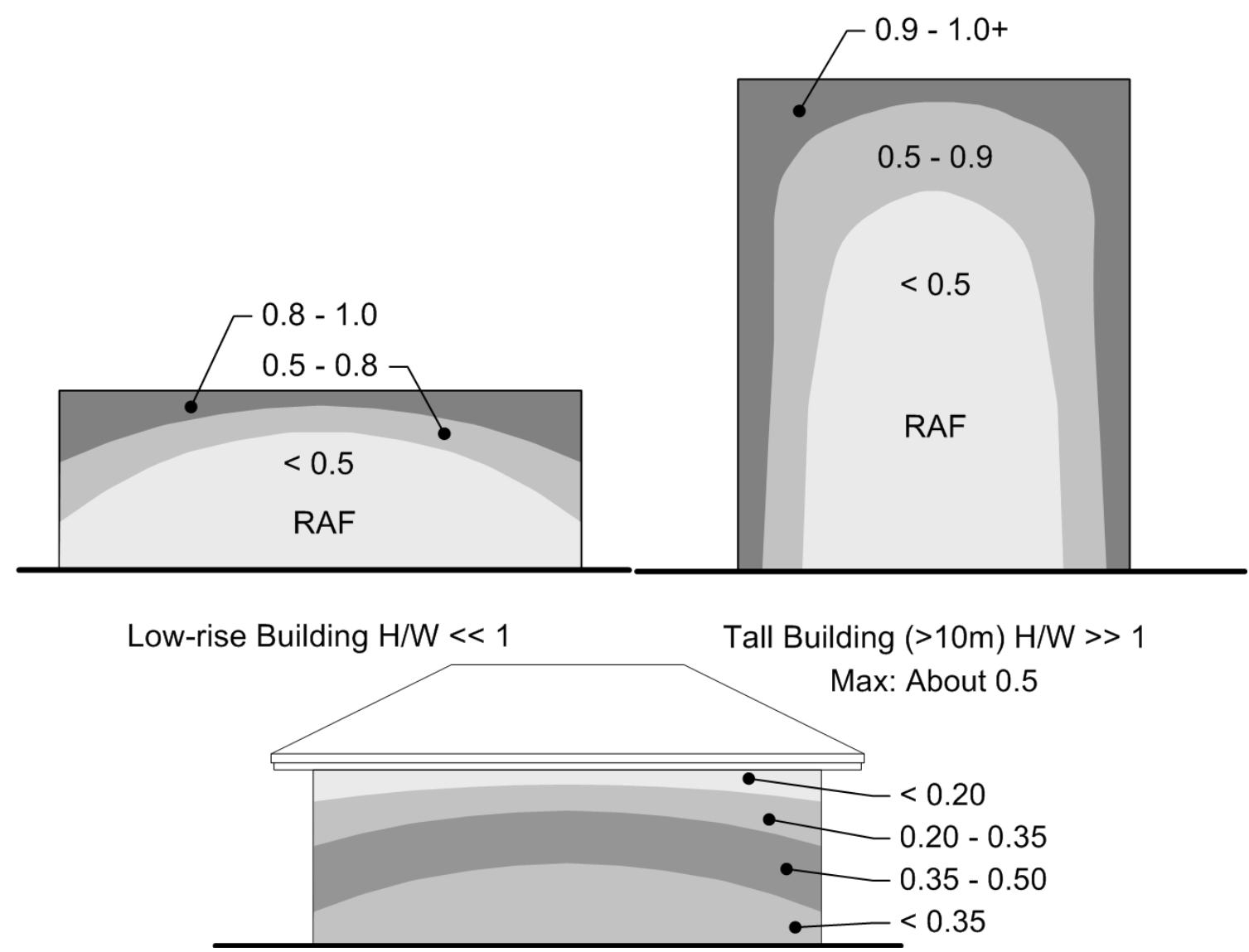

Figure 90. Rain deposition factor (RDF)

(Straube and Burnett 2005)

In addition, run down patterns can create rain deposition larger than estimated based on building geometry.

Monitoring of rain deposition with driving rain gauges is the most thorough method, as shown in Figure 91. This type of monitoring can reveal unexpected effects, such as microclimate wind patterns caused by adjacent buildings, or small surface features affecting runoff. Use of more detailed driving rain data provides greater certainty in the hygrothermal models described previously. 

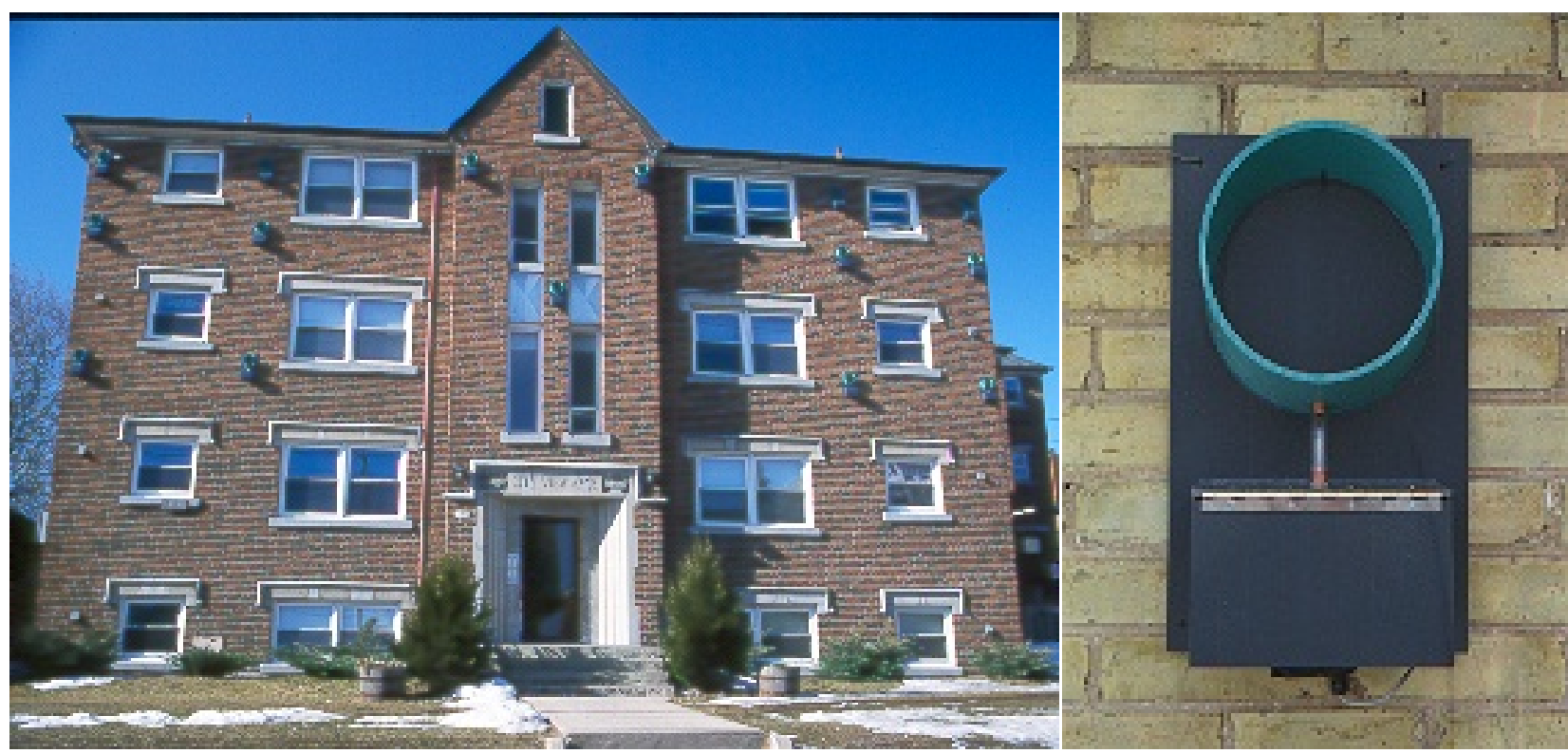

Figure 91. Instrumented occupied building (Waterloo, Ontario) with driving rain gauges

\subsection{Prototype Monitoring}

In some cases, the client may approach the interior insulation project with great caution, and/or have the time and budget to insulate a prototype section of the building prior to full-scale deployment. This is of even greater value if it is combined with monitoring the hygrothermal behavior of the existing, uninsulated portions versus the insulated portions. This is more common among institutional buildings, museums, and buildings of historic significance.

Typically, the interior insulation retrofit would be installed over a small area, and sensors are placed through the thickness of the assembly. Common sensors include temperatures, $\mathrm{RH}$, and moisture content (typically measured with a surrogate sensor; see Ueno and Straube [2008] and Figure 92). In addition, boundary conditions, including interior temperature/RH, exterior weather conditions, and insolation and driving rain on the monitored walls are commonly measured.

These monitored results can then be compared to hygrothermal simulation results to gauge the ability of the model to capture the existing conditions within the assembly. Furthermore, it is also possible to compare brick conditions after several years in service, including gravimetric moisture content and/or ultrasonic transit time (a measurement of density/construction quality). 

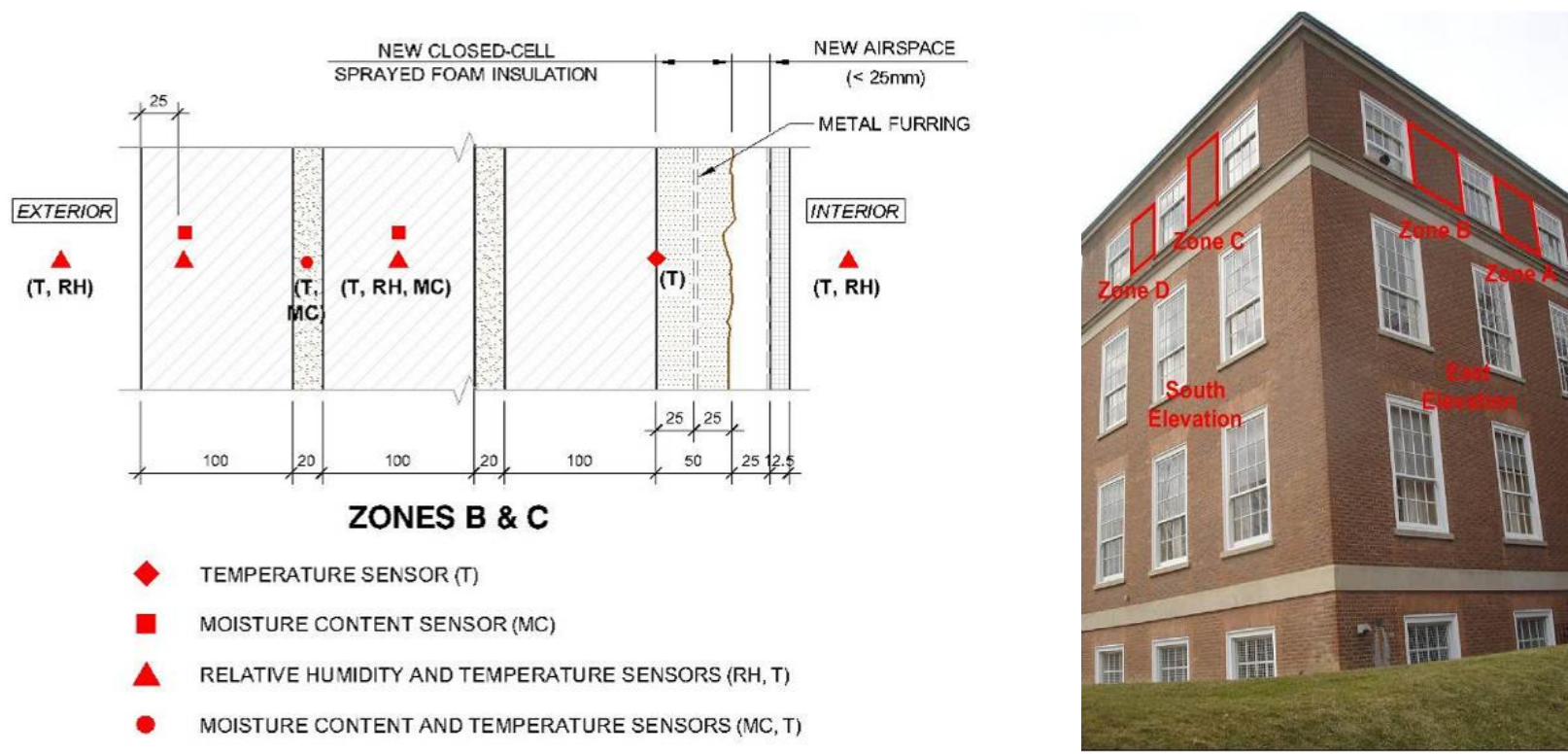

Figure 92. Instrumentation plan and monitoring locations, prototype installation in Toronto, Ontario

(Photo courtesy of Halsall Associates)

\subsection{Maintenance and Repair}

Finally, as for all building enclosures, maintenance of the building over time is critical for longterm durability. Note that interior retrofit buildings are particularly vulnerable: the masonry will be operating at colder, wetter conditions, with less available drying, and because of the interior retrofit, moisture intrusion into the masonry, might not be as obvious from interior observation as in the pre-renovation, uninsulated case (visible bubbling of plaster, water leakage, etc.).

Therefore, a continuous program of inspection of the exterior masonry, as well as repair of any damage, is a prudent step to recommend to any client undertaking an interior retrofit. Typically, mortar will be damaged (eroded) first by water intrusion and/or FT action, so it should be considered an indicator of incipient damage. The moisture source should be identified and eliminated, and the mortar repointed. Note that loss of mortar results in deeper penetration of surface runoff water into the masonry layers. Other details that were outlined in Section 6 should be kept under observation.

A formal manual for owners would be helpful to direct building operations personnel, and provide additional information on potential problem situations. 


\section{Conclusions}

Given the Building America goals of reducing home energy use by $30 \%-50 \%$ (compared to 2009 energy codes for new homes and pre-retrofit energy use for existing homes), insulation and air sealing of mass masonry walls will need to be components of this work if mass masonry residential buildings are to be addressed. Potentially millions of housing units could benefit from a better understanding of the moisture risks associated with interior retrofits, and the means of reducing these risks.

However, there are specific moisture control principles that must be followed for a successful interior insulation retrofit of a solid load-bearing masonry wall. This guideline provides engineering, architectural, and contractor guidance for assessing and minimizing the risk of FT damage arising from executing this measure.

Various interior assemblies can be successfully used for moisture-safe retrofits; relevant details are provided, with recommendations for optimizing thermal insulation performance.

One of the key steps for building durability after these retrofits is a site assessment of the as-built condition. Recommendations are provided for details commonly seen on mass masonry buildings, which are associated with water concentrations (and thus, increased risk in an interior retrofit situation). Controlling bulk water entry into the wall is of exceptional importance, especially because leakage will no longer be visible from inside until damage occurs to interior finishes. If rain control cannot be addressed and upgraded, interior insulation should not be implemented.

Although many of these retrofits have been implemented in locations throughout North America with successful results, there are still major needs for continued work on and research about this topic, including the following:

- Continued work comparing the scientific understanding of FT behavior of mass masonry walls to actual in-service behavior would provide greater feedback about the recommended measures and their relative value. This includes the use of monitoring of insulated and uninsulated walls, and comparison of their behavior to simulations.

- Compiling a database of mass masonry buildings with interior insulation in service that show acceptable performance over time in a variety of climates would provide a great deal of confidence for practitioners looking to execute this measure. There are significant numbers of these buildings, but follow-up studies have been limited in the United States. Concurrently, finding failures associated with interior masonry retrofits would be educational as well: they would demonstrate the limits of this technique, and what specific techniques do not work. Furthermore, measurements of energy performance before and after renovation, proving that insulation is a vital part of the improvement, would be beneficial for greater acceptance.

- An improved understanding of rain loading on the face of masonry buildings would result in greater certainty when providing inputs to hygrothermal modeling; it is one of the required boundary conditions that is often not well characterized. 
- Some practitioners espouse the use of clear water repellents such as silanes and siloxanes; ideally, they should reduce capillary uptake (water absorption) of the masonry, while still allowing drying to the exterior by vapor diffusion. Other practitioners have found these sealants to be problematic, resulting in cosmetic failures. Greater understanding of their effectiveness and limitations would be useful to allow their adoption where appropriate.

- In terms of moisture risks to embedded wood beams in masonry structures, there is substantial uncertainty in how these members actually behave in service after insulation retrofits, including the effects of the masonry material, exposures, and airflow. Further research is warranted, including the use of two-dimensional hygrothermal simulations, and in-situ measurements of beam pocket temperatures, $\mathrm{RH}$, and wood moisture content (in both insulated and uninsulated configurations). 


\section{References}

ASHRAE. (2009). 2009 ASHRAE Handbook-Fundamentals. Atlanta, GA: American Society of Heating, Refrigerating and Air-Conditioning Engineers, Inc.

[BIA] The Brick Industry Association. (1988) "Technical Notes on Brick Construction 15 Water Penetration Resistance - Design and Detailing.” Reston, VA.

[BIA] The Brick Industry Association. (2005) "Technical Notes on Brick Construction 7 Salvaged Brick." Reston, VA.

Butterworth, B.; Baldwin, L.W. (1964). Laboratory Test and the Durability of Brick: The Indirect Appraisal of Durability (continued). Transactions of the British Ceramics Society 63(11):647-61.

Dumont, R.; Snodgrass, L.; Kokko, J.; Schumacher, C. (2005). "Field Measurement of Wood Moisture Contents in Wood Joists Embedded in Masonry Exterior Walls." Proceedings of the 10th Annual Conference on Building Science and Technology. Ottawa, ON.

Gonçalves, M.D. (2003). "Insulating Solid Masonry Walls.” Ninth Conference on Building Science and Technology, Ontario Building Envelope Council, Vancouver, BC, pp. 171-181.

Hutcheon, N.B. (1964). NRC-IRC (Institute for Research in Construction) Canadian Building Digest CBD 50. "Principles Applied to an Insulated Masonry Wall." Ottawa, ON: National Research Council of Canada.

ICC. (2009). International Energy Conservation Code. Country Club Hills, IL: International Code Council.

Künzel, H. (2002). WUFI® PC-Program for calculating the coupled heat and moisture transfer in buildings. Fraunhofer Institute for Building Physics. Holzkirchen, Germany.

Litvan, G. (1975). Testing the Frost Susceptibility of Bricks. In Masonry: Past and Present, pp. 123-132. ASTM STP 589.

Lstiburek, J.W. (2006). "Understanding Drainage Planes.” ASHRAE Journal 49):74-78. Atlanta, GA: American Society of Heating, Refrigerating and Air-Conditioning Engineers, Inc.

Lstiburek, J.W. (2007a). "Building Sciences: The Perfect Wall.” ASHRAE Journal (vol. 49); pp. 74-78. Atlanta, GA: American Society of Heating, Refrigeration, and Air-Conditioning Engineers, Inc.

Lstiburek, J.W. (2007b). "Building Sciences: Capillarity-Small Sacrifices.” ASHRAE Journal (vol. 49); pp. 58-61. Atlanta, GA: American Society of Heating, Refrigeration, and AirConditioning Engineers, Inc. 
Lstiburek, J.W. (2010). "Building Sciences: Thick as a Brick.” ASHRAE Journal (vol. 52); pp. 50-56. Atlanta, GA: American Society of Heating, Refrigeration, and Air-Conditioning Engineers, Inc.

Maines, M. (2011). "Why Flash and Batt Makes Sense.” Fine Homebuilding Magazine. Newtown, CT: Taunton Press.

Maurenbrecher, A.H.P.; Shirtliffe, C.J.; Rousseau, M.Z.; Saïd, M.N.A. (1998). "Monitoring the Hygrothermal Performance of a Masonry Wall With and Without Thermal Insulation."

Proceedings of the 8th Canadian Masonry Symposium (Jasper, Alberta) pp. 174-193, (NRCC42462).

Mensinga, P.; Straube, J.; Schumacher, C. (2010). "Assessing the Freeze-Thaw Resistance of Clay Brick for Interior Insulation Retrofit Projects." Performance of the Exterior Envelopes of Whole Buildings XI. Atlanta, GA: American Society of Heating, Refrigerating and AirConditioning Engineers, Inc.

Morelli, M. (2010). "Internal Insulation of Masonry Walls with Wooden Floor Beams in Northern Humid Climate." Performance of the Exterior Envelopes of Whole Buildings XI. Atlanta, GA: American Society of Heating, Refrigeration, and Air-Conditioning Engineers, Inc.

Ritchie, T. (1971). NRC-IRC (Institute for Research in Construction) Canadian Building Digest CBD 138. "On Using Old Bricks in New Buildings." Ottawa, ON: National Research Council of Canada.

Straube, J.F. (2011). High Performance Enclosures: Design Guide for Institution, Commercial, and Industrial Buildings in Cold Climates. Building Science Press: Westford, MA.

Straube, J.F.; Schumacher, C.J. (2002). "Comparison of Monitored and Modeled Envelope Performance for a Solid Masonry Building.” CMHC Report, Ottawa.

Straube, J.F.; Schumacher, C.J. (2004). "Hygrothermal Modeling of Building Envelopes Retrofits." CMHC Report, Ottawa.

Straube, J.F.; Burnett, E.F.P. (2005). Building Science for Building Enclosure Design, Building Science Press: Westford, MA.

Ueno, K.; Straube J. (2008). "Laboratory Calibration and Field Results of Wood Resistance Humidity Sensors.” Proceedings of BEST 1 Conference, Minneapolis, June 10-12, 2008.

Wilson, A.G. (1961). NRC-IRC (Institute for Research in Construction) Canadian Building Digest CBD-23. "Air Leakage in Buildings." Ottawa, ON: National Research Council of Canada. 


\section{Appendix A (BEST 3 Paper)}

Ueno, K., "Masonry Wall Interior Insulation Retrofit Embedded Beam Simulations."

This paper was presented at the Building Enclosure Science \& Technology (BEST) Conference, BEST3: "High Performance Buildings - Combining Field Experience with Innovation" (April 2 4, 2012, in Atlanta, Georgia). 


\section{Masonry Wall Interior Insulation Retrofit Embedded Beam Simulations Kohta Ueno ${ }^{1}$}

\section{ABSTRACT}

There is a large existing stock of uninsulated mass masonry buildings: their uninsulated walls result in poor energy performance, which is commonly addressed with the retrofit of interior insulation. Some durability issues associated with interior insulation have been or are being addressed, such as interstitial condensation and freeze-thaw damage issues.

However, another durability risk is the hygrothermal behavior of moisture-sensitive wood beams embedded in the load-bearing masonry. Interior insulation reduces the beam end temperatures, reduces available drying potential, and results in higher relative humidity conditions in the beam pocket: all of these factors pose a greater risk to durability.

Three-dimensional thermal simulations were performed to examine the effect of interior insulation on embedded wood members. Simulations were run for the cases both of large wood members ("beams") and smaller dimension lumber members ("joists"). In addition, simulations were run of various methods that would increase heat flow to the beam ends; the resulting effect on overall heat loss was also examined. This was followed by one-dimensional hygrothermal simulations to gain greater insight into the beam end behavior, including airflow effects.

Results indicate that the methods to increase beam end temperature have mixed results. Metal spreader plates increase the temperatures at smaller joists, but they do not appear to be a worthwhile strategy in larger beams. The thinning of insulation near the embedded beam ends appears to have minimal thermal effects. Hygrothermal simulations give results that vary strongly based on starting assumptions and material properties: field monitoring to determine insitu conditions is recommended to better understand the problem and calibrate future simulations.

\section{Introduction}

There is a large existing stock of uninsulated mass masonry buildings: their uninsulated walls result in poor energy performance, which is commonly addressed with the retrofit of insulation. Although exterior insulation retrofits provide ideal protection of the existing structure (Hutcheon 1964, Nady et al. 1997), they are incompatible with goal of the preservation of the historic exterior appearance. Therefore, interior insulation of these buildings has become increasingly common.

Some durability issues linked with previous insulation techniques have been or are being addressed, including interstitial condensation and brick freeze-thaw damage However, another durability risk that has received less investigation is the hygrothermal behavior of moisturesensitive wood beams embedded in the load-bearing masonry. With the retrofit of interior insulation, the embedded beam ends will spend longer periods at colder temperatures than their pre-retrofit condition. Therefore, these wood members will have reduced drying potential due to reduced heat or energy flow (as described by Lstiburek 2008). The wood will also be subjected

\footnotetext{
${ }^{1}$ Kohta Ueno, Senior Associate, Building Science Corporation, Somerville, MA
} 
to higher relative humidity $(\mathrm{RH})$ conditions in the beam pocket, and therefore remain at a higher moisture content (MC): both of these factors increase the risk to the beam's durability.

Therefore, three-dimensional thermal simulations were performed to examine the effect of interior insulation on embedded wood members. Simulations were run for the cases both of large wood members ("beams") and smaller dimension lumber members ("joists"). In addition, simulations were run of various methods that would allow increased heat flow to the beam ends, including the use of passive (non-heated) metal "spreader" plates that bypass the insulation; use of less insulation at the beam pockets; and the elimination of insulation at the area surrounding the embedded member. The effect of these methods on overall heat loss through the opaque wall was also examined. The results of these thermal simulations were also used in conjunction with one-dimensional hygrothermal simulations to gain greater insight into the beam end behavior.

\section{Previous Work}

Interior insulation of mass masonry wall assemblies in cold climates poses some specific challenges, including interstitial condensation of interior-sourced moisture (at the insulationmasonry interface), and risks of freeze-thaw damage to the exterior masonry. Literature on this practice spans back several decades. Rousseau and Maurenbrecher (1990) provide an overview of the issues faced when adapting existing massive masonry buildings for current use. The overview paper by Gonçalves (2003) gives best practice recommendations for retrofitting insulation to massive masonry structures, based on existing practice in the Montreal region. Like Rousseau and Maurenbrecher, he emphasizes controlling both exterior rain penetration, and air leakage and vapor diffusion from the interior. In addition, he recommends limiting thermal insulation, in order to limit the reduced temperatures at the masonry. The problems and solutions are also outlined by practitioners such as Maurenbrecher et al. (1998), and Straube and Schumacher $(2002,2004)$.

Masonry freeze-thaw issues (due to reduced outward heat flow and drying) have been examined by Mensinga et al. (2010) (among others). They suggest the use of material property testing (determination of critical degree of saturation, or $\mathrm{S}_{\text {crit }}$ ) as an input to hygrothermal simulations, using a limit states design approach.

The embedded floor joist decay issue has been studied by several practitioners, including field monitoring and computer simulations.

Dumont et al. (2005) monitored moisture content of wood structural members embedded in masonry in two low-rise residences that were retrofitted with insulation in Wolseley, SK (DOE Zone 7, "dry" climate) and Kincardine, ON (DOE Zone 6A, "moist" climate). The Wolseley house was insulated with mineral wool, with a polyethylene vapor barrier; the Kincardine house was insulated with spray polyurethane foam. The foam insulation encased the wood members where they were seated in the masonry wall. Data showed that the wood members of the Wolseley house remained at safe moisture content levels (10-15\%) throughout the monitoring period. However, the Kincardine house showed consistently elevated moisture contents $(20 \%+)$ at several locations. It was suspected that the moisture source was capillary uptake from the wet foundation, but rainwater absorption through the face of the masonry (due to surface detailing) was not eliminated as a possible source. The limited drying to the interior available through spray polyurethane foam was also likely a contributing factor. 
Scheffler (2009) examined the problem of interior retrofits of masonry structures, focusing on moisture problem at wooden beam ends. He used DELPHIN two-dimensional hygrothermal simulation software to examine the geometry of a wooden beam embedded in brick masonry under steady state conditions $\left(23^{\circ} \mathrm{F} /-5^{\circ} \mathrm{C} / 80 \% \mathrm{RH}\right.$ exterior; $68^{\circ} \mathrm{F} / 20^{\circ} \mathrm{C} / 50 \% \mathrm{RH}$ interior; 90 days). These simulations indicated the moisture risks associated with insufficient control of airflow or moisture vapor flow (diffusion) from interior sources. This was followed by onedimensional and two-dimensional simulations using transient weather data (Bremen; mild, maritime climate with high rain and humidity), indicating increases in relative humidity and liquid water (condensation) at the beam ends due to the addition of insulation.

Scheffler also described the historic methods to increase embedded beam longevity, such as charring the beam end to increase moisture resistance, and the addition of exterior-to-interior ventilation at the beam pocket. He discussed current methods to ameliorate these moisture issues due to insulation retrofits, including replacement of wood floor/ceiling assemblies with nonmoisture sensitive materials (e.g., concrete), and possibly the addition of heat and/or ventilation at the wood beam end.

Morelli et al. (2010) collaborated with Scheffler, continuing examinations of this issue. They proposed the solution of leaving a gap in the insulation of 12 " $(300 \mathrm{~mm})$ above and below the floor, resulting in a 30 " $(770 \mathrm{~mm})$ gap $(12$ " gap $\times 2$ plus floor depth). Two- and threedimensional heat transfer simulation showed that the heat flow was reduced by $60 \%$ going from the uninsulated to insulated cases, while the "gap" case was only a $45 \%$ reduction. This work was followed by two-dimensional DELPHIN hygrothermal simulations of the embedded beam (in a Bremen climate). Relative humidity levels in a corner of the beam pocket (and equilibrium wood moisture content) were compared between cases. The existing, uninsulated wall showed a drying trend; the fully insulated wall showed seasonal increases in RH; and the gapped insulation wall showed performance between the two previous cases (but with increasing moisture levels). However, these results assumed a relatively high wind-driven rain loading factor: switching to a lower loading factor, the gapped insulation assembly showed a general drying trend.

\section{Thermal simulations}

The first portion of the work was to run three-dimensional finite-element thermal simulations using HEAT3 v. 5.1 (Blomberg 1996), to examine the effect of interior insulation on embedded wood members. Simulations were run for the cases both of large wood members ("beams") and smaller dimension lumber members (“joists”).

The simulated "beam" case was a 12 " x 8 " $(0.3 \mathrm{~m}$ x $0.2 \mathrm{~m})$ beam embedded in an 18 " $(0.45 \mathrm{~m})$ thick masonry to a depth of 8 " $(0.2 \mathrm{~m})$. A 78 " x 78" (2 $\mathrm{m}$ x $2 \mathrm{~m})$ square section of wall was simulated; the associated wood flooring was also included. A 1" thick $(25 \mathrm{~mm})$ cast iron or steel bearing plate is commonly used to spread the beam loads on the masonry; it has the added benefit of acting as a capillary break. This element was explicitly modeled (shown in pink). Beams are often "fire cut," with the end cut angled inwards to allow for beam collapse without disrupting the surrounding masonry; this was not modeled. Note that these dimensions remain identical throughout these simulations; differences in images are due to aspect ratio shifts in the graphic. 

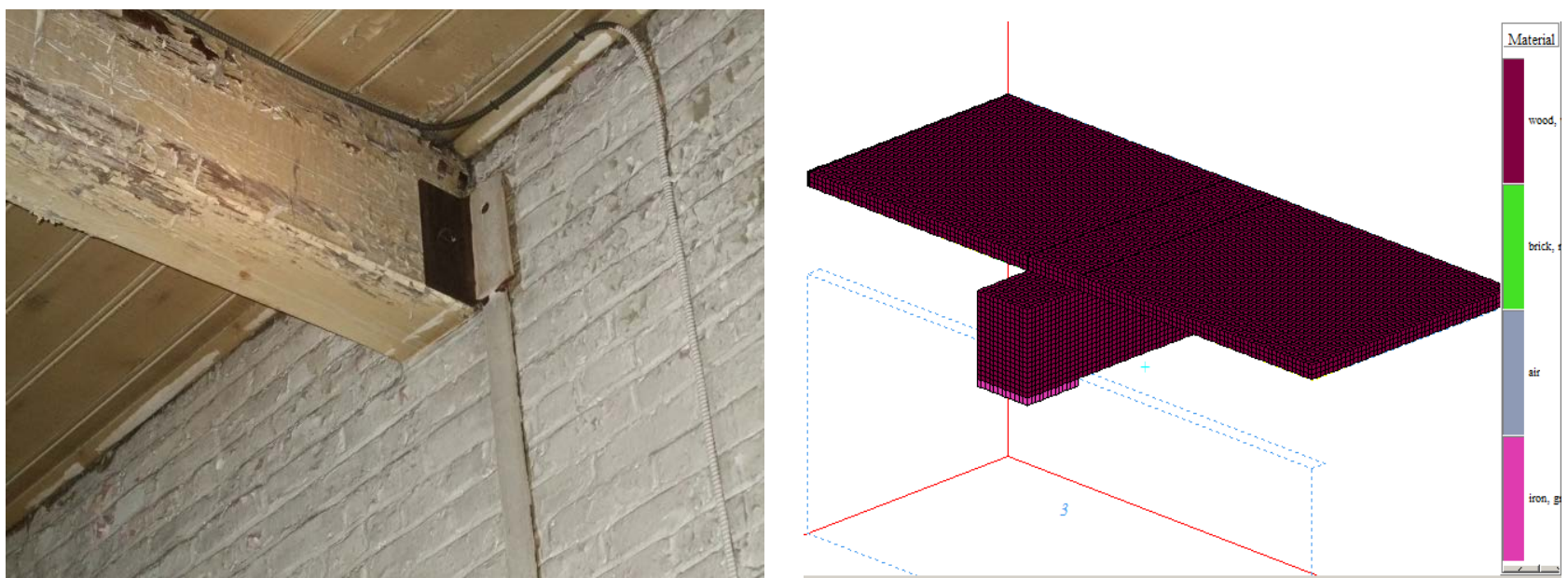

Figure 93: Typical embedded beam (left), and HEAT3 representation of beam, floor, \& plate (right)

Interior temperature was fixed at $68^{\circ} \mathrm{F}\left(20^{\circ} \mathrm{C}\right)$, and exterior temperature at $7^{\circ} \mathrm{F}\left(-14^{\circ} \mathrm{C}\right)$, which is the Boston $99.6 \%$ design temperature. The interior heat transfer coefficient was modified at two- and three-sided inside corners (wall-beam-floor intersection conditions, 6"/150 mm width), to account for the effect of reduced heat flow at these conditions.

The baseline uninsulated case is shown in Figure 2 (Case 1); beam end surfaces range from 28 to $44^{\circ} \mathrm{F}\left(-2\right.$ to $\left.6^{\circ} \mathrm{C}\right)$. The heat conduction through the bearing plate is clear from the asymmetric temperature distribution. Note that the coldest portions of the beam would actually not be present assuming a fire cut end. These simulations assume steady-state conditions, so no benefit from the thermal mass of the masonry is reflected here.

In addition, some early cases examined the effect of the air space that typically surrounds the beam in the pocket: $\mathrm{a} \sim 1 / 4$ " $(6 \mathrm{~mm})$ gap was used. The beam end temperatures were close to identical in the air gap and non-air gap cases; this might be explained by the small size of the gap, and the relative thermal conductivities of air at $0.0043 \mathrm{Btu} \cdot$ in $/\left(\mathrm{hr} \cdot \mathrm{ft}^{2} \cdot{ }^{\circ} \mathrm{F}\right)$ or $0.03 \mathrm{~W} / \mathrm{m} \cdot \mathrm{K}$ (R-4.8/inch) vs. wood at $0.0144 \mathrm{Btu} \cdot$ in $/\left(\mathrm{hr} \cdot \mathrm{ft}^{2} \cdot{ }^{\circ} \mathrm{F}\right)$ or $0.1 \mathrm{~W} / \mathrm{m} \cdot \mathrm{K}(\mathrm{R}-1.4 /$ inch $)$. Results were identical after setting air thermal conductivity to twice the previous value (R-2.2/inch). Note, however, that an air space has a significant effect in terms of capillary liquid water transport between the masonry and the wood.

This was followed by cases which added 2"/50 mm of spray foam insulation (R-12/RSI 2.1) to the interior surface of the masonry (Figure 2, Case 2). The surface temperatures of the beam end dropped to the $12-22^{\circ} \mathrm{F}\left(-5\right.$ to $\left.-11^{\circ} \mathrm{C}\right)$ range. These cold temperatures penetrate into the "core" of the beam; a temperature distribution at a horizontal section is shown in Figure 4. 


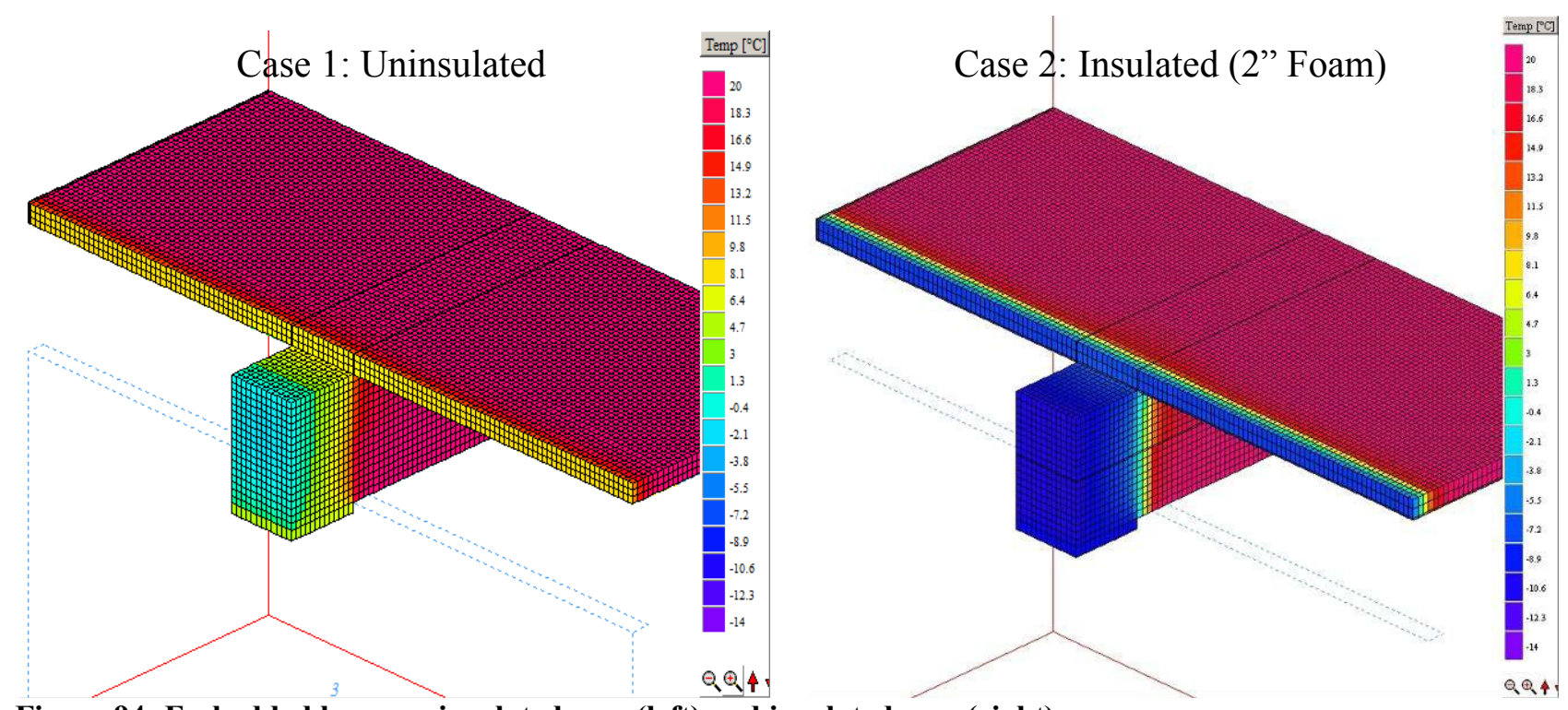

Figure 94: Embedded beam uninsulated case (left) and insulated case (right)

This was followed by simulations of methods to increase heat flow at the beam end, which increase the post-retrofit beam end temperature. One approach was to install thinner (1"/25 mm) thick foam in an area $16 \% / 0.4 \mathrm{~m}$ around the beam; a minimum thickness was included to provide an air seal at the beam penetration (Case 3). The resulting temperature distribution (Figure 3, left) appears very similar to the original insulated case (same beam end temperatures; slightly warmer sides)

Another option was to add metal plates to the sides of the beam, to bypass the insulation (Case 4). After several iterations, a pair of $3 \mathrm{~mm}$ aluminum plates was selected; they extended to the full depth of the beam pocket, and had an exposed length of roughly 2 times the pocket depth on the interior. These were simulated as having full contact with the beam. The results in Figure 3 (right) show that the vertical faces of the beam are close to the original, uninsulated temperatures (Case 1), but the middle of the beam is as cold as Case 2. This shows the limitation of the geometry of the problem: wood has a relatively high insulating value, thus making the nominal goal of "transmitting" heat laterally into the pocket more difficult. 

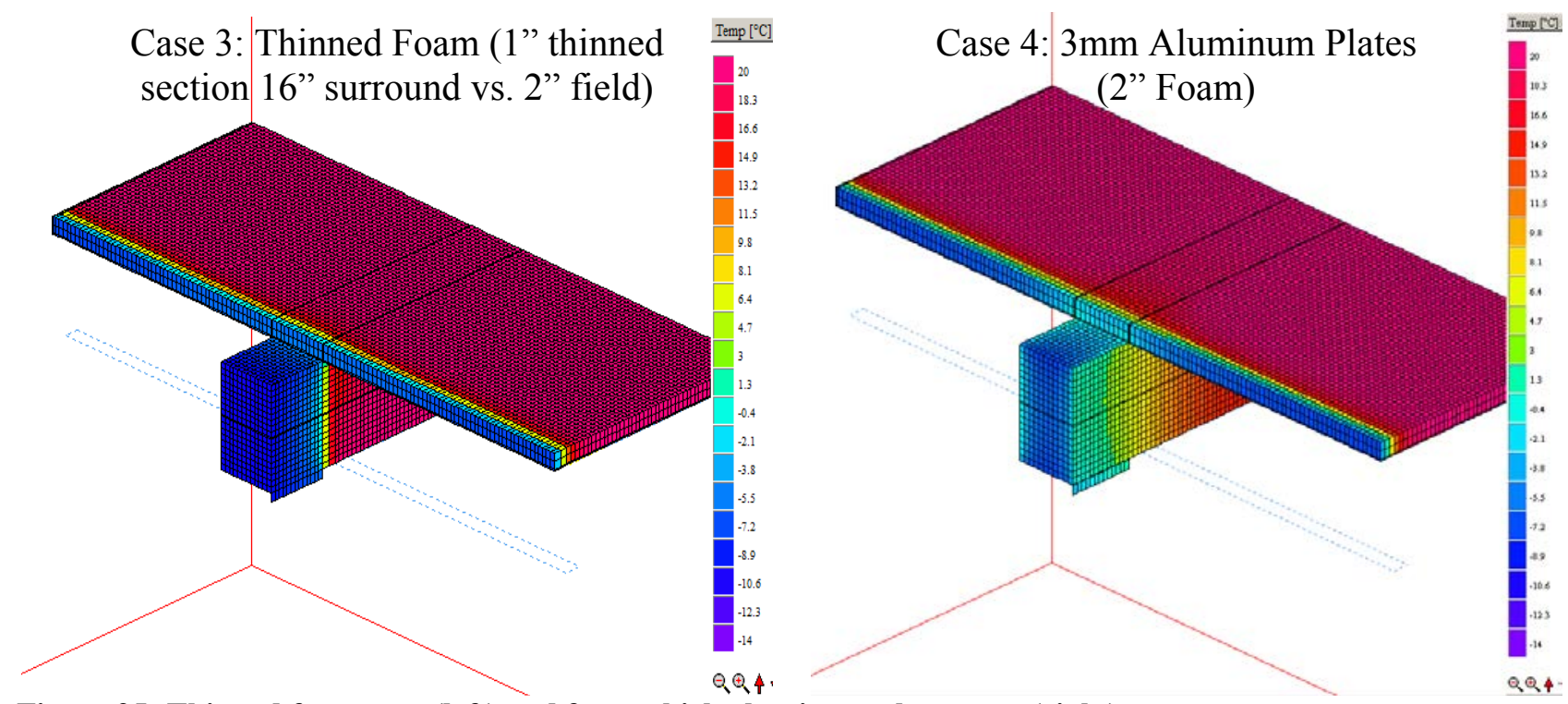

Figure 95: Thinned foam case (left) and $3 \mathrm{~mm}$ thick aluminum plates case (right)

These results are also shown in plan section in Figure 4, for the uninsulated, insulated, and "insulated with plates" cases. These images show that the plates definitely increase the beam temperatures through its thickness, although it is colder than the uninsulated case.
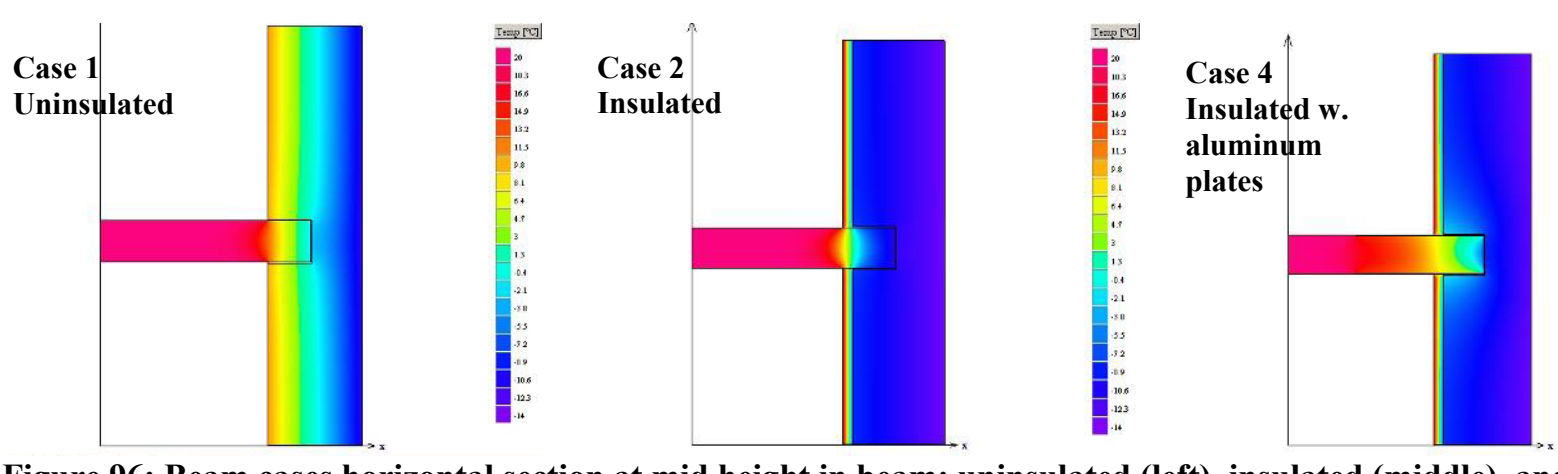

Figure 96: Beam cases horizontal section at mid height in beam: uninsulated (left), insulated (middle), and aluminum spreader plates (right)

However, there are several potential problems with the aluminum spreader plate solution: one is that there may be increased risk of interior air leakage into the beam pocket, given the difficulty of forming an air seal around the plate adjacent to the beam around the geometry of the plates. This could result in air-transported moisture from the interior, and condensation inside the beam pocket. Second, there is the potential risk of condensation of interior air on the cold exposed surfaces of the aluminum plates. The coldest surfaces temperatures of the interior exposed plate are in the range of $44-46^{\circ} \mathrm{F}\left(6-8^{\circ} \mathrm{C}\right)$; condensation would start at interior conditions of $70^{\circ} \mathrm{F}$ $\left(21^{\circ} \mathrm{C}\right), 35-40 \% \mathrm{RH}$. If interior wintertime humidity conditions were well controlled, this would minimize condensation risks.

This work was followed by simulations of smaller members at a closer spacing, or "joists." These simulations used 2"x12" $(0.5 \mathrm{~m} \mathrm{x} 0.3 \mathrm{~m})$ wood members at 16 " $(0.4 \mathrm{~m})$ o.c. spacing. Similar to previous work, cases were run with uninsulated (Case 1), insulated (Case 2), and insulated with aluminum plate (Case 4) conditions (Figure 5). The aluminum plates made the 
beam end temperatures at least as warm as their pre-insulation condition. However, it is difficult to imagine the installation of these plates at a large number of closely spaced joists, as opposed to the more widely spaced beams.
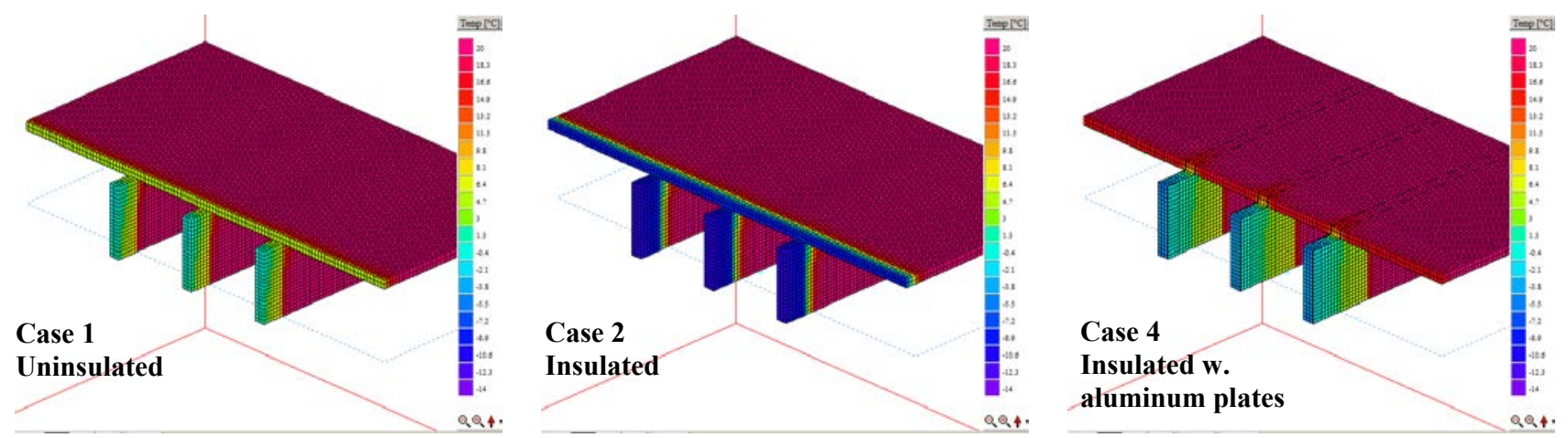

Figure 97: Joist cases: uninsulated (left), insulated (middle), and aluminum plates (right)

Therefore, several more possible options were run. One was to thin the foam to $1 " / 25 \mathrm{~mm}$ at the rim joist area, as per Figure 6 (Case 3, left): similar to the analogous beam case, a negligible increase in beam end temperatures was observed. Another option was to omit the rim joist insulation entirely, similar to Morelli et al.'s (2010) work (Case 5). The resulting temperatures are shown in Figure 6 (right), showing a temperature distribution close to the original, uninsulated case. However, without the addition of an air barrier at the beam pocket, there is a risk of interstitial condensation at the concealed masonry surface. Specifically, at design conditions $\left(7^{\circ} \mathrm{F} / 14^{\circ} \mathrm{C}\right)$, the beam pocket temperatures are in the 22 to $25^{\circ} \mathrm{F}\left(-4\right.$ to $\left.-6^{\circ} \mathrm{C}\right)$ range, which has condensation risks at $70^{\circ} \mathrm{F} / 12 \% \mathrm{RH}$ or higher. This condensation risk could not be addressed by controlling interior RH in an occupied building. A non-insulating, semi-vapor permeable liquid applied membrane might be an air barrier option, but further study is recommended before implementation.
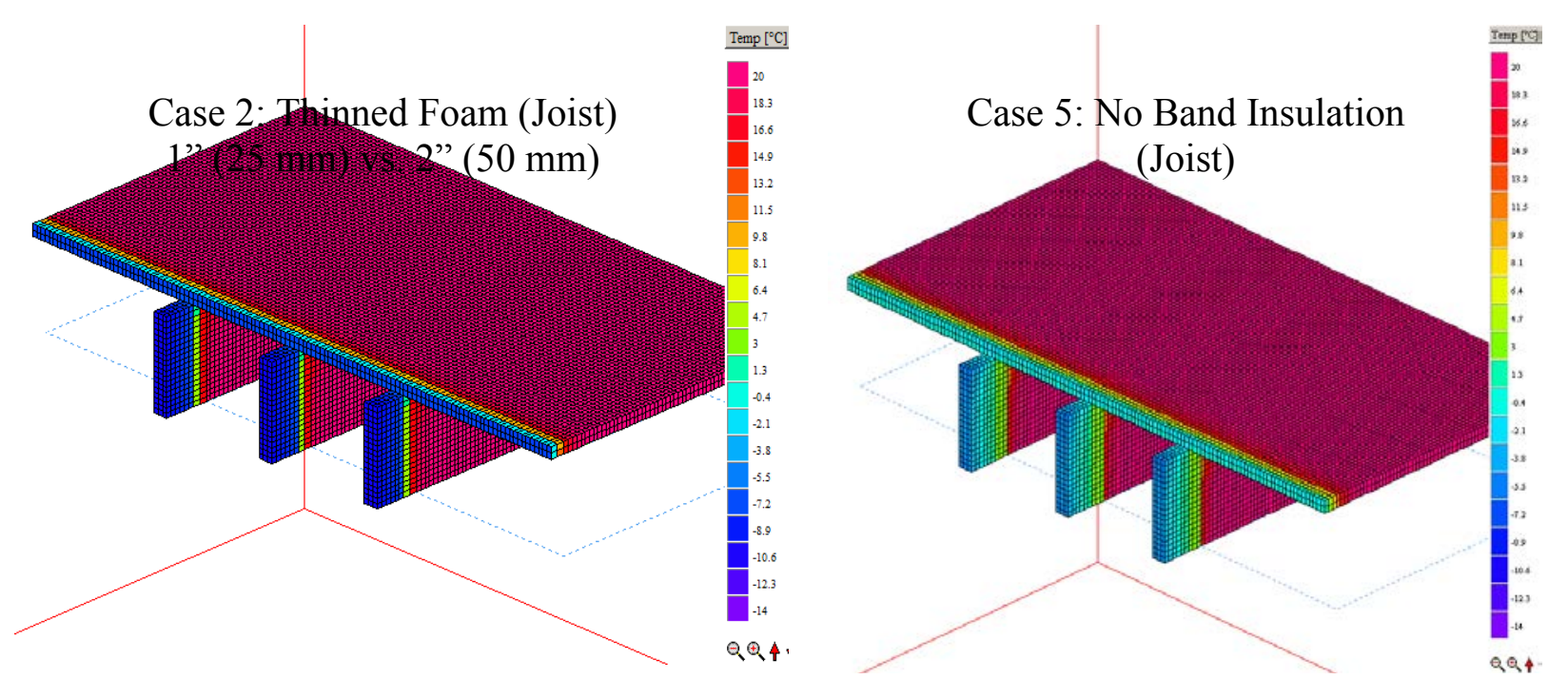

Figure 98: Joist cases: thinned foam at floor joist area (left) and omitted band joist insulation (right)

The impact of these methods of increasing beam end temperatures on overall heat loss is shown in Figure 7. It compares the heat flux (for $42 \mathrm{sf} / 4 \mathrm{~m}^{2}$ of wall assembly with joist framing, at 
Boston design conditions) for the uninsulated case, the insulated case, the use of aluminum plates, and the uninsulated band joist. The addition of insulation results in an $80 \%$ reduction in heat flux. The addition of the aluminum plates drops the reduction in heat loss to only $75 \%$ (vs. the uninsulated case). The use of an uninsulated rim joist space result has only a $66 \%$ reduction from uninsulated case). It should be noted that this is a substantial loss in $\mathrm{R}$ value: going from Case 2 to Case 5 is a change from R-13.6 to R-7.0.

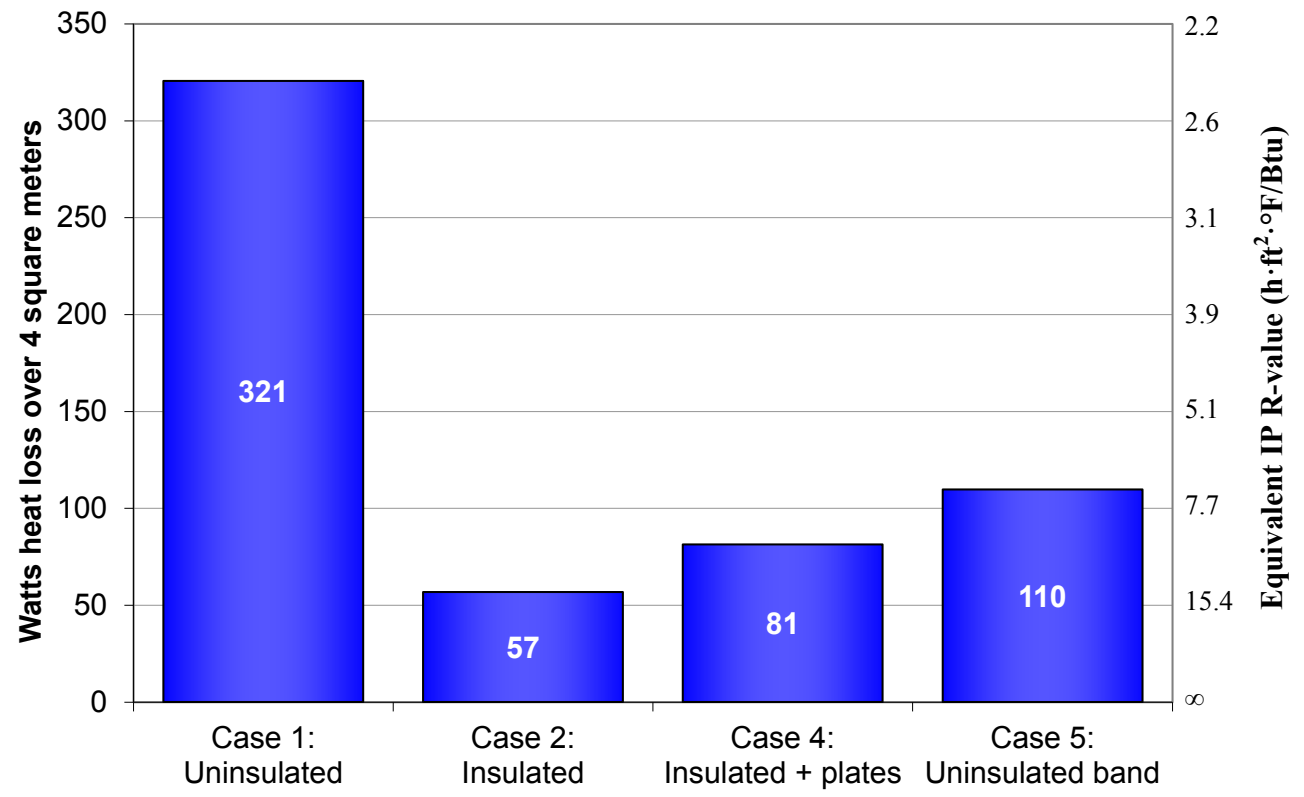

Figure 99: Heat loss through $42 \mathrm{sf}\left(4 \mathrm{~m}^{2}\right)$ of wall assembly with joist framing, various cases

\section{Hygrothermal simulations}

The thermal behavior of embedded beam and joist ends is only one facet for durability analysis: their hygrothermal behavior (and most importantly, the wetting and drying of the beam end) is of greater interest. Therefore, one-dimensional hygrothermal simulations were run of various insulated and uninsulated scenarios, using IBP WUFI Version 5.1. This version adds the ability to have air sourced from interior or exterior conditions into a cavity within the assembly, which was used in the sensitivity analysis.

However, one limitation was the use of a one-dimensional simulation. The cross-section at the beam end is the same in insulated and non-insulated cases, in a one-dimensional simulation. Therefore, the thermal properties of the wood material inboard of the beam pocket were changed, in order to "force" beam pocket temperatures similar to the three-dimensional thermal simulations.

The first step was to develop a temperature index of the beam pocket temperatures, of the insulated and uninsulated cases. HEAT3 models were run at a series of outdoor temperatures, and the resulting beam pocket temperatures were recorded and plotted in Figure 8. Note that these are steady state simulations, and do not account for the thermal mass of the masonry. This graph shows that in the uninsulated case, the thermal resistance inboard of the beam pocket is roughly $40 \%$ of the total, and the beam pocket temperatures are close to halfway between indoor 
and outdoor temperatures. Then in the insulated case, the thermal resistance inboard of the beam pocket is roughly $89 \%$ of the total, and the beam pocket temperature is close to exterior conditions.

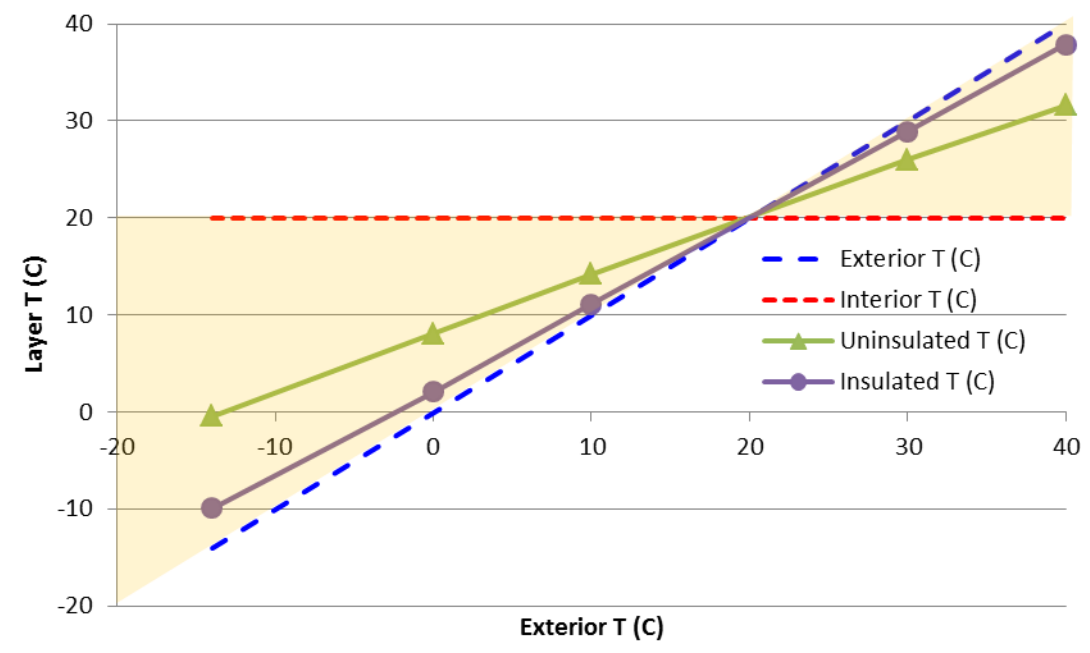

Figure 100: Temperature at end of beam for uninsulated and insulated cases

The one-dimensional hygrothermal simulations were then created to "force" these temperature differences; the approach was to calculate the relative thermal resistances inboard and outboard of the beam pocket air space, and to modify them as per the temperature index above. The initial dimensions and material chosen in the hygrothermal simulation resulted in thermal resistances close to the temperature index value ( $41 \%$ outboard $/ 59 \%$ inboard), and were used as-is. In the insulated hygrothermal simulations, the thermal conductivity of the oak beam was changed from $0.043 \mathrm{Btu} \cdot$ in $/\left(\mathrm{hr} \cdot \mathrm{ft}^{2} \cdot{ }^{\circ} \mathrm{F}\right)$ or $0.3 \mathrm{~W} / \mathrm{m} \cdot \mathrm{K}$ to $0.0072 \mathrm{Btu} \cdot$ in $/\left(\mathrm{hr} \cdot \mathrm{ft}^{2} \cdot{ }^{\circ} \mathrm{F}\right)$ or $0.05 \mathrm{~W} / \mathrm{m} \cdot \mathrm{K}$, resulting in an $11 \%$ outboard $/ 89 \%$ inboard thermal resistance balance. Note that these calculations are based on the dry thermal conductivities of these materials; the moisture-dependent thermal conductivities were not used in these calculations. The remaining moisture properties were left as per the default values.

The simulated assembly is shown below in Figure 9, which includes a brick masonry exterior, an air space, and an oak interior (or oak modified as per above; wood species was not examined as a variable in this work). 


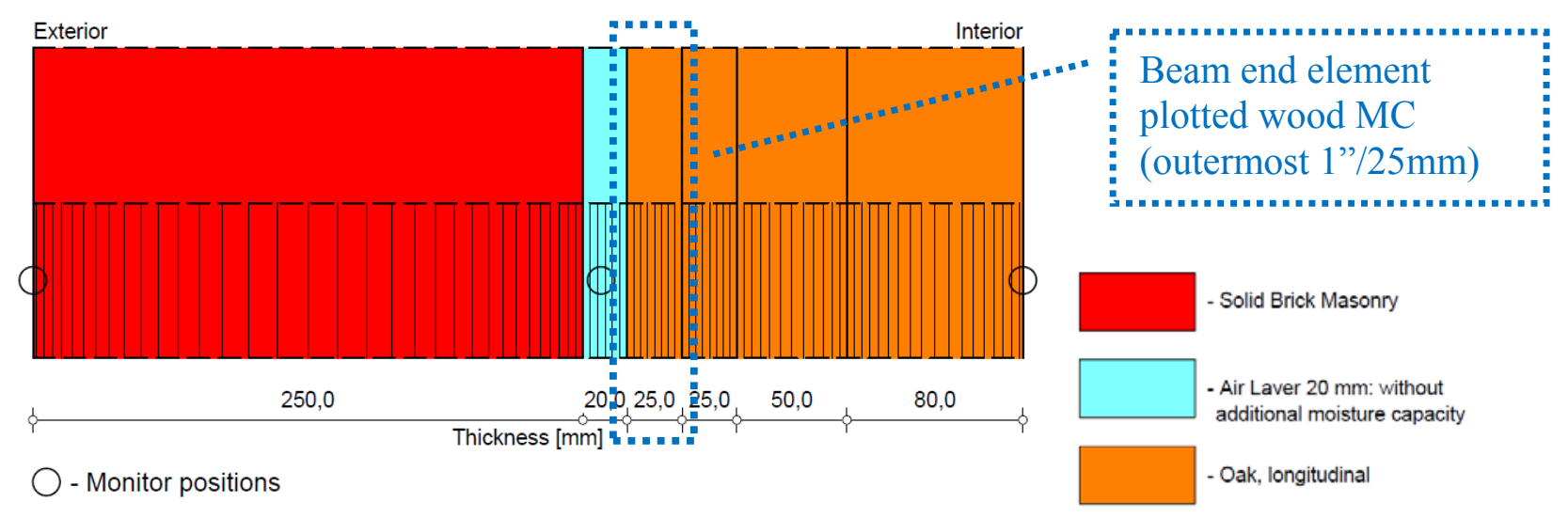

Figure 101: WUFI simulated assembly, showing components and dimensions

Simulations were run in a Boston (cold year) climate, facing northeast (worst driving rain orientation), for a period of three years. The interior conditions were $68^{\circ} \mathrm{F} / 20^{\circ} \mathrm{C}$ constant temperature, with a sinusoidally varying relative humidity (30\% winter to $60 \%$ summer).

In addition, in some cases, interior air was introduced into the air layer/beam pocket. In a typical existing installation, there is a noticeable gap around the beam, varying from roughly $1 / 8$ " to 1 " $(3-25 \mathrm{~mm})$. The amount of air movement is unknown, so several bounding cases were simulated.

Simulations were run, and the wood moisture contents of the outermost $1 " / 25 \mathrm{~mm}$ of the wood beam were compared, in order to gauge the relative durability risk of these assemblies. Traditional guidance is to keep wood moisture content below $20 \%$; decay fungi are inhibited below this level (Carll and Highley 1999), with optimum growth occurring in the $25-30 \% \mathrm{MC}$ range. Decay fungi become active at moisture content levels above $28 \%$ (Straube and Burnett 2005). Biological activity, however, is inhibited at low temperatures, so high moisture contents in mid-winter pose less risk than in warmer seasons. Sustained high moisture contents at moderate temperatures pose the greatest durability risks.

The first cases were all uninsulated simulations, with various airflow rates from the interior into the airspace: none, 10 air changes per hour (ACH), and $20 \mathrm{ACH}$ (Figure 10) This air movement would be caused by thermal convection due to temperature differences, and would vary as a function of temperature difference; however, a constant rate was chosen as a first approximation in these simulations. These assumed air change rates are associated with miniscule face velocities. If dimensions stated above are assumed, and the airflow at the open area is assumed to be $1 / 3$ inward, $1 / 3$ outward, and $1 / 3$ neutral, a rate of $10 \mathrm{ACH}$ is equal to a face velocity of 0.0013 meters/second. 


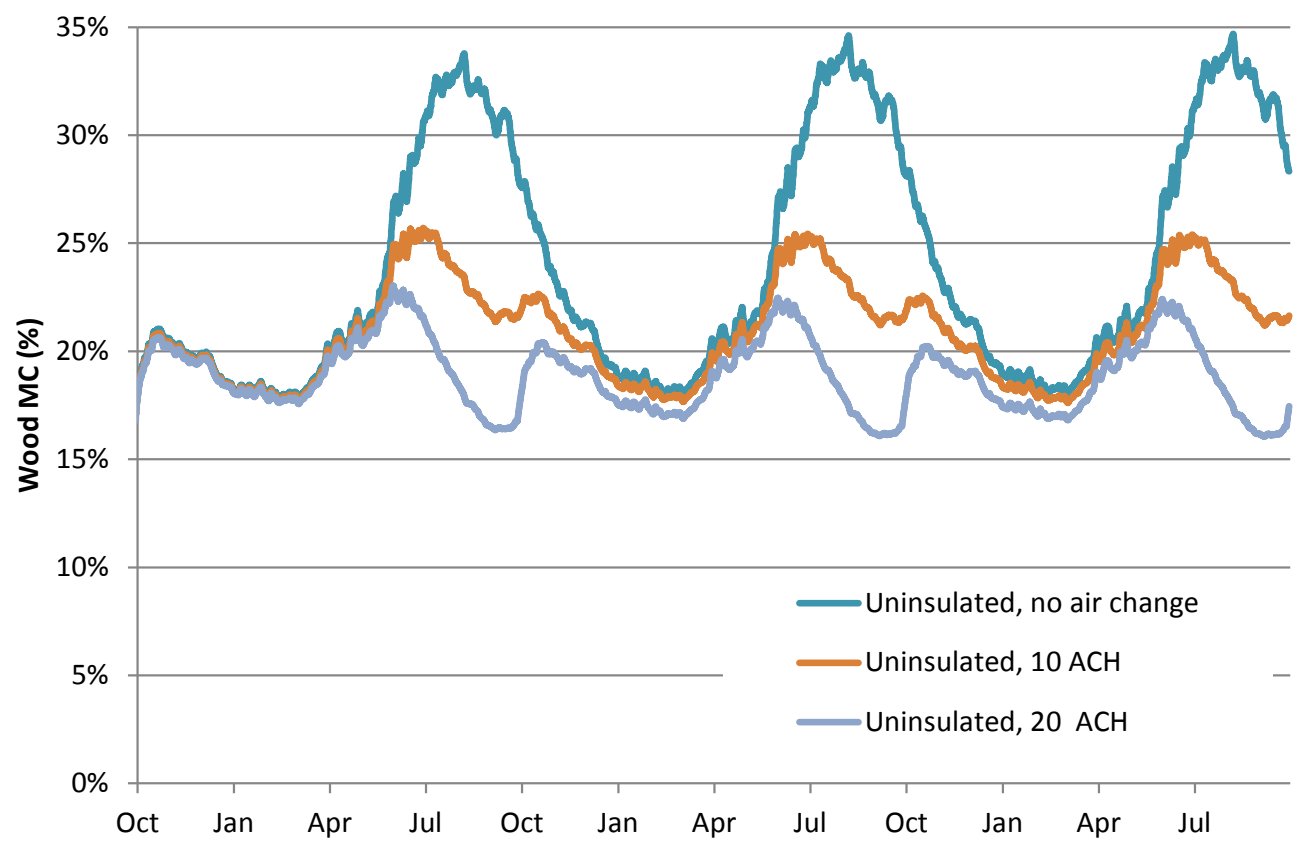

Figure 102: Wood beam end (1\%/25 mm) moisture contents; uninsulated cases

Starting with the "no air change" case, it was noted that the spikes in moisture content do not occur during the winter, as might be expected, but instead in the summertime. This was due to rainwater absorption in the outer brick layers, which was then driven into the beam end by the inward temperature gradient. The addition of air change from the interior resulted in summertime drying, with greater drying from higher air change rates (10 ACH vs. $20 \mathrm{ACH})$. This drying effect also occurred in the wintertime: high wood moisture content due to condensation of interior air on the beam end was not observed in these simulations. However, this was with low (30\% peak) wintertime interior $\mathrm{RH}$ conditions.

It was also noted that the moisture content spikes of the beam end in the "no air change" case were very high, at roughly $35 \% \mathrm{MC}$. Cycling to this level is unlikely in reality, given the likelihood of moisture damage at these conditions. This suggests that convective air change with the interior might play a role in the drying of beams in existing buildings. However, these simulations do not take into account the three-dimensional aspects of the beam pocket, such as redistribution of moisture from the outer face of the beam to the remaining sides of the pocket. In addition, as discussed below, this might not be a reliable drying mechanism after insulation, due to the change in temperature regimes.

The next sets of simulations examined the insulated cases, which created lower air space temperatures in wintertime by reducing the thermal conductivity through the wood elements. The resulting wood beam end moisture contents are shown in Figure 11. Surprisingly, the "no air change" case results in lower summer peak moisture contents in the beam end, compared to the uninsulated case (albeit with a similar seasonal pattern). This could be due to the shift in relative thermal resistances: the majority of the thermal resistance $(89 \%)$ is now inboard of the air pocket. Therefore, there is less temperature difference through the thickness of the masonry layer, resulting in less inward vapor drive. 


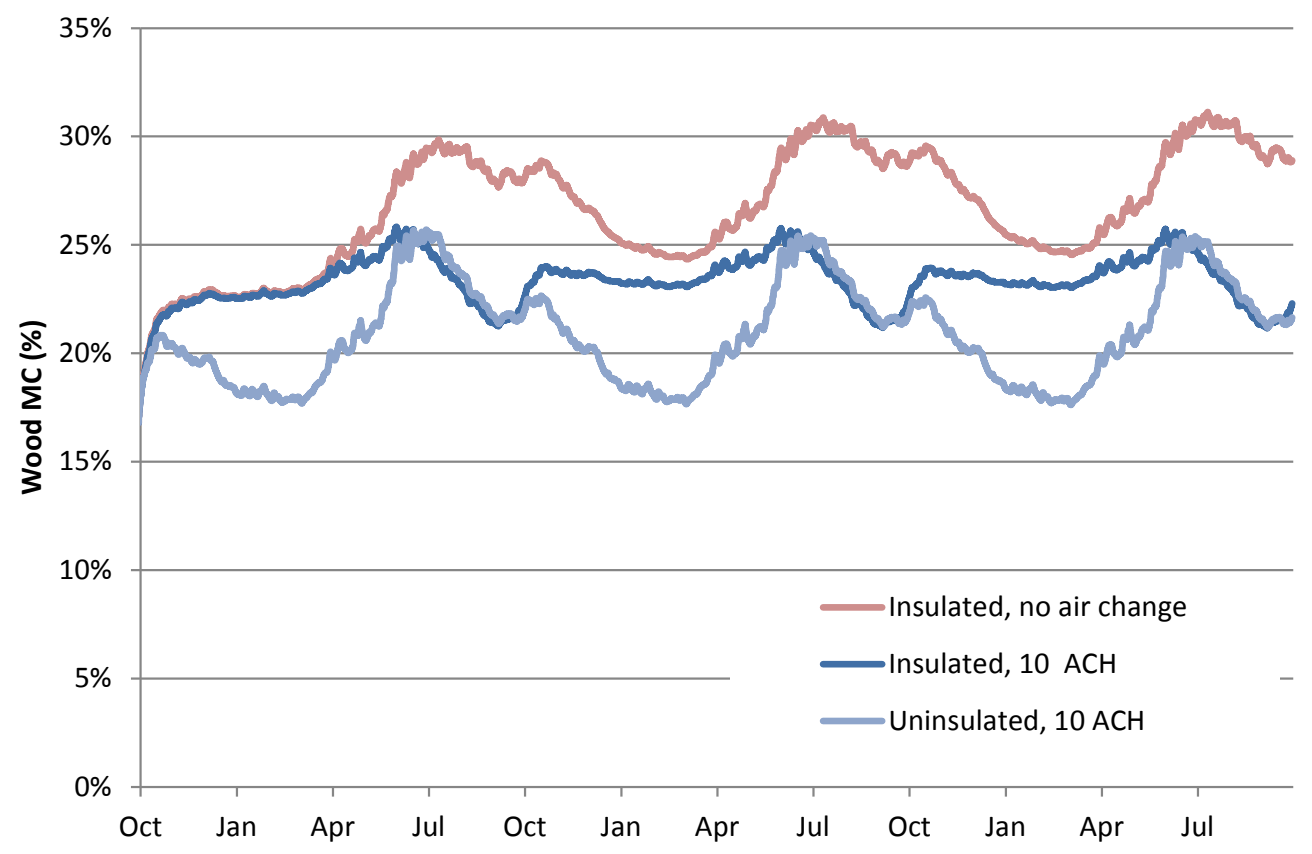

Figure 103: Wood beam end (1"/25 mm) moisture contents; insulated cases (+ uninsulated)

Again, the addition of air change results in reduced moisture accumulation at the beam end. The $10 \mathrm{ACH}$ insulated and uninsulated cases are shown together for comparison: summertime wood moisture contents are largely identical. But in wintertime, the insulated case has higher moisture contents: this is reasonable, given the risks of condensation on interstitial surfaces that are now colder, due to interior insulation. Note that these simulations use a low wintertime relative humidity (30\%); wintertime condensation issues would be substantially worse at higher interior RH levels.

The previous simulations use a monolithic exterior material ("Solid brick masonry"; IBP database), which is intended to simulate brick masonry (including mortar joints) as a composite material. Actual construction of mass masonry walls is composed of multiple wythes of brick, with incomplete infill. This results in some air spaces between layers, and less than perfect capillary contact. To get some indication of the effect of changing the exterior materials, another set of simulations were run building up the exterior wall with multiple brick wythes and a layer of mortar, as per Figure 12. All other simulation characteristics were kept the same; for reference, the proportion of dry thermal resistances was $14 \%$ outboard/ $86 \%$ inboard, similar to previous cases. 


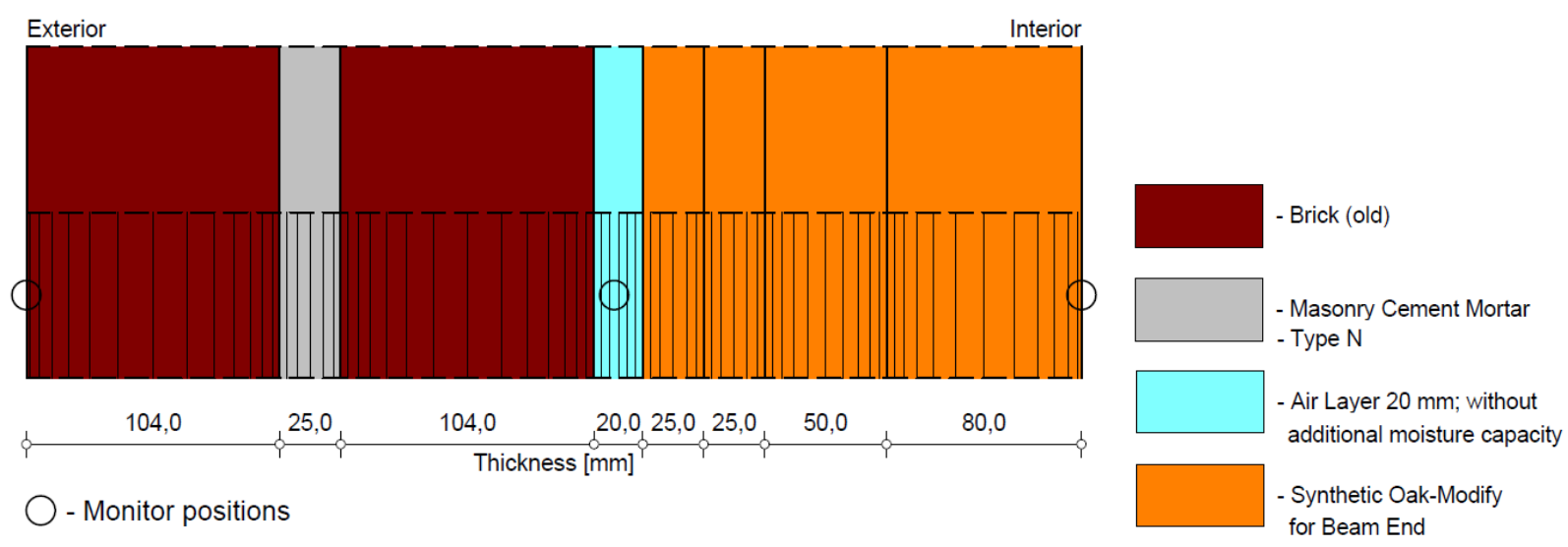

Figure 104: WUFI simulated assembly (components and dimensions), non-monolithic exterior

The resulting moisture contents at the end of the wood beam are shown below in Figure 13. All of the moisture content levels are markedly lower than previous simulations.

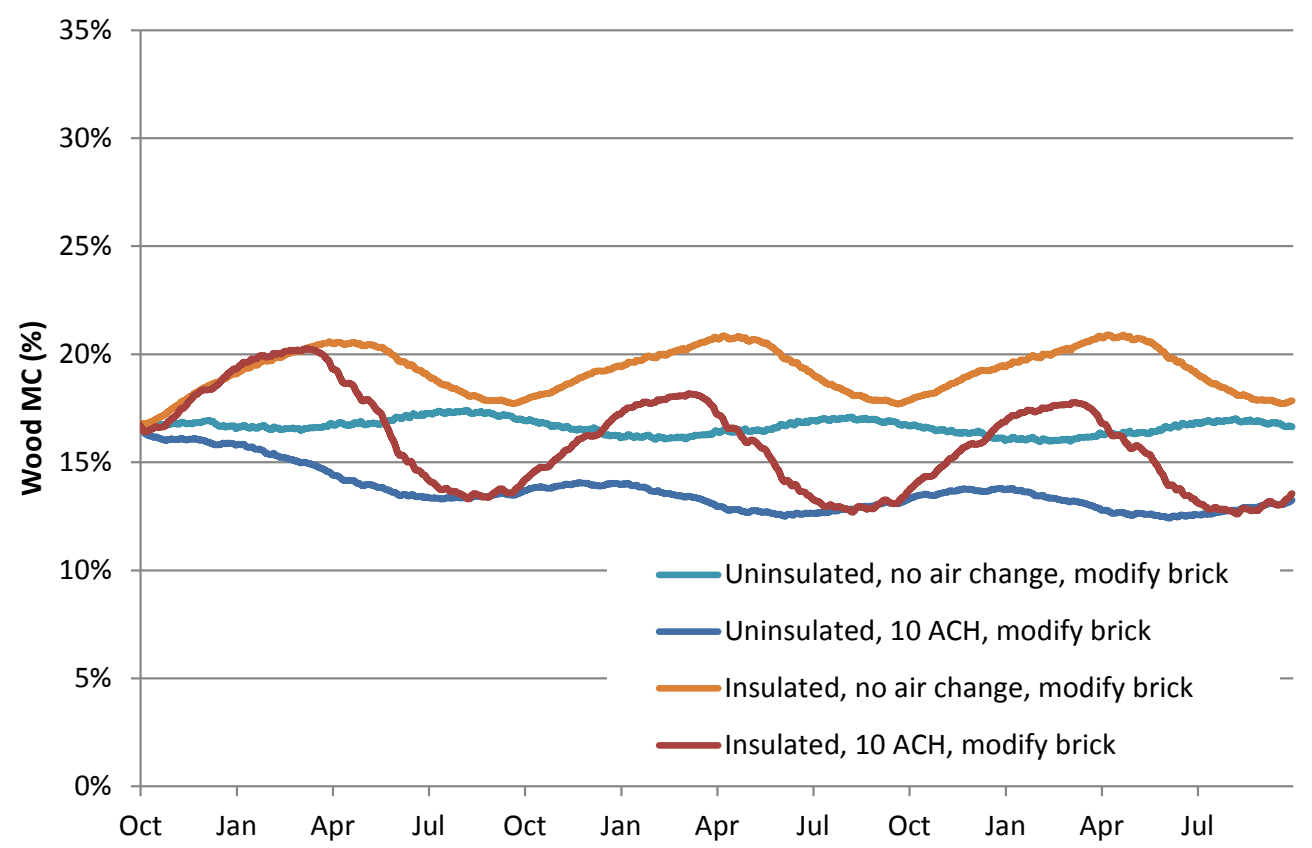

Figure 105: Wood beam end (1"/25 mm) moisture contents; modified exterior brick cases

General patterns of behavior are similar to previous cases though: the uninsulated (no air change) case has a sinusoidal pattern, but with moisture contents well within typical safe ranges. The addition of air change results in even lower moisture contents; however, the sinusoidal pattern reverses, with peaks in wintertime, which could be ascribed to moisture accumulation on cold surfaces.

The addition of insulation results in elevated moisture contents compared to the uninsulated cases; peaks are seen in wintertime conditions, but levels peak only slightly above $20 \% \mathrm{MC}$ (as opposed to $30 \%+$ ). The addition of air change in the insulated case results in drier conditions at the beam end; moisture content peaks occur in the winter and dry quickly in the summer. 


\section{Conclusions and further work}

Three-dimensional static thermal simulations of large ("beams") and small ("joist") embedded wood members in masonry assemblies showed the expected patterns, of colder wintertime beam end temperatures after the retrofit of interior insulation. Various methods to allow greater heat flow were simulated, with the goal of raising wintertime beam end temperatures. The use of passive aluminum plates adjacent to the beams and joists showed a moderate increase in beam end temperatures, with some penalty in overall assembly heat flux. The analogous joist case showed higher beam end temperatures, but it seems unlikely to be executed in practice. The use of thinned (1" thick $/ 25 \mathrm{~mm}$ vs. 2 " thick $/ 50 \mathrm{~mm}$ ) insulation near beam ends showed little effect on beam end temperatures. The elimination of insulation at the rim joist area resulted in temperatures close to original conditions. However, static thermal simulations indicate that there might be significant risk of wintertime condensation within the cavities at typical interior humidity conditions, based on the beam pocket surface temperatures relative to indoor dewpoints. In addition, this measure loses a significant fraction of the energy savings of the fully insulated case (roughly double the heat loss, from R-14 to R-7).

The hygrothermal simulations rely on a modification of material properties (thermal conductivity), in order to run uninsulated and insulated cases in a one-dimensional model. The moisture content of the outermost $1 " / 25 \mathrm{~mm}$ of the beam was plotted as a measure of relative performance. In addition, interior air was introduced into the air space between wood and masonry at various levels.

Simulations with initial assumptions showed that air leakage has a strong effect of wood moisture content: the uninsulated case showed summertime moisture peaks of almost $35 \%$, which is unlikely to be sustainable (in terms of durability) over decades of cycling. Increasing air flow rates into the pocket resulted in lower moisture contents. The addition of insulation (with no air flow) resulted in summer peak wood moisture contents lower than the uninsulated (no air flow) cases; however, peaks were still in the $30 \%$ range. The addition of airflow lowered summertime moisture contents.

A final set of simulations were run using an exterior masonry assembly with different material properties, which resulted in markedly different beam end moisture contents. Uninsulated performance was in the $13-17 \% \mathrm{MC}$ range, and insulated in the $13-21 \%$ range. Seasonal moisture peaks shifted as well; this may be due to the masonry material property change, which lowered rainwater absorption values, thus reducing rain effects (summertime-dominant precipitation).

Overall, these simulations indicate that there is substantial uncertainty in how embedded wood members in masonry actually behave in service after insulation retrofits. The properties of the exterior masonry has a tremendous effect of the beam end moisture contents: not only material properties (e.g., liquid water uptake), but also macroscopic effects (not simulated here) such as infill between brick wythes. The effect of airflow into the beam pocket can be significant, while actual air change rates are unknown. In addition, Morelli et al. (2010) demonstrated that rainwater exposure can have a tremendous effect on beam pocket relative humidity conditions. Finally, it is acknowledged that these one-dimensional hygrothermal simulations are a workaround for a complex three-dimensional problem. 
These factors suggest that further research is warranted: at a minimum, the use of twodimensional hygrothermal simulations, with more refined assumptions for air change rates. However, even these may prove to be of limited applicability, given the effect of material property assumptions. Ideally, in-situ measurements of beam pocket temperatures, relative humidity, and wood moisture content (in both insulated and uninsulated configurations, and various orientations and rainfall exposure levels) would provide the greatest insight into true behavior. For instance, the net effect of air leakage on wetting and drying could be examined more closely, such as whether it results in wintertime wetting (as would be indicated by surface temperatures), summertime drying (as indicated in simulations), or both. The exposure conditions may prove to be a key factor, based on Dumont et al. (2005): liquid water loading such as capillarity from the ground, splashback from adjacent rainfall, or poor rain control detailing might provide crucial differences between success and failure.

One solution that is worth considering in interior insulation retrofit cases might be to remove the beam end, and support the structure on a frame (e.g. wood stud), interior to the masonry structure. This is an effective, but costly and disruptive solution. Active heating (via aluminum spreader plates) has been used in some cases: it adds more heat than the passive plates discussed above, but with an associated energy penalty. Another potential solution is the use of so-called "hygric diode" materials, as used in commercially available "wicking" (but vapor impermeable) pipe insulation. This would have the effect of removing liquid water condensation (were it to occur) from the masonry beam pocket, and drying it to the interior.

\section{Acknowledgements}

The authors would like to thank the US Department of Energy's Building America Program for funding this research.

\section{References}

Blomberg, T. 1996. "Heat Conduction in Two and Three Dimensions: Computer Modeling of Building Physics Applications." Report TVBH-1008, Department of Building Physics, Lund University, Sweden.

Carll, C.G., and T.L. Highley. 1999. Decay of wood and wood-based products above ground in buildings. Journal of Testing and Evaluation 27(2):150-158.

Dumont, R., L. Snodgrass, J. Kokko, J. Goth, C. Schumacher. 2005. "Field Measurement of Wood Moisture Contents in Wood Joists Embedded in Masonry Exterior Walls." Proceedings of the 10th Annual Conference on Building Science and Technology. 2005. Ottawa, ON.

Gonçalves, M.D. 2003. "Insulating Solid Masonry Walls." Ninth Conference on Building Science and Technology, Ontario Building Envelope Council, Vancouver, BC, pp. 171-181.

Hutcheon, N.B. 1964. NRC-IRC (National Research Council of Canada-Institute for Research in Construction) Canadian Building Digest CBD-50. "Principles Applied to an Insulated Masonry Wall," Ottawa, ON: National Research Council of Canada. 
Lstiburek, J. 2008. "Building Sciences: Energy Flow Across Enclosures." ASHRAE Journal, August 2008. Atlanta, GA: American Society of Heating, Refrigeration, and Air-Conditioning Engineers, Inc.

Mensinga, P., J. Straube, C. Schumacher, C., et.al. 2010. “Assessing the Freeze-Thaw Resistance of Clay Brick for Interior Insulation Retrofit Projects" Performance of the Exterior Envelopes of Whole Buildings XI. Atlanta, GA: American Society of Heating, Refrigeration, and AirConditioning Engineers, Inc. Proceedings of Building XI Conference Clearwater, FL.

Morelli, M., G. Scheffler, T. Nielsen, S. Svendsen. 2010. "Internal Insulation of Masonry Walls with Wooden Floor Beams in Northern Humid Climate." Performance of the Exterior Envelopes of Whole Buildings XI. Atlanta, GA: American Society of Heating, Refrigeration, and AirConditioning Engineers, Inc.

Nady M., A. Saïd, W. Brown, I. Walker. 1997. "Long-Term Field Monitoring of an EIFS Clad Wall" Journal of Thermal Insulation and Building Envelopes, Vol 20, April 1997, pp 320-338

Rousseau, M.Z., A.H.P. Maurenbrecher. 1990. '"Rehabilitation of Solid Masonry Walls', Construction Practice Publication, Institute for Research in Construction (http://irc.nrc-cnrc.gc.ca /pubs/cp/wal1_e.html). Originally published in "Construction Canada" 32(5), 1990, p. 15-20

Scheffler, G.A. 2009. "Moisture Problems at Wooden Beam Ends after Building Renovation." LavEByg konference om strategi for lavenergirenovering, 22. April 2009, Hørsholm, Denmark.

Straube, J.F., and Schumacher, C.J. 2002. "Comparison of Monitored and Modeled Envelope Performance for a Solid Masonry Building." CMHC Report, Ottawa, ON.

Straube, J.F., and Schumacher, C.J. 2004. "Hygrothermal Modeling of Building Envelopes Retrofits." CMHC Report, Ottawa, ON.

Straube, J.F., and Burnett, E.F.P., 2005. Building Science for Building Enclosure Design, Building Science Press: Westford, MA. 


\section{Appendix B (Buildings XI)}

Mensinga, P., Straube, J., Schumacher, C. “Assessing the Freeze-Thaw Resistance of Clay Brick for Interior Insulation Retrofit Projects"

www.ornl.gov/sci/buildings/2010/B11\%20papers/203_Mensinga.pdf

This paper was presented at the ASHRAE Buildings XI Conference in Clearwater Beach Florida, December, 2010 


\section{Appendix C (Field Checklist)}

The following checklist is intended as a brief outline of key points and takeaways, which can be used by a field practitioner when assessing a mass masonry building for interior insulation.

\section{Exterior Insulation vs. Interior Insulation}

Is exterior insulation an option? This should always be considered due to durability and thermal performance benefits.

\section{Boundary Conditions (Temperature and Humidity)}

Interior: exceptional loading? Highly humidified in cold climate (museum, 50\% RH) is risky application; consider other options. Pressurized interior in cold climates adds substantial risk.

Exterior: cold climates have greatest risk (DOE Climate Zones 4 and higher); warmer climate have minimal condensation and FT risks. Dry climates (DOE "B" Zones) have reduced risks, but not immune.

\section{Overall Wall Assembly Requirements}

Assembly must avoid interstitial condensation (typically at insulation-masonry interface) due to air leakage and/or vapor diffusion; recommended solutions use air-impermeable insulation materials.

Insulation materials in contact with masonry should be moisture tolerant (polyurethane spray foams, rigid board foams typical).

Framing is spaced off of masonry surface to avoid thermal bridging and subjecting framing to cold/wet conditions. If steel framing, ideally stud bay cavity is left clear and all insulation placed outboard of framing. Clips attaching steel framing to masonry should ideally be non-thermally conductive material.

Ideally, wall assembly has some vapor permeance to the interior, to allow for inward drying. However, highly vapor open assemblies are not recommended due to risks of cold weather condensation (see item 3a.)

Specialized assemblies (interior drainage, pressure controlled assemblies) can be used in some cases; however, they are not recommended for the vast majority of retrofits.

\section{Problematic Details and Solutions}

The following items are details commonly seen on mass masonry buildings which are associated with water concentrations, and thus, increased risk in an interior retrofit situation. If rain control cannot be addressed and upgraded, interior insulation should not be implemented.

Windows and doors (impermeable surface; concentrates water below)

Rainwater must be shed from the face of the building with a sloped sill detail with end dams, and a sufficient drip edge ( $1 \frac{1}{2}$ " minimum) beyond the wall below. Retrofit existing sill as required.

Rowlock window sills are especially vulnerable: fix with overclad or similar detail. 
A subsill pan flashing should be installed, which directs any of this water out onto the sill to the exterior.

Copings and parapet caps: check for inadequate slope, incorrect slope, inadequate overhangs, or inadequate drip edges. Fix with projecting drip edges and waterproofing under the cap.

Stonework and band courses: check for water concentration and deposition at joints. Fix with overclad caps and drip edges below these features.

Roof-wall interfaces: fix with kick out flashings or similar details.

Downspouts, rainwater leaders and scuppers: failure can cause mass water concentration. Continuous maintenance or possibly interior roof drains (assuming roof structure is sufficient for ponding load).

Brick at or below grade: ground contact condition must be eliminated; consider protection from splashback.

Embedded wood members: check for existing moisture conditions and signs of deterioration; address exterior water control as needed.

\section{System Interactions}

Airtightness: retrofitted building will be more airtight than existing building; mechanical ventilation and pollution source control must be implemented.

Combustion Safety: risk of back drafting atmospherically vented combustion appliances increases; require closed combustion appliances or spillage testing.

\section{Continuing Maintenance}

Moisture intrusion into masonry will be less detectable from interior (i.e., visible bubbling of plaster, water leakage, etc.)

Periodic inspection and repair required: typical signs of incipient damage are mortar erosion, deposition of water on face of building. 


\section{U.S. DEPARTMENT OF Energy Efficiency \& ENERY Renewable Energy}

